A study in cooperation with the Minerals Management Service and the Energy Division, County of Santa Barbara, California

\title{
Natural Offshore Oil Seepage and Related Tarball Accumulation on the California Coastline-Santa Barbara Channel and the Southern Santa Maria Basin; Source Identification and Inventory
}

By Thomas D. Lorenson, Frances D. Hostettler, Robert J. Rosenbauer, Kenneth E. Peters, Jennifer A. Dougherty, Keith A. Kvenvolden, Christina E. Gutmacher, Florence L. Wong, and William R. Normark

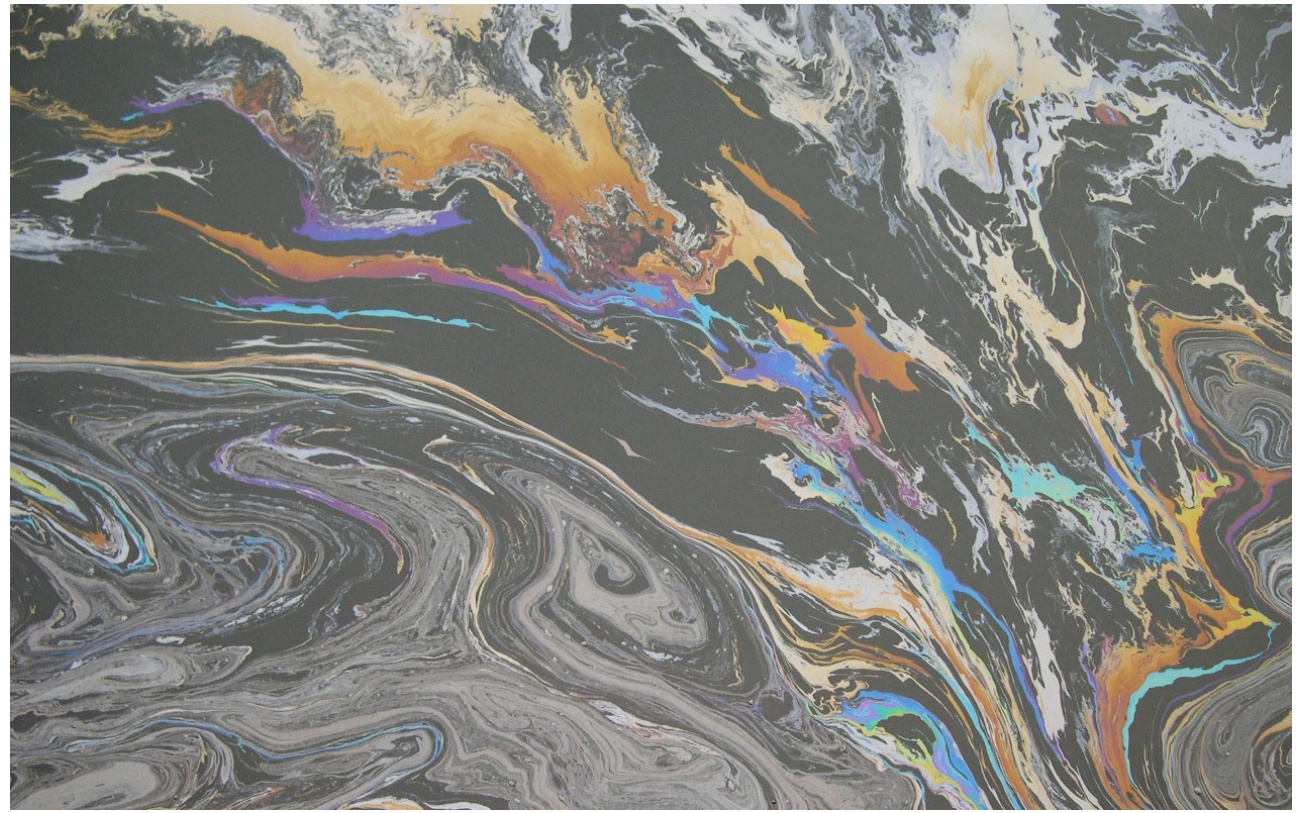

Open-File Report 2009-1225

Also released as MMS report 2009-030

This study was funded in part by the U. S. Department of the Interior, Minerals Management Service (MMS), through an Interagency Agreement No. 18985 with the U.S. Geological Survey, Western Coastal and Marine Geology Team, as part of the MMS Environmental Studies Program.

U.S. Department of the Interior U.S. Geological Survey 


\section{U.S. Department of the Interior \\ KEN SALAZAR, Secretary}

\section{U.S. Geological Survey \\ Marcia K. McNutt Director}

U.S. Geological Survey, Reston, Virginia 2009

For product and ordering information:

World Wide Web: http://www.usgs.gov/pubprod

Telephone: 1-888-ASK-USGS

For more information on the USGS-the Federal source for science about the Earth, its natural and living resources, natural hazards, and the environment:

World Wide Web: http://www.usgs.gov

Telephone: 1-888-ASK-USGS

Suggested citation:

Lorenson, T.D, Hostettler, F.D., Rosenbauer, R.J., Peters, K.E., Kvenvolden, K.A.,

Dougherty, J.A., Gutmacher, C.E., Wong, F.L., and Normark, W.R., 2009, Natural offshore seepage and related tarball accumulation on the California coastline; Santa Barbara Channel and the southern Santa Maria Basin; source identification and inventory: U.S. Geological Survey Open-File Report 2009-1225 and MMS report 2009-030, $116 \mathrm{p}$.

[http://pubs.usgs.gov/of/2009/1225/].

Any use of trade, product, or firm names is for descriptive purposes only and does not imply endorsement by the U.S. Government.

Although this report is in the public domain, permission must be secured from the individual copyright owners to reproduce any copyrighted material contained within this report. 


\section{Contents}

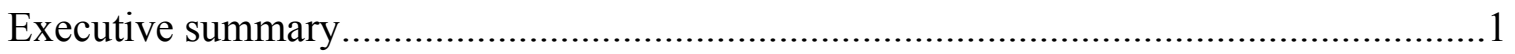

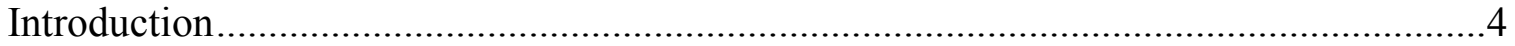

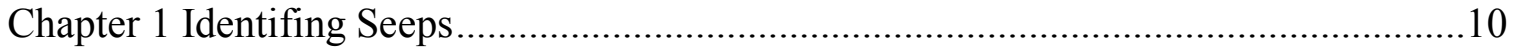

Chapter 2 Biomarker and Carbon Isotope Analysis ....................................................44

Chapter 3 Chemometric Modeling, Tarball Sources, and Distribution .............................54

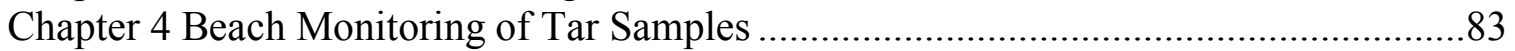

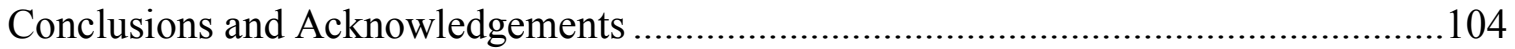

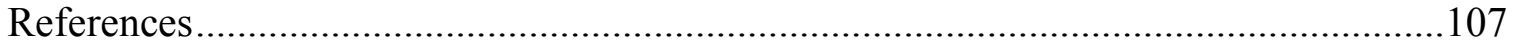

Appendix 1-1 Maps of beaches with samples locations and families ...........................28

Appendix 2-1 Location, classification, and geochemical data for crude oil, seep oil, and tarball samples. Link to http://pubs.usgs.gov/of/2009/1225/of2009-1225_appendix_2-1/ ..................................50

Appendix 2-2 Geochemical parameters used in tarball studies ......................................51

Appendix 3-1 Location, classification, and source/age related geochemical data for crude oil, seep oil, and tarball samples from coastal California, used in the chemometric model with classification of non-model tarballs. Link to http://pubs.usgs.gov/of/2009/1225/of2009-1225_appendix_3-1/.....

Appendix 3-2 Hierarchical cluster diagram of the 388-sample training set for the

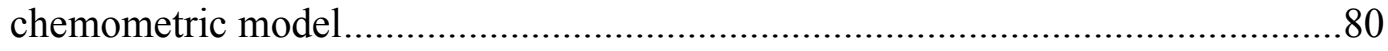

Appendix 4-1 Graphs of tar mass and number as influenced by season and tidal cycle 


\section{Natural Offshore Oil Seepage and Related Tarball Accumulation on the California Coastline-Santa Barbara Channel and the Southern Santa Maria Basin; Source Identification and Inventory}

By Thomas D. Lorenson, Frances D. Hostettler, Robert J. Rosenbauer, Kenneth E. Peters, Jennifer A. Dougherty, Keith A. Kvenvolden, Christina E. Gutmacher, Florence L. Wong, and William R. Normark

\section{Executive Summary}

Oil spillage from natural sources is very common in the waters of southern California. Active oil extraction and shipping is occurring concurrently within the region and it is of great interest to resource managers to be able to distinguish between natural seepage and anthropogenic oil spillage.

The major goal of this study was to establish the geologic setting, sources, and ultimate dispersal of natural oil seeps in the offshore southern Santa Maria Basin and Santa Barbara Basins. Our surveys focused on likely areas of hydrocarbon seepage that are known to occur between Point Arguello and Ventura, California.

Our approach was to 1) document the locations and geochemically fingerprint natural seep oils or tar; 2) geochemically fingerprint coastal tar residues and potential tar sources in this region, both onshore and offshore; 3 ) establish chemical correlations between offshore active seeps and coastal residues thus linking seep sources to oil residues; 4) measure the rate of natural seepage of individual seeps and attempt to assess regional natural oil and gas seepage rates; and 5) interpret the petroleum system history for the natural seeps.

To document the location of sub-sea oil seeps, we first looked into previous studies within and near our survey area. We measured the concentration of methane gas in the water column in areas of reported seepage and found numerous gas plumes and measured high concentrations of methane in the water column. The result of this work showed that the seeps were widely distributed between Point Conception east to the vicinity of Coal Oil Point, and that they by in large occur within the 3-mile limit of California State waters. Subsequent cruises used sidescan and high resolution seismic to map the seafloor, from just south of Point Arguello, east to near Gaviota, California. The results of the methane survey guided the exploration of the area west of Point Conception east to Gaviota using a combination of seismic instruments. The seafloor was mapped by sidescan sonar, and numerous lines of high -resolution seismic surveys were conducted over areas of interest.

Biomarker and stable carbon isotope ratios were used to infer the age, lithology, organic matter input, and depositional environment of the source rocks for 388 samples 
of produced crude oil, seep oil, and tarballs mainly from coastal California. These samples were used to construct a chemometric fingerprint (multivariate statistics) decision tree to classify 288 additional samples, including tarballs of unknown origin collected from Monterey and San Mateo County beaches after a storm in early 2007. A subset of 9 of 23 active offshore platform oils and one inactive platform oil representing a few oil reservoirs from the western Santa Barbara Channel were used in this analysis, and thus this model is not comprehensive and the findings are not conclusive. The platform oils included in this study are from west to east: Irene, Hildago, Harvest, Hermosa, Heritage, Harmony, Hondo, Holly, Platform A, and Hilda (now removed).

The results identify three "tribes" of ${ }^{13} \mathrm{C}$-rich oil samples inferred to originate from thermally mature equivalents of the clayey-siliceous, carbonaceous marl, and lower calcareous-siliceous members of the Monterey Formation. Tribe 1 contains four oil families having geochemical traits of clay-rich marine shale source rock deposited under suboxic conditions with substantial higher-plant input. Tribe 2 contains four oil families with intermediate traits, except for abundant 28,30-bisnorhopane, indicating suboxic to anoxic marine marl source rock with hemipelagic input. Tribe 3 contains five oil families with traits of distal marine carbonate source rock deposited under anoxic conditions with pelagic but little or no higher-plant input. Tribes 1 and 2 occur mainly south of Point Conception in paleogeographic settings where deep burial of the Monterey Formation source rock favored generation from all three members or their equivalents. In this area, oil from the clayey-siliceous and carbonaceous marl members (Tribes 1 and 2) may overwhelm that from the lower calcareous-siliceous member (Tribe 3) because the latter is thinner and less oil-prone than the overlying members. Tribe 3 occurs mainly north of Point Conception, where shallow burial caused preferential generation from the underlying lower calcareous-siliceous member or another unit with similar characteristics.

It is very desirable to be able to clearly distinguish the naturally occurring seep oils from the anthropogenically derived platform oils. Within the "training set" of oils and tars (388 samples), the biomarker parameters are sometimes sufficient to allow unique discrimination of individual platform oils. More often however, platform samples and seep samples with sources geographically close to each other are too similar to each other, with respect to the biomarker parameters, to definitively differentiate them on that basis alone. In some cases other parameters can be helpful. These other parameters are related to the degree of biogeochemical degradation or weathering that the oils or tars have experienced. These components include the typical oil distribution of n-alkane hydrocarbons and isoprenoids pristane and phytane. All of the platform oils in our sample set contain these components. On the other hand, the seep oils or tars have been exposed to significant biodegradation while in the near subsurface. The majority, but not all of seep oils or tars have been biodegraded up to or beyond the loss of n-alkanes and isoprenoids. Seep oils found in the vicinity of Coal Oil Point or Arroyo Burro are apparently the least weathered and are particularly likely to retain significant $n$-alkanes and isoprenoids. Therefore the combination of chemometric fingerprinting and the presence or absence of $n$-alkanes and isoprenoids help to differentiate anthropogenic production oils versus natural seeps oils and tars. The differentiation is not always definitive because of the close chemical similarity of some samples and the variability in the biodegradation progression. This is the case near Coal Oil Point, and near Platform A 
(Dos Cuadros Field) where seep oils and Platform Holly and Platform A oils are genetically very similar and cannot be definitively distinguished after a period of a few days of weathering. In contrast, oils from the Point Conception platforms can be distinguished on the basis of chemometric fingerprinting alone. In the middle of this spectrum are oils from Platforms Harmony, Heritage, and Hondo, where it is expected that oil weathering would take on the order of two weeks to a month to produce tarballs similar to those seen near Point Conception. In this case there is a much greater degree of weathering needed to proceed from produced oil to the biodegraded tar characteristic of tarball stranded on the beach.

Tar deposition on beaches was monitored as part of cooperative with the County of Santa Barbara Energy Division and the U.S. Geological Survey during 2001-2003. We found tar deposition varies on a seasonal basis. In general, tarballs accumulate at a faster rate or remain longer on all beaches during the summer and fall months. The reasons for this are unclear based on our limited observations, however we speculate that factors such as prevailing winds and currents combined with more quiescent wave conditions favors the accumulation and preservation of tarballs on the beach during the summer and fall months. In contrast, winter storms, with much greater wave action remove beach sand and other materials, and stormy seas tend to break up oil that might weather into tarballs. Natural seepage is affected by the spring/neap tidal cycle; however, the link to tar deposition is unclear. Longer periods of monitoring are needed to address the variability in the data and provide a more robust statistical analysis. 


\section{Introduction}

This study has developed a living geochemical chemometric (fingerprint) model tuned for oils and tars sourced from the California Monterey Formation. The model allows for inquiry of new unknown tars or oils to build upon our library of coastal tar fingerprints as a database for future investigations. Our study area includes the entire coastline of California (Fig. I-1) however we are currently concentrating our efforts in southern California. We have also examined the possible origins of tars and provides qualitative rates of deposition measured during a three-year period on Santa Barbara county beaches from 2001-2003.

The California coastline contains long stretches of sandy beaches, rocky inlets, high cliffs hanging precipitously over crashing waves, and many other scenic wonders. This beautiful natural resource is, however, continually exposed to contamination from both natural and anthropogenic sources. In particular, the coastline is impacted by petroleum hydrocarbons that occur as tarballs washed up all along the shorelines and as onshore seepages from rocky outcrops and cliff faces. Natural sources for these petroleum hydrocarbons include prolific, frequently chronic, onshore and offshore shallow oil seeps, especially prominent along the southern California coast (State Lands Commission Staff Report, 1977). Anthropogenic sources include possible accidental oil spills from commercial vessel traffic, from offshore drilling rigs, and from ships involved in the processing and transport of oil along the coastal shipping lanes.

Differentiating between natural and anthropogenic petroleum sources and determining specific sources of coastal contamination is essential to evaluate threats to the ecosystems and to limit contaminant impact. Although crude oils and source rocks in the California borderland oil fields have been extensively characterized (Curiale and others, 1985), published geochemical work on the substantial (approximately 20,000 tonnes/year discharged into the ocean, as estimated by a U.S. Academy of Sciences report, NAS, 2002) hydrocarbon beach tar accumulations along the California coast is limited. Reed and Kaplan (1977) used stable isotopic ratios of sulfur, nitrogen, and carbon to distinguish seep oils, beach tars, and crude oils from the southern California Borderland. Another early study utilized stable isotopic ratios of carbon and sulfur and total sulfur content of asphaltene fractions to correlate beach tars deposited near Los Angeles with their probable sources, to distinguish natural seep oils from imported tanker crude oils and local production wells, and to evaluate seasonal distribution patterns and transport (Hartman and Hammond, 1981). Hartman and Hammond (1981) determined that more than 50 percent of asphalt found in Santa Monica Bay is from the Coal Oil Point (COP) seeps, which are $\sim 150 \mathrm{~km}$ to the west. They proposed that asphalt transport from COP to Santa Monica is dependent on seasonal ocean currents and gyres. A significant decrease in asphalt deposition along Santa Monica Bay beaches was observed during winter months. Hartman and Hammond (1981) proposed that during the winter, COP asphalt is transported westward in the Santa Barbara Channel (SBC) and subsequently northward by the Davidson Current that emerges near the Channel Islands. A more recent study used various molecular parameters of tar residues on beaches within the Monterey Bay National Marine Sanctuary to try to ascertain sources (Kvenvolden and others, 2000). Reports on coastal tar and oil seeps considers the 
geologic framework and some potential tarball correlations related to this study (Kvenvolden and Hostettler, 2003; Hostettler and others, 2004).

The Santa Barbara County Energy Division, in conjunction with the United States Geological Survey (USGS), conducted a two year long "fingerprinting" and monitoring study of stranded asphalt on Santa Barbara County beaches, oil samples from natural oil seeps and offshore oil platforms (examples given in figs. I-2, 3, 4, and 5) (Lorenson and others, 2004). The samples were analyzed for biomarkers (persistent hydrocarbons) and various isotopic compositions, and then incorporated into an asphalt "fingerprint" database. The fingerprints of COP beach asphalt, COP natural seep oil, and Platform Holly crude oil are very similar and require sophisticated chemical analysis to discriminate between the samples. All beach asphalt analyzed was determined to be natural oil from the Monterey Formation, the main petroleum source and reservoir rock in the area (Lorenson and others, 2004).

Although the county study was inconclusive in identifying sources, information was gathered on the distribution of beach asphalt (tarballs), its variation, and possible sources. Lorenson and others, 2004 observed higher asphalt accumulations during the summer and fall months and proposed variations in tides, currents, winds, and surf zone energy to be the cause. Of the southern beaches, COP accumulated the most asphalt mass. Of all the beaches surveyed, the largest number of tarballs was observed at COP, but not the most asphalt in terms of mass. COP tarballs on average were smaller than those collected at beaches in the northern part of the county. The northern beaches generally had much larger tarballs than the southern beaches, resulting in more asphalt mass. Differences in observed tar balls sizes between northern and southern beaches were attributed to different sources and confirmed by geochemical analyses. Tarballs on northern and southern beaches were chemically determined to have different sources (Lorenson and others, 2004). Lorenson and others, 2004 proposed that the difference in sizes was due to the different sources.

These works all conclude that much of the tar accumulation originates from the Miocene Monterey Formation. Source rock in the Monterey Formation shares several chemical characteristics with local tars, including 1) unusually "heavy" $\delta^{13} \mathrm{C}$ (around $23 \%$ ); 2) aliphatic biomarker parameters 28,30-bisnorhopane indicating an anoxic marine depositional environment (Curiale and others, 1985), high $\mathrm{C}_{35} \alpha \beta$-hopane $22 \mathrm{~S}$ and 22R epimers compared to $\mathrm{C}_{34}$, and the presence of gammacerane (Peters and Moldowan, 1993); 3) a characteristic value (>3) for the biomarker parameter called "the triplet" (Kvenvolden and others, 1995), defined in appendix 1;4) a small but consistent presence of oleanane; 5) sterane parameters indicating low maturity as opposed to fully mature hopane parameters; 6) very low diasteranes relative to regular steranes, indicating a clastic-poor marine source rock; 7) abundant aromatized steranes, especially monoaromatics relative to triaromatics, indicating low thermal maturity (Curiale and others, 1985); and 8) sulfur-rich PAH, such as dibenzothiophenes.

Although the above chemical components are common to all the tarballs, their relative proportions vary. A fingerprinting technique utilizing ratios of these constituents, and other biomarker parameters from both the aliphatic and aromatic hydrocarbon suites, allows discrimination among different tar samples. Tars can be correlated with each other and with distant sources. 
The chemical composition of the tarballs is linked to its geochemical history. Despite the large number of offshore shallow hydrocarbon seeps, and the constant impingement of tar onto the shoreline, little is known about the mechanics of hydrocarbon formation in shallow seeps, specific sources of tarballs, or their transport from the marine environment onto the shore. At present there is no irrefutable data linking tar on beaches to specific offshore natural seeps (Leifer and others, 2002, Del Sontro, and others, 2007).

Because many of the tarballs from offshore seeps are transported significant distances from their sources by ocean currents, geochemical assignment of their origin provides insight into the circulation patterns of the coastal currents. The circulation patterns within the Santa Barbara Channel are well studied (Hickey, 1998; Harms and Winant, 1998; Winant and others, 1999, 2003). Persistent cyclonic circulation, upwelling conditions, and wind-relaxing drive the currents in a seasonally dependent pattern. The net result of drifter studies is a combination of in-channel deposition, both on the mainland coast and on the Channel Islands, with flow predominantly toward the south and east in the spring and summer (California Current) and to the west and north in the late fall and winter (Davidson Current and the Southern California Countercurrent). Mapping depositional sites of tarballs that also drift with these ocean currents, complement these drifter studies, as well as provide information on the fate of these petrogenic contaminants in the coastal environment.

Our results demonstrate that tar accumulations on California beaches can be related to natural sources and that there is extensive offshore seepage as documented in this report. Offshore seepage results in producing tarballs, some of which find their way to nearby beaches. Seepage is also responsible for creating unique seafloor oases for sessile organisms that would otherwise not survive on the sand-covered seafloor.

We have also have shown that natural seeps can, in many occurrences, be distinguished from produced oil with gas chromatography - mass spectrometry, chemometric fingerprinting, and statistical analyses provided that the produced oil is not biodegraded. In some cases even produced oils, biodegraded near the sea floor or on the sea surface are sufficiently different from natural seepage and can be distinguished. Further, this conclusion can be applied to California Monterey Formation-sourced oils common to the study area. 


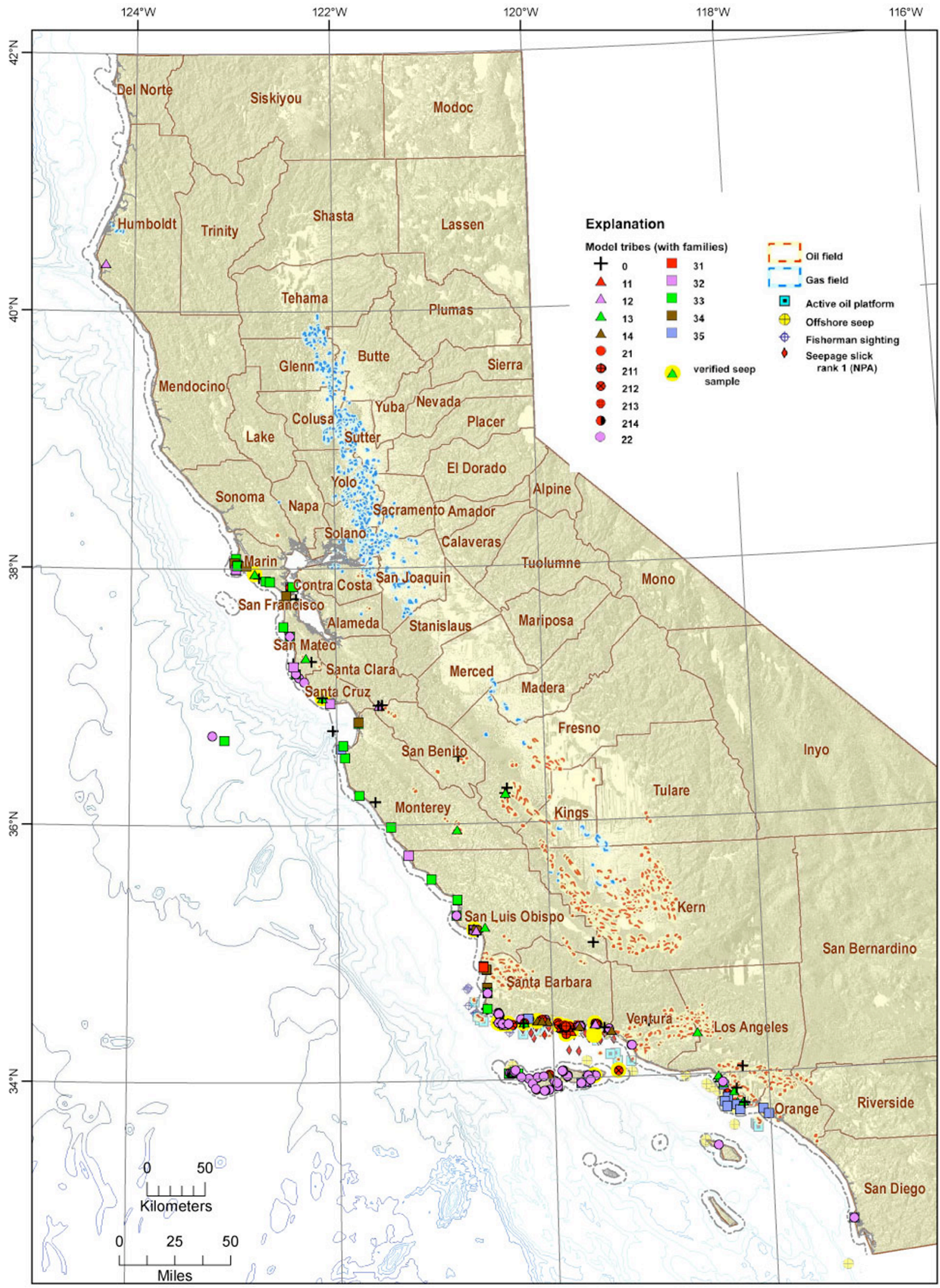

Figure I-1. Map showing locations of beaches, sampled oil platforms and natural seep samples. 


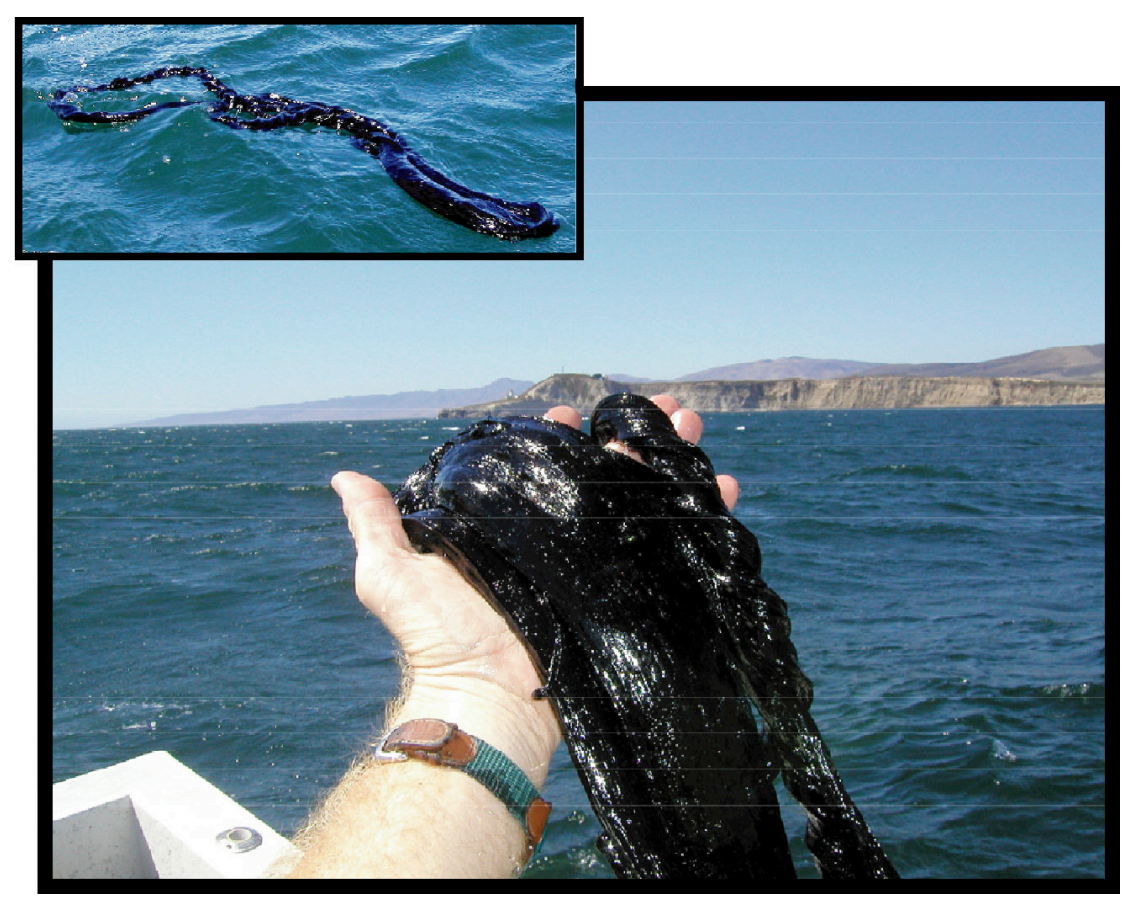

Figure I-2. Photographs showing viscous tar sampled offshore Point Conception. This tar differs in both morphology and chemical composition from oil and tar found offshore of the southern coast of Santa Barbara.

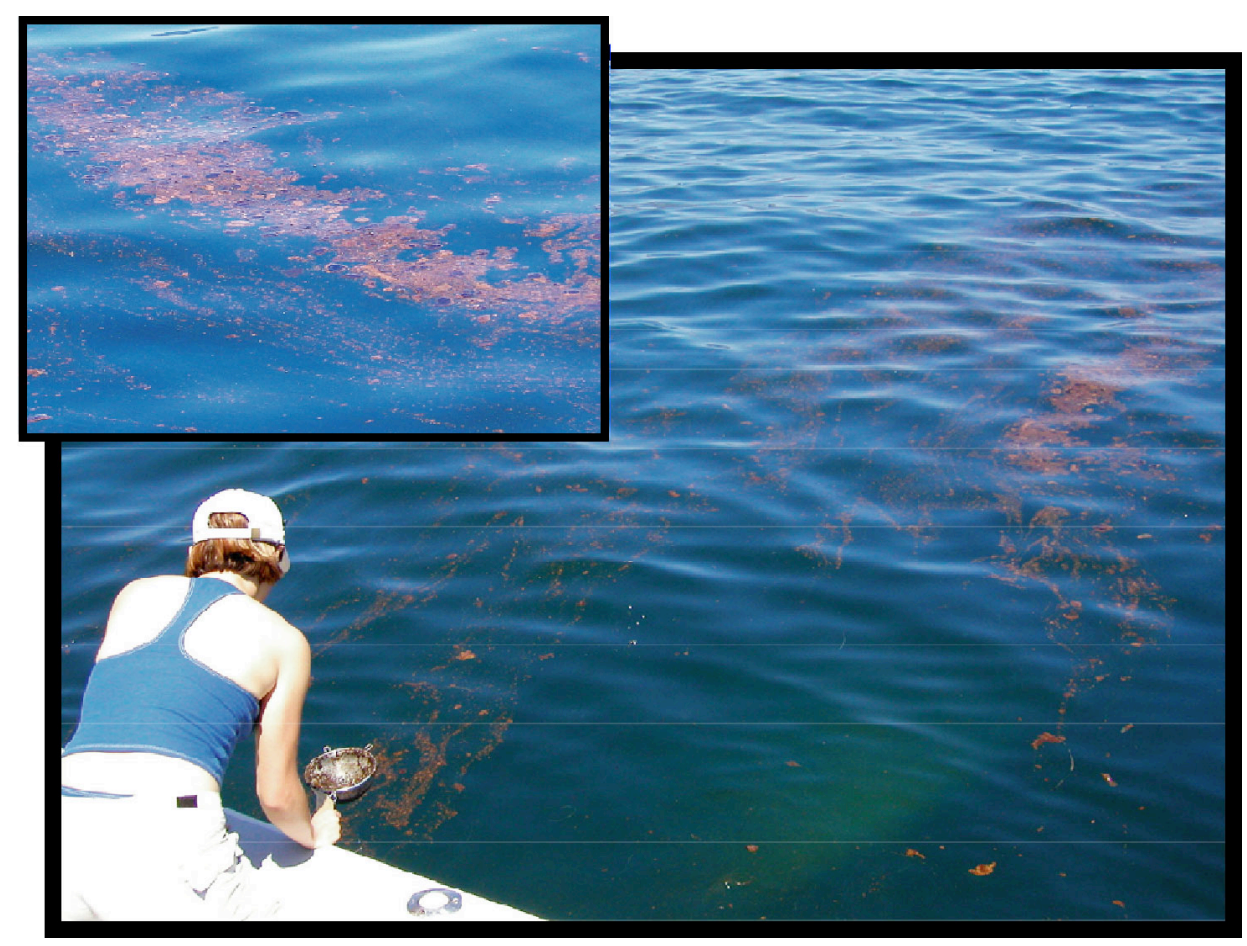

Figure I-3. Photograph showing the sampling of a natural oil slick. Inset shows the evolution of oil and mousse into tar patties that are often found on the southern Santa Barbara County coastline. 


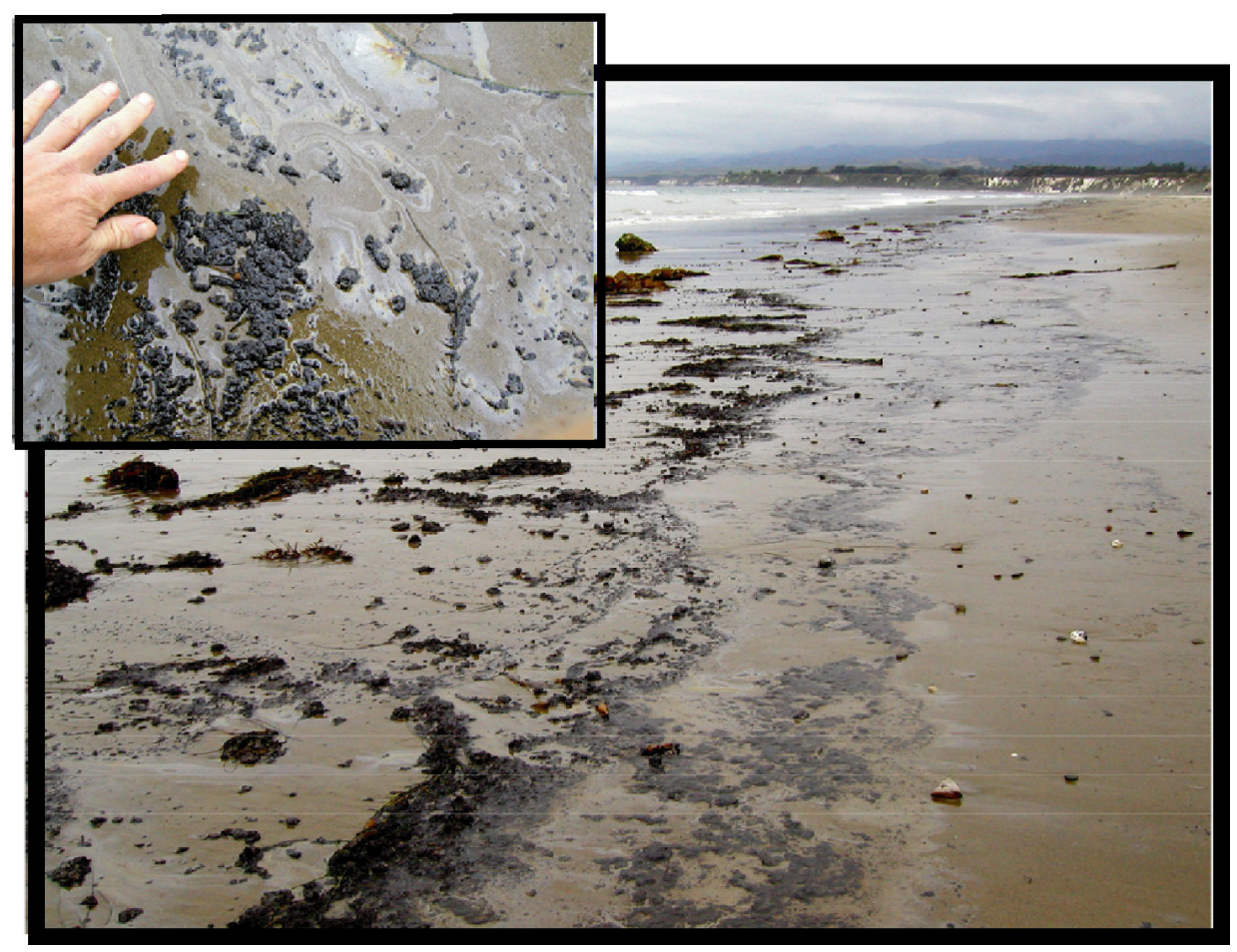

Figure I-4. Photographs showing fresh tar residue at Coal Oil Point. Photograph was taken on June 10, 2003.

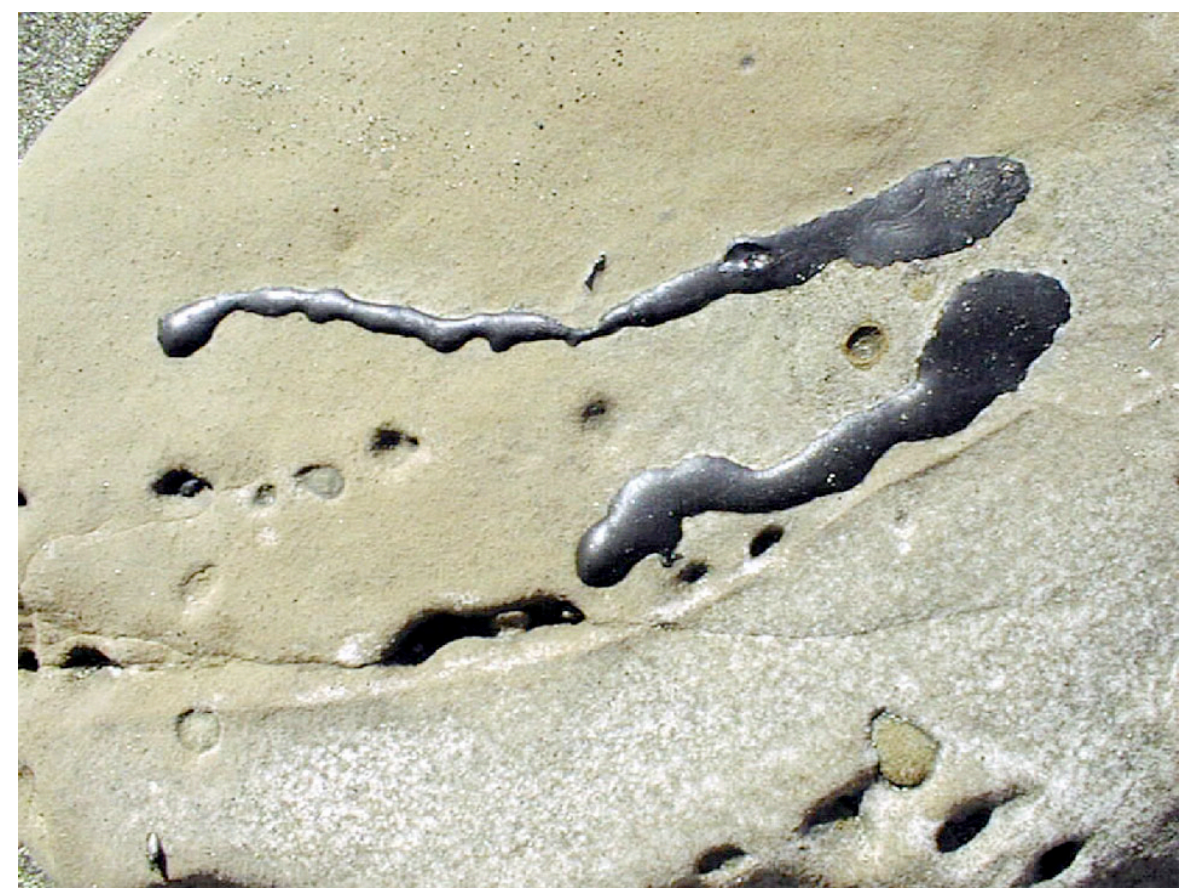

Figure I-5. Photograph showing tarball morphology typically found on Santa Barbara County's northern beaches and rocks. 


\section{Chapter 1. Identifying Seeps}

\section{Previous Studies and Background}

Petroleum in the ocean is a problem of enormous concern, impacting the environment, economy, and quality of life for coastal inhabitants. Globally, 1,300,000 tons of oil entered the oceans annually in the 1990s, of which natural seeps emitted 600,000 tons. Vessel spills accounted for 100,000 tons, run-off accounted for 140,000 tons, and pipelines accounted for 12,000 tons. Annually, California marine seeps contribute 20,000 tons of oil to North Americas estimated total seepage of 160,000 tons (NRC 2002). Despite the significance of oil in the ocean, there is a misconception that natural oil seepage on the California coastline is from pollution. Thus, finding seeps and fingerprinting their chemical signature is the first concrete step in documenting the role of natural oil seepage and its impact on the shoreline.

\section{Offshore Santa Maria Basin}

The offshore Santa Maria Basin contains two types of hydrocarbon seeps in surficial marine sediments and the water column: active and passive (Saenz, 2002; fig. 11). Active seeps (macroseeps) occur where gas bubbles, pockmarks, gas-vent craters, tar seeps, or bright spots are visible on seismic profiles or side-scan sonar records. These hydrocarbon seeps presumably occur where generation and migration of hydrocarbons from source rocks are ongoing today and where migration pathways have developed along structural conduits through the overlying sediments of late Neogene to Quaternary age. In the northern and central areas of the basin, passive and microseeps occur where the concentration of migrated hydrocarbons is low and there are no visible geophysical anomalies. Microseeps are detected by sniffer or geochemical surveys that sample and analyze hydrocarbon concentrations in the water column. It is probable that passive seeps occur in areas where effective regional seals or deep-water depths limit vertical migration.

Primary controls for the location and distribution of hydrocarbons in near-surface sediments are active faults and eroded or fractured anticlinal folds. Active seeps have been detected near the water-sediment interface, in the water column or on the sea surface, sometimes at relatively large distances from major surface leak points interpreted as gas seeps. The northern and southern portions of the study area in the offshore Santa Maria Basin contain numerous active hydrocarbon seeps (fig. 1-1) (Saenz, 2002). The west central Santa Maria Basin study area contains isolated areas of passive seeps. In these areas, there is little evidence of shallow pools of migrated hydrocarbons, and geophysical anomalies are rare (Saenz, 2002).

Active seeps in the study area were detected near the water-sediment interface and within the water column. Using only geophysical data, the presence of passive seeps or microseeps can only be inferred or detected indirectly. The presence of near-surface to shallow gas-charged sediment horizons and numerous seafloor features (e.g.; gas-vent craters, pockmarks, etc.) strongly implies the presence of passive, episodic seeps or microseeps. The presence of microseeps in the offshore Santa Maria Basin is confirmed by sniffer data (Sigalove, 1985). Our studies conducted in the area during 2002 saw little evidence of active seepage such as gas and oil in the water, however there was elevated methane in the water column west of Point Conception. The likely origin of the elevated 
methane is from the seeps within the Santa Barbara Channel moving westward with the currents as described by Mau and others, (2007).

Numerous water-column anomalies were observed on seismic reflection profiles and side-scan sonar records. Most were mapped on the shallow hazard maps. As illustrated by Saenz (2002), water-column anomalies are present as small, discrete vshaped plumes, zones of plumes, and large diffuse zones. Water-column anomalies represent the seismic response of gas bubbles rising and expanding in the water column. These plumes are similar to those mapped by Fischer and Stevenson (1973); Fischer (1976); and other workers off Coal Oil Point (COP) and Goleta Point in the Santa Barbara Basin. In the COP area, the rising gas and oil are visible on the sea surface and have been collected, analyzed $\left(\mathrm{C}_{1}\right.$ through $\left.\mathrm{C}_{20}\right)$, and mapped using an experimental sniffer system (P. J. Fischer 1976, unpublished; Sigalove, 1985; and Saenz 2002).

Water-column anomalies are concentrated in the northern and central portions of the offshore SMB study area and overlie shallow subsurface gas horizons within fault zones, and over anticlinal crests. Water-column anomalies in the study area were identified and mapped using echo sounder, $3.5 \mathrm{kHz}$ subbottom profiler and side-scan sonar records. These water-column anomalies are generally observed to be in association with shallow zones of gas-charged sediment and vent craters (Saenz, 2002).

In the southern offshore Santa Maria Basin and northwestern Santa Barbara Basin, tar seep mounds and sheets are present on the seafloor (Saenz, 2002). Tar accumulations are most abundant near Point Conception where sheets of tar cover large areas (to 10 $\mathrm{km}^{2}$ ) (this study) and form a 3 - $4 \mathrm{~m}$ high, seaward facing scarp (Vernon and Slater, 1963). East of Point Conception, mounds range in size up to $30 \mathrm{~m}$ in diameter and $2.5 \mathrm{~m}$ in height. These mounds are irregularly distributed along an east-west trending faulted anticline and overlie exposed Monterey Formation outcrops. To the west of Point Conception in Area S-II, one mound imaged by $3.5 \mathrm{kHz}$ profiling is about $15 \mathrm{~m}$ high and 55-60 m in length (Saenz, 2002). Offshore of Point Arguello, several distinctive, moundlike seafloor features appear on the geophysical records. In this area, gas seeps seen as water-column anomalies are associated with tar mounds (Saenz, 2002). As observed, on subbottom and side-scan sonar records, these mounds are gently rounded and have a vertical relief of 1 - 5 m (Saenz, 2002). 


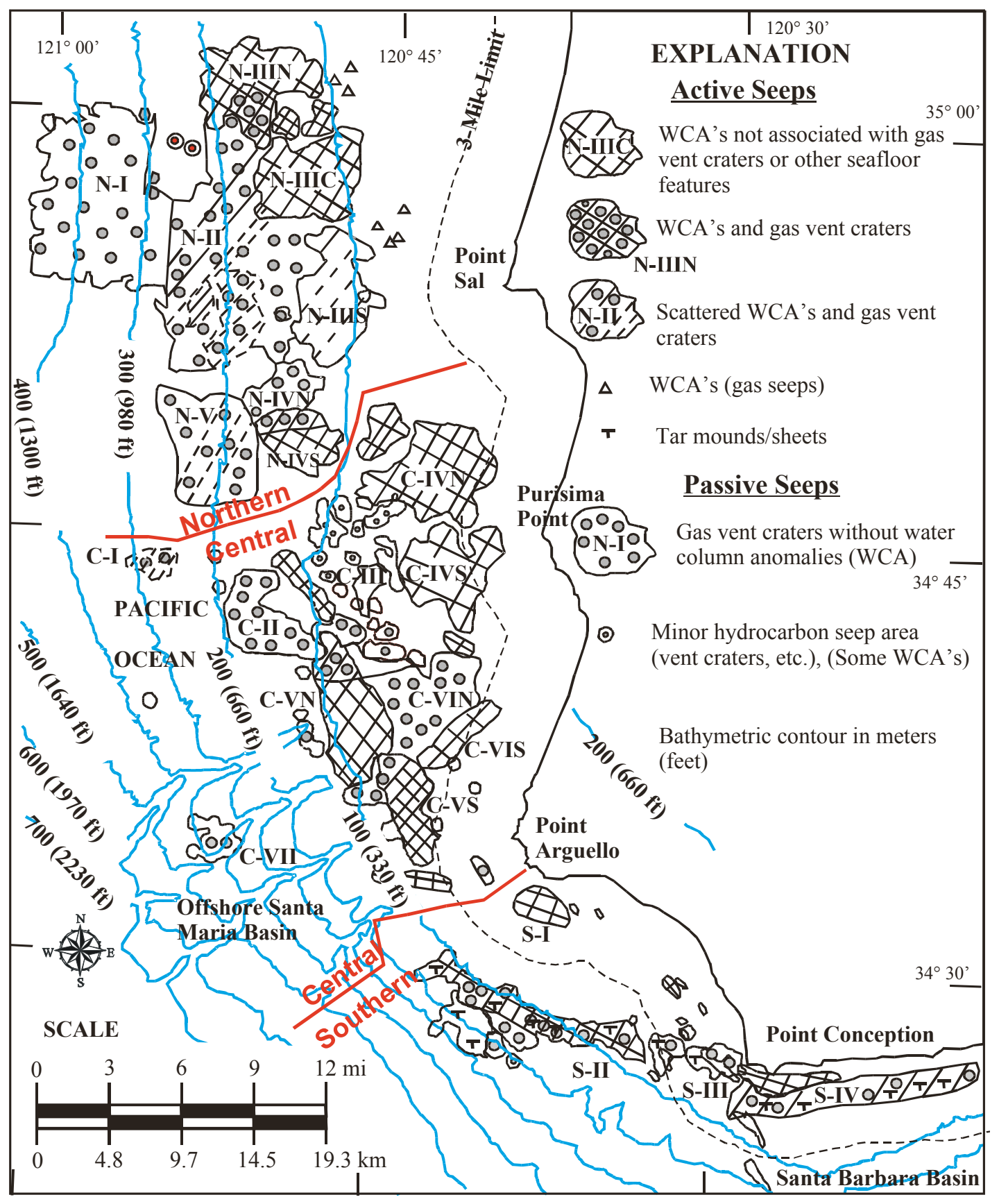

Figure 1-1. Map showing hydrocarbon seep locations in the offshore Santa Maria Basin and northwestern Santa Barbara Basin by Saenz (2002) from Fischer, (1972, 1998); Fischer and Stevenson (1973), and unpublished reports compiled by Saenz (2002). Water-column anomalies (WCAs).

\section{Coal Oil Point Seep Field}

There are many seepage locations offshore of California, but Santa Barbara Channel has the richest recorded history of seepage and includes one of the most prolific seep fields in the world; the COP seep field (Landes, 1973). Between the 16th and 18th centuries, several European explorers noted the presence of petroleum within the region 
of modern Santa Barbara County and offshore, as well as its use by the native Chumash Indians. Oil slicks and surfacing bubbles were observed on the sea surface, meanwhile, the Chumash used asphalt found on COP beaches and elsewhere to caulk their canoes (Galloway, 1998). Asphalt mining flourished within Santa Barbara County during the mid-1800s, and its products were used to pave the first streets of San Francisco and Santa Barbara (Galloway, 1998). During the 1920s and 1930s, the Ellwood field, located just west of COP, was drilled below shallow waters from more than sixteen oil piers (Bartlett, 1998). During the next three decades, wells were drilled at the point (COP) from piers and submarine platforms. Production of the South Ellwood field began in 1967 with the construction of platform Holly (Galloway, 1998). The production of oil from the South Ellwood field from Platform Holly continues today. The wells at the eastern and western extents of the original Ellwood field were abandoned by 1971 and 1993, respectively (Bartlett, 1998).

The COP seep field produces a wide diversity of oil and gas seepage rates. Gas seepage spans many orders of magnitude, and although oil to gas ratios remain unquantified, oil chromatograms suggest the oil/gas ratio also varies widely (Leifer and others 2006a). Studies have quantified seep-area (e.g., Allen and others, 1970; Fischer and Stevenson, 1973) and emission fluxes (e.g., Hornafius and others, 1999; Quigley and others, 1999; Clark and others, 2000) using sonar techniques, ocean chemistry, and direct gas capture with floating buoys. Fischer and Stevenson (1973) noted changes in seepage on decadal time scales in the COP area with a significant decrease in seepage areas between 1946 and 1973, which was attributed to offshore production localized to platform Holly. During the past decade, the University of California Santa Barbara (UCSB) seep group has mapped the seeps in the area using sonar images and quantified seepage flux from sonar and direct gas capture using a flux buoy (Washburn and others, 2001). Results indicate that $\sim 15,000 \mathrm{~m}^{3}$ per day of seep gas escapes to the atmosphere from $\sim 3 \mathrm{~km}^{2}$ of sea floor (Hornafius and others, 1999), and roughly an equal amount dissolves into the coastal ocean (Clark and others, 2000). Using data collected in 1973 and 1995, Quigley and others, (1999) demonstrated a decrease in area and number of seeps within $1.5 \mathrm{~km}$ of Platform Holly, which they attributed to production. Seeps are located above anticlines along three trends. The inner trend ( $20 \mathrm{~m}$ depth) includes Shane and IV Super seeps. A second trend ( $\sim 0 \mathrm{~m}$ depth) includes the Horseshoe and Coal Oil Point seeps. The deepest trend ( $70 \mathrm{~m}$ depth) includes the La Goleta and Seep Tent seeps as well Coal Oil Point (fig 9, appendix 1-1).

\section{Oil Emission measured at Coal Oil Point}

Allen and others (1970) used a combination of aerial, sea surface, and underwater techniques to estimate a field flux of 50 -70 barrels of oil per day. The area surveyed was directly south of COP covering over $3000 \mathrm{~m}^{2}$ of seafloor (not the entire seep field).

Underwater-flux estimates were calculated by measuring the volume of oil collected in an inverted gallon jug during a known time. Surface flux estimates were determined by measuring slick width and drift rate with aerial photography and measuring slick thickness through absorbance analysis of oil collected on oil-adsorbent material (cheesecloth). They state that their estimate is only an average for the shallow seeps surveyed and that the flux can range from $10-100$ barrels per day easily (Allen and others, 1970). Fischer (1977) suggested that the COP seep field emits from 25-400 
barrels day per day and represents $\sim 60 \%$ of the total flux for the entire Santa Barbara Channel (SBC). Hornafius and others (1999) used sonar to identify and quantify gas seepage. They used their gas seepage estimate and an oil-to-gas ratio for the field (Clester and others, 1996) to estimate oil seepage of 100 barrels per day $(16,000 \mathrm{~L} /$ day $)$ for all seeps deeper than those studied by Allen and others (1970). Including oil from the shallow seeps surveyed by Allen and others (1970), 150 to 170 barrels of oil per day $(\sim 23,800-27,000 \mathrm{~L} /$ day) is emitted from the COP seep field (Hornafius and others, 1999).

Since 2000, Del Sontro and others, (2007) have identified additional, informally named major seeps by sea surface surveys and/or sonar. In addition, areas of less intense seepage and areas of dispersed seepage that have been the focus of scientific research also were informally named. Many of these seep areas have been surveyed at the seabed by divers and submersibles. Based on observations collected at the sea surface and seabed for named seeps in the seep-field, general seep field characteristics can be described. The shallowest ( 3 to $\sim 12 \mathrm{~m}$ water depth) seeps emit gas with trace hydrocarbons, while deeper seeps emit gas and non trace oil. Seep oiliness varies significantly between seeps, visible at the sea surface and in chromatograms of seep samples (Clark and others, 2003; Leifer and others, 2006b). For example, hundreds of oil droplets can be seen surfacing in less than thirty minutes at the main plume of the Patch and La Goleta seep areas, thereby producing a large surface slick. However, Tonya and Shane seeps emit much less oil compared to their gas flux and produce much smaller surface slicks. Plume intensity was based on the surface observation of flux as identified by the apparent upwelling and outwelling flows and the depth of the seep. A seep with high or very high plume intensity does not necessarily cover a larger surface area of the seabed or sea surface. Highintensity plumes have fast upwelling rates and a pronounced outwelling flow at the sea surface. Low intensity plumes may also have an outwelling flow, but in general are weak. Many low-intensity plumes cover extensive areas of dispersed seepage.

Exposed asphalt mounds have been confirmed at Jackpot and Ira seeps, as well as an area recently mapped in $2008 \mathrm{SW}$ of Goleta point in about $40 \mathrm{~m}$ water depth. Asphalt mounds are small volcano-shaped mounds made almost entirely out of asphalt and can be hard or elastic. Jackpot asphalt mounds have a ropey appearance, similar to pahoehoe lava, indicating that oil or asphalt once flowed from the mound's center. During dives, active oil or asphalt seepage was not observed at either seep, however, gas seepage was observed (Del Sontro et al, 2007). The asphalt mounds are similar to those discovered by Vernon and Slater (1963). Unexposed asphalt mounds may be present at other seeps, particularly at those with high sedimentation rates. Shane Seep, for example, has a layer of asphalt buried beneath the fine-grained sediment near the major seabed features (Leifer and others, 2004). Note that the lack of some seepage characteristics, such as asphalt mounds and oil stringers, does not indicate non existence. Many seeps have not been visited and seepage can be intermittent at those that have been observed.

\section{P-1-02-SC Cruise to Locate Water-Column Methane Anomolies}

Water-column acoustic anomalies and methane concentrations were documented in coastal waters surrounding Pt. Conception, California, in March 2002. The purpose of this survey, was to locate active oil and gas seeps in the area as a background for further studies to determine likely sampling sites for tar or oil seeps and develop a knowledge 
base for studies of hydrocarbon flux, mainly oil, into the environment. Our study focused on the area from offshore roughly between Pt. Arguello and Gaviota, California

Concentrations were measured in water samples collected with Nisken bottles aboard the R/V Point Sur between March 19 and 23, 2002 in order to locate active oil and gas seeps. Nine stations were sampled outside this area to provide a regional context. Overall, 724 water samples from 94 stations (fig. 1-2) were measured for methane concentration (stations 17, 28, 43, 47, and 77 were not sampled). Hull-mounted, echo sounder $(3.5$ and $12 \mathrm{kHz})$ data were collected in conjunction with the methane survey to detect acoustic water column anomalies that might be associated with gas bubbles and tar-cemented mounds on the seafloor. Water column properties were measured for conductivity, temperature and density (CTD), as well as fluorescence of chlorophyll A as a proxy for phytoplankton concentration. CTD profiles are given for each station can be seen in Lorenson and others, 2003 (http:/geopubs.wr.usgs.gov/open-file/of03-122/). Additional cruise data and navigation can be found on the USGS Web site at: http://walrus.wr.usgs.gov/infobank/p/p102sc/html/p-1-02-sc.meta.html.

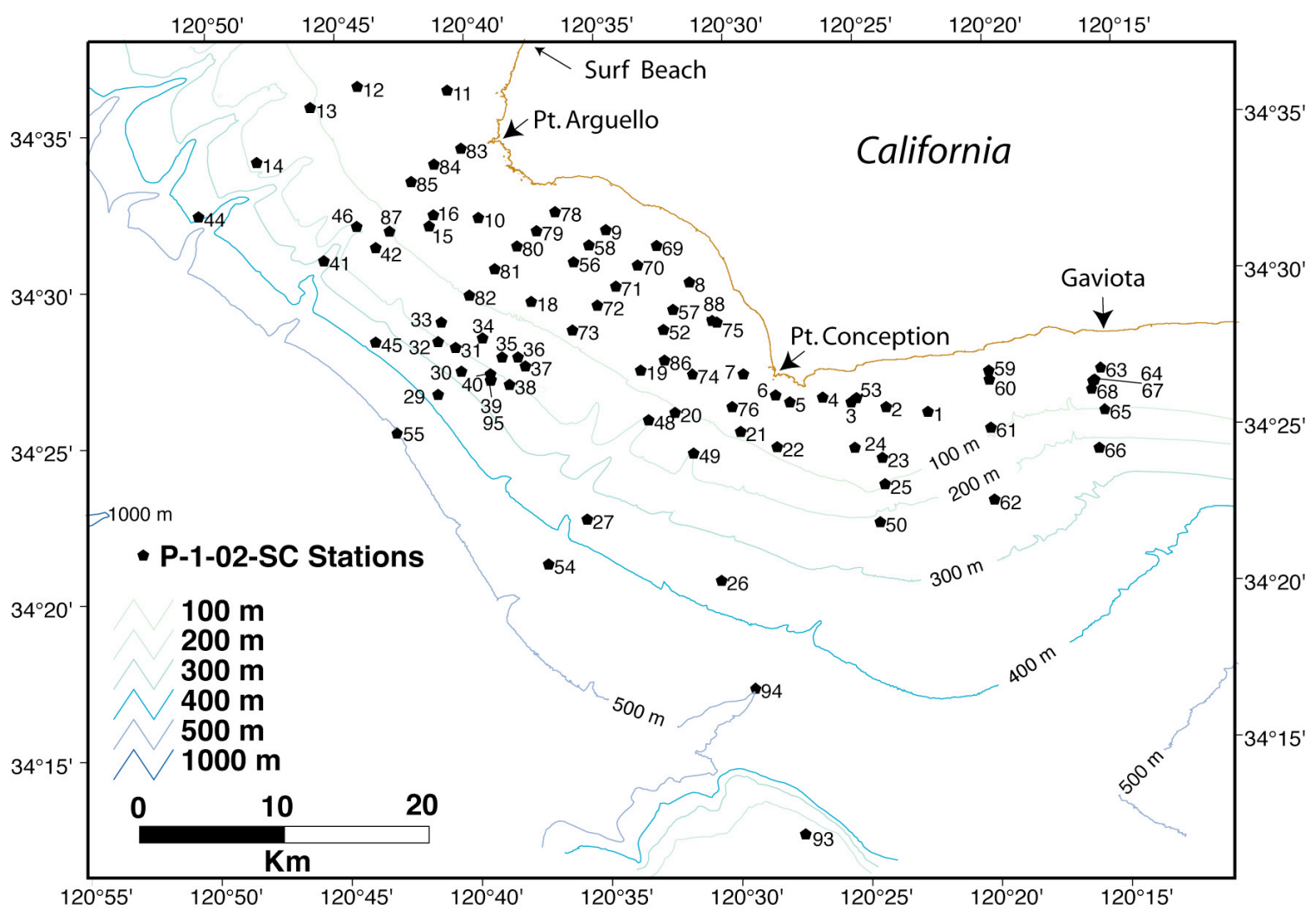

Figure 1-2. Map showing the stations occupied and sampled during cruise P-1-02-SC. Stations not shown: 89, 90, 91, and 92 near San Miguel Island, and stations 51, 96, 97 , 98 , and 99 north of the area shown. 


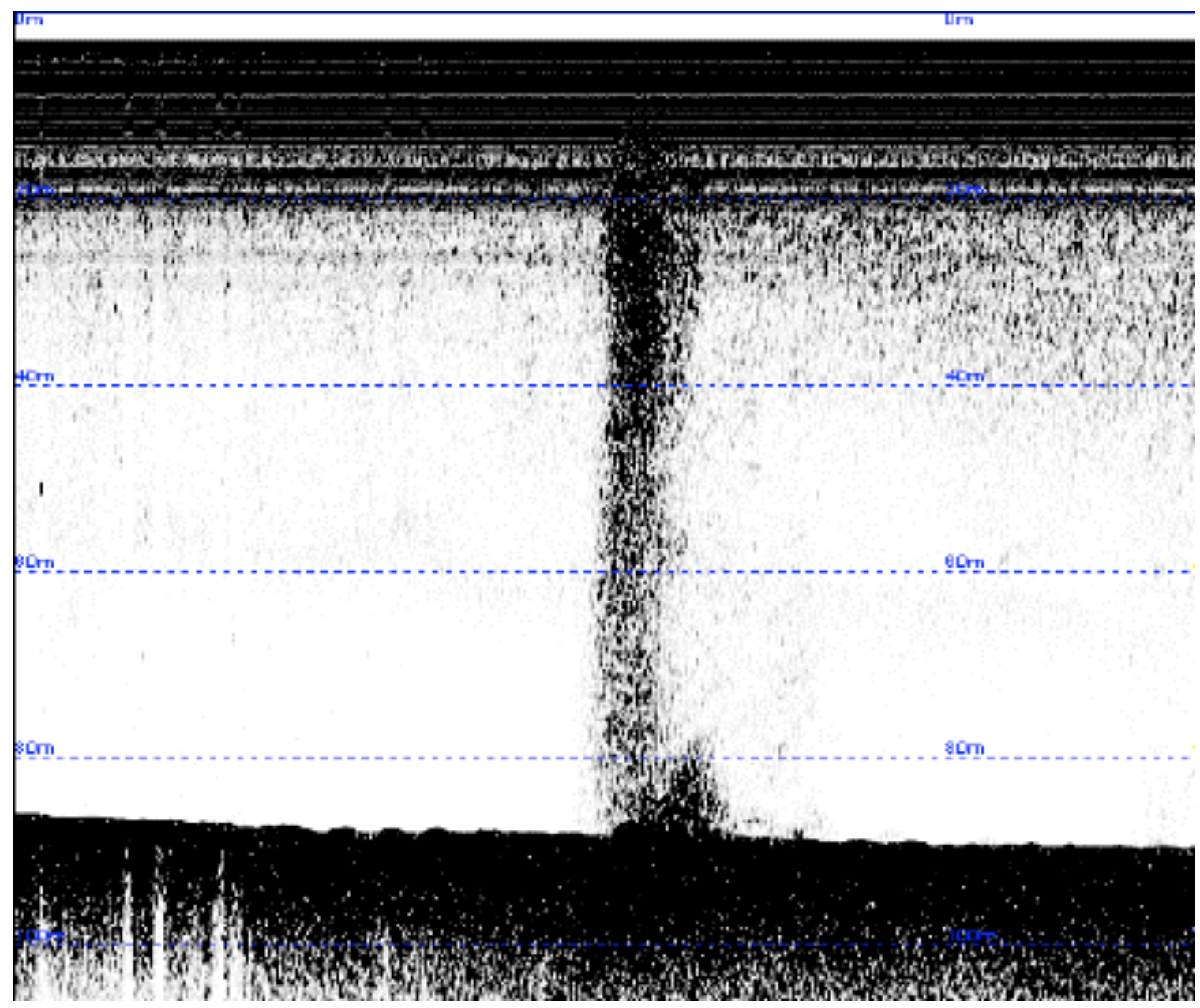

Figure 1-3. Example of an acoustic anomaly recorded by a $12 \mathrm{kHz}$ echo sounder and interpreted to be from gas bubbles rising through the water column from a depth of about $90 \mathrm{~m}$ in between stations 24 and $77\left(1.7 \mathrm{~km} \mathrm{SW}\right.$ of station 24 bearing $\left.219^{\circ}\right)$. Note that the gas-bubble train (water-column anomaly) extends as a straight line from a mound on the seafloor to the surface, unlike acoustic imagse of schooling fish that are typically seen as near-spherical masses that do not extend from the seafloor to the sea surface. 


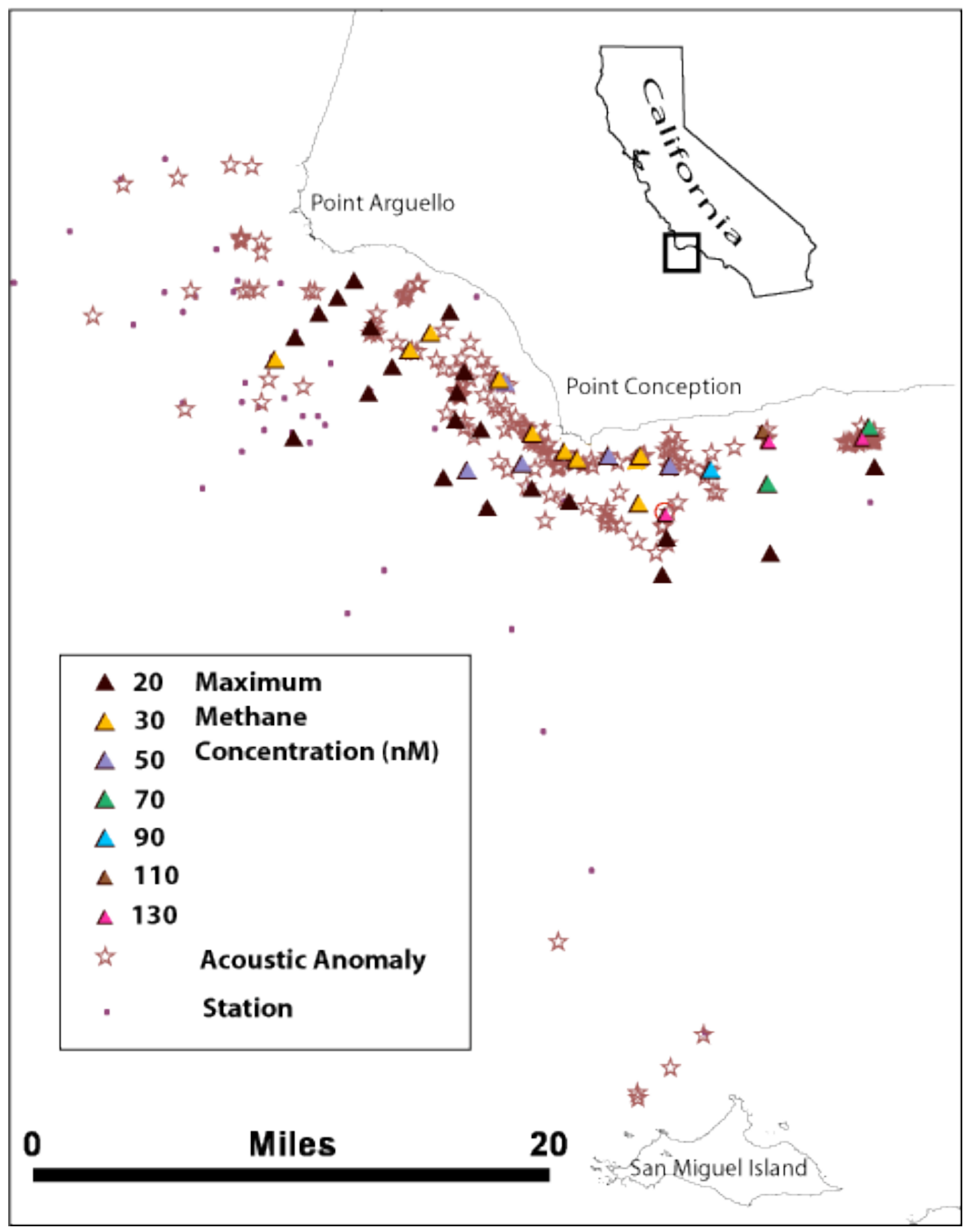

Figure 1-4. Maximum methane concentration measured at stations where the methane concentration exceeded $20 \mathrm{nM}$. Acoustic anomalies attributed to gas bubbles from natural oil and gas seeps with features similar to those shown in fig. 1-3 are seen as stars.

Overlapping occurrences of high methane concentration and acoustic anomalies are likely areas of active oil and gas seepage. 
In general, methane concentrations were highest, as much as $160 \mathrm{nM}$, directly adjacent to the coast east of Pt. Conception with an apparent plume of methane extending northwest along the coastline and dissipating about $5 \mathrm{~km}$ south of Pt. Arguello. The study area contains three offshore oil platforms, an oil pipeline, and three additional offshore oil platforms just outside the study area. No methane anomalies were associated with these facilities. For reference, minimum and maximum methane concentrations measured at $2 \mathrm{~m}$ depth in the water column were 3.44 and $71.9 \mathrm{nM}$, respectively. The maximum methane concentration $(160 \mathrm{nM})$ was measured from a bottom water sample taken over an active oil and gas seep (station 60, depth $35 \mathrm{~m}$ ).

Hull-mounted, echo-sounder ( 3.5 and $12 \mathrm{kHz}$ ) data collected in conjunction with the methane survey detected acoustic water column anomalies that might be associated with gas bubbles and mounds on the seafloor. Figure 1-4 shows that 59 of the acoustic anomalies were associated with methane concentrations of $>20 \mathrm{nM}$, and 15 acoustic anomalies occurred in areas where methane concentrations were $<20 \mathrm{nM}$. Overlapping occurrences of high methane concentrations and acoustic anomalies are likely areas of active oil and gas seepage. Anomalies located during this cruise were used as a basis for more detailed geophysical surveys conducted in June 2002.

\section{A1-02-SC-Cruise to Detect Seeps with Sidescan and High- Resolution Seismic Reflection}

A study of natural oil and gas seeps on the inner shelf of the western Santa Barbara Channel and at the southern end of the Santa Maria Basin, offshore California, was conducted in collaboration with the Minerals Management Service (MMS). The goal was to establish the geologic framework for, and to document the locations of, active seeps.

A sidescan-sonar survey of the area around Point Conception, California (fig. 1-5) was conducted to image and identify the most active natural hydrocarbon seepages to permit later sampling by remotely operated vehicles (ROVs). The area surveyed forms a broad V-shaped swath 3 - 5-km wide both north and east of Pt. Conception. Each side of the $\mathrm{V}$ is about $15-\mathrm{km}$ long, covering water depths from 40-150 m. Sidescan sonar with a resolution of $50-\mathrm{cm}$ along-track, and 17-cm across-track, was collected throughout. For most of the survey, a chirp sonar system provided high-definition profiles of the underlying geology and seep structures.

Seeps were found as solitary mounds, coalescing mounds, and in areas of bare rock outcrop, eroded during the last sea-level transgression. These mounds range from a few meters across to large accumulations that can exceed a kilometer in width and $8 \mathrm{~m}$ height. We recognize them primarily just west and south of Pt. Conception, where they cover an irregular area of approximately $8.4 \mathrm{~km}^{2}$. Estimates of accumulated tar volume are 31 million $\mathrm{m}^{3}$, or an equivalent volume of $2.6 \times 10^{7}$ barrels of oil. Overall, more than 100 likely active seeps were identified that are the targets for ongoing collection of gas and tar samples. More details of this cruise and findings can be found in Normark and others, (2003) and an isopach map depicting the extent and thickness of tar mounds and sheets can be found in Draut and others (2009). 


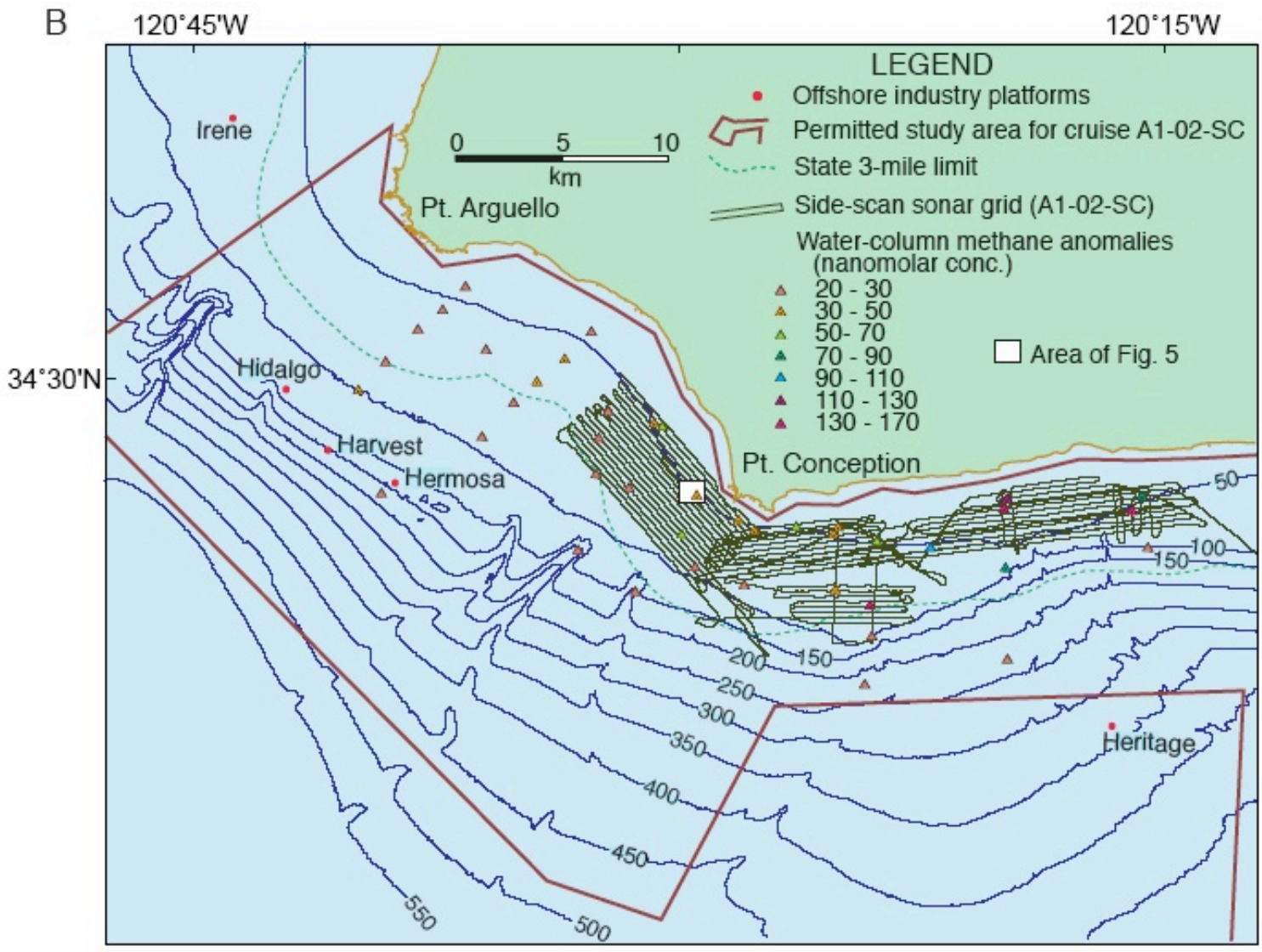

Figure 1-5. Map showing the study area and tracklines for U.S. Geological Survey cruise A1-02-SC. Overlain are the highest concentration of methane observed previously. Black, closely spaced lines indicate the area of sidescan-mapping coverage. Highresolution seismic lines were completed within this framework.

Figure 1-6 shows a portion of the sidescan record, including an area of coalescing tar mounds approximately $8.4 \mathrm{~km}^{2}$. The red lines along centers of some sidescan swaths show where large tar accumulations are, as interpreted from chirp-sonar records. The "likelihood" rating of anomalies mapped from sidescan and chirp-sonar records is based on the strength of apparent anomaly and whether it was observed on one or more data types. The "other anomalies" are from water samples and water-column anomalies seen on $12-\mathrm{kHz}$ records. 


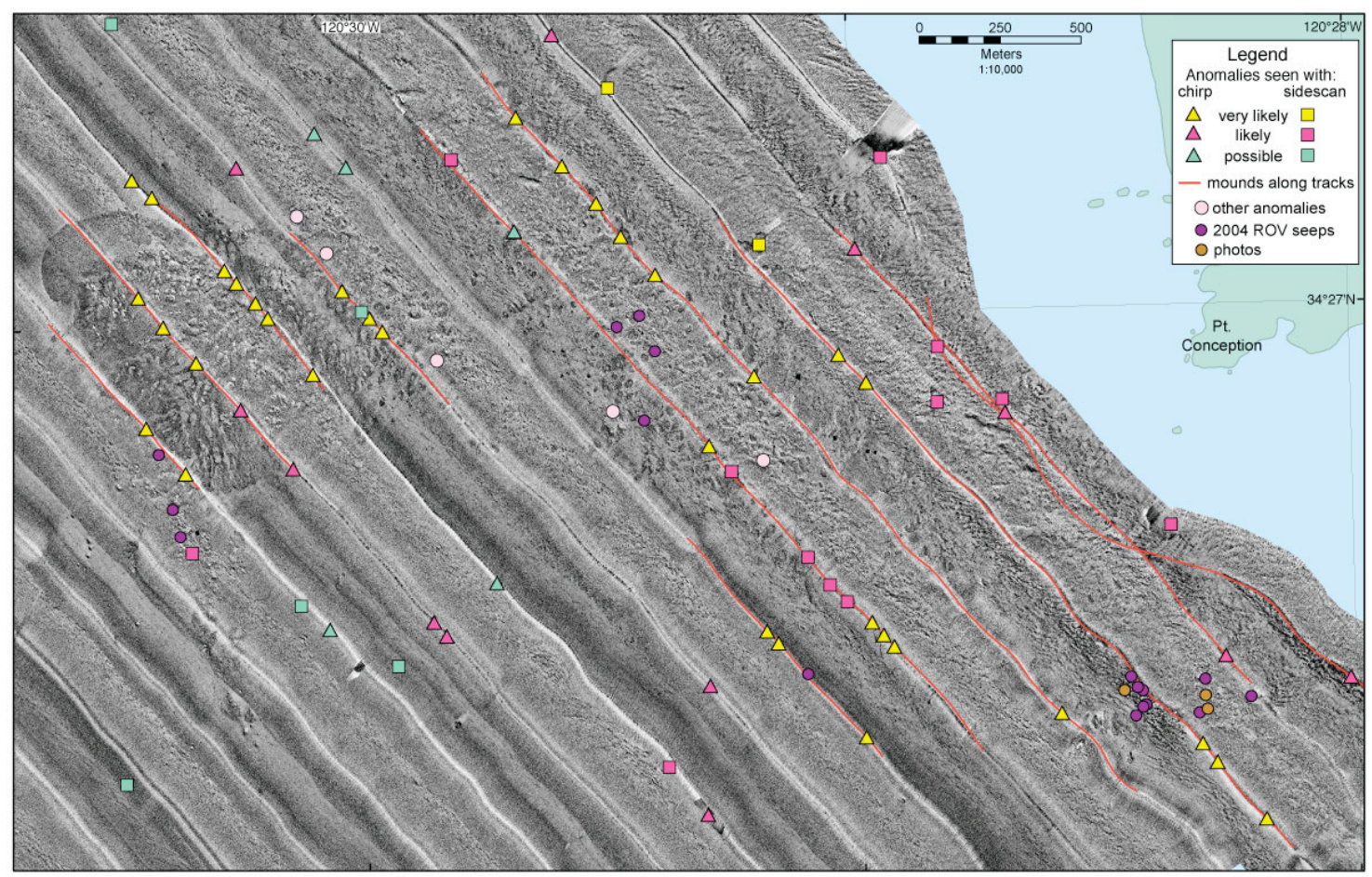

Figure 1-6. Sidescan-sonar mosaic from the area west of Point Conception. Watercolumn anomalies in southeast quadrant of this image are in an area of numerous semicircular mounds on the seafloor that are associated with seep activity.

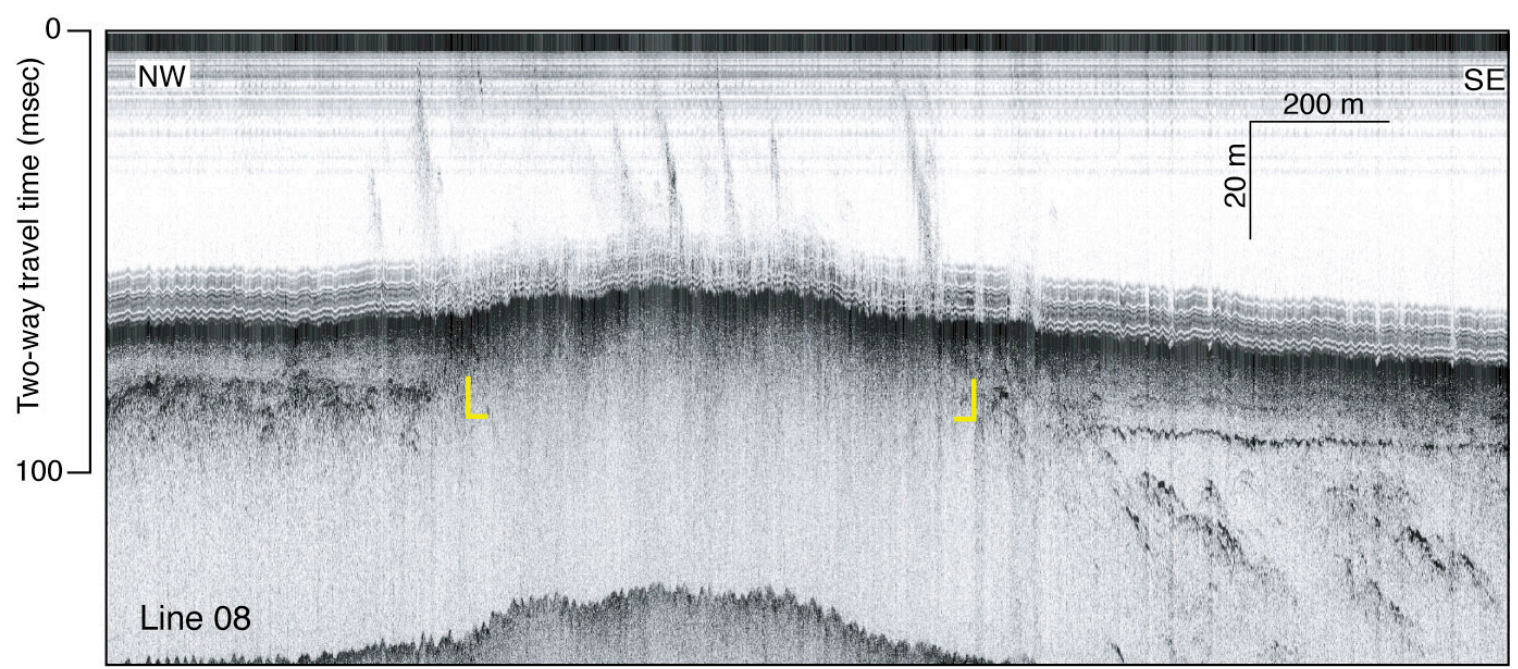

Figure 1-7. Example of a Huntec "chirp" high-resolution seismic profile over an area of active seepage west of Point Conception. The area of gas seepage corresponds to a rise in the seafloor of about $5 \mathrm{~m}$ interpreted to be an area of commingled asphalt mounds.

The chirp sonar profiles shown in Figure 1-7 are typical of those from active seep areas in this vicinity. The folded sedimentary rocks underlying this part of the shelf have been eroded during sea-level transgressions and regressions, and generally form a lowrelief surface. For much of this study area, the erosive surface is covered by a layer of sandy sediment ranging from a few meters to as much as $15 \mathrm{~m}$ in thickness. In the areas 
of the active seeps, however, gas accumulation blocks acoustic energy and the rock substrate is not seen on the chirp sonar. The seafloor above these areas is often mounded, with as much as $5 \mathrm{~m}$ of relief. We believe that tar residues from the seeps bind the sediment, gradually forming these large accumulations as strong bottom currents constantly supply new sediment.

The results of this work demonstrated that there were promising areas for tar, oil, and gas collection in areas west, south, and east of Point Conception, and that the methane previously measured in the water column has some contribution from this study area. Additional cruise data and navigation can be found on the USGS Web site at: http://walrus.wr.usgs.gov/infobank/a/a102sc/html/a-1-02-sc.meta.html.

\section{Cruise P-2-04-SC Remotely Operated Vehicle (ROV) sampling of seeps}

As part of this study, a (ROV) survey was conducted in the Point Conception area where previous studies had noted tar seeps (Vernon and Slater, 1963) and methane water column anomalies (Lorenson and others, 2003). Sidescan imagery (Normark and others, 2003) suggested unusual seafloor features (e.g., fig. 1-8), and subsequent ROV surveys confirmed vast areas of tar-mound accumulation. The tar mounds are typically $10-100$ $\mathrm{m}$ in diameter, and in many areas, coalesce into extensive tar reefs. The largest of these areas covers an area of about $2 \mathrm{~km}^{2}$ and is up to $8 \mathrm{~m}$ thick. The entire area of seepage covers at about $8.4 \mathrm{~km}^{2}$. Closer inspection of the tar mounds shows pronounced viscous extrusion of tar (fig. 1-9), often producing whip-like extrusions that break off and float to local beaches (fig. 1-10). Older areas of tar extrusion are heavily colonized by marine invertebrates and resemble reef communities found on submarine rock outcrops (fig. 111). Adjacent sand-covered areas contain fewer invertebrates and fish.

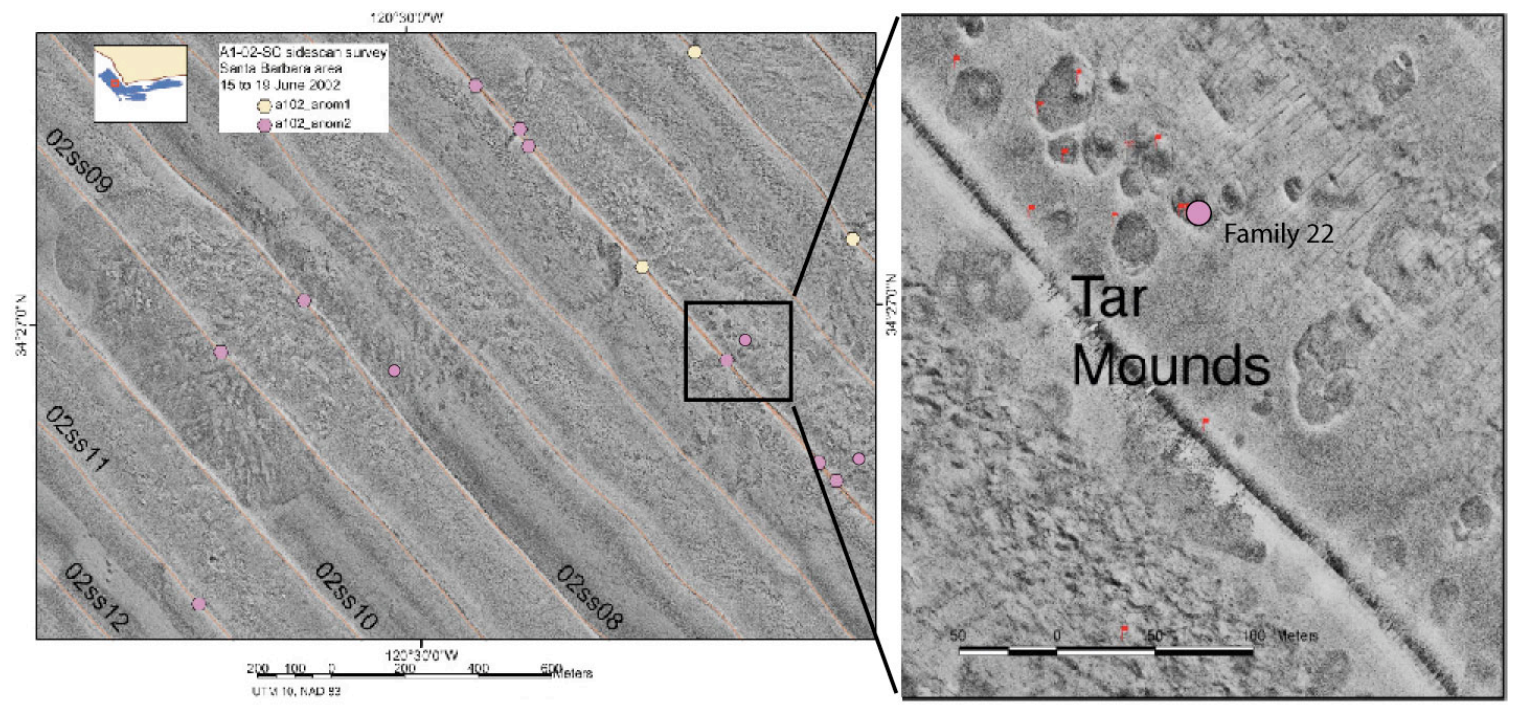

Figure 1-8. Sidescan image of the seafloor southwest of Point Conception, California, shows several tar mounds ranging in diameter from about $10-100 \mathrm{~m}$. Tar mounds such as these are confined to the area near Point Conception. They cover at least $8.4 \mathrm{~km}^{2}$ and contain about 150,000 barrels of oil. Red flag symbols indicate remotely operated vehicle dive sites. 


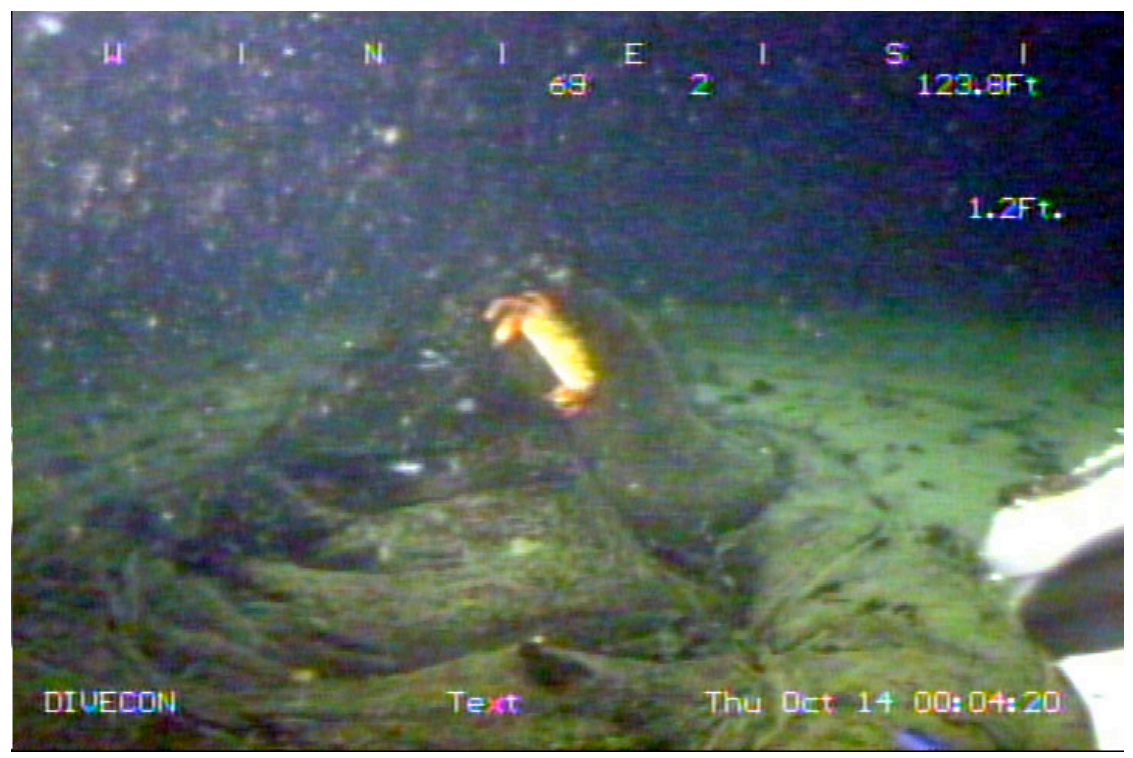

Figure 1-9. Remotely operated vehicle video image shows a crab near the top of extruding tar on a tar mound like those shown in figure 3. Lack of colonizing sessile organisms suggests that this mound is quite young.

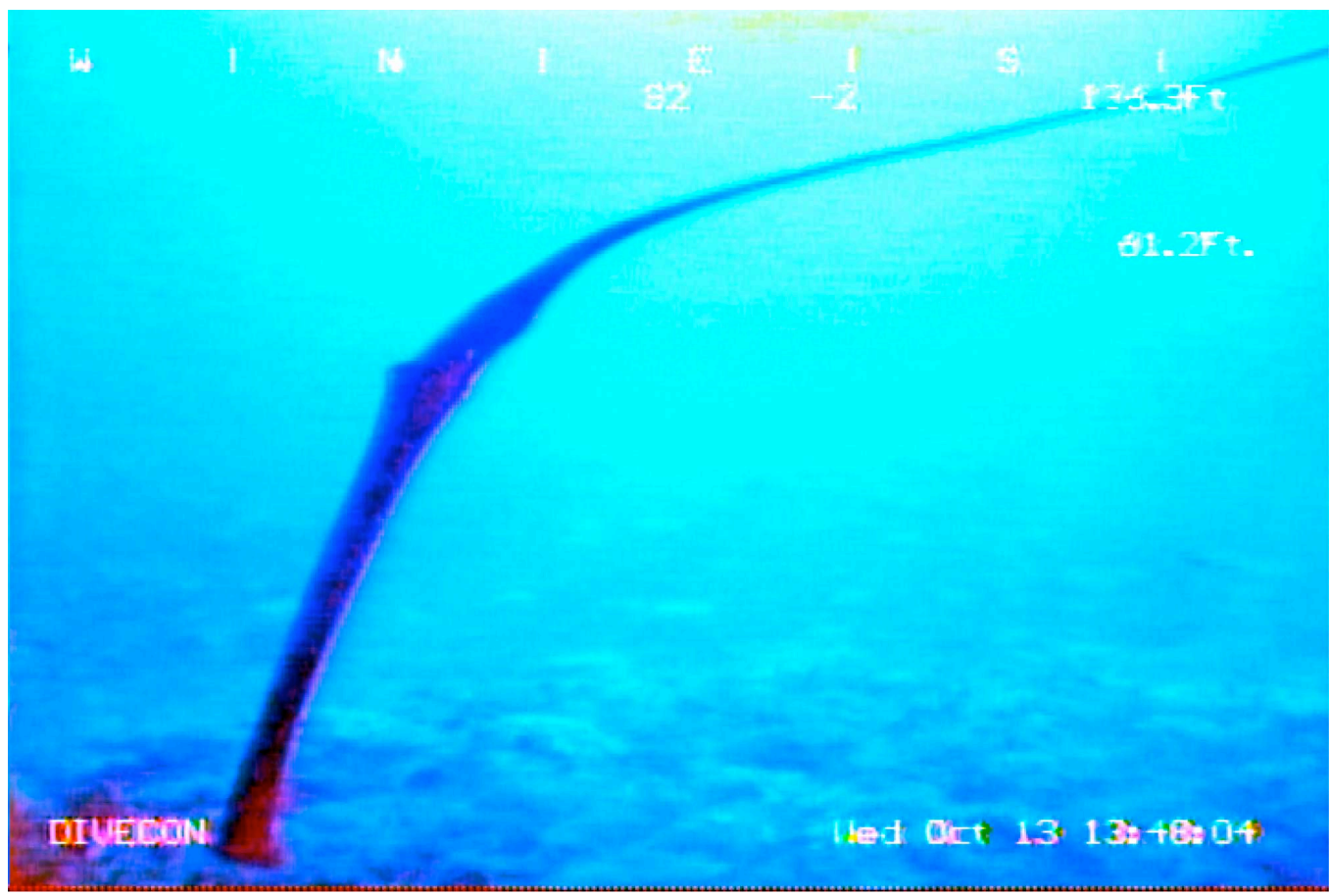

Figure 1-10 A tarwhip extruding from an extensive tar mound offshore Pt. Conception at a water depth of $41 \mathrm{~m}$. The length seen in the photo is estimated to be about $3 \mathrm{~m}$. Several tar whips were observed, all extruding from tar mounds, some of which were clearly broken off, and some that did not retain buoyancy and fell to the ocean floor. 


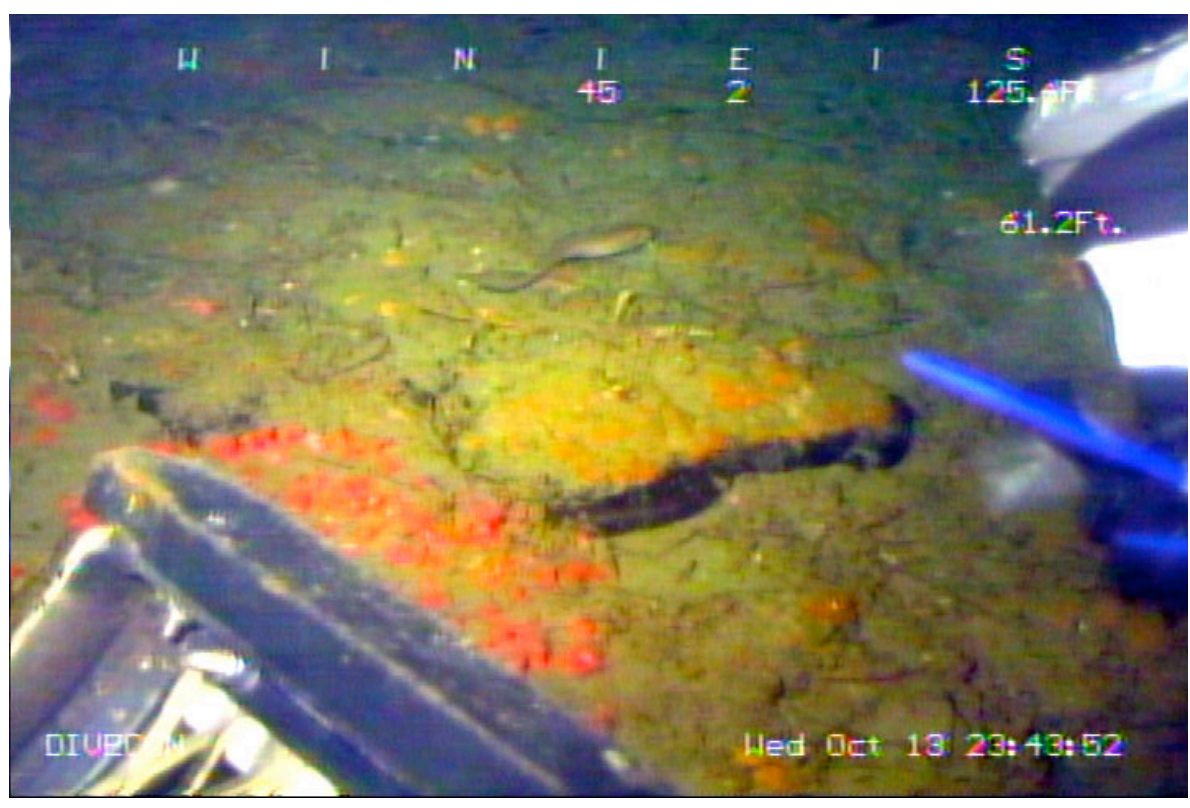

Figure 1-11. Remotely operated vehicle (ROV) video image of a colonized tar mound likely older than than that shown in figure 1-9. This tar "reef" is similar to those in figures 1-2 and 1-3. Sea anemones and other sessile organisms are covering the tar, some of which can be seen in the middle of the photo. Objects in the foreground are part of the ROV.

Results from the short two-day cruise include 22 tar samples from seeps, mainly west and south of Point Conception, 4 gas samples from submarine seeps, and 2 samples of oil from offshore Gaviota and Coal Oil Point. Subsequent analysis showed that these samples are characteristic of hydrocarbons from the Monterey Formation. The classification of the samples is further described in Chapters 2 and 3, and their geographic distribution can be viewed in map form in Appendix 1-1. Additional cruise data and navigation can be found on the USGS Web site at http://walrus.wr.usgs.gov/infobank/p/p204sc/html/p-2-04-sc.meta.html.

\section{Synthetic Apeture Radar (SAR) Detection of Oil Seepage}

SAR imagery provides high-resolution $(6,100 \mathrm{~m}$ ground resolution) active microwave observations of sea-surface roughness that are independent of weather and availability of light. Factors affecting surface roughness include wind, interactions of waves and currents, the presence of surfactants, and oil on the ocean surface. The surfactants and oil smooth capillary and small gravity waves, which reduces surface roughness and thus radar backscatter. The smoothed surfactant-covered areas appear darker on SAR imagery compared with the usually wind-roughened surrounding ocean, which has higher backscatter and thus appears brighter on SAR imagery. SAR imagery also visualizes complex, small-scale oceanographic processes, such as coastal eddies (Munk and others, 2000; DiGiacomo and Holt, 2001). SAR imagery has been used to identify significant, and often illegal, discharges from ships (Gade and Alpers, 1999; Lu, 2003; Pavlakis and others, 2001), to examine natural seeps in the Gulf of Mexico (De Beukelaer and others, 2003), and monitoring oil spills from ships and platforms (Fingas and Brown, 1997; Espedal and Johannessen, 2000; Jones, 2001). 
The ability of SAR to identify oil slicks is limited by environmental conditions, particularly wind and waves (Gade and others, 1998; Trivero and others, 1998;

DiGiacomo and Holt, 2001; Svejkovsky and Jones, 2001). Successful imaging of oil slicks using SAR requires that surface wind speeds fall in a fairly narrow range. At very low wind speeds (less than $2-3 \mathrm{~m} / \mathrm{sec}$ ), little microwave energy transmitted to the sea surface is backscattered toward the SAR, resulting in dark areas, broadly distributed in a SAR image. Under these conditions oil slicks cannot be differentiated from smooth ambient waters. At high wind speeds increased surface roughness results in dispersal and mixing of the oil into the upper ocean. Petrogenic hydrocarbons may be detectable on SAR imagery until winds exceed 10-14 m/sec, depending on sea state and heaviness of oil (Espedal and others, 1998; Espedal and others, 1999; Wismann and others, 1998). Biogenic oils (e.g., phytoplankton exudates) are generally not detectable when winds exceed 7-8 m/sec (DiGiacomo and Holt, 2001). Sorting out ambiguous surface-slick signatures is an area of active research, requiring repeat imaging, analysis of wind-time series, and knowledge of sources (Espedal and Wahl, 1999; Solberg and others, 1999).

Fugro NPA Limited satellite mapping services provided a survey of the Santa Barbara Channel using available space-borne SAR to examine potential oil slicks. Iterative mapping of possible oil slicks provides information as to the possible seep location based on persistent observations of oil. Results of the survey show that there are a multitude of possible seep sites (fig. 1-12; in appendix 1-1, fig. 1-15) for each beach area and vicinity. The amount of oil seepage in the channel overwhelms the ability to discern specific sites, at least around COP, for example. The SAR-mapped seep sites were in the vicinity of known oil seeps, however, there was not a direct correspondence with reported seep sites, thus, we conclude that SAR is not an especially effective tool to locate individual seeps in this area. In addition, few seeps were mapped around Point Conception owing to the lack of oil on the sea surface, however, tar seepage is here is prolific. In this case SAR is not effective in detecting the floating tar extrusions common to the Point Conception area.

\section{Dispersion of Tarballs by Currents and Winds}

The Santa Barbara Channel Basin is oriented east-west, bounded to the north by the central California coast and to the south by the Santa Barbara Channel Islands with two sills (entrances) on the east and west ends. Point Conception, located at the western extent of the channel is the point at which the Pacific coast of the United States rotates from a general north-south direction to an east-west direction. The channel is $\sim 100 \mathrm{~km}$ long and $\sim 40 \mathrm{~km}$ wide with a central basin depth of $\sim 500 \mathrm{~m}$ (Harms and Winant, 1998). The normal surface-current flow in the central and western parst of the channel is acyclonic (counterclockwise), which is strongest during summer and fall (fig. 1-13 A,B,C). The gyre is set up by westward flowing currents that gradually increase velocity to the west along the northern extent (nearshore) of the channel and eastward flowing currents that gradually decrease velocity to the east along the southern extent (offshore) (Harms and Winant, 1998). 


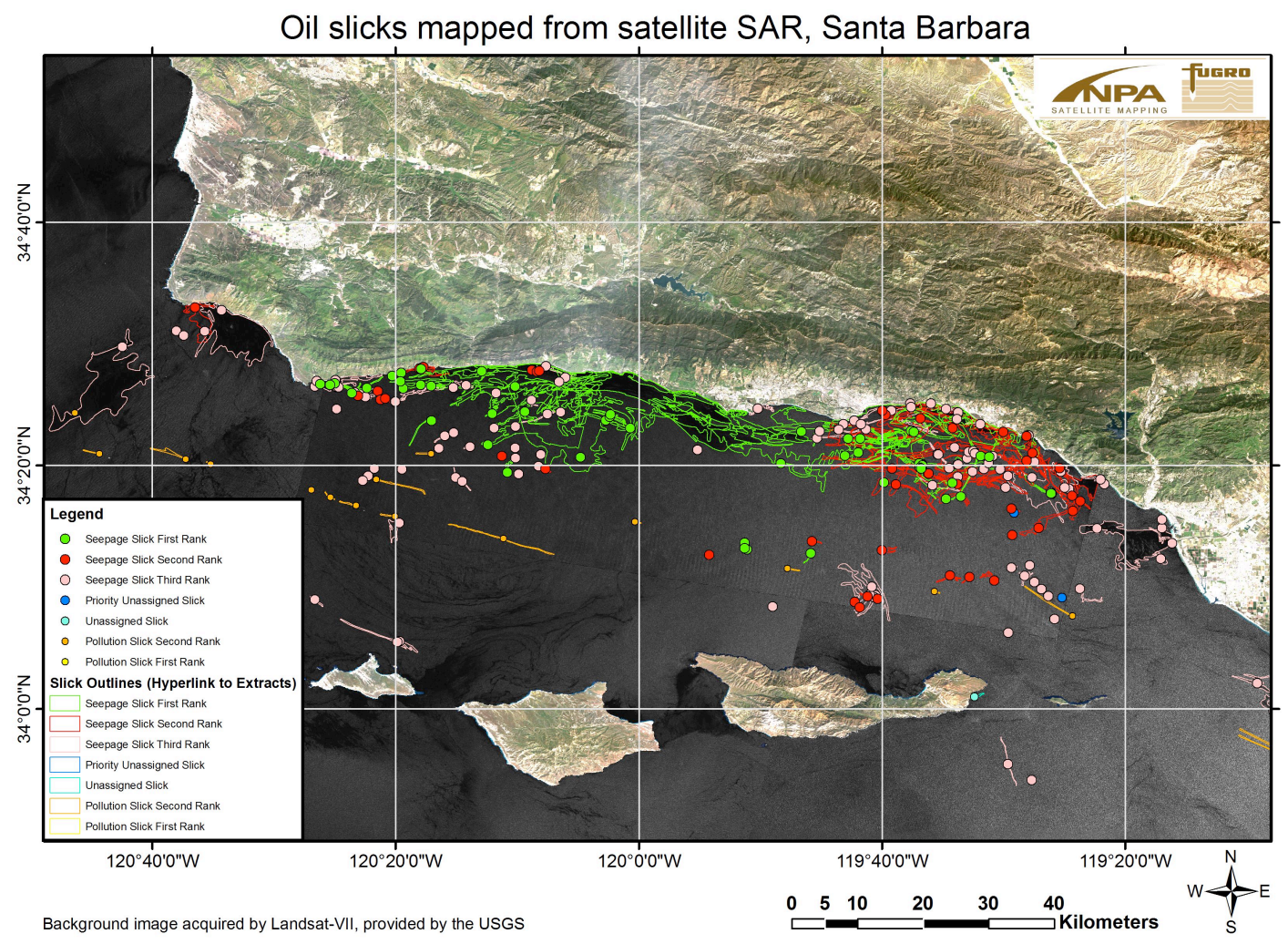

Figure 1-12. Composite SAR image of the Southern California Bight showing possible oil slicks and seeps. COP corresponds to Coal Oil Point. The results are color coded by confidence level where green $>$ red $>$ pink. Possible oil pollution slicks are seen in yellow tones. Courtesy Fugro NPA Limited satellite mapping services.

From late winter through spring, currents outside the channel are typically equatorward (south). The result is a southerly flow west of Point Conception, which enters the SBC through the western sill, and exits out of the eastern sill (fig. 1-13-A). During summer, fall, and early winter, the larger-than-SBC scale current flow is poleward (north), known as the Davidson current. The SBC, therefore, experiences a westerly current flow entering from the eastern sill, northwest through the channel, and out of the channel through the western sill (fig. 1-13-B; (Harms and Winant, 1998).

The eastern entrance or sill of the channel is much shallower than the western sill; therefore, bottom currents are stronger at the eastern end of the channel, which aids in westward sediment transport into the basin (Kolpack, 1977). The COP seep field is located at the eastern end of the gyre. Nearshore currents are almost always directed westward with monthly maximums in the summer and fall when the larger-than-SBC scale flow is poleward. However, reversals can occur in seasonal trends for up to days at a time (Harms and Winant, 1998). Variations in SBC circulation have been characterized. Harms and Winant (1998) categorized $\sim 60 \%$ of their observations into one of six categories: upwelling, relaxation, cyclonic, propagating cyclones, flood east, or flood west (fig. 1-13). In general, the upwelling, relaxation, cyclonic, and propagating cyclone systems occur spring through fall and include the counterclockwise gyre typical of the channel. The flood-east and flood-west systems generally only occur during winter and are described as all currents in the channel either flowing east or west. Flood events are 
usually shorter lived than the other four current regimes (Harms and Winant, 1998).

The large-scale cyclonic gyre of the SBC can be observed in high-frequency (HF) radar. In addition, submesoscale eddies offshore of COP have been observed (Bassin and others, 2005). Bassin and others (2005) observed eddies near COP $\sim 11 \%$ of the time between 1998 and 2001 using HF radar. The eddies ranged from 4 to $15 \mathrm{~km}$ in diameter and lasted from 1 to 6 days. Bassin and others (2005) proposed that such eddies are a mechanism for cross-isobath transport of nutrients nearshore and onto the inner shelf. The eddies occurred between the $50-300 \mathrm{~m}$ isobaths and no seasonal trend was observed in their occurrences (Bassin and others, 2005).

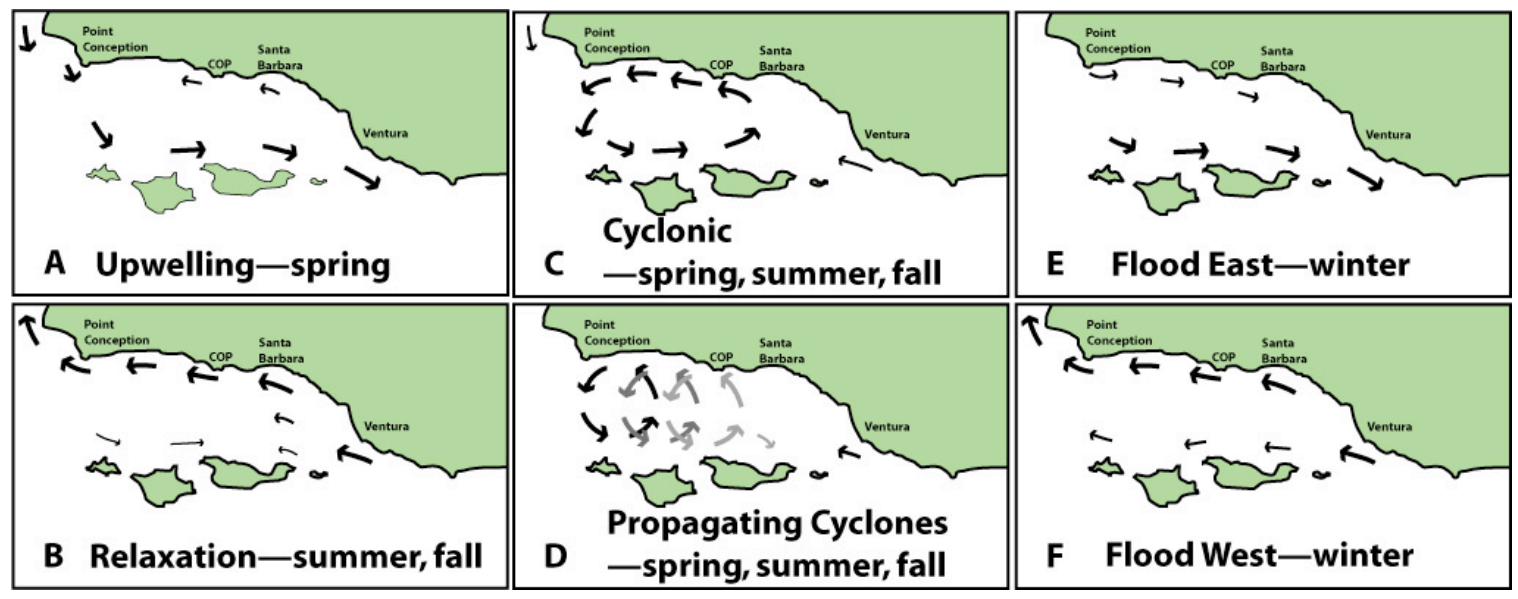

Figure 1-13. Diagrams showing the six characteristic patterns of Santa Barbara Channel circulation - About $60 \%$ of SBC observations can be characterized by one of these patterns. (a) Upwelling - strongest during the spring, (b) Relaxation - strongest during summer and fall, (c) Cyclonic - can happen during spring, summer, or fall, (d) Propagating Cyclones - can happen during spring, summer, or fall, (e) Flood East usually only occurs during winter, and (f) Flood West - usually only occurs during winter. From Harms and Winant (1998).

Harms and Winant (1998) determined that wind stress plays an important role in SBC circulation, specifically the cyclonic gyre. Wind direction tends to be southward west of Point Arguello and then toward the southeast offshore of Point Conception and into the channel. Wind stress is strongest on the southern edge of the channel aiding in the formation of the counterclockwise gyre. Along the northern edge of the channel, wind direction is typically to the southeast during the summer and to the east-southeast during the rest of the year. The winds along the northern edge of the channel are always weaker than the southern edge, which allows for the westward current flow along the northern edge that completes the formation of the SBC cyclonic gyre (Harms and Winant, 1998).

Coastal winds, although weaker, usually are more complex due to interactions with land, including, for example, the diurnal cycle (land/sea breezes). During the fall, when there is a very high-pressure system over the inland desert areas of southern California, strong, warm offshore winds called "Santa Ana" winds push surface waters offshore, initiating coastal upwelling. During the winter, a northeastern Pacific high-pressure system migrating southward causes less persistent winds, which do not counteract high onshore wind and wave activity from periodic storm fronts. The result is an intense removal of coastal beach sands, a typical winter occurrence (Kolpack, 1977). 
The expected dispersion of tar and oil in most of our study area should mainly be to the west along the coast of southern Santa Barbara County. Near Point Conception there is also significant potential for currents carrying tar from local seeps south and then along the northern and western coastlines of the Channel Islands. Occasionally, during periods of relaxation or the wintertime western floods, (Figure 1-13B and F) tar and oil can move westward out of the Santa Barbara Channel. If these events are coupled with a eastern Pacific winter storm that brings strong and persistent winds from south, tar expelled in southern California has a significant potential in moving northward along the central California coastline. Drifter studies by Winant and others, (2003) have shown that during winter time relaxation can result in transport from the SCB as far north as Bodega Bay, California. 


\section{Appendix 1-1. Tarball, Seep, and Platform Oil Sample Locations.}

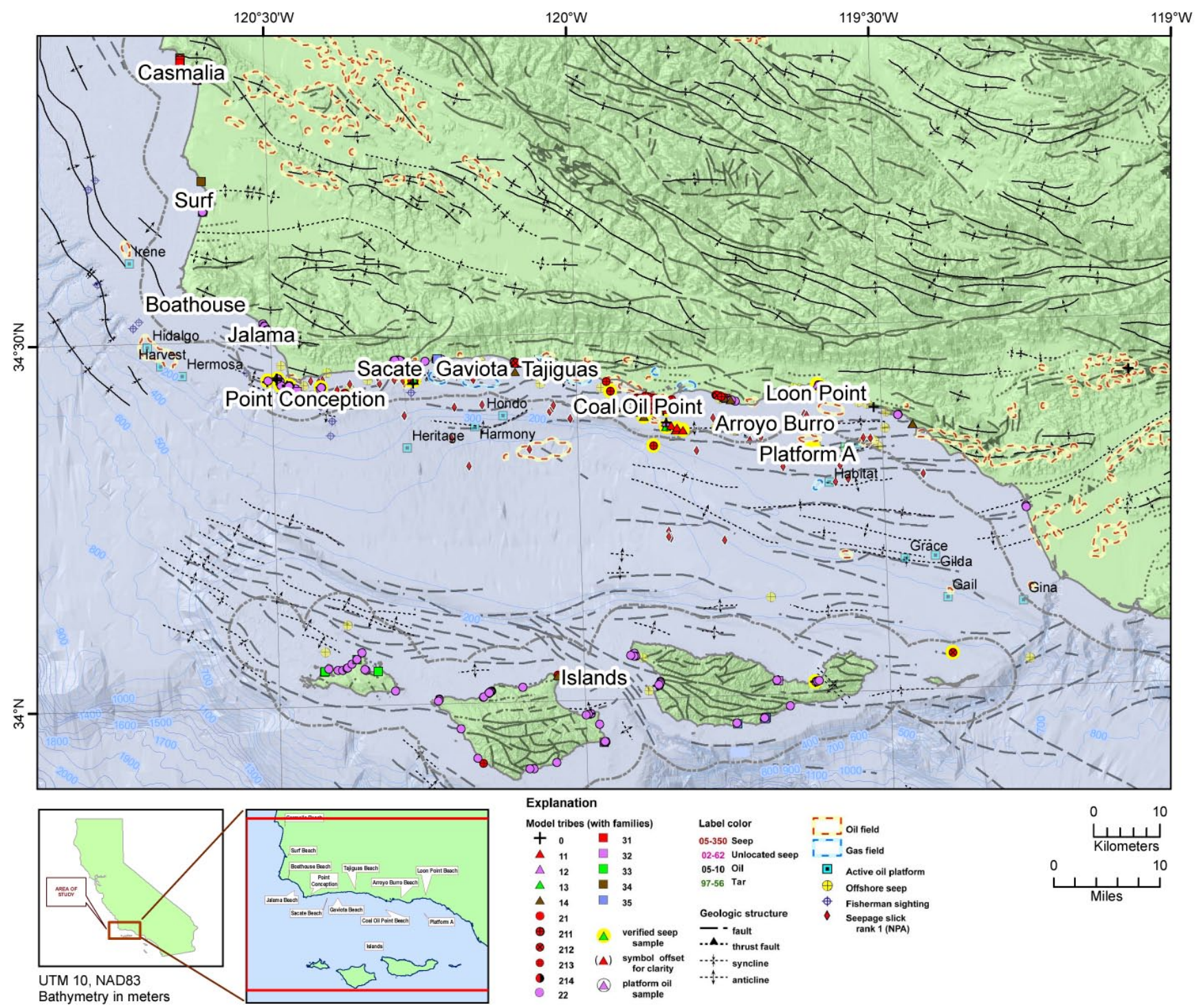

Figure 1. Map showing location of beaches and offshore platforms discussed in text. 


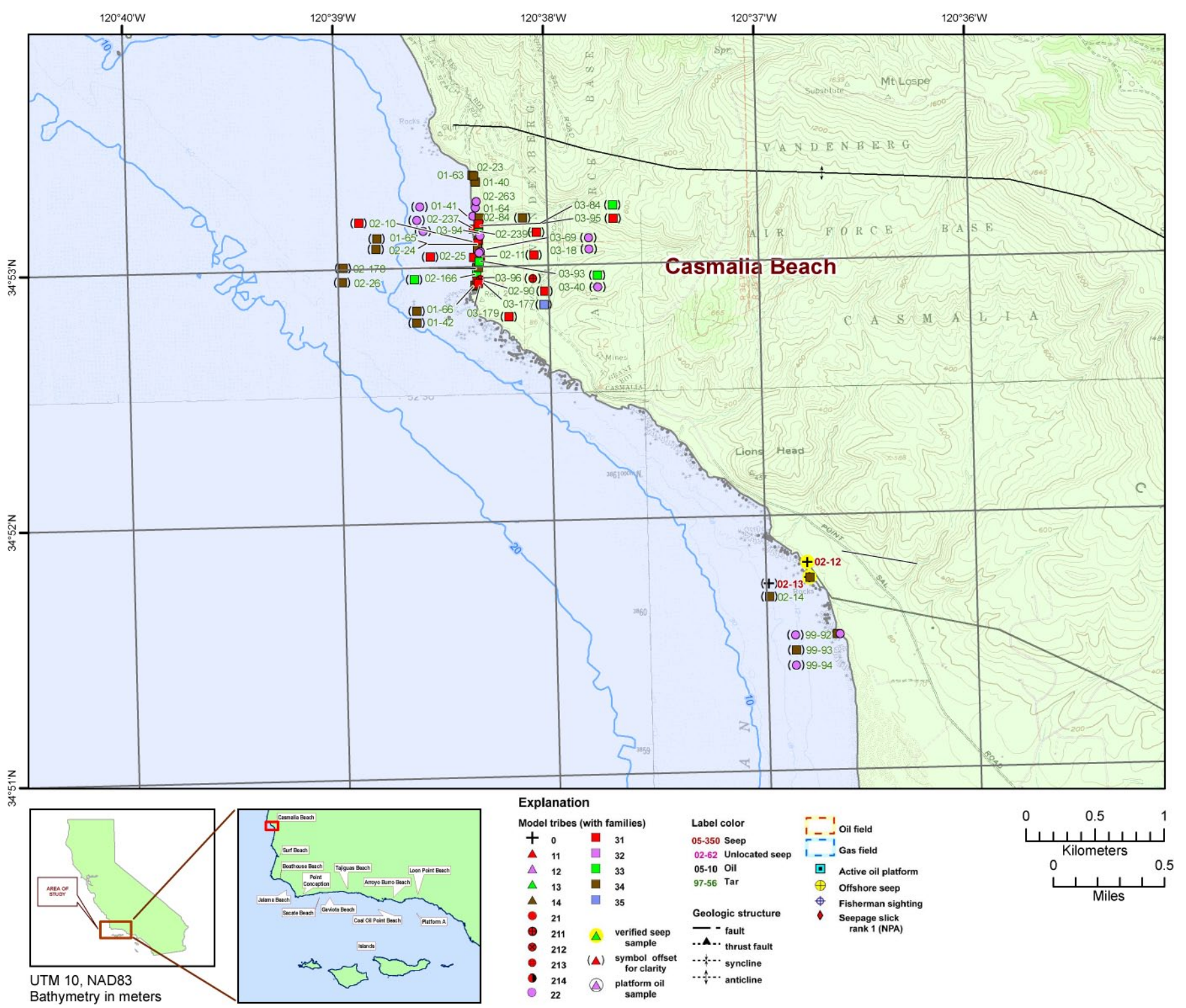

Figure 2. Map showing tarball collection sites on Casmalia Beach and vicinity, California. 


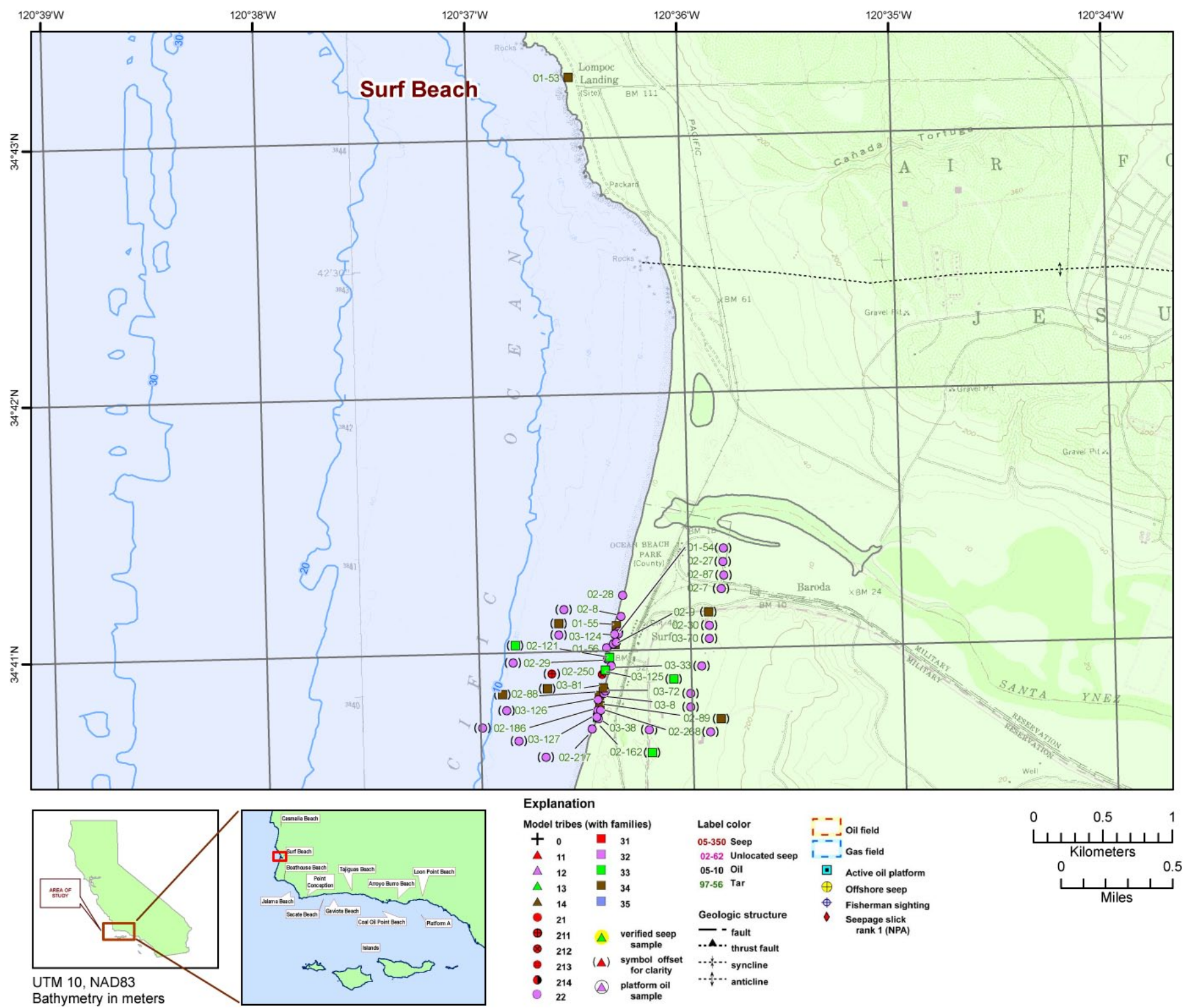

Figure 3. Map showing tarball collection sites on Surf Beach and vicinity, California.. 


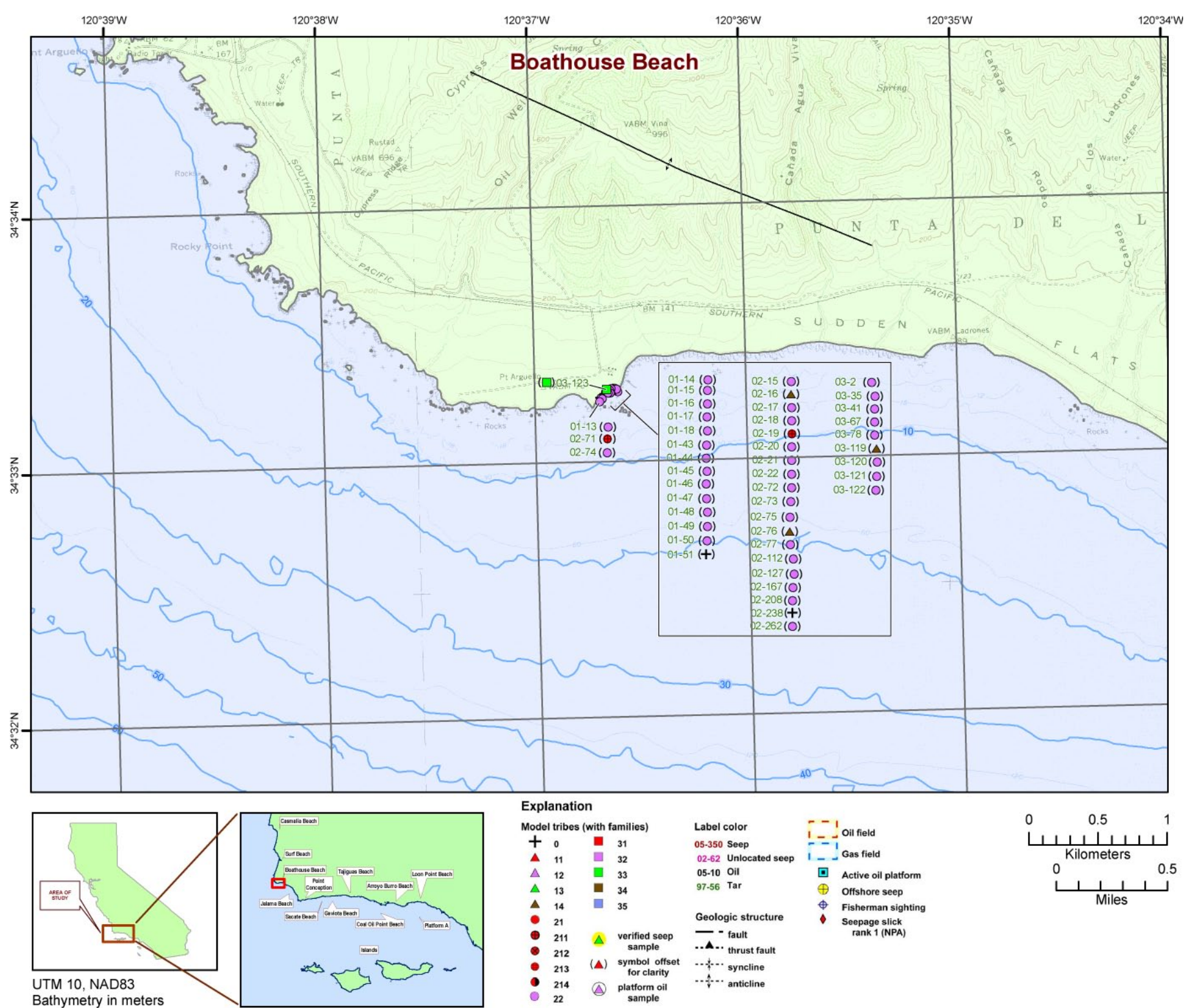

Figure 4. Map showing tarball collection sites on Boathouse Beach and vicinity, California. 


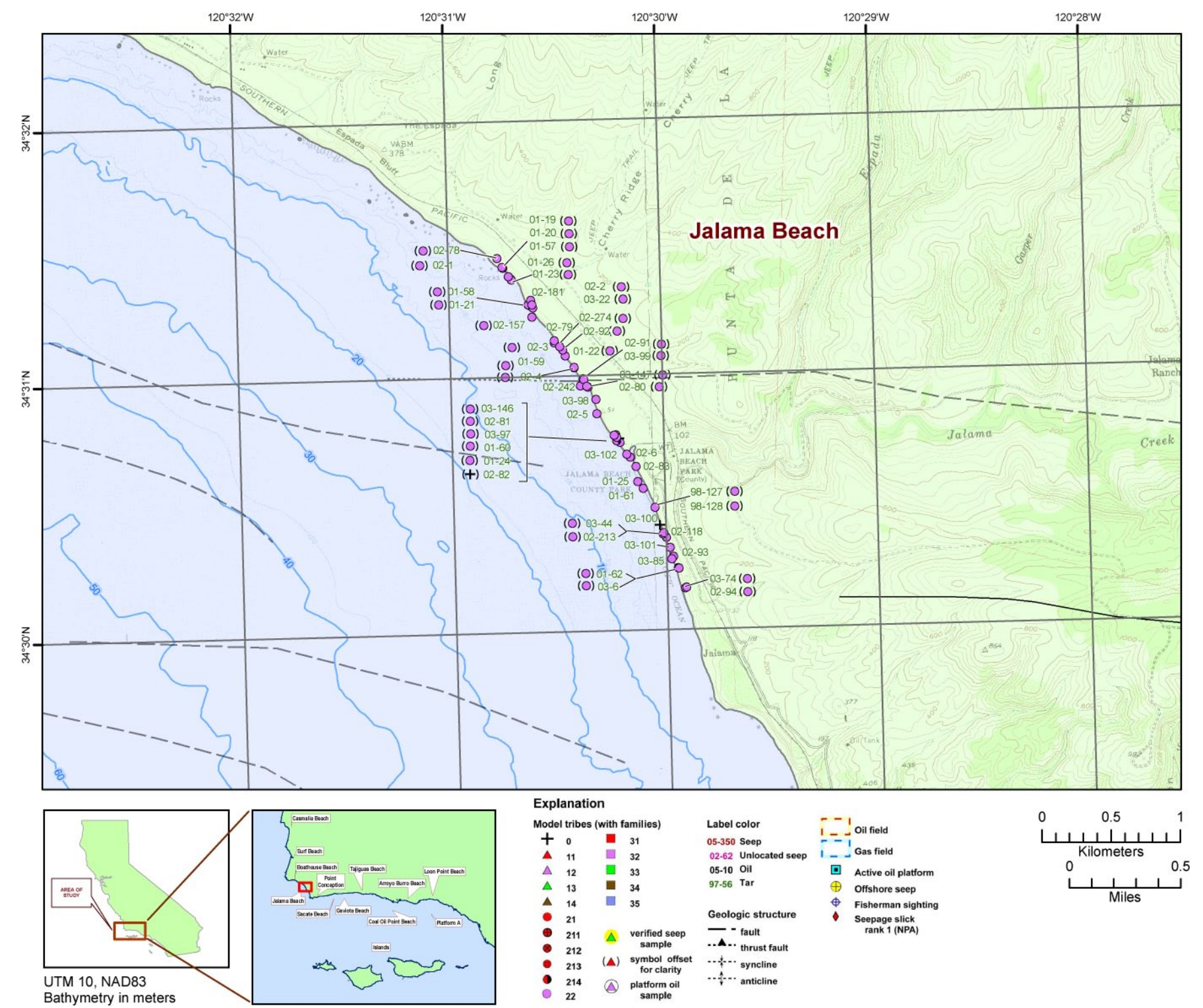

Figure 5. Map showing tarball collection sites on Jalama Beach and vicinity, California. 


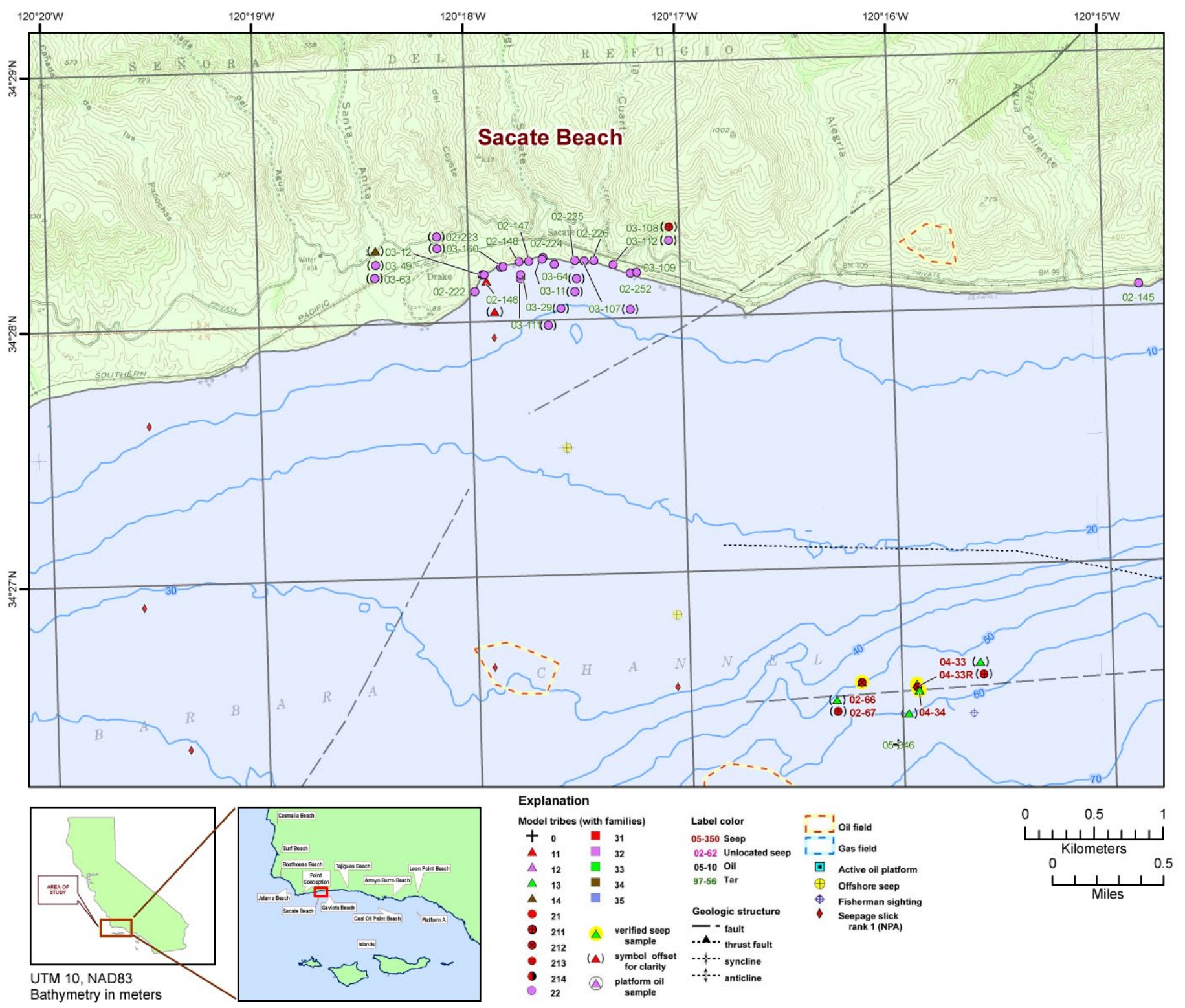

Figure 6. Map showing tarball collection sites on Secate Beach and vicinity, California. 


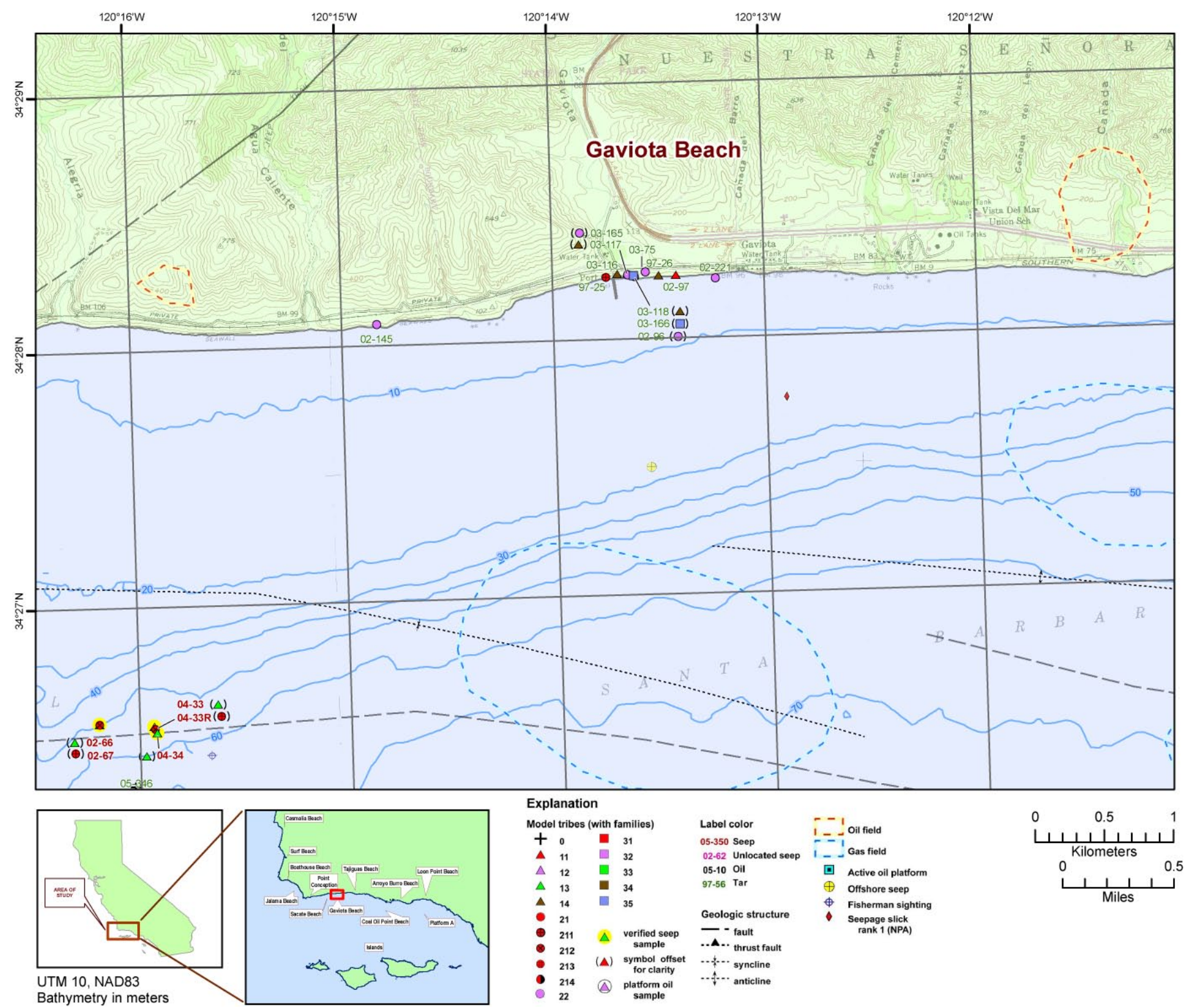

Figure 7. Map showing tarball and seep collection sites on Gaviota Beach and vicinity, California. 


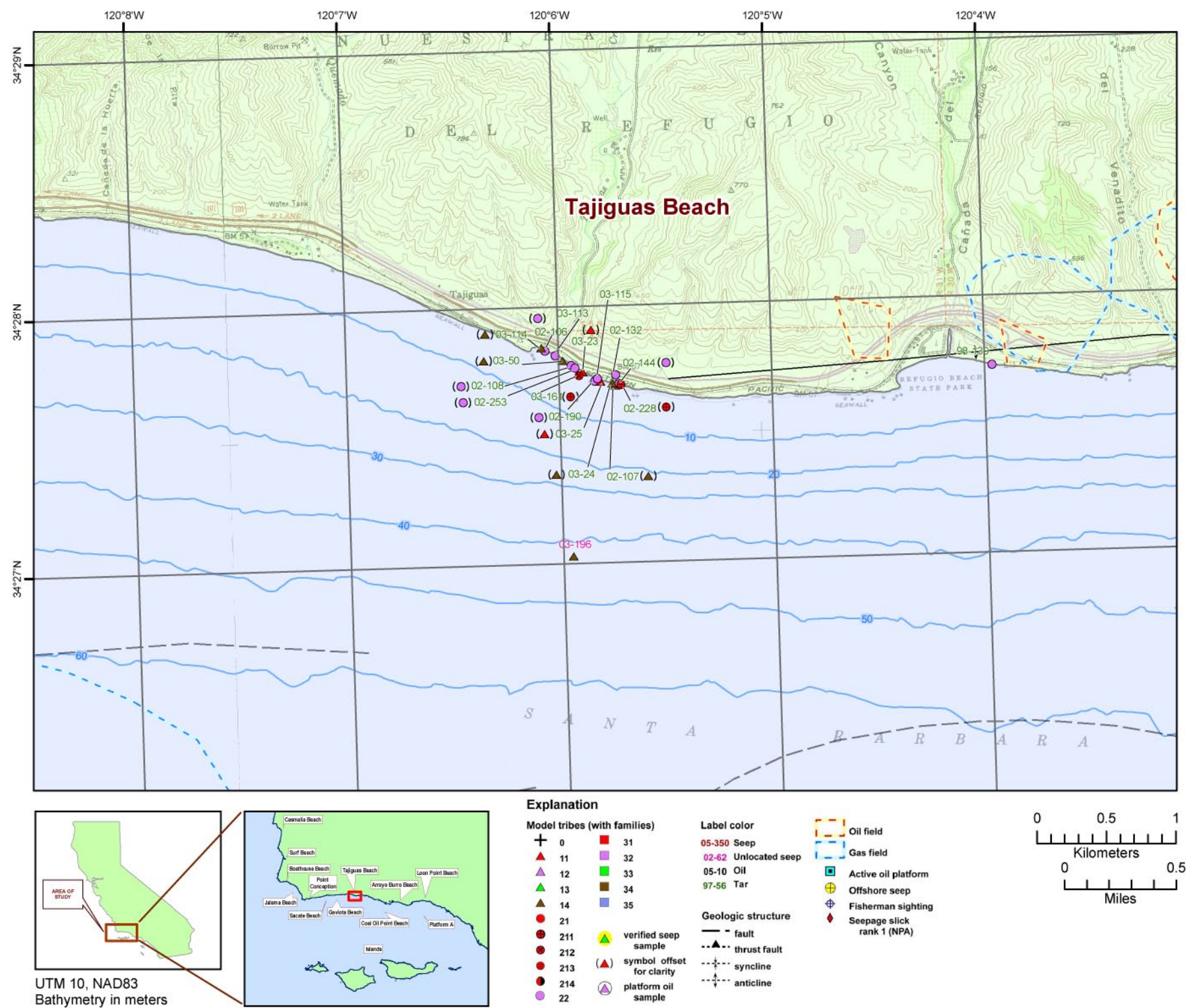

Figure 8. Map showing tarball and seep collection sites on Tajiguas Beach and vicinity, California. 


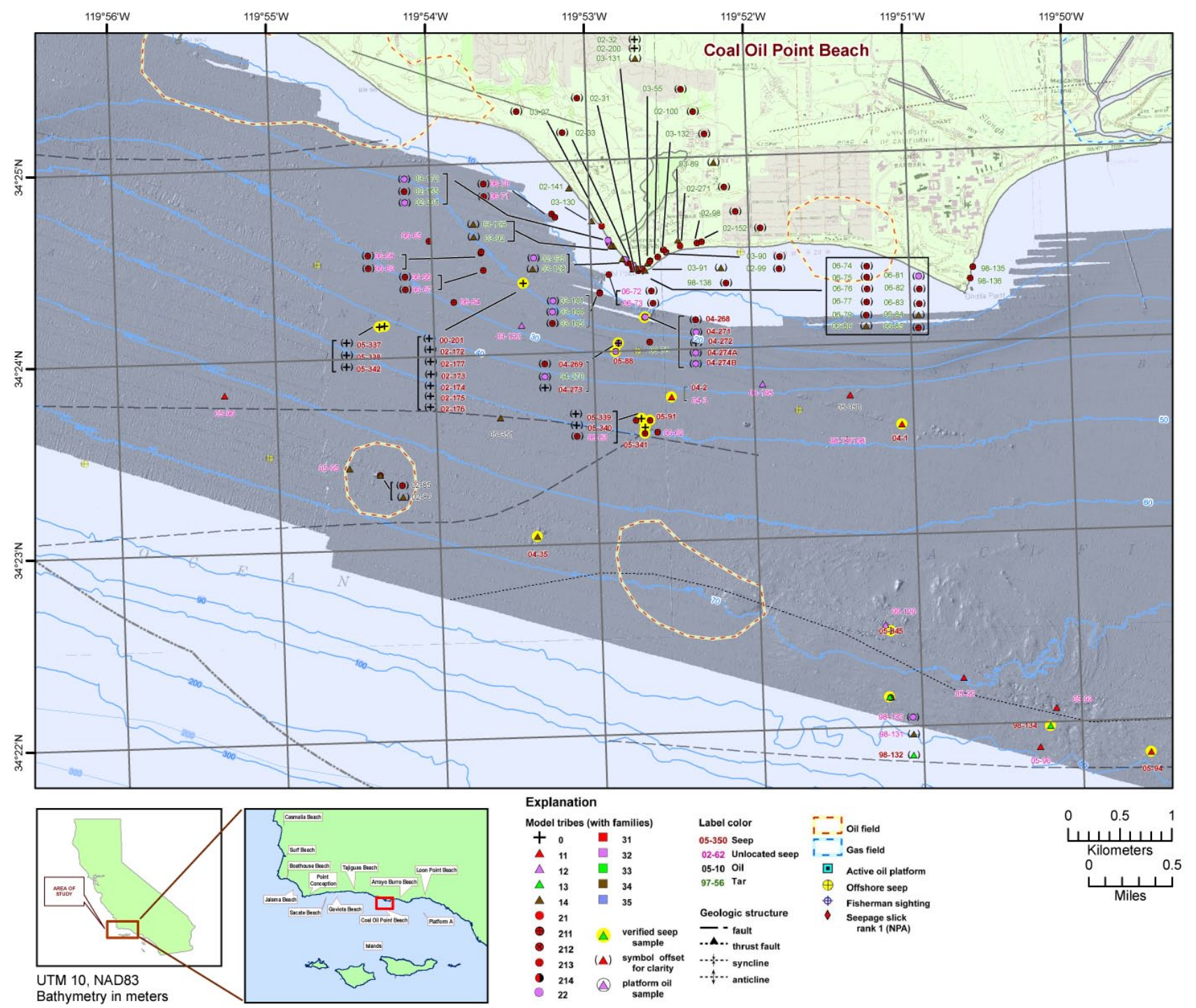

Figure 9. Map showing tarball and seep collection sites on Coal Oil Point Beach and vicinity, California. Shaded relief bathymetry was acquired in June, 2006 and shows outcropping bedrock associated with the La Goleta seep field in the SE corner of the map. 


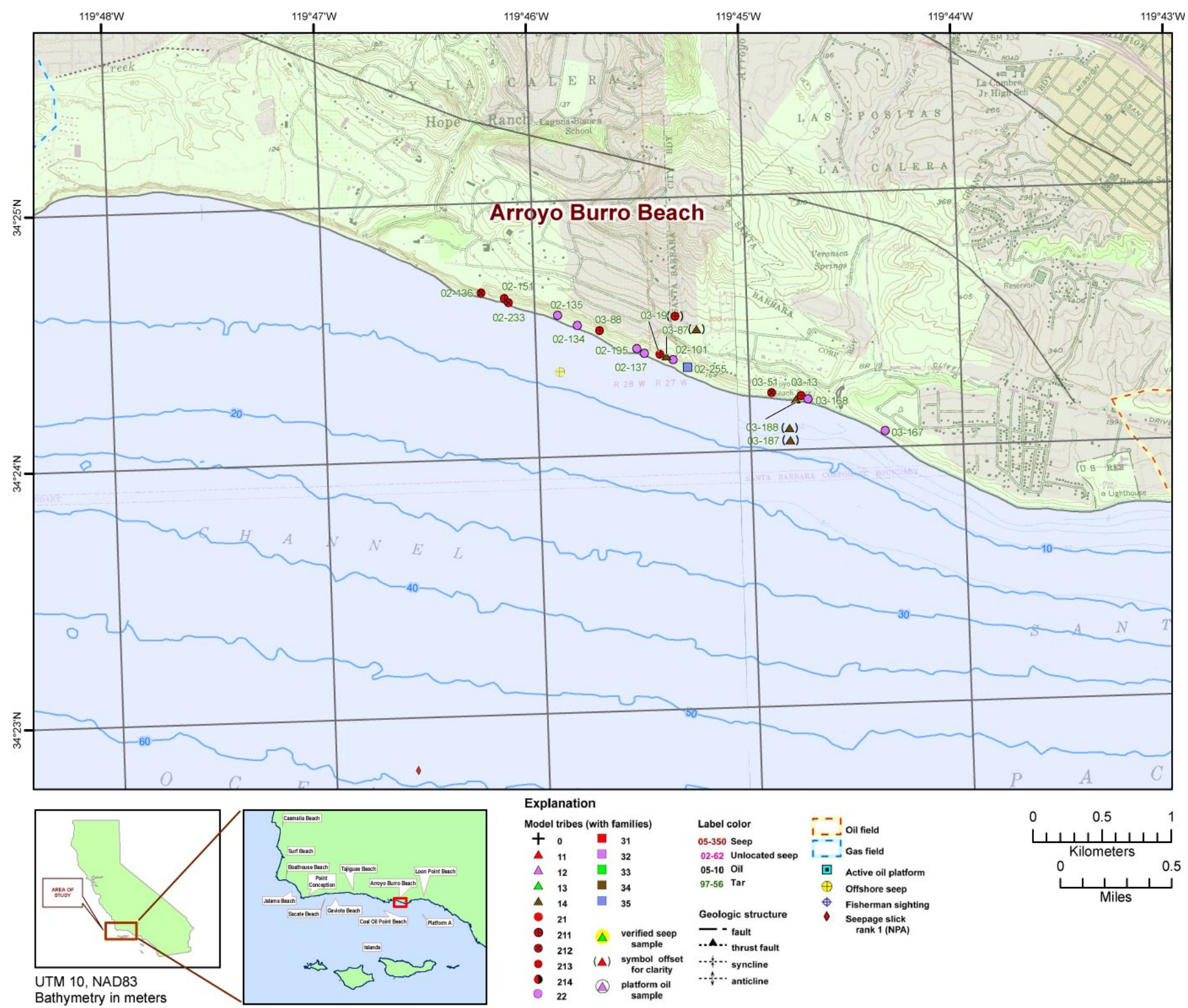

Figure 10. Map showing tarball collection sites on Arroyo Burro Beach and vicinity, California. 


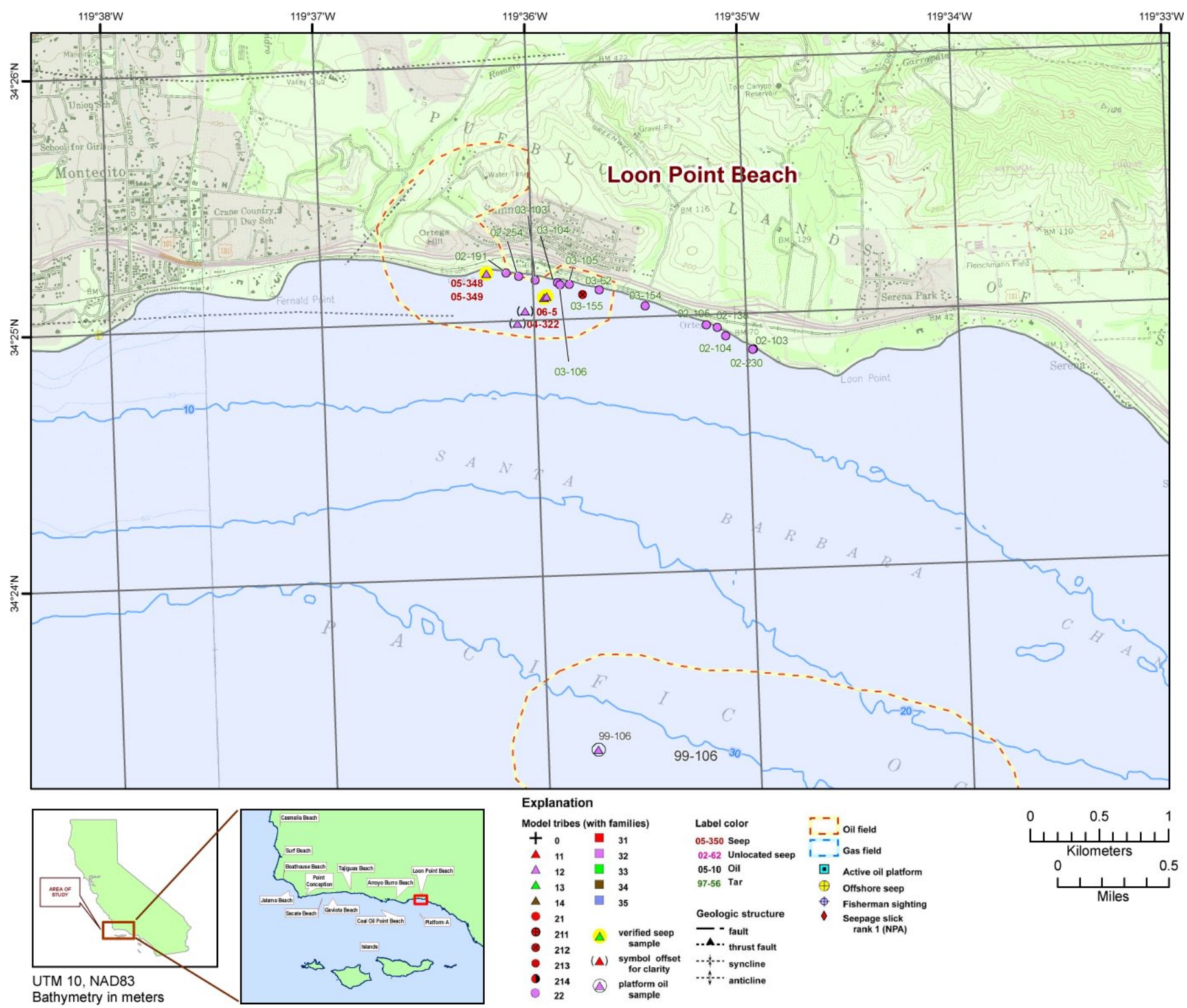

Figure 11. Map showing tarball collection sites on Loon Point Beach and vicinity, California. 


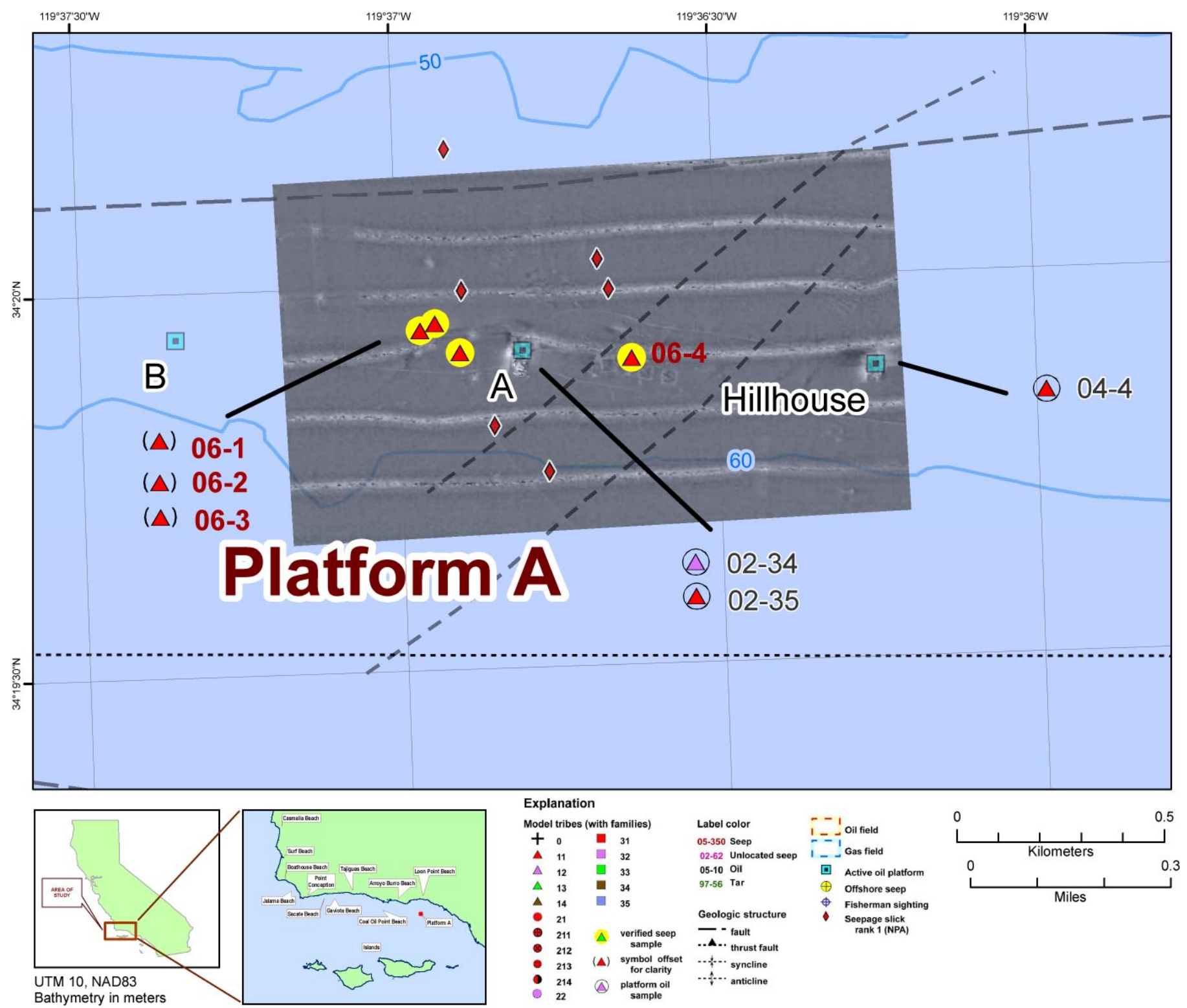

Figure 12. Map showimh Seep and produced oil collection sites from Platform A and vicinity, Dos Cuadras oil field, California. 

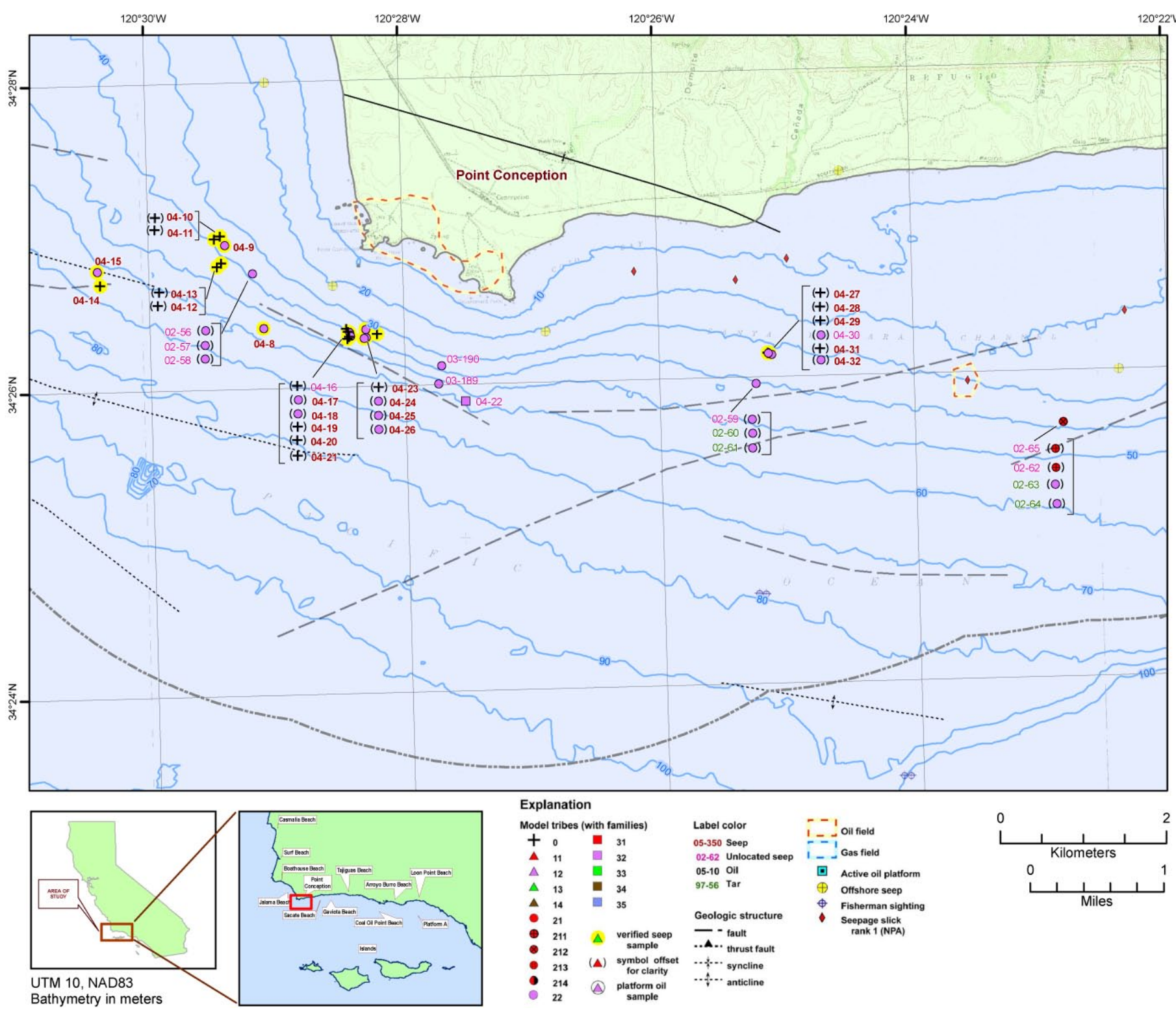

\section{Explanation}

Model tribes (with families) Label color

i: oil field

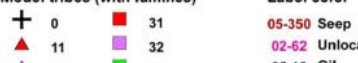

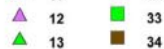

$02-62$
$05-10$
$97-56$ Oar

I - Gas field

4
4
4

- 21 Geologic struct

$211 \Delta$ verifed seep $\overline{\text { sample }}^{-. . \mathrm{A}-. . \text { tault }}$

$\oplus$ Offshore seep

Offshore seep
- Fssherman sightin
Seepage slick

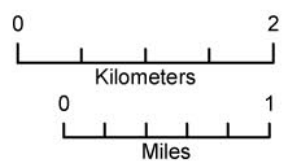

UTM 10, NAD83

213
213 (A) symbol offset ... thrust faut

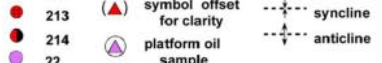

Figure 13. Map showing seep oil and tar sample collection sites offshore Point Conception and vicinity, California. 


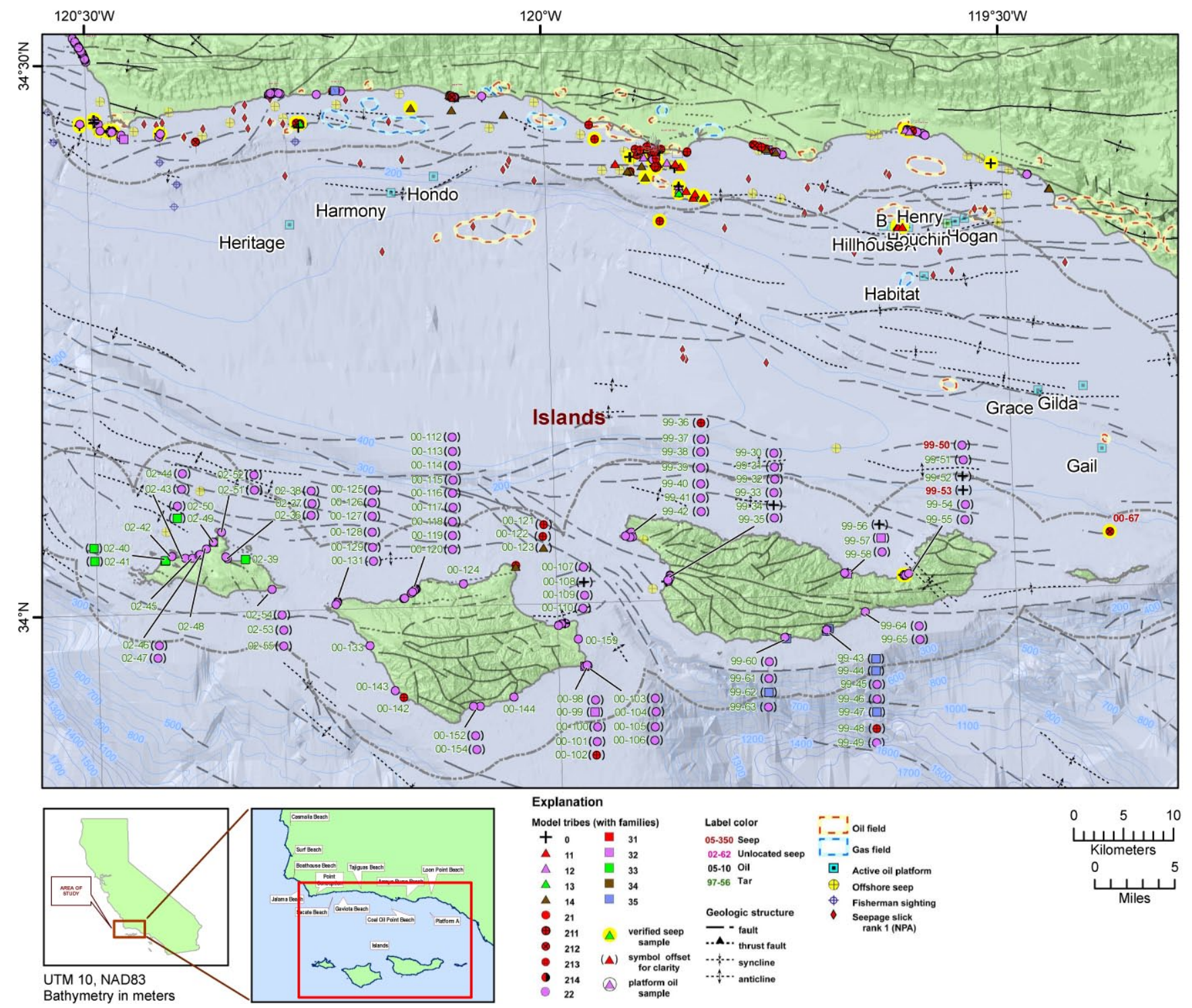

Figure 14. Map showing tarball, seep and produced oil sample collection sites in the Santa Barbara Channel and along the coastline, including the northern Channel Islands, California. 


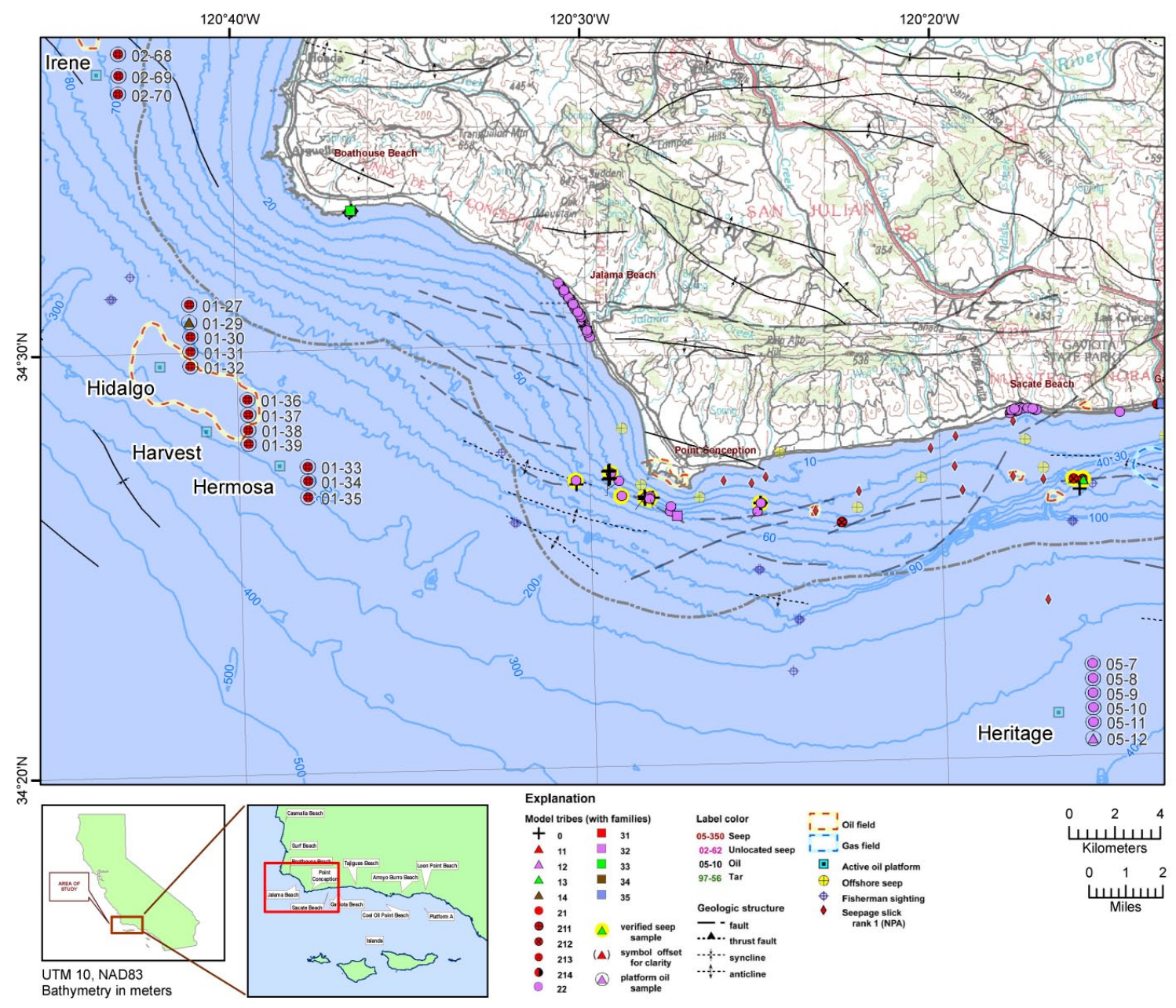

Figure 15. Map showing tarball, seep, and produced oil sample collection sites near Point Conception and Point Arguello, California. 


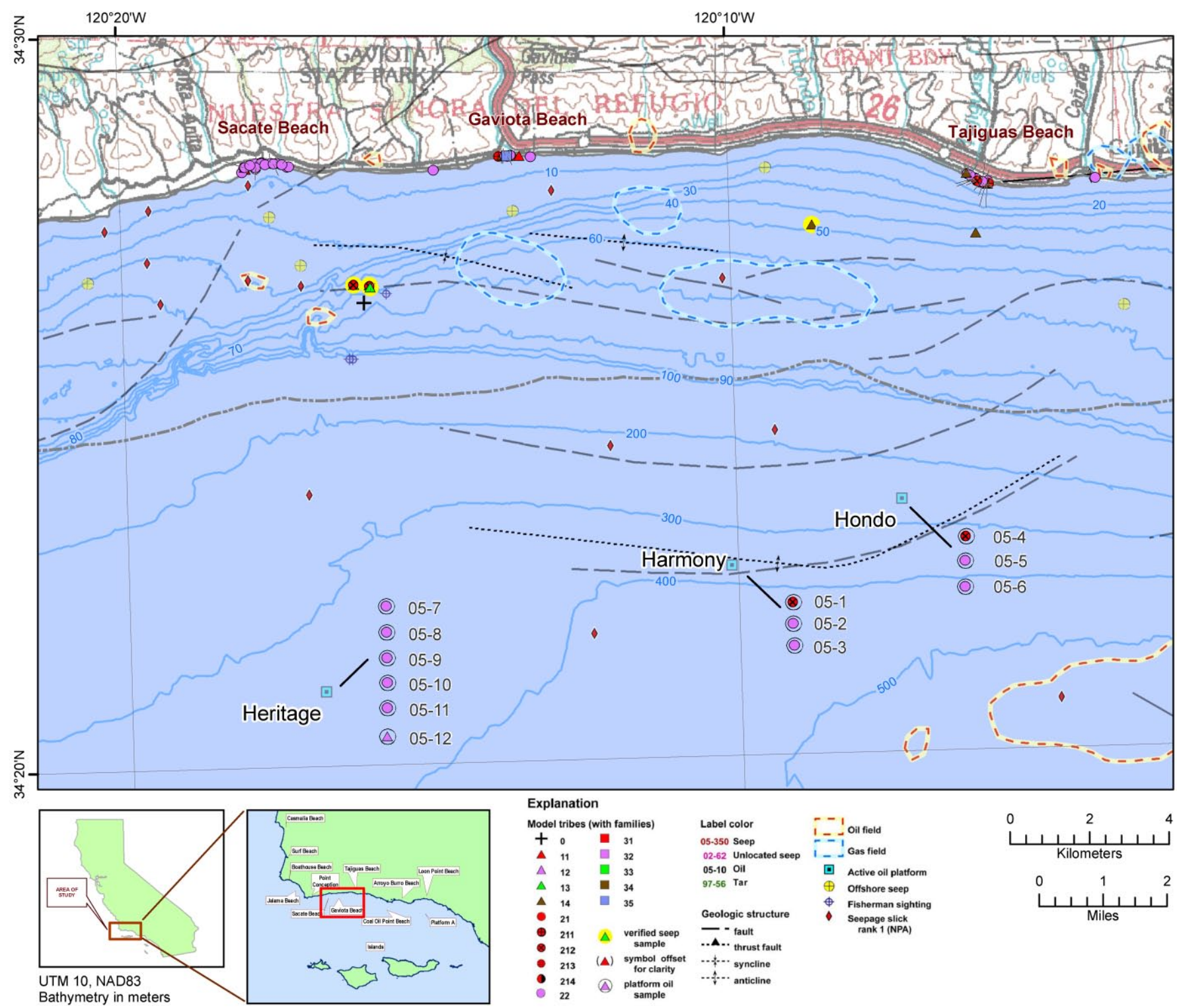

Figure 16. Map showing produced oil sample collection sites from Platforms Heritage, Harmony and Hondo, California. 


\section{Chapter 2. Biomarker and Carbon Isotope Analysis}

Biomarkers are complex organic compounds that occur in petroleum, rocks, and sediments and show little change in structure from their parent organic molecules in living organisms (Peters et al., 2005). Our approach has been to utilize these compounds to fingerprint oil, seep, and tar samples in order to track deposition of tar on beaches from their seep sources.

Previous work outlined in Chapter 1 has shown that much of the tar contamination originated from the Miocene Monterey Formation. Samples generated from source rock in the Monterey Formation share several chemical characteristics, including 1) unusually "heavy" $\mathrm{d}^{13} \mathrm{C}$ (around -23\%o); 2) aliphatic biomarker parameters indicating an anoxic marine depositional environment, such as high 28,30-bisnorhopane (Curiale et al., 1985), high $\mathrm{C}_{35}$ ab-hopane $22 \mathrm{~S}$ and $22 \mathrm{R}$ epimers compared to $\mathrm{C}_{34}$, and the presence of gammacerane (Peters and Moldowan, 1993); 3) a characteristic value ( $>3$ ) for the biomarker parameter called "the triplet" (Kvenvolden and others, 1995), defined in appendix I; 4) a small but consistent presence of oleanane; 5) sterane parameters indicating low maturity versus fully mature hopane parameters; 6) very low diasteranes relative to regular steranes, indicating a clastic-poor marine source rock; 7) abundant aromatized steranes, especially monoaromatics relative to triaromatics, indicating low thermal maturity (Curiale et al., 1985); and 8) prominent sulfur-containing PAH, such as dibenzothiophenes.

Although the above chemical components are common to the tarballs, their relative proportions within different tarball sources vary. Chemical fingerprints utilizing ratios of these constituents, plus additional biomarker parameters from both the aliphatic and aromatic hydrocarbon suites, allow discrimination between the different samples, as well as correlation of tarballs that have been transported far from their source by ocean currents (Hostettler et al., 2004).

The chemical composition of the tarballs also sheds light on their geochemical history. Despite the proliferation of offshore shallow hydrocarbon seeps, and the constant impingement of tar onto the shoreline, little is known about the mechanics of the hydrocarbon formation in the shallow seeps, specific sources of tarballs, or their transport from the marine environment onto the shore.

Because many of the tarballs from offshore seeps are transported significant distances from their sources by ocean currents, geochemical assignment of their origin provides insight into the circulation patterns of the coastal currents. The circulation patterns impacting the Santa Barbara Channel have recently been studied (Hickey, 1998; Harms and Winant, 1998). Persistant cyclonic circulation, upwelling conditions, and wind-relaxing act in different seasons to drive the currents. The net result on drifters in these studies is a combination of in-channel deposition, both on the mainland coast and on the channel islands, with flow predominantly toward the south and east in the spring and summer (California Current) and to the west and north in the late fall and winter (Davidson Current and the Southern California Countercurrent). Mapping deposition sites of tarballs that also drift with these ocean currents, therefore, may further validate past drifter studies, as well as provide information on the fate of these petrogenic contaminants in the coastal environment. 


\section{Methods}

During a period of ten years, 667 tarballs, tar residues, seeps, bitumen in rock, and production oils, mainly from coastal locations. The samples are listed in Appendix 2-1 with accompanying metadata and chemical fingerprint data in its entirety. Each tarball was separated from rocks or sand with a clean knife and placed in pre-cleaned glass jars for transport to the laboratory. Tars or oil floating in the salt water were placed in a clean glass jar, and any water was poured off before analysis. Production oils were sampled directly from sampling ports at their respective sites of production. Samples were dissolved in dichloromethane (DCM), filtered through glass wool to remove particulates, and air-dried under a hood to remove the DCM. After filtration and removal of DCM, a portion of the clean extract was removed to determine bulk stable carbon isotope composition. The results are reported in the d notation in parts per thousand (\%o) relative to the Pee Dee Belemnite (PDB) standard. Stable carbon isotope ratios of whole oil samples were determined by the combustion technique of Sofer (1980) using a Finnigan Delta $\mathrm{E}$ isotope ratio mass spectrometer.

A second portion of the extract $(\sim 25 \mathrm{mg}$ ) was dissolved as completely as possible by sonication and mechanical agitation in $5 \mathrm{ml}$ of hexane. This solution was then loaded onto a liquid chromatography column for compound class separation. Each column was layered at the bottom with about $5 \mathrm{~mm}$ of activated copper (to remove elemental sulfur), and with $2.5 \mathrm{~g}$ of $5 \%$ deactivated neutral alumina and $2.5 \mathrm{~g}$ and $5.0 \mathrm{~g}$ of 62 and 923 silica gels, respectively. Two separate fractions were collected-saturate (hexane eluent) and aromatic (30\% DCM eluent) and analyzed by gas chromatography/mass spectrometry (GC/MS). Compound identifications were made either by comparison with known standards or with published reference spectra. Chromatograms of a typical coastal tar residue, including a total ion chromatogram (TIC) and selected ion monitoring (SIM) mass chromatograms of terpanes (mass/charge, $\mathrm{m} / \mathrm{z}, 191)$ and steranes $(\mathrm{m} / \mathrm{z} 217)$ are shown in figure 2-1. Compound identifications are in table 2-1.

$n$-Alkanes and isoprenoids, and a suite of b-carotenoid-related compounds were profiled with extracted ion (EI) chromatograms (m/z 57 and 125, respectively). Selected biomarker ratios, listed below, were calculated from GC/MS/SIM chromatograms of m/z 191 (terpanes/hopanes) and 217 (steranes) using peak heights. 25,28,30-Trisnorhopane $\left(\mathrm{T}_{177}\right)$ and the presence or absence of a 25-norhopane series was monitored by $\mathrm{m} / \mathrm{z} 177$. Extracted ion profiles from TICs of the aliphatic and aromatic hydrocarbon fractions were used for the following ions: $\mathrm{m} / \mathrm{z} 253$ for monoaromatic steroids (M, summed from contributions in both the aromatic and aliphatic fractions), $\mathrm{m} / \mathrm{z} 231$ for triaromatic steroids (T), m/z 242 for monomethyl chrysenes, and m/z 212 and 206 for dimethyl-, and $\mathrm{m} / \mathrm{z} 226$ and 220 for trimethyl-dibenzothiophenes and phenanthrenes, respectively. Either summed areas or peak heights (see appendix 2-1) of the compounds were used to determine the parameter ratios. The biomarker and isotope values were used to correlate the samples and group them according to their probable source locations. 
Table 2-1. Identification of prominent compounds in GC/MS chromatograms seen in Figure 2-1.

(A) Saturates

13,14,15,16,18,19,20: homologs of 1,1,3-trimethyl-2-isoprenoidal cyclohexanes (shown;

$$
\mathrm{R}=\mathrm{H}, \backslash, \sim, \sim, \cdots, \cdots
$$

MAS: monoaromatic steroid hydrocarbon suite

$\mathrm{BN}$ : 28,30-bisnorhopane, common in Monterey oils

Steranes: $\mathrm{C}_{26}$ to $\mathrm{C}_{29}$ steranes as shown in Figure 2-1, D, E, and F

Hopanes: $\mathrm{C}_{29}$ to $\mathrm{C}_{35}$-pentacyclic triterpanes (hopanes), shown in Figure 2-1C.

(B) Aromatics

MAS: as above

TAS: triaromatic steroid hydrocarbon suite, $\mathrm{C}_{26}$ to $\mathrm{C}_{28}$

PAH: polycyclic aromatic hydrocarbons, typical of oils

(C) $\underline{\text { Hopanes }}$

$\mathrm{C}_{23}: \mathrm{C}_{23}$-tricyclic terpane

Triplet: $\mathrm{C}_{24}$-tetracyclic terpane, $\mathrm{C}_{26}$-tricyclic terpane $\left(\mathrm{S}\right.$ ?) $+\mathrm{C}_{26}$-tricyclic terpane( $\mathrm{R}$ ?).

Ts: 17a-22,29,30-trisnorhopane

Tm: 18a-22,29,30-trisnorneohopane

BN: 28,30-bisnorhopane

ab 29,30,31,32,32,34,35: 17a,21b(H)-hopanes, $\mathrm{C}_{31}-\mathrm{C}_{35}: \mathrm{S}+\mathrm{R}$ epimers

O: oleanane

G: gammercerane

(D),(E),(F) Steranes

$\mathrm{baD}_{27}$ : $13 \mathrm{~b}, 17 \mathrm{a}(\mathrm{H})$-diacholestane, $\mathrm{S}+\mathrm{R}$ epimers

24-norC 26 : 24-nor-5a-cholestane

27-norC 27 : 27-nor-24-methyl-5a-cholestane

aaa27, 28, 29: S+R epimers of 5a, 14a, 17a(H)-cholestane, 24-methyl- and 24-ethyl-

bb27,bb28,bb29: R+S epimers of 5a,14b,17b(H)-cholestane, 24-methyl- and 24-ethyl-.

\section{Geochemical Parameters}

The parameter ratios used in this study are defined in appendix 2-2, and the values listed in appendix 2-1. The various parameters were chosen to include as many as possible of the chemical families and constituents common to these tars. This was necessary for the overall geochemical characterization and because, with a common Miocene Monterey Formation source, many of the differences between groups of tarballs are small. The ubiquitous triterpane, $\mathrm{C}_{30}$ ab-hopane, was used to normalize seven of the parameters, thus serving as a pseudo conserved-internal-standard (Wang et al., 1998). Ease of measurement was also a factor in choosing parameters in order for this study to be more broadly utilized. 


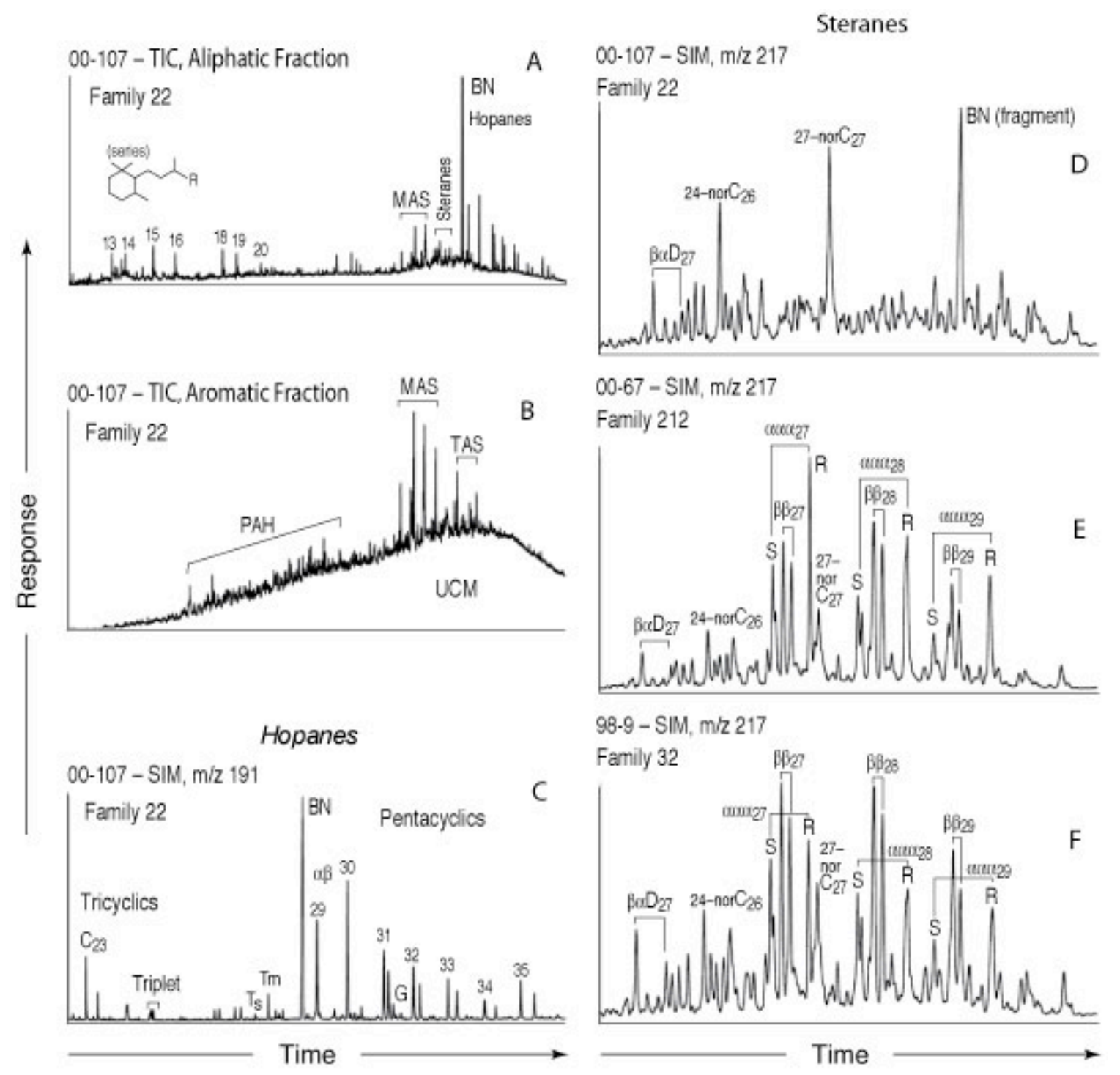

Figure 2-1. Chromatograms of selected tarball samples. Total ion chromatogram (TIC) of aliphatic $(\underline{A})$ and aromatic $(\underline{B})$ fractions; Selected ion monitoring (SIM) chromatograms of $\mathrm{m} / \mathrm{z} 191$, Hopanes $(\underline{\mathrm{C}})$, and $\mathrm{m} / \mathrm{z}$ 217, Steranes (D,E,F). Compounds identified in Table 2-1. Legend : MAS, monoaromatic steranes; Steranes, $\mathrm{C}_{26}$ to $\mathrm{C}_{29}$ regular steranes; Hopanes, $\mathrm{C}_{27}$ to $\mathrm{C}_{35}$ regular hopanes; $\mathrm{BN}$, 28,30-bisonorhopane; UCM, Unresolved Complex Mixture. 23T, $\mathrm{C}_{23}$-tricyclic terpane; $\mathrm{C}_{24}, \mathrm{C}_{25}, \mathrm{C}_{27}, \mathrm{C}_{38}$, tricyclic terpanes; T, triplet, defined in text; Ts and Tm, defined in text; BN, bisnorhopane; ab29, ab30, ab31 through 35 (S \& R epimers), ab-hopanes with carbon numbers; O, Oleanane; and $\mathrm{G}$, Gammacerane. ( $\underline{\mathrm{D}}, \mathrm{E}, \mathrm{F})$ Mass chromatograms (m/z 217) of $\mathrm{C}_{27}, \mathrm{C}_{28}$, and $\mathrm{C}_{29}$ steranes and $\mathrm{C}_{27}$ diasteranes in a selected coastal tar residues representing Families 22, 212, and 32. Legend: $\mathrm{S}, \mathrm{R}=$ epimers of aaa27, 28, 29 and bb27, 28, 29 steranes.

\section{Results}

A set of 34 parameters was calculated and compiled for the 667 samples in the data set (appendix 2-1). The group of parameters includes bulk carbon isotope analysis and 33 biomarker ratios or descriptors. The biomarker parameters are listed in Appendix 2-2 
along with references to their use and the kind of information they give as to the age, thermal maturity, depositional environment, degree of biodegradation, and general character of each oil sample.

These parameter ratios show that in general, all of the tarball samples in this sample set exhibit all of the characteristics of source rock in the Miocene Monterey Formation. Particularly notable is the prominence of bisnorhopane (BN) in the saturate fraction, monoaromatic steroids in both fractions, and a prominent but highly variable presence of perylene in the aromatic fraction. One additional common characteristic in the saturate fractions of the tarball samples (fig. 2-1) is a prominent series of 1,1,3-trimethyl-2isoprenoidal-cyclohexanes $\left(\mathrm{C}_{13}-\mathrm{C}_{16}, \mathrm{C}_{18}-\mathrm{C}_{20}\right.$; ; representative spectrum in Philp, 1985), probably derived from cleavage of $b$-carotane, a marker for bacterial input and a hypersaline depositional environment (Peters and Moldowan, 1993). Most of the tarball samples lack free $n$-alkanes and isoprenoids, although a few contain enough of the isoprenoids to allow calculation of the pristane/phytane $(\mathrm{Pr} / \mathrm{Ph})$ ratio, and one sample (00-126, Appendix 2-1) contains low levels of $n$-alkanes in an oil-like distribution. Sterane chromatograms contain, in addition to the regular steranes, two unusual steranes that in some samples are the dominant m/z 217 peaks (fig. 2-1 E). These compounds are tentatively identified from published spectra and retention times as $\mathrm{C}_{26}$ 24-nor-5acholestane (Moldowan et al., 1991) and $\mathrm{C}_{27}$ 27-nor-24-methyl-5a-cholestane (Schouten et al., 1994). The 24-nor-5a-cholestanes are generally rare but are known to be present in some oils from the Monterey Formation. They have been attributed to widespread Tertiary diatom-rich siliceous sediments and occur in oils from siliceous source rocks like the Monterey Formation (Holba and others, 1998). The two nor-cholestanes may be related to each other and are reported to co-occur (Schouten and others, 1994). They are ubiquitous in the samples of this study, and the parameter nor26\&27/Hop shows that they maintain a very consistent level throughout the sample set when indexed to $\mathrm{C}_{30} \mathrm{ab}$ hopane (appendix 2-1), or $\mathrm{C}_{29}$ ab-30-norhopane in the few samples where the $\mathrm{C}_{30}$ is degraded (Hostettler and others, 2004). Tarballs are characterized by maturity parameters indicating low thermal maturity, for example, very high Tm/Ts and BI, and very low $\mathrm{T} /(\mathrm{T}+\mathrm{M})$, and high values for the dibenzothiophene source parameters.

From the data set 388 samples were chosen whose parameters indicated that they were either non biodegraded (such as platform production oils) or mildly biodegraded below the point of sterane loss (such as many of the beached tarballs) that is, $</=$ stage 5 on the scale in Peters and others, (2005). Chemometric analysis, described in detail in Chapter 3, was then applied to these 388 samples using 19 of the above parameters (appendix 3-1), specifically parameters that were source-related and would not reflect significant biodegradative, thermal maturity or migration alteration. This set of samples is named the "Training Set," that is, the baseline sample set that, after chemometric analysis, is divided into groupings and subgroupings within three levels of increasingly correlated individual samples, and thus defines the sample set. After the Training Set is in place, further chemometric analysis can be applied to the more biodegraded samples or to new samples such as the ten 2007 samples recently washed up onto Monterey National Marine Sanctuary beaches and further north discussed in Chapter 3. These samples can then be evaluated to see where they fall in the groupings defined by the Training Set, thus gaining source, formation-facies and transport information on each new sample. The 
classification of tars and the geographic distribution with implications will be discussed in Chapter 3.

\section{Conclusions}

All beached tarballs in this sample set share geochemical source characteristics typical of source rock in the Monterey Miocene formation. Differences in relative amounts of constituents reflecting different inputs, levels of thermal maturity, degrees of biodegradation, and probably slightly different depositional facies allow fingerprinting and correlation by chemometric analysis. The range of individual fingerprint parameters within tarball families, however, is somewhat broad, and correlations are not as tight as might be expected from, for example, a spill of a specific crude oil such as the Exxon Valdez. Apparently, seep oil and related shoreline tarballs, even if from the same source, have small local variations in constituent concentrations, giving broader ranges within the chemical signature.

The tarballs originated from shallow reservoirs, as indicated by their low relative thermal maturity and abundant bisnorhopane. Significant but variable proportions of perylene, a PAH of biogenic origin found in surface marine sediments, implies inclusion by migration through these sediments.

Biodegradation in these shallow subsurface reservoirs impacts sterane distributions and can cause tars from similar sources to appear different. The family with the greatest number of samples, 22, represents a continuum of sterane loss, from abundant regular steranes dominated by $a_{a a C} C_{27} \mathrm{R}$ to samples which have lost most of the regular steranes. A number of tars cannot be classified and are characterized by biodegradation even beyond the regular steranes, showing a diminished $\mathrm{ab}_{30}$-hopane and, to a lesser extent, bisnorhopane.

A pair of unusual steranes prominent in this sample set, $\mathrm{C}_{26}$ 24-nor-5a-cholestane and $\mathrm{C}_{27}$ 27-nor-24-methyl-5a-cholestane, are not impacted by biodegradation, and maintain a consistent level relative to $C_{30}$ ab-hopane, throughout the data set. 


\section{Appendix 2-1 \\ Location, classification, and geochemical data for crude oil, seep oil, and tarball samples.}

Appendix 2-1 is provided as Excel .xls, comma-separated values .csv, and tab-delimited ASCII .txt files. Follow this link to

http://pubs.usgs.gov/of/2009/1225/of2009-1225_appendix_2-1/ to download any of these files. 


\section{Appendix 2-2}

\section{Geochemical Parameters used in Tarball Studies}

Parameters used for the chemometric analysis described in Chapter 3 are indicated in red.

\section{Whole oil:}

1. $\delta^{13} \mathrm{C}$, the carbon isotopic composition of whole tar residues. These compositions are useful for oil and source rock correlations (Peters and Moldowan, 1993).

\section{Saturate fraction:}

2. Alkanes. A descriptor where $0=$ no $n$-alkanes present in the tar/oil and $1=n$-alkanes present.

3. $\mathrm{Pr} / \mathrm{Ph}$, pristane/phytane. This is a widely used source parameter (Peters and Moldowan, 1993) based on the two most common isoprenoids in crude oils. These compounds are readily lost by degradation and are not present in most of the tarballs in this study, although they are prominent in unweathered production or crude oils.

\section{Triterpanes (hopanes), m/z 191 SIM chromatograms:}

4. Ts/Tm, 18 $\alpha-22,29,30$-trisnorneohopane/17 $\alpha-22,29,30$-trisnorhopane. This ratio is used as both a source and maturity parameter (Seifert and Moldowan, 1978).

5. Triplet, $\left[\mathrm{C}_{26}\right.$-tricyclic terpane $\left(\mathrm{S}\right.$ ?) $+\mathrm{C}_{26}$-tricyclic terpane $\left(\mathrm{R}\right.$ ?) $/ \mathrm{C}_{24}$-tetracyclic terpane $]$. This source parameter was used to distinguish coastal tar residues in Prince William Sound (Kvenvolden and others, 1995). Abundant $\mathrm{C}_{24}$ tetracyclic is cited (Peters and others, 2005) as indicating carbonate and evaporite source facies, therefore lower values of this ratio (since $\mathrm{C}_{24}$ is the denominator) indicate this characteristic.

6. 23 Tri $/ \mathrm{C}_{30}, \mathrm{C}_{23}$ tricyclic terpane $/ 17 \alpha, 21 \beta(\mathrm{H})$-hopane. This ratio is a source parameter adapted from Peters and Moldowan (1993).

7. 23 Tri $/ \mathrm{C}_{29}, \mathrm{C}_{23}$ tricyclic terpane/17 $\alpha, 21 \beta(\mathrm{H})-30$-norhopane. This ratio is a source parameter adapted from Peters and Moldowan (1993).

8. 20Tri/23Tri, $\mathrm{C}_{20}$ tricyclic terpane/ $\mathrm{C}_{23}$ tricyclic terpane. Source parameter.

9. 22Tri/21Tri, $\mathrm{C}_{22}$ tricyclic terpane/ $\mathrm{C}_{21}$ tricyclic terpane. Source parameter, used by Peters and others, 2005, to help distinguish lithofacies.

10. 24Tri/23Tri, $\mathrm{C}_{24}$ tricyclic terpane/ $\mathrm{C}_{23}$ tricyclic terpane. Source parameter, used by Peters and others, 2005, to help distinguish lithofacies.

11. 26Tri/25Tri, $\mathrm{C}_{26}$ tricyclic terpanes/ $\mathrm{C}_{25}$ tricyclic terpanes. peak areas. Source parameter; high values $(>1)$ indicate a lacustrine depositional environment, whereas lower values indicate a marine source.

12. 28 Tri/29Tri. $\mathrm{C}_{28}$ tricyclic terpanes/ $\mathrm{C}_{29}$ tricyclic terpanes, peak areas. Source parameter.

13. $\mathrm{C}_{29} / \mathrm{C}_{30}, 17 \alpha, 21 \beta(\mathrm{H})-30$-norhopane $/ 17 \alpha, 21 \beta(\mathrm{H})$-hopane. This ratio is a source parameter adapted from Palacas and others (1984).

14. 29D/29H, 18 $\alpha(\mathrm{H})-30$-norneohopane/17 $\alpha, 21 \beta(\mathrm{H})-30$-norhopane. Source parameter. 
15. $\mathrm{C}_{31} \mathrm{~S} /(\mathrm{S}+\mathrm{R}), 17 \alpha, 21 \beta(\mathrm{H})$-homohopane (22S)/17 $\alpha, 21 \beta(\mathrm{H})$-homohopane (22S+22R).

This epimer ratio is a hopane maturity parameter used extensively in petroleum geochemistry; the equilibrium ratio at full maturity is $\sim 0.6$ (Ensminger and others, 1974; Mackenzie, 1984).

16. $\mathrm{C}_{31} \mathrm{~S} / \mathrm{C}_{30}, 17 \alpha, 21 \beta(\mathrm{H})$-homohopane $(22 \mathrm{~S}) / 17 \alpha, 21 \beta(\mathrm{H})$-hopane. Source parameter.

17. 35S/34S, 17 $\alpha, 21 \beta(\mathrm{H})-29$-pentakishomohopane (22S)/17 $\alpha, 21 \beta(\mathrm{H})-29$ tetrakishomohopane (22S). Higher $\mathrm{C}_{35}$ than $\mathrm{C}_{34} 22 \mathrm{~S}$ homohopanes is an indication of carbonate/evaporite facies or anoxic depositional environment.

18. BI, Bisnorhopane Index, 28,30-bisnorhopane/17 $\alpha, 21 \beta(\mathrm{H})$-hopane. This source ratio has been used to characterize oils from the Monterey Formation. The presence of 28,30-bisnorhopane, in addition to indicating a marine, highly reducing depositional environment (Curiale and others, 1985), is reported to be passed on from bitumen rather than generated from kerogen and therefore decreases with thermal maturity (Peters and Moldowan, 1993). Therefore, this ratio would be higher in oils sourced from near-surface facies.

19. OI, Oleanane Index, $18 \alpha+\beta(\mathrm{H})$-oleanane $/ 17 \alpha, 21 \beta(\mathrm{H})$-hopane. This commonly used source parameter indicates a contribution from Cretaceous and younger plant material (Peters and Moldowan, 1993). In the California coastal tars, oleanane is generally present, but in low amounts.

20. GI, Gammacerane Index, gammacerane $/ 17 \alpha, 21 \beta(\mathrm{H})$-hopane. This ratio is used as a source parameter; abundant gammacerane is a carbonate/evaporite facies indicator and a marker for highly reducing, hypersaline depositional environments (Peters and Moldowan, 1993).

\section{Steranes, m/z 217 SIM chromatograms:}

21. $\mathrm{C}_{29} \mathrm{~S} /(\mathrm{S}+\mathrm{R}), 24$-ethyl-5 $\alpha, 14 \alpha, 17 \alpha(\mathrm{H})$-cholestane $(20 \mathrm{~S}) / 24$-ethyl-5 $\alpha, 14 \alpha, 17 \alpha(\mathrm{H})$ cholestane $(20 \mathrm{~S}+20 \mathrm{R})$. This sterane epimer ratio is commonly used as a maturity parameter; the equilibrium value at full maturity is $\sim 0.5$ (Mackenzie and others, 1980).

22. $\mathrm{C}_{28} / \mathrm{C}_{29}, 24$-methyl-5 $\alpha, 14 \alpha, 17 \alpha(\mathrm{H})$-cholestane (20R)/ 24-ethyl-5 $\alpha, 14 \alpha, 17 \alpha(\mathrm{H})$ cholestane (20R). This source parameter has been modified from discussions in Grantham and Wakefield (1988) and Waples and Machihara (1991).

23. Dominant sterane(s). This descriptor indicates the sterane(s) that are most prominent in the $\mathrm{m} / \mathrm{z} 217$ chromatogram. The $\mathrm{m} / \mathrm{z} 217$ chromatogram may also include a fragment of bisnorhopane $(\mathrm{BN})$, which is noted if it is one of the most prominent peaks. This gives information on the extent of sterane degradation in these systems.

24. $\alpha 27 \mathrm{R} / \mathrm{Hop}$, a Sterane Index, $5 \alpha, 14 \alpha, 17 \alpha(\mathrm{H})$-cholestane/17 $\alpha, 21 \beta(\mathrm{H})$-hopane. This parameter gives an indication of relative proportions of a common regular sterane to hopane. In this study it helps track sterane biodegradation.

25. nor26\&27/Hop, another Sterane Index, two tentatively identified steranes, $\mathrm{C}_{26}$ 24-nor$5 \alpha$-cholestane (Moldowan and others, 1991) and $\mathrm{C}_{27}$ 27-nor-24-methyl-5 $\alpha$ cholestane (Schouten and others, 1994), indexed to hopane. This is a source parameter and may serve as a maturity parameter, particularly in subsequent studies when deeper production oils are considered.

26. $\alpha 27 \mathrm{R} /$ nor27, $5 \alpha, 14 \alpha, 17 \alpha(\mathrm{H})$-cholestane/ $\mathrm{C}_{27}$ 27-nor-24-methyl-5 $\alpha$-cholestane. A sterane parameter that also tracks sterane biodegradation. 
$27,28,29 . \% 27, \% 28, \% 29$. Percentage of $\mathrm{C}_{27}, \mathrm{C}_{28}$, and $\mathrm{C}_{29}$ steranes, from the $\mathrm{m} / \mathrm{z} 218$ extracted ion profile.

\section{Aromatic fraction}

30. PAH-RI, Polycyclic Aromatic Hydrocarbon-Refractory Index. This index is a source parameter, the ratio of the second, usually major, peak containing the $\mathrm{C}_{26} \mathrm{R}$ and $\mathrm{C}_{27} \mathrm{~S}$ members in the highly refractory $\mathrm{C}_{26}$ to $\mathrm{C}_{28}$ triaromatic sterane suite (TAS, $\mathrm{m} / \mathrm{z} 231$ ) to that of the first, usually dominant, peak in the monomethyl chrysenes (m/z 242) (Hostettler and others, 1999). In this very large data set it can be seen that this previously descriptive-only parameter does reflect a specific facies characteristic. PAH-RI goes from low values in shale, mid values in marl, and high values in carbonate (increasingly anoxic facies) environments. Since PAH-RI compares TAS to a typical petrogenic $\mathrm{C}_{1} \mathrm{PAH}$, high values indicate higher levels of TAS. TAS are known to be a stable product of diagenesis of steranes in a reducing or anoxic environment. Therefore, PAH-RI is another indicator of the anoxic nature of the source environment.

31. $\mathrm{T} /(\mathrm{T}+\mathrm{M}) . \mathrm{T}=$ triaromatic steranes (areas), $\mathrm{C}_{26}$ to $\mathrm{C}_{28}, \mathrm{~m} / \mathrm{z} 231 ; \mathrm{M}=$ monoaromatic steranes (areas), $\mathrm{C}_{26}$ to $\mathrm{C}_{28}, \mathrm{~m} / \mathrm{z} 253$. Aromatic steroid parameter. This is a thermal maturity and source parameter, widely used, modified from that described in Peters and Moldowan (1993). Low values, reflecting relatively higher levels of the monoaromatic steroids, indicate low thermal maturity.

32. $\Sigma \mathrm{C} 2 \mathrm{D} / \Sigma \mathrm{C} 2 \mathrm{P}$, dimethyl dibenzothiophenes $(\mathrm{m} / \mathrm{z} 212) /$ dimethyl phenanthrenes $(\mathrm{m} / \mathrm{z}$ 206). Source parameter indicating relative levels of sulfur-containing PAH to regular PAH (Kaplan and others, 1997; Bence and others, 1996).

33. $\Sigma \mathrm{C} 3 \mathrm{D} / \Sigma \mathrm{C} 3 \mathrm{P}$, trimethyl dibenzothiophenes $(\mathrm{m} / \mathrm{z} 226) /$ trimethyl phenanthrenes $(\mathrm{m} / \mathrm{z}$ 220). Source parameter as \#32.

34. Pery/Chr, a PAH parameter, perylene normalized to chrysene. Perylene helps distinguish shallow-seeping oils from deeper oils. Perylene has a biogenic origin and is associated with near-surface bitumens (Ventakesan, 1988). It is known to be present in variable amounts in shallow Monterey sediments (Kvenvolden and others, 2002). 


\section{Chapter 3. Chemometric Modeling, Tarball Sources, and Distribution}

\section{Introduction}

The discipline of chemometrics was applied to the biomarker data to better understand the origin and distribution of oil samples, including crude oil from wells, seeps, and floating or beached tarballs from coastal California, and to build upon the work of Hostettler and others, (2004). The objectives of this study were to 1) classify the samples into generic families using geochemical data (oil-oil correlation), 2) create an automated chemometric decision tree to classify additional samples as they become available, and 3 ) identify the source rock for each sample (oil-source rock correlation). The latter was attempted by indirect and direct correlation. First, geochemical data for the oil samples were used to indirectly infer the age, lithology, organic matter input, and depositional environment of the source rock. Second, the geochemical compositions of the oil samples and source rock extracts were directly compared. Correlations are geochemical comparisons among crude oils and/or extracts from prospective source rocks to determine whether a genetic relationship exists (Waples and Curiale, 1999; Peters and others, 2005). Oil-oil and oil-source rock correlation are based on the concept of similarity through heritage, where migrated oil collected from seeps or reservoir zones in wells has sourcerelated compositional parameters similar to bitumen remaining in the effective source rock.

The following discussion comes mainly from Peters and others (2008) and uses the terms tribe and family to indicate generic divisions of samples. An oil tribe consists of samples that are broadly similar in their geochemical characteristics, but may originate from different source rocks or different organofacies (Jones, 1987) of the same source rock. A family is a division of a tribe that consists of geochemically similar samples that originated from the same or very similar source rock.

\section{Methods}

\section{Oil Samples}

The initial data set included 676 samples of production oil (59), seep oil (130), and floating or beached tarballs (487) collected from coastal California, mostly between Los Angeles in the south and Point Reyes in the north (Appendix 3-1; Fig. 3-1). Many of the samples show evidence of biodegradation, including loss of $n$-alkanes, acyclic isoprenoids, and other compounds that are more resistant to microbial alteration, such as steranes. Collection of the oil samples, chromatographic separation into saturate and aromatic fractions, and gas chromatography-mass spectrometry (GC/MS) were carried out as described in Chapter 2 modified from Hostettler and others (2004).

After GC/MS analysis, 397 samples determined to be nonbiodegraded or mildly biodegraded (rank 5 or less based on the 1-10 biodegradation scale of Peters and Moldowan, 1993) were selected as a training set to establish oil families by means of a chemometric decision tree based on comparison of 19 biomarker and stable carbon isotopic ratios for each sample. Nine of these samples were rejected from the training set because of anomalous geochemical traits (see below), leaving 388 samples. A training set is a collection of samples used for learning, where characteristics of the samples are used to describe generic families. After the training set was established, an additional 279 samples 
(including samples that were too biodegraded for use in the training set) were evaluated using the chemometric decision tree to determine genetic affinities. Fifty-seven of the 279 new samples could not be reliably classified by the decision tree for various reasons, such as heavy biodegradation.

\section{Screening of the Training Set}

The following samples were excluded from the training set 1) source rock extracts, and 2) extensively biodegraded samples (rank 6 or more on the 1-10 scale of Peters and Moldowan, 1993). Steranes and terpanes are more resistant to biodegradation than $n$ alkanes and linear isoprenoids and thus are versatile tools for oil-oil correlation. While $n$ alkanes and linear isoprenoids are degraded in crude oil that ranks 5 on the biodegradation scale, the steranes are at most only mildly altered. Steranes in crude oil having rank 6 or more have been biodegraded, thus limiting their use for oil-oil correlation. Source rock extracts were omitted from the training set because core or cuttings samples from a narrow depth range may fail to adequately represent the composition of crude oil generated from a thick section of thermally mature source rock. However, thermally mature source rock extracts can be conveniently compared to crude oil samples for oil-source rock correlation using a chemometric decision tree based on the oil training set.

\section{Source- and Age-Related Geochemical Parameters}

The chemometric analysis included 19 source-related biomarker and isotopic ratios that are not readily affected by migration, biodegradation, or thermal maturation. These parameters are a subset of the 34 parameters listed in Chapter 2. The parameters are described in Chapter 2, Hostettler and others (2004) and Peters and others (2005) and include 14 terpane ratios: 22,29,30-trisnorneohopane/22,29,30-trisnorhopane (Ts/Tm), $\mathrm{C}_{26}$ $22 \mathrm{~S}$ and $22 \mathrm{R}$ tricyclic terpanes/ $\mathrm{C}_{24}$ tetracyclic terpane $\left(\mathrm{C}_{26} / \mathrm{Tet}\right), \mathrm{C}_{20} / \mathrm{C}_{23}, \mathrm{C}_{22} / \mathrm{C}_{21}, \mathrm{C}_{24} / \mathrm{C}_{23}$, $\mathrm{C}_{26} / \mathrm{C}_{25}$, and $\mathrm{C}_{28} / \mathrm{C}_{29}$ tricyclic terpanes $\left(\mathrm{C}_{20} / \mathrm{C}_{23} \mathrm{TT}, \mathrm{C}_{22} / \mathrm{C}_{21} \mathrm{TT}, \mathrm{C}_{24} / \mathrm{C}_{23} \mathrm{TT}, \mathrm{C}_{26} / \mathrm{C}_{25} \mathrm{TT}\right.$, and $\mathrm{C}_{28} / \mathrm{C}_{29} \mathrm{TT}$, respectively), 17a,21b(H)-30-norhopane/hopane $\left(\mathrm{C}_{29} \mathrm{H} / \mathrm{H}\right), \mathrm{abC}_{31} 22 \mathrm{~S} /$ hopane $\left(\mathrm{C}_{31} \mathrm{~S} / \mathrm{H}\right), \mathrm{C}_{35} 22 \mathrm{~S} / \mathrm{C}_{34} 22 \mathrm{~S}$ hopanes $\left(\mathrm{C}_{35} / \mathrm{C}_{34} \mathrm{~S}\right), 28,30$-bisnorhopane/hopane $(\mathrm{BNH} / \mathrm{H})$, oleanane/hopane $(\mathrm{Ol} / \mathrm{H})$, gammacerane/hopane $(\mathrm{G} / \mathrm{H})$, and 18a-30-norneohopane/ab-30norhopane $\left(\mathrm{C}_{29} \mathrm{Ts} / \mathrm{C}_{29} \mathrm{H}\right)$. Other parameters include the whole-oil stable carbon isotope ratio $\left(\mathrm{d}^{13} \mathrm{C}_{\mathrm{PDB}}\right), \mathrm{C}_{28} / \mathrm{C}_{29}$ aaa20R steranes $\left(\mathrm{C}_{28} / \mathrm{C}_{29}\right)$, and three aromatic compound ratios polycyclic aromatic hydrocarbon refractory index (PAH-RI; Hostettler and others, 1999), dimethyldibenzothiophene/dimethylphenanthrene (SC2D/2P), and trimethylbenzothiophene/trimethylphenanthrene (SC3D/3P).

\section{Analytical Error}

Analytical error in the geochemical data is minimal, as indicated by the similarity of training set samples from similar depth intervals in the same wells or samples from the same location. For example, five oil samples (00-74 to 00-78) from different wells in the onshore Sargent Field south of Gilroy, California (Fig. 3-1), show nearly identical biomarker and isotope compositions. These five oil samples belong to Tribe 1, Family 12 (Figs. 3-2, 3-3). 


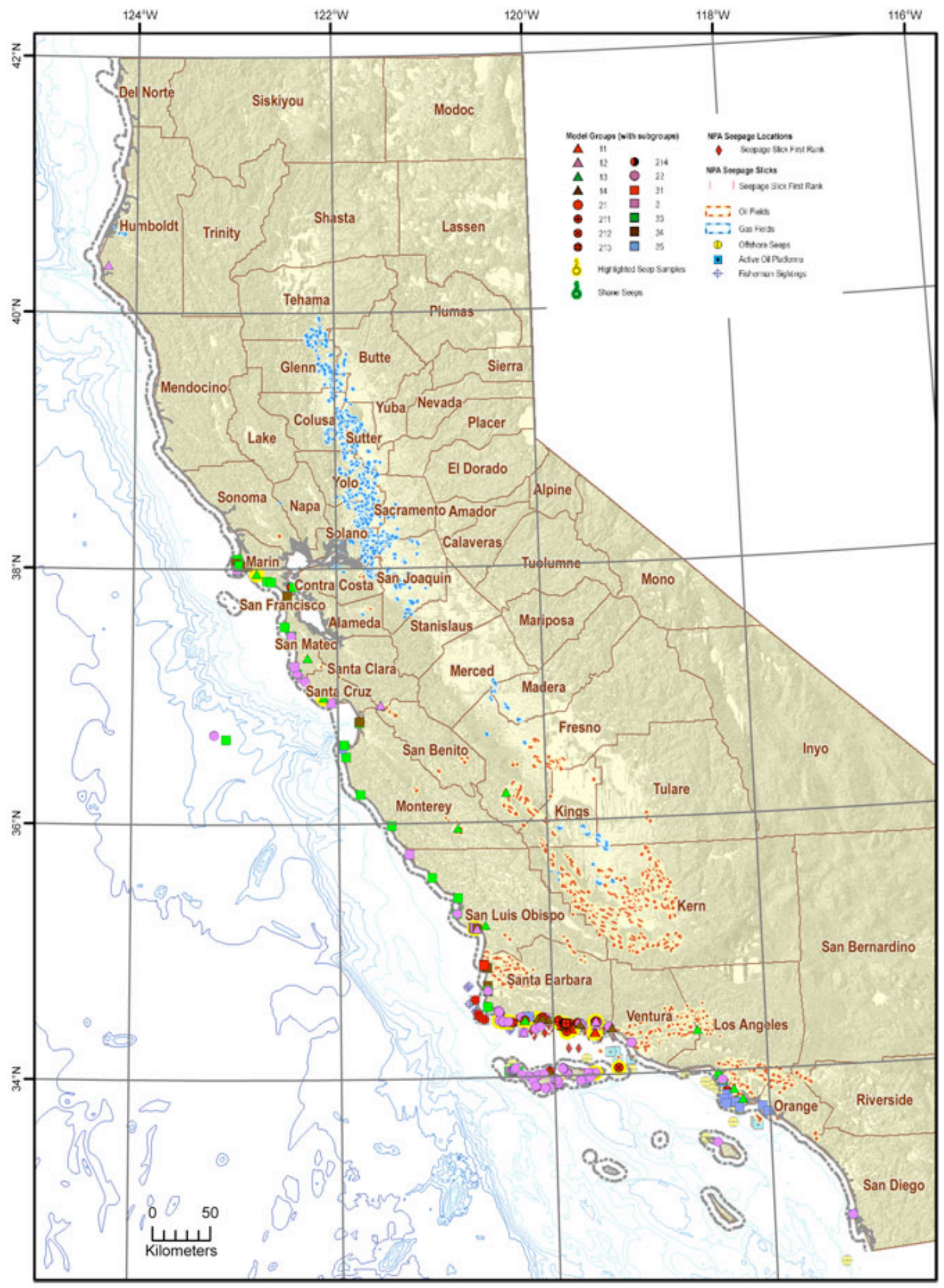

Figure 3-1. Map of California showing the locations of samples included in the chemometric analysis. 


\section{Hierarchical Cluster Analysis (HCA) Distinguishes Tribes 1, 2, and 3}

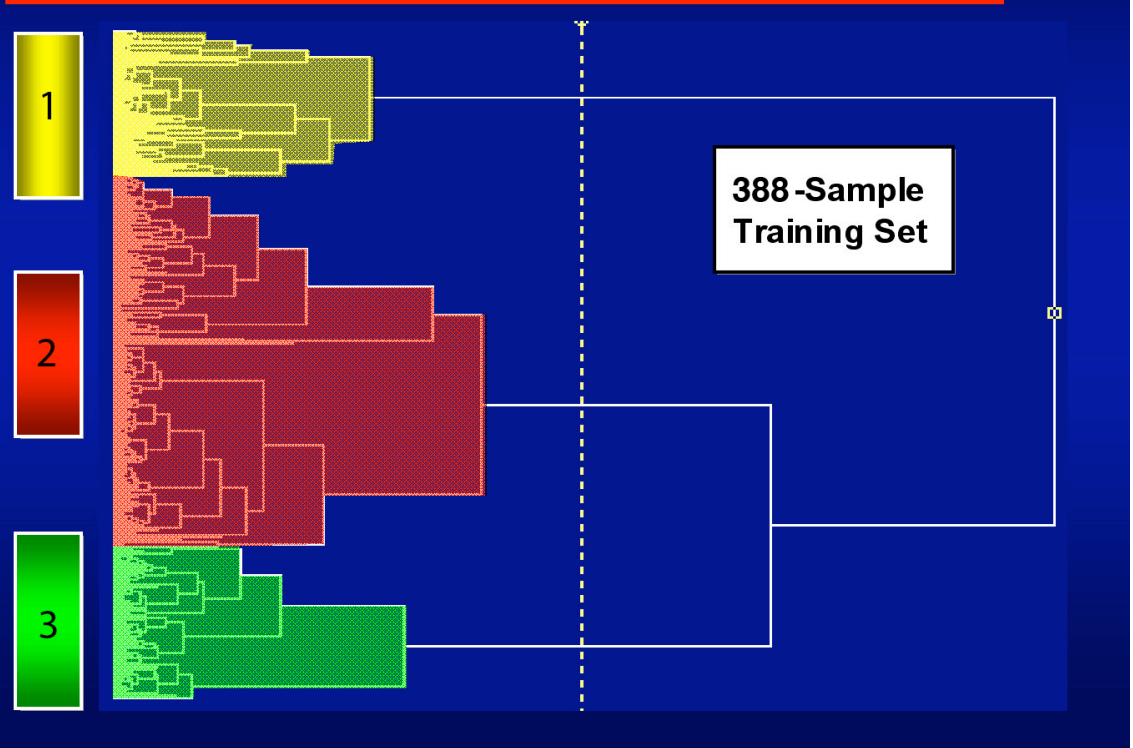

Figure 3-2. Hierarchical cluster analysis (HCA) distinguishes Tribes 1, 2, and 3 among 388 training set oil, seep, and tarball samples from coastal California as defined by the vertical dashed similarity line. Because of the large number of samples, the left axis identifies oil tribes, but not families or individual samples at this scale. Cluster distance is a measure of genetic similarity indicated by the horizontal distance from any two samples on the left to their branch point on the right. 


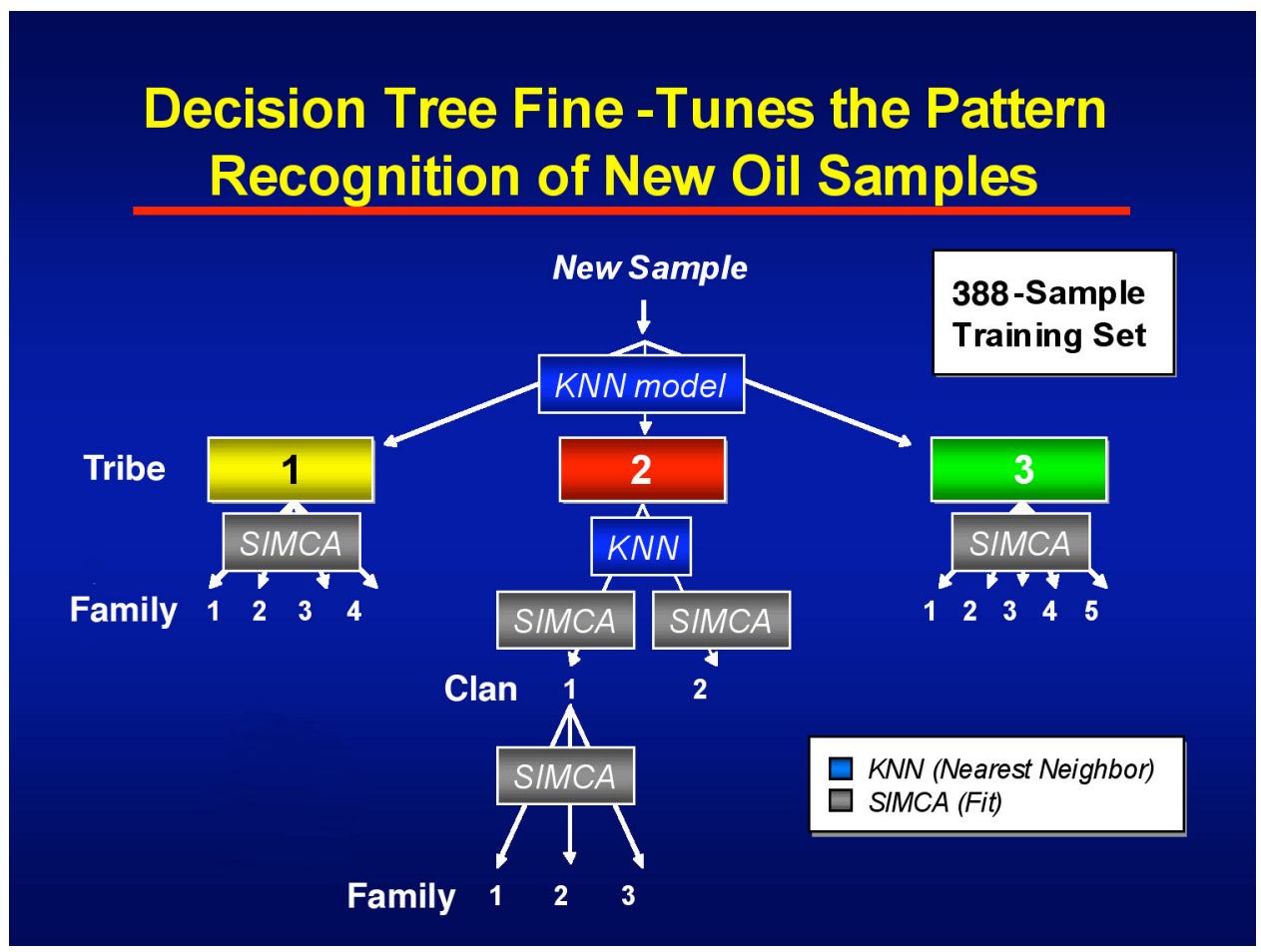

Figure 3-3. The chemometric decision tree uses a 388-sample training set to classify new oil, seep, tarball, or source rock extract samples based on 19 source-related biomarker and isotope ratios. KNNis K Nearest Neighbor, SIMCA is soft independent modeling of class analogy (see Methods). Statistical criteria for SIMCA fit (confidence in the assignment of a sample to a given family) are based on a ratio of residuals as described in the footnote to the appendix 3-1.

\section{Chemometric Analysis}

Hierarchical cluster analysis (HCA) and principal component analysis (PCA) were completed to identify genetic affinities among the 388 training set samples by using autoscale preprocessing, Euclidean metric distance, and incremental linkage options in Pirouette $^{\circledR}$ (Infometrix, Inc.). In autoscale preprocessing, all values for each parameter are normalized to the standard deviation for that parameter, resulting in equal weight for each parameter during the chemometric analysis.

In many chemometric applications, all available parameters are included in PCA. However, our approach differs because we use geochemical expertise to select the parameters that differentiate the samples. We know that certain parameters are affected by secondary processes, such as biodegradation or thermal alteration, while other parameters, such as the $\mathrm{C}_{28} / \mathrm{C}_{29}$ sterane homolog ratio, are key indicators of genetic relationships among oil and source rock bitumen samples (Peters and others, 2005).

We used decision-tree chemometrics (Peters and others, 2007) to classify new oil, seep, and tarball samples, not included in the training set and to assign corresponding confidence limits. The automated decision tree was created in InStep ${ }^{\mathrm{TM}}$ (Infometrix, Inc.) by using PCA, including multiple tiers of K-Nearest Neighbor (KNN) and soft independent modeling of class analogy (SIMCA) models. PCA is statistically more rigorous than HCA and a PCA-based decision tree can be used to classify unknown samples without the need 
to modify the training set. Generic families are defined here as crude oil, seep oil, or tarball samples having similar geochemical characteristics that indicate distinct source rock organofacies.

The KNN and SIMCA models were based on 388 training set samples from an original collection of 397 samples. Nine of the original 397 samples were omitted from the chemometric models because of anomalous geochemical data that caused them to be outliers in PCA space (99-18, 99-19, 99-101, 99-103, 00-68, 03-94, 04-7, 04-272, and 0595 in appendix 3-1). For example, sample 99-101 is crude oil from Coalinga Field in the San Joaquin Basin; it has a stable carbon isotope ratio of $-26.4 \%$, which is outside the range of typical Miocene oil (-22 to -25\%, Chung and others, 1992). Most oil in Coalinga Field originated from Eocene Kreyenhagen Shale source rock and has carbon isotope ratios in the range of -27 to $-29 \%$ (Peters and others, 1994). Some new samples were successfully categorized despite having as many as four parameters that were unreliable due to biodegradation or analytical problems (labeled "nd" in Appendix 3-1). Each missing value was replaced by the mean value of that parameter for all samples in the data set (mean fill). Appendix 3-1 includes the 388 training set samples plus 279 additional (new) oil samples. The decision tree successfully classified 222 of these 279 samples, while 57 samples could not be classified because of heavy biodegradation and/or incomplete data.

\section{Discussion}

HCA of 19 source-related biomarker and isotope ratios yields a dendrogram that divides 388 crude oil, seep, and tarball samples from coastal California into three generic tribes (Fig. 3-2, appendix 3-2 for the expanded version). This training set was selected from a much larger collection of samples by using screening criteria described in Methods. For example, heavily biodegraded oil samples were excluded because this secondary process can obscure generic relationships by altering source-related ratios. The location of the similarity line on the cluster distance axis in Fig. 3-2 was adjusted toward the right portion of the figure to minimize the number of tribes. This resulted in tribes that were clearly distinct from each other based on large cluster distances. Each tribe was subsequently divided into families using more refined chemometric analyses discussed below. Due to the large number of samples, each tribe contains families of oil samples that have broadly similar geochemical characteristics, but differ in detail and could originate from different source rocks or different organofacies of the same source rock.

We used decision-tree chemometrics (Peters and others, 2007) to classify heavily biodegraded samples, source rock extracts, and new oil samples not included in the training set (Fig.3-3). The power of the decision tree to resolve each family increases from top to bottom in the figure, partly because each tier within the decision tree consists of different KNN or SIMCA models. The first tier in the decision tree is based on a KNN model that uses all 19 source- and age-related biomarker and isotopic parameters to establish three oil tribes. However, some of these parameters can be eliminated from KNN or SIMCA models in the subsequent tiers of the decision tree because they do not further contribute to the resolution of families. For example, oleanane occurs in many samples within Tribe 1, but is low or absent from Tribe 3. Oleanane/hopane $(\mathrm{Ol} / \mathrm{H})$ ratios for Tribe 3 samples are $<0.04$ (appendix 3-1), indicating that if oleanane is present, it is below detection limits. Therefore, it would be unwise to use $\mathrm{Ol} / \mathrm{H}$ to classify families within Tribe 3 because the measurements represent analytical noise near a value of zero. 


\section{Inferred Source Rock Age}

Several key studies show that the geochemical composition of crude oil can be used to characterize the age, lithology, organic matter input, and depositional environment of the source rock (for example, Moldowan and others, 1985; Mello and others, 1988) and that these interpretations are best confirmed using multivariate statistics (Peters and others, 1986; Zumberge, 1987). Two parameters were used to infer Miocene age for the source rock of the training set oil samples. The $\mathrm{C}_{28} / \mathrm{C}_{29}$ sterane ratio for all but one of the 388 successfully classified the training set samples is $>0.7$, consistent with Upper Jurassic to Miocene source rock (Grantham and Wakefield, 1988). All of these samples have stable carbon isotope ratios $\left(\mathrm{d}^{13} \mathrm{C}_{\mathrm{PDB}}\right)$ in the range of -22 to $-25 \%$, which characterizes most Miocene crude oil and source rock extract samples (for example, Chung and others, 1992). Minor tar residues on beaches in Prince William Sound having isotopic compositions in this range are distinct from Exxon Valdez oil residues and likely originated as products from the Monterey Formation in California that were shipped by barge to Alaska (Kvenvolden and others, 1993). However, isotope values in this range are not diagnostic of the Miocene Monterey Formation. For example, extracts from overlying Miocene Sisquoc Formation and underlying Miocene Rincon Shale have isotope compositions similar to the Monterey Formation in the Santa Barbara Channel area (Katz and Royle, 2001). Although the Sisquoc Formation at Naples Beach in this area is lean in organic carbon $(<1.0 \mathrm{wt} . \%$ TOC) and has only fair source rock potential, the Rincon Shale contains more than $2.0 \%$ TOC and has good to excellent potential as a source rock (Michael, 2001).

\section{Inferred Source Rock Depositional Environment}

Six biomarker ratios were used to describe source rock lithology of the produced oil, seep, and tarball samples (table 3-2). We use the qualitative terms shale, marl, and carbonate, acknowledging that rocks from the Monterey Formation exhibit a complex spectrum of compositions, such as siliceous shale, phosphatic-calcareous shale, and calcareous-siliceous mudstone. This wide range or rock types is due to both the original composition of the siliceous sediment and subsequent diagenesis. The Monterey Formation began as calcareous and siliceous ooze that consisted of detrital material (such as clay, feldspar, and quartz), biogenic calcite from benthic and pelagic foraminifera and nannoplankton, and biogenic silica from diatoms (Pisciotto and Garrison, 1981; Isaacs and others, 1983b). The descriptions of lithology in (table 3-2) are qualitative because they do not indicate the precise proportions of shale and carbonate. Likewise, the values of biomarker ratios that we use to distinguish crude oil generated from different source rock lithologies are gradational rather than abrupt.

Tribes 1,2, and 3 can be inferred to originate from shale, marl, and carbonate source rocks respectively, based on $\mathrm{C}_{22} / \mathrm{C}_{21}$ and $\mathrm{C}_{24} / \mathrm{C}_{23}$ tricyclic terpane ratios (table 3-2, fig. 3-4). Tribes 1, 2, and 3 plot in regions of the figure similar to those for more than 500 worldwide crude oils known to originate from shale, marl, and carbonate source rocks, respectively (table 2; fig. 13.76 in Peters and others, 2005). This interpretation is supported by other ratios in Table 3-2. For example, Ts/Tm is sensitive to clay-catalyzed reactions (Peters and others, 2005) and shows high values for Tribe $1(0.51 \pm 0.17)$ and lower values for Tribes 2 and $3(0.28 \pm 0.10$ and $0.22 \pm 0.05$, respectively). 


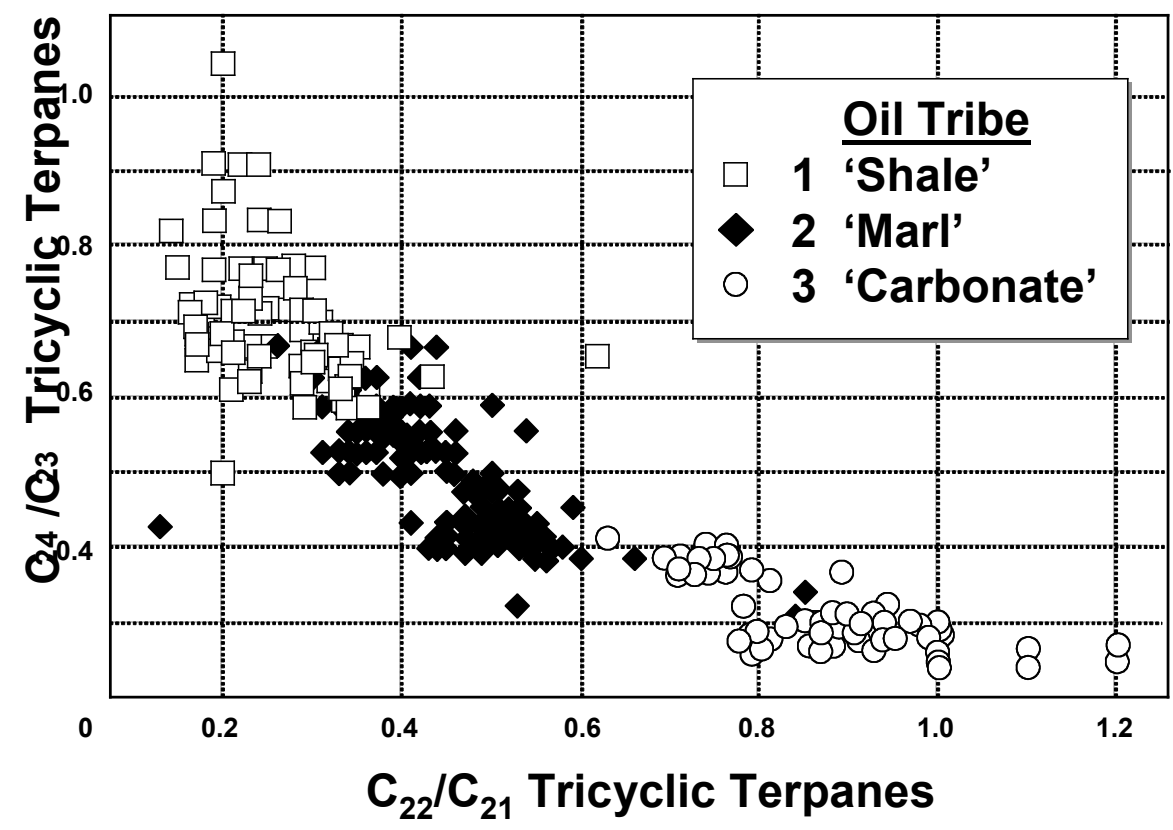

Figure 3-4. C22/C21 and C24/C23 tricyclic terpane ratios for training set oil Tribes 1, 2, and 3 (table 2, appendix 3-1) are consistent with shale, marl, and carbonate source rock, respectively. A similar plot based on more than 500 worldwide crude oil samples was used to predict source rock lithology (fig. 13.76 in Peters and others, 2005). Symbols identify the tribe of each oil sample determined by decision-tree chemometric analysis (fig. 3-3). 


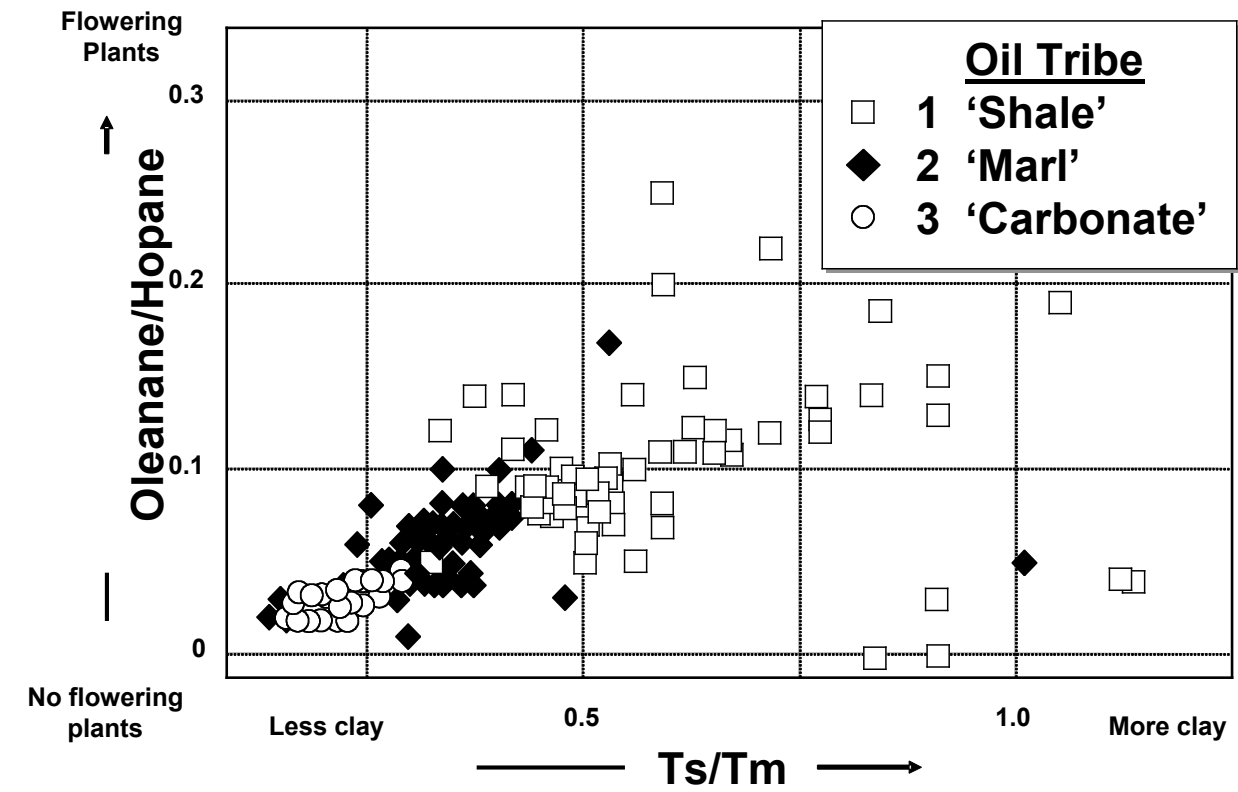

Figure 3-5. Ts/Tm and $\mathrm{Ol} / \mathrm{H}$ ratios for training set oil samples (table 2, appendix 3-1) can be used to infer relative contributions of clay and higher-plant organic matter to the source rock. For example, Tribe 1 samples have high Ts/Tm and $\mathrm{Ol} / \mathrm{H}$ values, indicating clay-rich source rock with substantial higher-plant input, while low values for Tribe 3 indicate carbonate source rock with little or no higher-plant input. Ts/Tm is $22,29,30-$ trisnorneohopane/22,29,30-trisnorhopane; $\mathrm{Ol} / \mathrm{H}$ is oleanane/hopane.

Tribe 1 originated from clay-rich shale source rock deposited under suboxic conditions with substantial higher-plant input. Tribe 1 has high Ts/Tm, consistent with a clay-rich shale source rock (Moldowan and others, 1986) and high oleanane/hopane). Oleanane is a biomarker from terrigenous higher plants (angiosperms) in source rocks and related crude oils of Cretaceous or younger age (Moldowan and others, 1994). Low 28,30bisnorhopane/hopane $(\mathrm{BNH} / \mathrm{H})$ and $\mathrm{C}_{35} \mathrm{~S} / \mathrm{C}_{34} \mathrm{~S}$ hopane ratios for Tribe 1 compared to Tribe 3 are consistent with a suboxic source rock setting (Katz and Elrod, 1983; Peters and Moldowan, 1991). The same parameters for Tribe 3 indicate anoxic clay-poor carbonate source rock dominated by pelagic organic matter with little or no higher-plant input (table 3-2, figs. 3-4, 3-5). Trace element, sediment fabric, and benthic biofacies data support low oxygen concentrations in bottom water during deposition of the Monterey Formation (Isaacs, 2001 and references therein).

Except for high 28,30-bisnorhopane (BNH; also called 28,30-dinorhopane), the data for Tribe 2 in table 3-2 iindicate a composition between Tribes 1 and 3, i.e., suboxic to anoxic marine marl source rock having hemipelagic (mixed marine and terrigenous) organic matter input. BNH originates from sulfur-oxidizing bacteria similar to Beggiatoa, although the exact precursor organisms remain unidentified (Schoell and others, 1992). Beggiatoa grow at the dysoxic interface between oxic and anoxic zones, commonly at the sediment-water interface. They were identified as the mat-forming bacteria that contribute 
to laminated sediments in the present-day Santa Barbara Basin (Soutar and Crill, 1977; Williams, 1984), a possible modern analog for depositional conditions in the Monterey Formation (Pisciotto and Garrison, 1981). At the Naples Beach exposure of the Monterey Formation, BNH dominates the terpane distributions of the laminated rocks, but is less abundant in massive clay-rich rocks (Brincat and Abbott, 2001). Laminated phosphatic marlstones dominate the carbonaceous marl member (Garrison and others, 1987), but are also intercalated with sediments having massive texture in other members of the Monterey Formation in the area (Isaacs and others, 1983a). In thermally immature Monterey Formation rock, like that at Naples Beach, BNH occurs as a free hydrocarbon rather than one bound to the kerogen (Noble and others, 1985).

\section{Indirect Oil-Source Rock Correlation}

The biomarker and stable carbon isotope results discussed above allow indirect correlation of Tribes 1, 2, and 3 with informal members of the Monterey Formation previously described in a coastal outcrop at Naples Beach (Isaacs, 1983) and a nearby offshore stratigraphic test (COST) well (OCS-Cal 78-164) in the Santa Barbara Channel (Isaacs and others, 1983a; Peters and others, 2008) or their equivalents elsewhere in coastal California. These rock units are more deeply buried and, therefore, could be more thermally mature in the COST well than in the coastal outcrops (see below), thus increasing the possibility that the rock extracts might correlate with thermally mature oil samples. Lithology of the Monterey Formation at Naples Beach and in the COST well varies from carbonate-rich siliceous rock at the base (calcareous-siliceous member) through calcareous clay (carbonaceous marl member) to clay-rich rock (clayey-siliceous member) near the top. These large-scale lithofacies variations identified by the informal members occur in most exposed sections of the Monterey Formation in the vicinity of the Santa Barbara Channel and represent upsection shoaling from middle bathyal to upper bathyal water depths $(1,000-$ $1,500 \mathrm{~m}$ to $200-500 \mathrm{~m})$ and from distal to more proximal settings (100 km or more to 20 km or less; Isaacs, 2001). However, the stratigraphy of the Monterey Formation and other Miocene rocks within the area of figure. 3-1 is complex and incompletely investigated. Thus, the informal members of the Monterey Formation established by Isaacs (1983) have not be recognized or mapped outside the area of the Santa Barbara Channel.

The principal members, including the clayey-siliceous member, carbonaceous marl member, and lower-calcareous siliceous member have attributes that are remarkably similar to those predicted from the geochemistry of Tribes 1, 2, and 3, respectively (fig. 3-6). The figure depicts the prograding margin model of Isaacs (2001; discussed below), where the clayey-siliceous member received mixed terrigenous and marine organic matter as well as significant clay detritus due to a more proximal location compared to the other two members. The lower calcareous-siliceous member received pelagic organic matter with little to no higher plant organic matter and the carbonaceous marl member has an intermediate composition with hemipelagic organic matter and mixed clay and carbonate. 


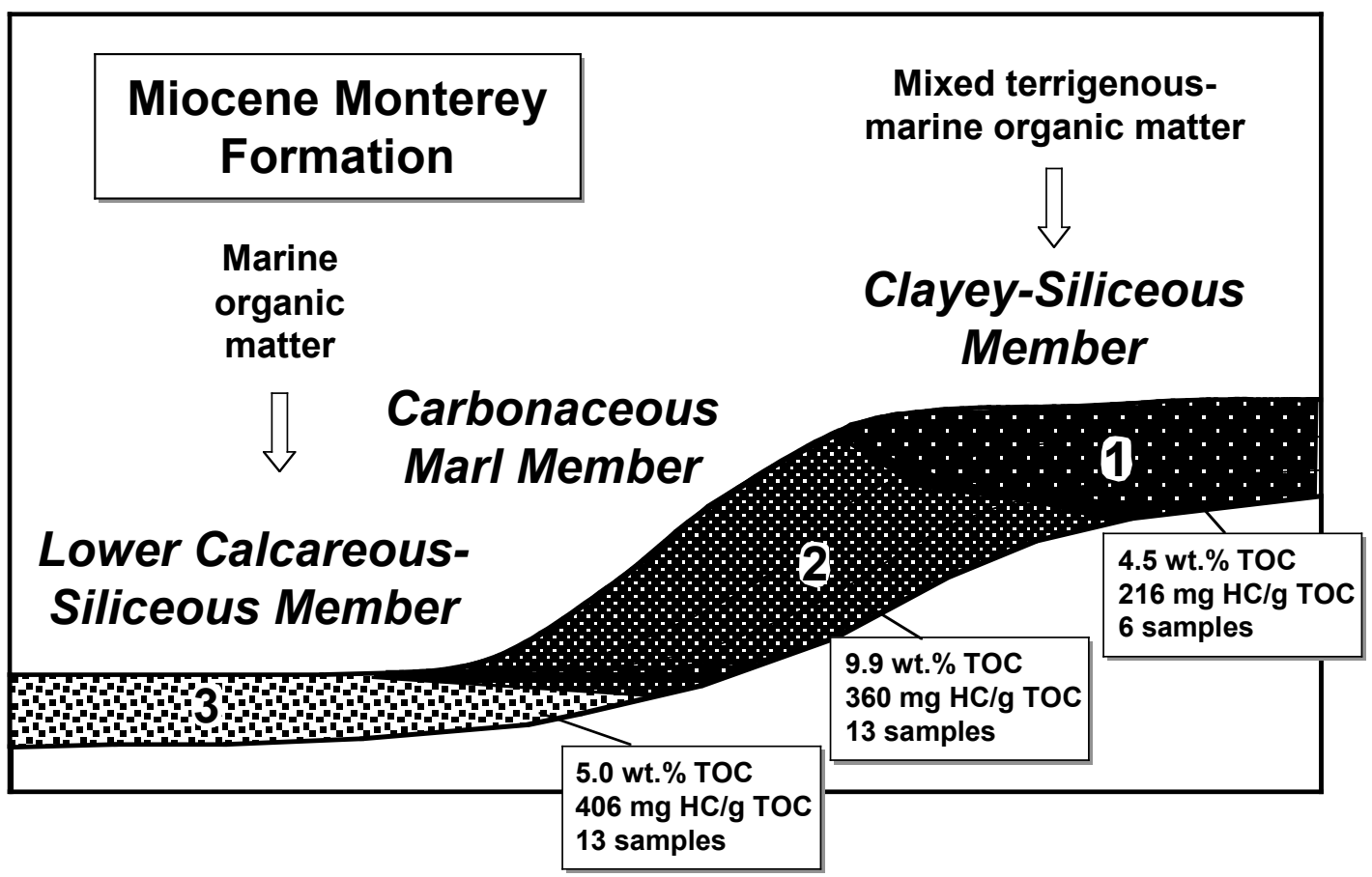

Figure 3-6. Prograding margin model shows depositional settings for the three main informal members of the Miocene Monterey Formation (modified from Isaacs, 2001) and the inferred origin of oil Tribes 1, 2, and 3 (numbers). Insets show average total organic carbon (TOC, wt.\%), Rock-Eval pyrolysis hydrogen index (mg hydrocarbons (HC)/g TOC), and number of samples from Naples Beach analyzed by Katz and Royle (2001). Similar results were obtained for rock samples in this study (Table 3-3).

Because the oils and tars are from the same sources, when looking only at the source and age related biomarker data as described by the chemometric model, some platform produced oils may fall into the same family as beached tarballs. We stress that platform oils can easily be distinguished from tarballs based on other criteria, such as the presence of lighter molecular weight alkanes and aromatics, however, over time, likely approaching one month at sea, a spilled platform oil may not be distinguishable from tarball of the same family. Furthermore our study only incorporated oils from nine of 23 active platforms and only oils from platforms Irene, Hermosa, Hildalgo, and Harvest could be fingerprinted unequivocally. Although there are too many samples in the data set to describe individually, the following discussion gives examples and distinguishing biomarker characteristics of each family listed in appendix 3-1.

Tribe 1 contains Families 11, 12, 13, and 14 (19, 19, 18, and 36 samples, respectively). Examples of Family 11 include produced oil from Dos Cuadras Field (Platform A, sample 02-35), nearby seep oil (06-1 to 06-4), seep oil from COP in Goleta (04-1 to 04-3, 05-90, 05-92 to 05-94, 05-96) and tarballs from COP (05-350) and Gaviota (02-97) in southern California. Two samples, 04-4 (Rincon platform oil) and 02-35 
(Platform A oil), cluster closely on the dendogram and have intact $n$-alkanes, indicating that they are nonbiodegraded oils, whereas the four surface-water oils collected as oil bubbles, or floating oil on an adsorbant have neither $n$-alkanes nor the isoprenoids pristane and phytane. The four surface-water oils are closely related to the two production oils, but are from nearby seeps rather than from spillage of produced oil.

The other samples in Family 11 have small differences relative to the complete data set but distinct enough to differentiate them from the six Platform A oils. In particular, the CP PAH-RI is higher for the Platform A oils (ranging from 14-22, as opposed to 1.1-3.2 for the tars), and the NCPs 23 Tri/C30 and 23Tri/C29 are distinctly different (ranging from 0.31-.47 as opposed to $0.72-1.0$ and from $0.64-0.96$ as opposed to $1.3-1.7$, respectively). In other words, the tricyclic suite of biomarkers is lower relative to the pentacyclics in the Platform A oils. In addition, the sterane/hopane ratio a27R/Hop is very high for the Platform A samples (ranging from 1.1-1.4 as opposed to 0.41-.58). One other characteristic of this set of samples is that half of them still have residual isoprenoids, and one fresh beached tar (03-25) still has some $n$-alkanes. This is unusual for beached tars, although some beached and floating tars do retain some of their $n$-alkanes for example some near COP.

Examples of Family 12 include produced oil from the Dos Cuadras Field (Platform A sample 02-34), produced oil from Hilda platform in the offshore Summerland Field (99$106)$ nearby seep oils $(05-348,05-349)$ in southern California, and five samples of produced oil from the onshore Sargent field in northern California (00-74 to 00-78). Three seep samples from near the Sargent Field (00-79 to 00-81) are geochemically similar to the five oil samples. However, the chemometric decision tree cannot classify the samples because they lack some parameters due to heavy biodegradation (rank $>5$; Peters and Moldowan, 1993) and do not satisfy the statistical criteria for significant correlation.

In general, Family 12 samples have very low anoxia-indicators (very low or zero Bisnorhopane Index, and particularly low PAH-RI, sulfur-PAH ratios, and 22/21 tri and $35 \mathrm{~S} / 34 \mathrm{~S}$ parameters) and are more thermally mature (high $\mathrm{T} /(\mathrm{T}+\mathrm{M})$ and low $\mathrm{Tm} / \mathrm{Ts}$ values). The Platform A oil is somewhat different from those in the group in family 11, but again it contains the $n$-alkanes and isoprenoids indicative of a platform oil. Family 12 seems to be a mixed group of various shale-sourced oils.

Examples of Family 13 include produced oil from the El Segundo (99-14), Playa del Rey (99-15), Torrance (99-16), and Wilmington fields (97-14, 99-17, 99-20) in the Los Angeles basin and seep oil from COP in Goleta (98-132, 98-134). Family 13 also includes oil from the onshore Arroyo Grande (99-105), San Ardo (97-13), and South La Honda (99110) fields in central and northern California. Based on stable carbon isotope ratios, Lillis and others (2001) concluded that oil samples from the San Ardo, Sargent, and South La Honda fields were related and originated from middle and upper Miocene source rock. Having higher values for the Bisnorhopane Index and C35/C34, these oils show more of the Monterey Formation-like character than do the oils in Family 12.

Examples of Family 14 include produced oil from Point Arguello Field (Platform Hidalgo, 01-29), the South Ellwood Field (Platform Holly, 02-86), seeps offshore COP (04-35, 98-131), and tarballs from beaches at COP (02-141, 03-89, 03-91, 03-92, 03-128 to 03-131, 03-351, 06-80, 06-84), Gaviota (97-26, 03-116 to 03-118), and Arroyo Burro (03$187,03-187,03-188)$. 
All the samples are from geographically close areas, namely the east-west running beaches near COP, from Boathouse to Arroyo Burro, and are probably from local offshore sources. Most of these seep and tar samples have some $n$-alkanes and pristane and phytane. This makes differentiating them from platform oils difficult. An unlocated seep oil collected on the surface (05-96) and the Platform Holly oil (02-86) are quite similar. The $\mathrm{d}^{13} \mathrm{C}$ value for 05-96 is high, but that is probably an artifact of the adsorbent cloth on which it was collected. The only significant difference is, again, the $n$-alkanes and isoprenoids present in the produced oil as opposed to the lack of these compounds in the floating oil. This likely indicates that the floating oil was basically the same as production oil, but having leaked from a seep was subject to biodegradation, that removed the $n$-alkanes. In contrast, the produced oil is being collected from a somewhat deeper reservoir that is unimpacted by biodegradation. On the other hand, the four beached tars from Tajiguas and Gaviota clustered close on the HCA (appendix 3-2) to sample 02-86 and cannot reliably be distinguished from the produced platform oil, especially since they still have some $n$ alkanes

Tribe 2, the most populated tribe, contains four families $(211,212,213$, and 22 having 51, 29, 15, and 316 samples, respectively). Unlike Tribe 1 where the Bisnorhopane Index is generally low $(>1)$, within Tribe 2 this Index is variable within families. Examples of Family 211 include produced oil from the South Ellwood Field (Venoco Holly platform, 02-85) and the offshore Ellwood Field (97-15), samples from the Trilogy seep offshore COP (05-91, 05-341) and nearby surface oil slicks (for example, 06-61 to 06-65, 06-67 to 06-74) and tarballs from Goleta Point (98-135, 98-136), COP (for example, 02-31, 02-32, 98-138, 02-98 to 02-100, 06-76 to 06-79), and Santa Rosa Island (00-102, 00-121, 00-122, 00-142).

Family 211 is constrained within the same general area of east-west beaches as Tribe 1, particularly around COP, with a few samples coming from sites a little more south, on the Channel Islands Santa Rosa and Santa Cruz. Subsequent chemometric matching of the sterane-biodegraded samples and other samples collected later showed that a large number of samples from active seeps off COP near Trilogy Seep also correlate in this group. The family, in general, has typical mid-range anoxia parameters, with BI, for example, at just less than 1.0 and $35 \mathrm{~S} / 34 \mathrm{~S}$ averaging about 1.5 . In the training set samples, unlike the samples in Family 14 from the same general area, most of the beached tars did not contain $n$-alkanes, although several did have low levels of pristane and phytane. The sample from Platform Holly (02-85) correlated closely with a COP beached tar (02-31), with the Holly production oil having $n$-alkanes while the tar does not. As suggested above, this could be a platform oil as opposed to a nearby seep oil difference. Platform Holly is in a particularly active seep area. By contrast with the training set tars, many of the oil slick and mousse samples from Trilogy Seep had variable distributions of $n$-alkanes. The other production oil, (97-15) from Elwood, is an onshore crude oil that groups within this family but not closely, as its long tie-line indicates in the HCA (appendix 3-2).

Examples of Family 212 include produced oil from the Hondo Field in the ExxonMobil Harmony HA-4 (05-1) and Hondo H-3 (05-4) wells, seep oil from COP (04268, 04-269) and Anacapa Island (00-67), and tarballs from COP (02-271, 03-27, 06-75) and Arroyo Burro Beach (02-136, 02-233, 03-51). Some Family 212 samples also occur in northern California as tarballs collected by bottom trawls $4000 \mathrm{~m}$ deep in Monterey Canyon (05-217, 05-219) and tarballs on Angel Island in San Francisco Bay (00-20, 00-21, 
00-23). Family 212 is a more diverse group of tars and oils, at least in terms of its geographic distribution. This family has representatives along the California coast from Redondo Beach in the south to Angel Island in San Francisco Bay in the north. The first grouping in the HCA (Appendix 3-2) of 10 beached or sea-floor tars contains samples from Coal Oil Pt. and Arroyo Burro, plus two offshore COP seep samples, as well as the samples from Surf and Casmalia Beaches, north from Pt. Conception, and then further north from the deep sea-floor of the Monterey Canyon. A single source for these samples is not obvious.

The samples from Angel Island are closely correlated with each other. Their location within San Francisco Bay requires some sort of transport because there is no known seep in this area, so again, it is not clear from where they might be sourced. Also included in Family 212 are two platform oils, one from Hondo (05-4) and one from Harmony (05-1), linked to an oil/mousse sample from Cojo offshore. These two platforms and Cojo are just east of Pt. Conception and west of COP, and are quite close to each other geographically. Once again, the platform oils have $n$-alkanes and isoprenoids, whereas the floating oil does not, so there could be a natural seep or production oil link as suggested above. The Redondo Beach sample (99-7) does not appear to correlate well with any other sample in this group, although its closest link is to the two samples from the Santa Barbara Channel, 00-67 (offshore Anacapa Island) and 99-49 (Santa Cruz Island beach). There are a number of previously documented seeps offshore Redondo Beach for which we do not have samples, however these seeps could be a potential source of Family 212.

Examples of Family 213 include produced oil from the Point Arguello Field Platforms Hidalgo (01-27, 01-30 to 01-32), Hermosa (01-33 to 01-35), and Harvest (01-36 to 01-39), the Point Pedernales Field, Irene platform (02-68 to 02-70); and a tarball on Boathouse Beach (02-71) collected in 2002 by the USGS. Family 213 is a clearly related group. Four samples are related to the Torch Spill from Platform Irene in 1997, three of which are production oil that was spilled in the pipeline break, and one Surf Beach sample that was washed ashore from the Torch spill. The remainder are located south and are linked to Platforms Hildago, Harvest, and Hermosa. The oils and the tar all contain both $n$ alkanes and isoprenoids, and correlate closely. These oils, then, are also similar to the other 11 platform oils in Family 213, and therefore were probably formed from the same or similar source rock facies. The 213 platform oils have the mid-range anoxia indicators of Tribe 2, for example, a particularly low Bisnorhopane Index relative to the rest of the Tribe 2 tars/oils, and relatively low PAH-RI, medium high 35S/34S and Sulfur-PAH ratios, and mid-range Tri22/21 and Tri24/23. No beached samples correlate within this group. The Platform Irene samples are somewhat less thermally mature $(\mathrm{T} / \mathrm{T}+\mathrm{M})$ ratio of 0.26-.29) as opposed to $0.38-0.79$ for the other Family 213 oils, have low but observable levels of perylene compared to no perylene in the others, and lower C23 tricyclic relative to hopane. Examples of Family 22 include produced oil from Hondo Field, ExxonMobil Platforms Harmony (05-2, 05-3), Hondo (05-5, 05-6), and Heritage (05-7 to 05-11), seep (99-50) and tarball samples (for example, 99-30 to 99-33, 99-35, 99-37 to 99-42, 99-45, 9946, 99-49, 99-51, 99-58 to 99-61) from Santa Cruz Island, and tarball samples from San Miguel (02-37, 02-38, 02-42 to 02-48, 02-50 to 02-55) and Santa Rosa Islands (00-100, 00$101,00-103$ to $00-107,00-109$ to $00-120,00-124$ to $00-129,00-131,00-133,00-143,00-$ $144,00-152,00-154,00-159)$. Seven of 10 tarball samples collected by submersible trawls 
from the Monterey Canyon submarine sea fan at depths greater than 4,000 meters in northern California also belong to Family 22 (05-218, 05-220 to 05-225).

Family 22 within Tribe 2 is the largest group within the data set. Unlike Tribes 1 and 3 , where the chemometric analysis allowed division into three families by inspection of the three-dimensional rotational structure of the PCA, Family 22 does not allow that level of subdivision (fig. 3-2). The HCA (appendix 3-2) shows that the tie-lines are generally quite short within Family 22, so the correlations are fairly close throughout the group. Almost all of the first set of 37 samples seen on the HCA in appendix 3-2 are beached tars from both the north-south and the east-west beaches near Pt. Conception, although the first four samples are tars recovered from a deep dive within Monterey Canyon (two other samples from this dive appeared in Family 212, and another in Family 33). There are two local seep samples and one platform oil (05-11, Platform Heritage), all coming from east of Pt. Conception. The platform oil is the only one from this group, as well as from the nextlower group, that contains $n$-alkanes and isoprenoids. So, again, we see chemical similarities in the biomarker parameters of geographically closely sourced oils, both from a platform and from beached tars coming from offshore seeps, with the only substantial difference being that the produced oil still contains $n$-alkanes and isoprenoids, which allows easy for time-sensitive distinction between platform oil and tarballs in this group.

Continuing down the HCA the next group of samples (appendix 2-3) contains 18 beached tars from four beaches just north of Pt. Conception. Differences between this group and the previous group are minor, with PAH-RI and 20/23tri ratios somewhat lower and $35 \mathrm{~S} / 34 \mathrm{~S}$ ratios slightly higher on average. The geographic closeness of these samples implies a local offshore seep source.

The grouped samples on the HCA (appendix 2-3) contains a much more diverse set of samples. At the top it includes five samples from Jackpot and Tonya Seeps, offshore COP, then eight platform oils from the Harmony, Heritage, and Hondo group west of COP; and one odd sample from south of Los Angeles, Huntington Beach. Again, the production oils from the three platforms are the only ones in this group to have the suite of petroleum $n$-alkanes and isoprenoids present. The remaining tars in this subgroup are scattered at locations from COP offshore seeps, beached tars from the Channel Islands - Santa Rosa, San Miguel and Santa Cruz, and beached tars from locations as far north as Año Nuevo, Pebble Beach and Santa Cruz. There is more scatter in the data from the northern samples, as seen in the longer tie-lines in the dendogram. In this diverse group a single local source seems less likely, but longer distance ocean current transport may be involved.

The next group seen on the HCA (appendix 3-2) consists of two offshore seeps and 34 beached and floating tar samples, all but two from beaches in or near the Santa Barbara Channel, including Surf Beach to the north of Pt. Conception and Loon Beach to the east, plus beaches on Santa Rosa and San Miguel Islands. The two seeps and the four floating tars are from near Pt. Conception and could represent sources for these tars. Areal oceanic circulation and transport could explain their varied locations. Biomarker parameters are similar to the above Family 22 values, with the PAH-RI ratios towards the higher end of the range, along with the $35 \mathrm{~S} / 34 \mathrm{~S}$ ratios. The NCPs indicate that $23 \mathrm{Tri} / \mathrm{Hop}$ ratios are somewhat lower than those for the previous sample group, and the $\mathrm{T} /(\mathrm{T}+\mathrm{M})$ ratios are slightly higher, indicating somewhat higher thermal maturity. No samples in this sub-group have any $n$-alkanes or isoprenoids. 
The next group on the HCA (appendix 3-2) is populated by 22 beached tars mostly from Santa Rosa and Santa Cruz Island beaches, with a few from across the channel, at Surf Beach, near Santa Barbara, and near Ventura. There are two from longer distances, namely Windansea Beach in San Diego to the south and Limintour Beach near Pt. Reyes. Again, differences are relatively minor from the other Family 22 tars and oils, and none of the samples have $n$-alkanes or isoprenoids. The final group is a small group of one unrelated oil (Wilmington) and six beached tars from Santa Rosa Island (two) and from the beaches near Pt. Conception. These samples have long tie-lines on the HCA, except for the two Santa Rosa samples, so are not considered further.

Finally, comparing the members of Family 22 to the other Tribe 2 members, those in Families 211,212, and 213, in terms of the other chemometric parameters, it is seen that the Bisnorhopane Index is higher, as is the anoxia indicator 35S/34S and PAH-RI. In terms of the (nonchemometric parameters, the samples in 22, in general, have lower thermal maturity (values of $\mathrm{T} /(\mathrm{T}+\mathrm{M})$ ratios are about $0.1-.2$ ) and significant values of Pery/Chry ratios, implying residence close to the surface of the ocean floor where perylene is present.

Tribe 3 contains five oil families $(31,32,33,34$, and 35 having 8, 11, 40, 27, and 21 samples, respectively) that are dominated by tarballs rather than produced oil or seep samples. In general, the geographic scatter of these families is broader than in the other Tribes, with most of the scatter being to the north of Pt. Conception, except for one Family with most of its members collected south of Los Angeles and a few samples in another group from the westernmost and smallest of the Channel Islands, San Miguel. None of the Tribe 3 samples are related to any of our platform oil samples, and none contain any $n$ alkanes or isoprenoids.

Family 31 consists exclusively of tarballs from Lompoc Landing (01-52) and Casmalia Beach (02-10, 02-11, 02-25, 02-90, 02-239, 03-95, 03-179) in central coastal California. The close clustering in the HCA (appendix 3-2) suggests a local offshore seep source. This family has a particularly high Bisnorhopane Index and 35S/34S ratio.

Examples of Family 32 include seep samples from Morro Bay (98-91) and Point Conception (04-22), tarballs from Ragged Point near Big Sur (98-102, 98-125), Pebble Beach in Monterey Bay (98-47), Asilomar (07-9), and Point Reyes (00-43). Family 32 is another small group of beached tars, with 11 members, but in this case its members are widely dispersed, from Santa Rosa Island north to Pt. Reyes. The parameters that differ from those of Family 31 include the Bisnorhopane Index and Sulfur-PAH ratio (both lower).

Family 33, populated with 40 samples, covers a broad geographic area, from Surf Beach in the south to Pt. Reyes and Drakes Beach north of San Francisco. Examples of Family 33 include a deep sea tarball collected by submersible from the Monterey submarine fan (05-226), and tarballs from Ragged Point (98-98, 98-100, 98-101), Half Moon Bay (07-14 to 07-16), Drakes Beach in San Francisco Bay (00-44, 0045, 00-47, 0048), Stinson Beach (00-54, 00-55), and Point Reyes (00-38, 00-41). Family 33 parameters include particularly high Tri22/21 ratios, only mid-range Bisnorhopane Index, quite high PAH-RI and Sulfur-PAH ratios, and high 35S/34S ratios. Family 33 levels of thermal maturity $(\mathrm{T} / \mathrm{T}+\mathrm{M})$ ratios are fairly low, and the perylene to chrysene ratios are consistently fairly high.

Family 34 consists exclusively of tarballs, including examples from Casmalia Beach (99-93, 01-40, 01-42, 01-63, 01-65, 01-66, 02-14, 02-23, 02-24, 02-26, 02-84, 02-178), 
Shell Beach (99-98), Surf Beach (01-53, 01-55, 02-9, 02-88, 02-89, 03-81), and Avila Beach in Morro Bay (94-41, 97-72, 97-72A). Family 34 is characterized by a progressively lower Bisnorhopane Index than the above Tribe 3 families, and particularly high PAH-RI Sulfur-PAH, and 35S/34S ratios.

Family 35 is quite different from the preceding four families. It also consists of only beached tars, but most of its samples come from beaches south of Los Angeles, like Palos Verdes and San Diego, or from beaches on the southeastern shore of Santa Cruz Island. There is a little scatter, with a few samples to the north, at Gaviota, Arroyo Burro, the Monterey peninsula, and Angel Island. Oceanic transport may contribute to the scatter of samples. The family is characterized by low-end of the range Bisnorhopane Index, very high PAH-RI and Sulfur-PAH ratios, and modest 35S/34S ratios.

Because tarballs can be widely dispersed by ocean currents, the origin of Tribe 3 tarballs is uncertain. However, as discussed above, Tribe 3 contains two seep samples from onshore Morro Bay (98-91; Family 32), and Point Conception (04-22; Family 32) that suggest the related tarballs originate mainly from seeps to the north of, and including Point Conception. However we cannot exclude the possibility that some Tribe 3 tarballs originate from south of Point Conception. For example, in addition to the south-flowing California Current, there is the north-flowing Davidson Current that is strongest in surface water during winter of each year. The Davidson Current has been documented to carry research "drifter" devices northward from the Santa Barbara Channel to Monterey Bay and Point Reyes (Winant and others, 2003).

\section{Distinguishing Production Oils from Natural Seepage Oils and Tars}

It is desirable to be able to clearly distinguish the naturally-occurring seep oils from the anthropogenically derived platform oils in order to evaluate and track man-made spillage events or other environmental contamination. Representative oils from nine of 23 active platforms in our chemometric model training set are from the western Santa Barbara Channel where we have collected most of the beached tarballs in this study. In particular four platforms in the southern Santa Maria Basin — Platforms Irene, Hildalgo, Harvest and Hermosa; three Santa Ynez platforms - Platforms Heritage, Hondo and Harmony; and two platforms near Santa Barbara; Platform A, and Platform Holly. Platform A and Platform Holly are within known areas of natural oil seepage and we targeted these platforms specifically to test our chemometric and biomarker protocols.

Within the statistical dendogram (Fig. 3-2, Appendix 3-2) of the entire training set of oils and tars (388 samples), the biomarker parameters are sometimes sufficient to allow unique discrimination of individual platform oils. However platform samples and seep samples with sources geographically close to each other are more often too similar to each other (for example Platform A and Platform Holly), with respect to the biomarker parameters, to definitively differentiate them on that basis.

In some cases other parameters can be helpful. These other parameters are related to the degree of biogeochemical degradation or weathering that the oils or tars have experienced. Oil in a deep underground reservoir is generally protected from biodegradation or weathering by lack of access of microbes and oxygen. Therefore, all of its easily degradable components are preserved and are the dominant constituents when the oil is viewed by gas chromatography/mass spectrometry. These components include the 
typical oil distribution of $n$-alkane hydrocarbons and isoprenoids pristane and phytane. All of the platform oils in our sample set contain these components. On the other hand, the seep oils, although they might have originated from similar reservoirs as the production oils, have migrated upward to the surface in the geologically complex and tectonically active environment of offshore southern California.

In the shallow sea-floor seeps, these oils are exposed to significant biodegradation. The majority, but not all, of seep tars in our sample set have been biodegraded to or beyond the point of loss of $n$-alkanes and isoprenoids. Tars found in the vicinity of COP or Arroyo Burro are apparently the least weathered and are particularly likely to retain significant $n$ alkanes and isoprenoids. Therefore, a combination of chemometric separation and the presence or absence of $n$-alkanes and isoprenoids help to differentiate these two classes (anthropogenic production oils as opposed to natural seeps) of oils and tars. But the differentiation is not always definitive because of the close chemical similarity of some samples and the variability in the biodegradation progression. The following is a summary of the platform oils in the current sample set in terms of how they correlated within the chemometric model.

Family 11: Platform A - Two production oils (04-4 Rincon oil containing composite oil including Platform A oil, and 02-35, Platform A oil) correlate closely with each other. Four other tars from surface waters near Platform A (06-4 and 04-4; 06-2 and 06-1) group close by. However, only the two platform oils have intact $n$-alkanes and isoprenoids. The other 12 tars in Group 11 are in a separate portion of the HCA (i.e., chemometrically distinct) and were collected from nearby seeps or local beaches. One sample (03-23 from Tajiguas beach) contains some residual $n$-alkanes and a few others have traces of isoprenoids, but overall the biomarker parameters distinguish the two subgroups, and the presence of $n$-alkanes distinguishes the two Platform A oils.

Family 12: Oils from Summerland Becker onshore well (05-349, 348; 99-106), Platform A (02-34), and other onshore oils (Petrolia, Sargent) - Two of the Summerland Becker well samples (05-349, 05-348) are very similar and uniquely grouped, without $n$ alkanes. The third Summerland oil,sample groups differently,and has $n$-alkanes. The Platform A oil is produced from a deeper reservoir than the Family 11 pair and is chemometrically different. Its $n$-alkanes are intact. The other oils in Family 12 are not produced platform oils.

Family 14: Two oils, one each from Platforms Hidalgo (01-29) and Holly (02-86), fall into this rather densely crowded group. Both are somewhat uniquely located on the dendogram, and both have $n$-alkanes and isoprenoids, allowing some discrimination. However, this group is populated with many tars with $n$-alkanes and isoprenoids, many from the COP/Arroyo Burro area, so clear differentiation is marginal. In addition, this group contains a "mystery spill" with samples from Mussel Shoals taht correlate with a local surface grab sample and samples from Arroyo Burro, Tajiguas, and Sacate Beaches. This sub-grouping is chemometrically distinct from the platform samples and seems to come from a different unknown source. Otherwise, this large group is populated mostly with small groups of seep and beached tars, clustered geographically fairly close together.

Family 211: Platform Holly-One oil (02-85) is present in the first of the Tribe 2 (marine marl litho-facies) subgroups. It contains the $n$-alkanes and isoprenoids, unlike any of its near neighbors in the dendogram. Most of the rest of this large family are seeps, slicks from seeps and beached tars. 
Family 212: Platforms Hondo and Harmony - One oil from each of these platforms (05-4 and 05-1) group closely within Family 212. Many other beached tars correlate within this family also, but the platform oils are the only ones with $n$-alkanes and isoprenoids.

Family 213: Platform Irene oils and the Torch oil spill, Platforms Harvest, Hermosa, and Hidalgo - This family is completely populated by produced platform oils. All contain prominent $n$-alkanes and isoprenoids. The Platform Irene samples $(02-68,02-$ $69,02-70)$ and a beached Torch oil spill sample (02-71) separate into one distinct group, indicating that both chemometrics and $n$-alkane/isoprenoid presence distinguish this set. The other produced platform oils (Harvest 01-39, 01-36, 01-38, 01-37; Hermosa 01-34, 0133, 01-35; Hidalgo 01-27, 01-31, 01-32, 01-30) group fairly closely to each other and are quite similar.

Family 221: Platform Heritage - In this large group containing mostly beached tars, one platform oil is found, Heritage (05-11). It is somewhat chemometrically distinct, and it is the only oil/tar in the group to have $n$-alkanes and isoprenoids present.

Family 223: Platforms Hondo, Harmony and Heritage - This is a diverse group containing seep tars, produced platform oils, and geographically separated beached tars. The platform oils, however, cluster closely in two groups (Hondo/Harmony 05-6, 05-3, 055 and Heritage/Harmony 05-10, 05-7, 05-9, 05-8, 05-2) and are the only samples with $n$ alkanes and isoprenoids, except for one tarball unrelated according to the dendogram.

Tribe 3 groups: No platform oils are found in this tribe.

\section{Origin and Evolution of Tribe Source Rock}

The relative abundance of Tribes 1 and 2 to the south and Tribe 3 to the north of Point Conception appears to be linked to early Miocene paleogeography (fig. 3-7) and subsequent burial history. Paleomagnetic data show that the Santa Barbara-Ventura basin block rotated clockwise, in a zone of transrotational domains in the western Transverse Ranges. The northern boundary of the transrotational belt is marked by a dotted line in figure 3-7. The block rotated from an approximately north-south orientation during the early Miocene to the present-day east-west orientation (Hornafius and others, 1986). The location of the block prior to rotation remains controversial. However, there is general agreement that the discontinuity marked by the Amberjack High near Point Conception (fig. 3-1; Crain and others, 1987) separates northern and southern areas having distinct depositional and structural histories (Crouch and Suppe, 1993; Isaacs, 2001). 

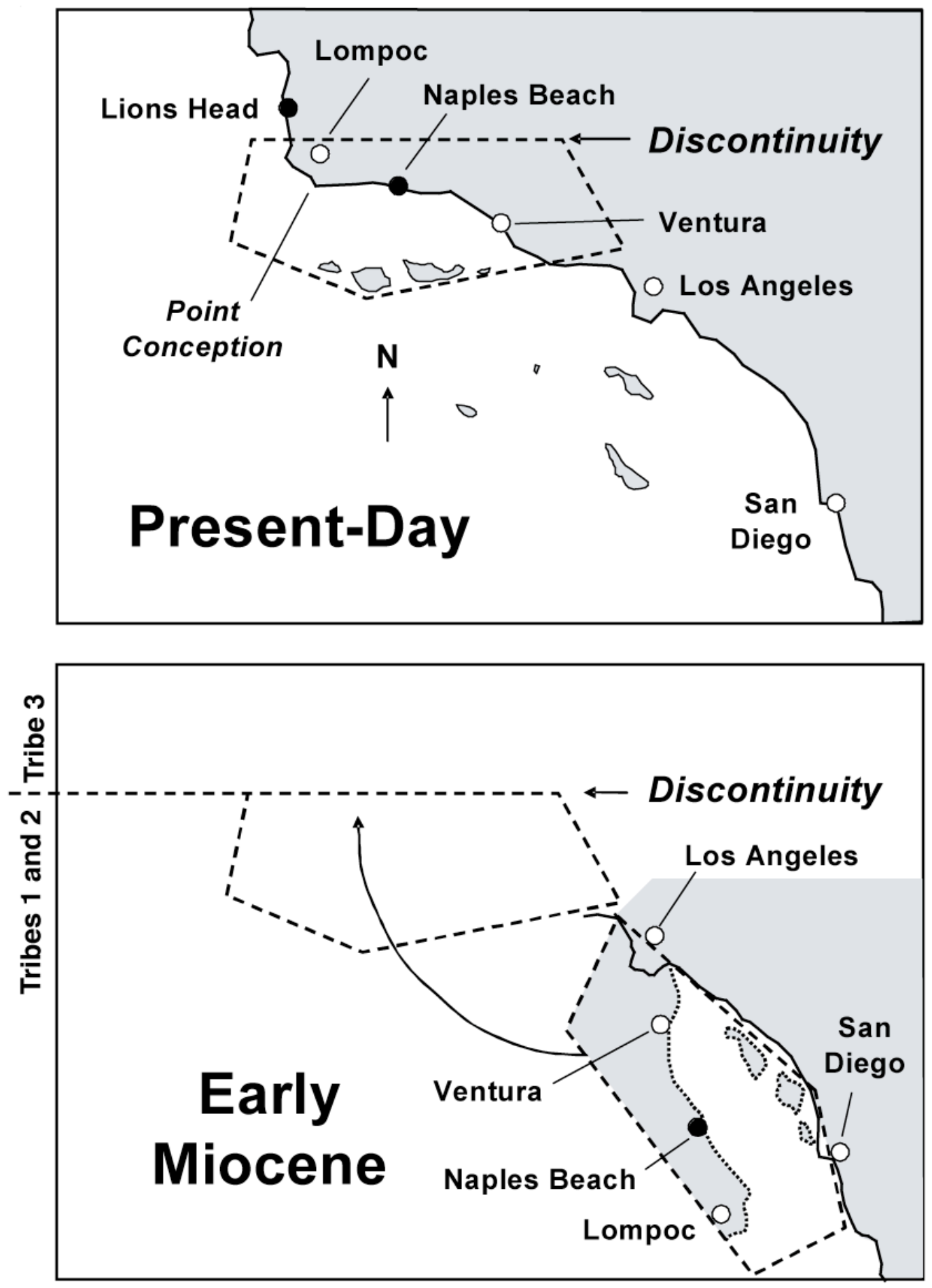

Figure 3-7. Comparison of present-day and Early Miocene paleogeography helps to explain the distribution of Monterey Formation oil Tribes 1,2, and 3. Solid dots are coastal exposures of Monterey Formation described by Isaacs (2001). Modified from Isaacs (2001). 
Tectonics was dominated by strike-slip movement to the north of the discontinuity. Here, we hypothesize that the Miocene was characterized by slope deposition of diatomaceous sequences followed by burial to comparatively shallow depth. South of the discontinuity, large-scale crustal extension and rotation beginning about 16-18 Ma (Luyendyk, 1991; Stanley and others, 1996; Wilson and others, 2005) resulted in Miocene deposition that ranged from shelf $(<150 \mathrm{~m})$ to lower bathyal depth $(>1,500 \mathrm{~m})$. In the area of the Santa Barbara Channel, the Miocene Monterey Formation was deposited mainly at middle to upper bathyal depth. Complex structural histories characterize the areas south of Point Conception. For example, major compressional deformation beginning in late Miocene time in the offshore Santa Maria and Santa Barbara Basins resulted in structurally influenced depocenters where the Monterey Formation source rock was buried in deep petroleum generative kitchens (Tennyson and Isaacs, 2001).

The thickness and organic richness of the different Monterey Formation members probably plays a role in the dominance of Tribes 1 and 2 south of Point Conception. For example, the total thickness of rock that might generate Tribe 1 or Tribe 2 oil, including the clayey-siliceous, upper calcareous-siliceous, transitional marl-siliceous, and carbonaceous marl members in the COST well, is about $610 \mathrm{~m}$ (Isaacs and others, 1983a). Rock that might generate Tribe 3 oil, represented by the lower calcareous-siliceous member in the well, is about $427 \mathrm{~m}$ thick. North of the tectonic discontinuity near Point Conception, the Monterey Formation is generally not as deeply buried as in depocenters to the south and the relative abundance of Tribe 3 oil may result from deeper stratigraphic position and slightly higher maturity of an equivalent of the lower-calcareous siliceous member compared to the other members. This interpretation assumes that the organofacies of the lower Monterey Formation were similar to the south and north of the tectonic discontinuity. However, little is known about the Monterey Formation as a petroleum source rock north of Point Conception. The informal members of the Monterey Formation established by Isaacs (1983) have not been recognized or mapped outside of the area of the Santa Barbara Channel.

The geochemical similarities among the three tribes of Monterey Formation oil samples from different coastal basins in this study indicate an underlying simplicity resulting from three source rock organofacies 1) suboxic clay-rich, higher-plant rich detrital deposit, 2) suboxic to anoxic marly, hemipelagic deposit; and 3) anoxic carbonate-rich, pelagic deposit. The produced oil and seep samples from the three oil tribes that represent these organofacies occur in broad areas of coastal California as might be expected if their source rocks were deposited on low-gradient slopes and in broad depressions like those in the present-day Gulf of California. By this line of reasoning, the geochemical data support the prograding margin model of Isaacs (2001) for deposition of the Monterey Formation, but do not exclude the banktop-slope-basin model of Hornafius (1991) for outboard basins in the Santa Barbara Channel.

\section{Decision-Tree Classification of Mystery Tarballs}

Various tarballs appeared on California beaches from Monterey to San Mateo counties during February 2007. Speculation on the origin of the tarballs ranged from natural seepage to anthropogenic pollution, such as a spill from a tanker, pipeline, or offshore platform. Ten samples of these tarballs were collected, analyzed, and submitted to the chemometric decision tree. Chemometric analysis shows that the tarballs have multiple 
origins, but all are related to Monterey Formation source rock rather than a single anthropogenic pollution event (table 3-3). The data suggest that seven of the eight Tribe 3 tarball samples likely originated from seeps well north of Pt. Conception like those represented by seep samples from Morro Bay (Family 32) and tarballs flushed deep into Monterey Canyon (Family 33). The origin of the tarball from Moss Beach (sample 07-7) is unclear because all Family 34 samples are tarball rather than seep samples. The two Tribe 2 tarball samples in Table 3-4 (07-5 and 07-18; Family 212 and 22, respectively) may come from seeps near COP or Point Conception in the Santa Barbara Channel. Family 22 seeps occur at COP (for example, 04-271, 04-274A, 04-274B) and Point Conception (for example, 02-56 to 02-59 and 04-24 to 04-26; appendix 3-1). Family 212 seeps also occur at COP (for example, 04-269 and 04-269) and Point Conception (for example, 02-62 and 0265). Alternately, the two Tribe 2 tarball samples in table 4 might originate from Monterey Canyon (for example, 05-220 to 05-225, Family 22; 05-217 and 05-219, Family 212).

\section{Conclusions}

Several criteria were used to select 388 samples of produced oil, seeps, and tarballs from coastal California for use as a chemometric training set. For example, heavily biodegraded samples were excluded because source-related geochemical parameters might be altered. 19 source- and age-related biomarker and isotopic parameters for each sample in the training set were used to identify three genetically distinct tribes of oil samples (oil-oil correlation) that contain thirteen families based on principal component analysis. The stable carbon isotope ratios for all 388 samples (-22 to -25\%o) are consistent with Miocene source rock. Various biomarker ratios, such as $\mathrm{C}_{22} / \mathrm{C}_{21}$ and $\mathrm{C}_{24} / \mathrm{C}_{23}$ tricyclic terpanes, $\mathrm{C}_{29} \mathrm{H} / \mathrm{H}$ and $\mathrm{C}_{35} \mathrm{~S} / \mathrm{C}_{34} \mathrm{~S}$ show that Tribes 1,2 , and 3 originated from suboxic marine shale, suboxic to anoxic marl, and anoxic carbonate source rock lithologies, respectively. The oleanane/hopane ratio shows that source rocks for Tribes 1,2, and 3 received substantial, intermediate, and little or no higher plant input, respectively. These data were used to indirectly correlate Tribes 1,2 , and 3 with source rock organofacies like those in the clayey-siliceous, carbonaceous marl, and lower calcareous-siliceous members of the Monterey Formation in the Santa Barbara Channel area described by Isaacs (1983).

Produced platform oils can be distinguished from seep-derived oils under most circumstances by using a combination of this chemometric model and the presence or absence of ligther $n$-alkanes and isoprenoids. Biodegradation of produced platform oil on the order of two weeks to a month in the environment before analysis can lead to erroneous interpretation as a seep-derived oil.

The 388 samples were used as a training set to construct a multitiered chemometric decision tree for classification based on 19 biomarker and isotope ratios. The power of the decision tree to resolve geochemical differences among samples increases through each tier, thus allowing detailed generic classification of newly collected samples. More than 600 coastal California samples can be assigned to genetically distinct families identified in appendix 3-1. In one application of the decision tree, 10 tarball samples collected from beaches in Monterey and San Mateo Counties were found to originate from multiple seeps from five different oil families, all are related to Monterey source rock rather than from a single anthropogenic pollution event. 
Table 3-1. Repeatability of 19 biomarker and isotope ratios based on five crude oil samples from different wells in the onshore Sargent Field, south of Gilroy, California. See Fig. 1 for location.

\begin{tabular}{|l|c|c|c|c|c|c|c|c|c|c|c|c|c|c|c|c|c|c|c|}
\hline Sample & $\mathbf{1}$ & $\mathbf{2}$ & $\mathbf{3}$ & $\mathbf{4}$ & $\mathbf{5}$ & $\mathbf{6}$ & $\mathbf{7}$ & $\mathbf{8}$ & $\mathbf{9}$ & $\mathbf{1 0}$ & $\mathbf{1 1}$ & $\mathbf{1 2}$ & $\mathbf{1 3}$ & $\mathbf{1 4}$ & $\mathbf{1 5}$ & $\mathbf{1 6}$ & $\mathbf{1 7}$ & $\mathbf{1 8}$ & $\mathbf{1 9}$ \\
\hline $00-74$ & -24.1 & 0.50 & 5.0 & 0.98 & 5.0 & 0.22 & 0.23 & 0.84 & 0.27 & 0.17 & 0.68 & 0.90 & 0.28 & 0.56 & 0.59 & 0.18 & 0.06 & 0.03 & 0.19 \\
\hline $00-75$ & -24.1 & 0.50 & 5.4 & 1.00 & 6.0 & 0.23 & 0.25 & 0.87 & 0.24 & 0.17 & 0.65 & 0.88 & 0.28 & 0.59 & 0.63 & 0.15 & 0.06 & 0.03 & 0.19 \\
\hline $00-76$ & -24.1 & 0.50 & 4.9 & 1.00 & 5.0 & 0.23 & 0.24 & 0.85 & 0.25 & 0.17 & 0.68 & 0.90 & 0.27 & 0.56 & 0.64 & 0.18 & 0.05 & 0.03 & 0.19 \\
\hline $00-77$ & -24.0 & 0.53 & 5.5 & 1.00 & 6.0 & 0.23 & 0.24 & 0.90 & 0.25 & 0.17 & 0.69 & 0.90 & 0.28 & 0.59 & 0.66 & 0.13 & 0.07 & 0.03 & 0.18 \\
\hline $00-78$ & -24.2 & 0.56 & 5.0 & 1.00 & 5.0 & 0.22 & 0.23 & 0.85 & 0.25 & 0.17 & 0.67 & 0.92 & 0.29 & 0.59 & 0.63 & 0.18 & 0.05 & 0.03 & 0.19 \\
\hline Average & -24.1 & 0.52 & 5.16 & 1.00 & 5.3 & 0.23 & 0.24 & 0.86 & 0.25 & 0.17 & 0.67 & 0.90 & 0.28 & 0.58 & 0.63 & 0.16 & 0.06 & 0.03 & 0.19 \\
\hline Std. Dev. & 0.1 & 0.02 & 0.27 & 0.01 & 0.6 & 0.01 & 0.01 & 0.02 & 0.01 & 0.00 & 0.02 & 0.01 & 0.01 & 0.02 & 0.03 & 0.02 & 0.01 & 0.00 & 0.00 \\
\hline
\end{tabular}

1, $\mathrm{d}^{13} \mathrm{C}$ whole oil (PDB, \%o); 2, Ts/Tm; 3, $\mathrm{C}_{26}$ /Tet; 4, $\mathrm{C}_{28} / \mathrm{C}_{29} ; 5$, PAH-RI; 6, SC2D/SC2P; 7, SC3D/SC3P; 8, $\mathrm{C}_{28} / \mathrm{C}_{29} \mathrm{TT} ; 9, \mathrm{C}_{20} / \mathrm{C}_{23} \mathrm{TT}$; $10, \mathrm{C}_{22} / \mathrm{C}_{21} \mathrm{TT} ; 11, \mathrm{C}_{24} / \mathrm{C}_{23} \mathrm{TT} ; 12, \mathrm{C}_{26} / \mathrm{C}_{25} \mathrm{TT} ; 13, \mathrm{C}_{31} \mathrm{~S} / \mathrm{H} ; 14, \mathrm{C}_{29} \mathrm{H} / \mathrm{H} ; 15, \mathrm{C}_{35} / \mathrm{C}_{34} \mathrm{~S}$ hopanes; 16, BNH/H; 17, Ol/H; 18, G/H; 19, $\mathrm{C}_{2} 9 \mathrm{Ts} / \mathrm{C}_{29} \mathrm{H}$. Std. Dev., standard deviation. See text for further details. 
Table 3-2. Biomarker ratios for oil Tribes 1, 2, and 3 in 388 training set samples from coastal California can be used to infer lithology, oxicity, and higher-plant input to the source rock.

[Biomarker ratios are defined in Methods and Peters and others (2005). The $\mathrm{C}_{27}$ Dia/St ratio was not used in the chemometic analysis and corresponds to $13 \mathrm{~b}, 17 \mathrm{a}$-diacholestane (20S)/5a-cholestane (20R).

Marl is a sedimentary rock having lithology intermediate between shale and carbonate, i.e., calcareous clay]

\begin{tabular}{|c|c|c|c|c|c|c|c|c|c|c|c|}
\hline \multirow{2}{*}{$\begin{array}{c}\text { Trib } \\
\text { e }\end{array}$} & \multirow{2}{*}{$\begin{array}{c}\text { Inferred } \\
\text { setting }\end{array}$} & \multirow{2}{*}{$\begin{array}{c}\text { Numbe } \\
\mathbf{r} \\
\text { sample } \\
\text { s }\end{array}$} & \multicolumn{4}{|c|}{ Clay } & \multicolumn{2}{|c|}{ Carbonate } & \multicolumn{2}{|c|}{ Oxicity } & \multirow{2}{*}{$\begin{array}{c}\begin{array}{c}\text { Higher } \\
\text { plants }\end{array} \\
\mathrm{Ol} / \mathrm{H}\end{array}$} \\
\hline & & & $\mathbf{T s} / \mathbf{T m}$ & $\begin{array}{c}\mathrm{C}_{29} \mathrm{Ts} / \mathrm{C}_{29} \\
\mathrm{H}\end{array}$ & $\begin{array}{c}\mathrm{C}_{27} \mathrm{Dia} / \mathrm{S} \\
\mathrm{t}\end{array}$ & $\begin{array}{c}\mathbf{C}_{24} / \mathbf{C}_{23} \mathrm{~T} \\
\mathbf{T}\end{array}$ & $\begin{array}{c}\mathbf{C}_{22} / \mathbf{C}_{21} \mathrm{~T} \\
\mathbf{T}\end{array}$ & $\mathbf{C}_{29} / \mathbf{H}$ & $\mathrm{C}_{35} / \mathrm{C}_{34} \mathrm{~S}$ & BNH/H & \\
\hline 1 & Shale & 82 & $\begin{array}{c}0.55 \pm 0.1 \\
6\end{array}$ & $0.25 \pm 0.08$ & $\begin{array}{c}0.32 \pm 0.1 \\
5\end{array}$ & $0.69 \pm 0.08$ & $0.27 \pm 0.07$ & $\begin{array}{c}0.60 \pm 0.0 \\
9\end{array}$ & $\begin{array}{c}0.95 \pm 0.2 \\
9\end{array}$ & $\begin{array}{c}0.41 \pm 0.2 \\
6\end{array}$ & $\begin{array}{c}0.10 \pm 0.0 \\
4\end{array}$ \\
\hline 2 & Marll & 215 & $\begin{array}{c}0.27 \pm 0.0 \\
6\end{array}$ & $0.13 \pm 0.04$ & $\begin{array}{c}0.18 \pm 0.0 \\
7\end{array}$ & $0.47 \pm 0.07$ & $0.47 \pm 0.08$ & $\begin{array}{c}0.68 \pm 0.0 \\
5\end{array}$ & $\begin{array}{c}1.70 \pm 0.2 \\
4\end{array}$ & $\begin{array}{c}1.31 \pm 0.5 \\
2\end{array}$ & $\begin{array}{c}0.04 \pm 0.0 \\
2\end{array}$ \\
\hline 3 & $\begin{array}{c}\text { Carbonat } \\
\mathrm{e}\end{array}$ & 91 & $\begin{array}{c}0.21 \pm 0.0 \\
3\end{array}$ & $0.08 \pm 0.03$ & $\begin{array}{c}0.15 \pm 0.1 \\
2\end{array}$ & $0.30 \pm 0.05$ & $0.91 \pm 0.15$ & $\begin{array}{c}0.76 \pm 0.0 \\
9\end{array}$ & $\begin{array}{c}2.03 \pm 0.3 \\
1\end{array}$ & $\begin{array}{c}0.92 \pm 0.4 \\
3\end{array}$ & $\begin{array}{c}0.03 \pm 0.0 \\
1\end{array}$ \\
\hline
\end{tabular}


Table 3-3. The Chemometric model classied ten tarballs found on beaches from Monterey to San Mateo Counties, California, in February 2007. Geochemical data are in Appendix 31.

[Statistical criteria for soft independent modeling of class analogy (SIMCA) fit are described in the footnote of Appendix 3-1]

\begin{tabular}{|c|r|r|l|l|}
\hline \multirow{2}{*}{ Location } & Sample & Family & $\begin{array}{l}\text { Inferred Source } \\
\text { Rock Lithology }\end{array}$ & SIMCA Fit* \\
\hline \multirow{2}{*}{$\begin{array}{l}\text { Moss Beach, } \\
\text { San Mateo Co. }\end{array}$} & $07-1$ & 32 & Carbonate & Excellent \\
\cline { 2 - 5 } & $07-5$ & 212 & Marl & Excellent \\
\cline { 2 - 5 } & $07-7$ & 34 & Carbonate & Excellent \\
\hline \multirow{2}{*}{$\begin{array}{l}\text { Asilomar Beach, } \\
\text { Monterey Co. }\end{array}$} & $07-8$ & 33 & Carbonate & Excellent \\
\cline { 2 - 5 } & $07-9$ & 32 & Carbonate & Good \\
\hline \multirow{3}{*}{$\begin{array}{l}\text { Half Moon Bay, } \\
\text { San Mateo Co. }\end{array}$} & $07-12$ & 33 & Carbonate & Excellent \\
\cline { 2 - 5 } & $07-15$ & 33 & Carbonate & Excellent \\
\cline { 2 - 5 } & $07-16$ & 33 & Carbonate & Excellent \\
\cline { 2 - 5 } & $07-18$ & 22 & Marl & Excellent \\
\hline \multirow{2}{*}{} & \multicolumn{3}{|l}{} & Excellent \\
\hline
\end{tabular}




\section{Appendix 3-1}

\section{Location, classification, and source/age related geochemical data for crude oil, seep oil, and tarball samples from coastal California, used in the chemometric model with classification of non-model tarballs}

Appendix 3-1 is provided as Excel .xls, comma-separated values .csv, and tab-delimited ASCII .txt files. Follow this link to

http://pubs.usgs.gov/of/2009/1225/of2009-1225_appendix_3-1/ to download any of these files.

\section{Appendix 3-1 Footnote}

* Statistical criteria for soft, independent modeling of class analogy (SIMCA) fit are based on a ratio of residuals determined for all samples submitted to the decision tree (fig. 3-3). The ratio of residuals consists of the test sample residual divided by the standardized residual in the PCA model for the training set. An F-test at a designated probability level allows evaluation of the hypothesis that the sample is a member of the category. Quality of fit was assigned by conducting this evaluation at probability levels: excellent $(<95 \%)$, good $(95-99 \%)$, poor (99-99.9\%), and no fit (>99.9\%).

Rank is 1-10 biodegradation scale of Peters and Moldowan (1993).

1, stable carbon isotope ratio whole oil (PDB, \%o); 2, Ts/Tm; 3, $\mathrm{C}_{26} / \mathrm{Tet} ; 4, \mathrm{C}_{28} / \mathrm{C}_{29} ; 5$, PAH-RI; 6, SC2D/SC2P; 7, SC3D/SC3P; 8, C $28 / \mathrm{C}_{29} \mathrm{TT} ; 9, \mathrm{C}_{20} / \mathrm{C}_{23} \mathrm{TT} ; 10, \mathrm{C}_{22} / \mathrm{C}_{21} \mathrm{TT} ; 11$, $\mathrm{C}_{24} / \mathrm{C}_{23} \mathrm{TT} ; 12, \mathrm{C}_{26} / \mathrm{C}_{25} \mathrm{TT} ; 13 ; \mathrm{C}_{31} \mathrm{~S} / \mathrm{H}, 14 ; \mathrm{C}_{29} \mathrm{H} / \mathrm{H} ; 15, \mathrm{C}_{35} / \mathrm{C}_{34} \mathrm{~S}$ hopanes; $16, \mathrm{BNH} / \mathrm{H}$; $17, \mathrm{Ol} / \mathrm{H} ; 18, \mathrm{G} / \mathrm{H} ; 19, \mathrm{C}_{29} \mathrm{Ts} / \mathrm{C}_{29} \mathrm{H}$ (see Methods).

The following nine samples were removed for constructing the decision tree: 99-18, 9919, 99-101, 99-103, 00-68, 03-94, 04-7, 04-272, and 05-95 as discussed in Methods. 


\section{Appendix 3-2}

Hierarchical cluster diagram of the 388-sample training set for the chemometric model.

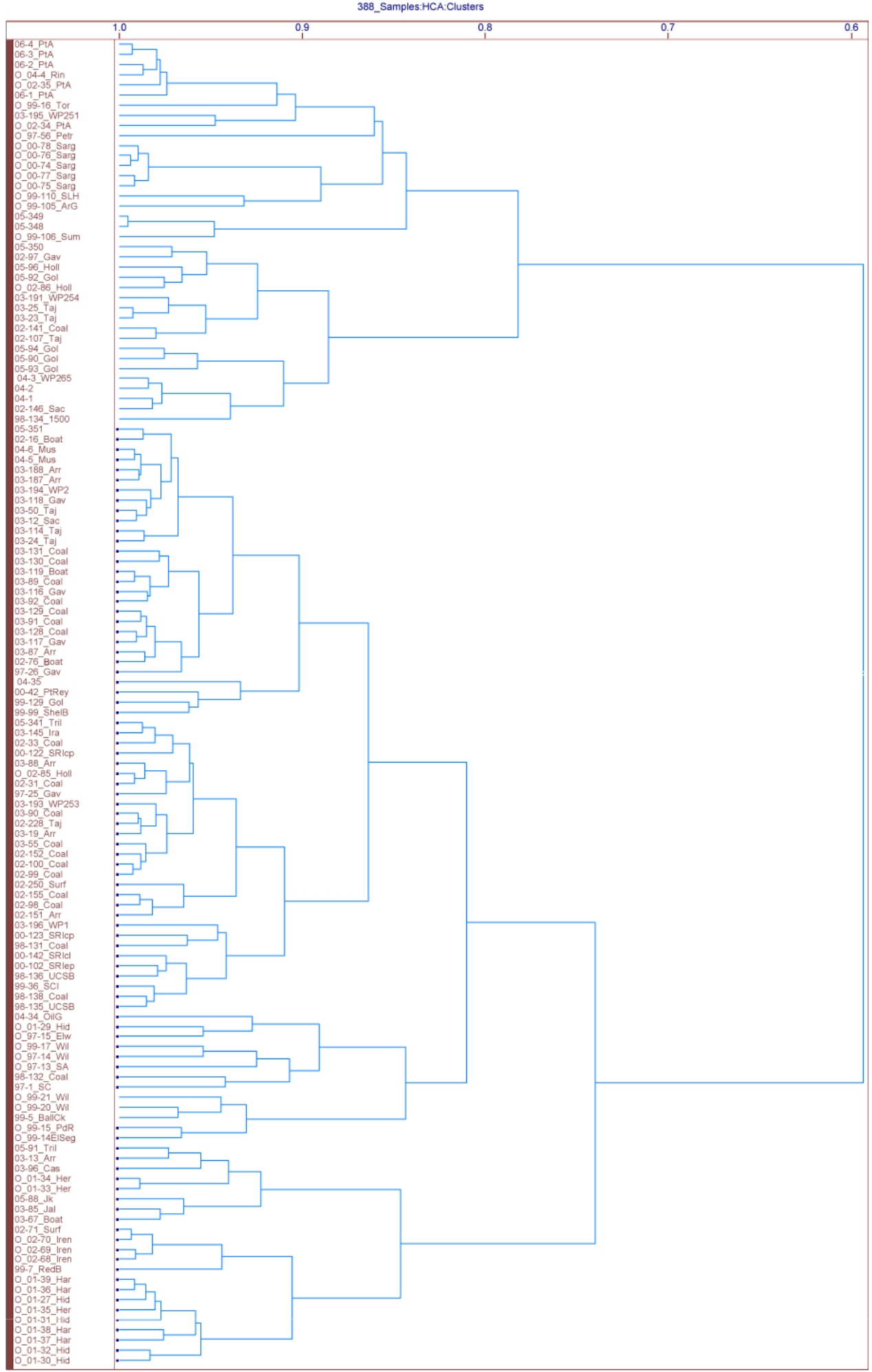

Figure 1. HCA of Tribe 1. 


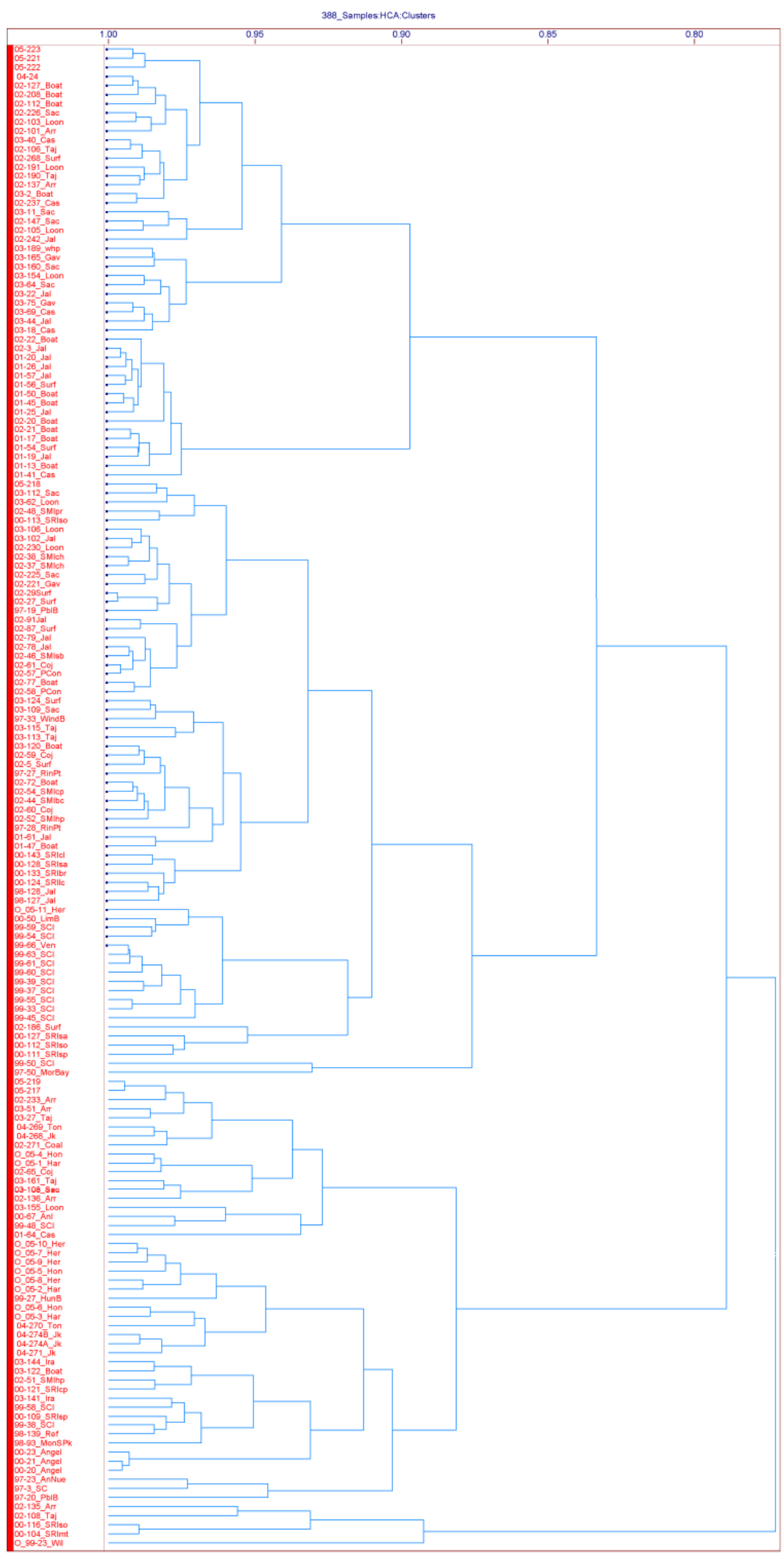

Figure 2. HCA of Tribe 2. 


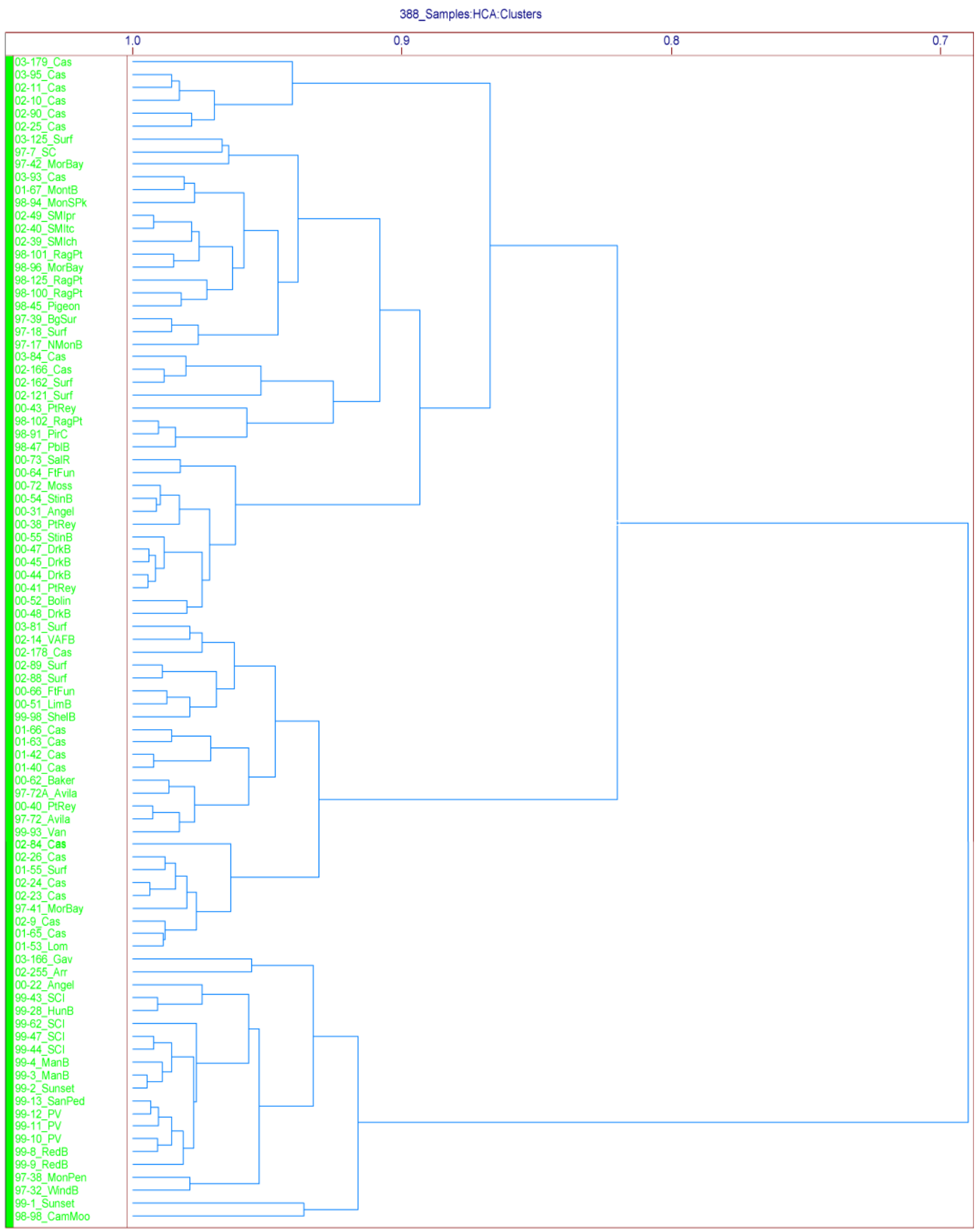

Figure 3. HCA of Tribe 3. 


\section{Chapter 4. Beach Monitoring of Tar Samples}

This chapter examines qualitative rates of tarball deposition measured during a three-year period. We monitored tarball accumulation on 10 beaches spanning the Santa Barbara County coastline on a monthly basis from June 2002 to June 2003 to address tarball accumulation patterns, (fig. 4-1). Prior to that we monitored the four northern county beaches on a quarterly basis from July 2001 through April 2002, thus the record for these beaches extends from July 2001 through August 2003. Specifically addressed are the following questions: 1) Does tar deposition and therefore seepage vary on a seasonal scale? 2) Does the spring/neap tidal cycle affect tarball deposition by affecting seepage? and 3) Is there a spatial pattern to the data that corroborates the different tarball morphologies observed? The monthly monitoring effort is analyzed in a statistically rigorous fashion later in this chapter, whereas more qualitative data for the entire data set is introduced first.

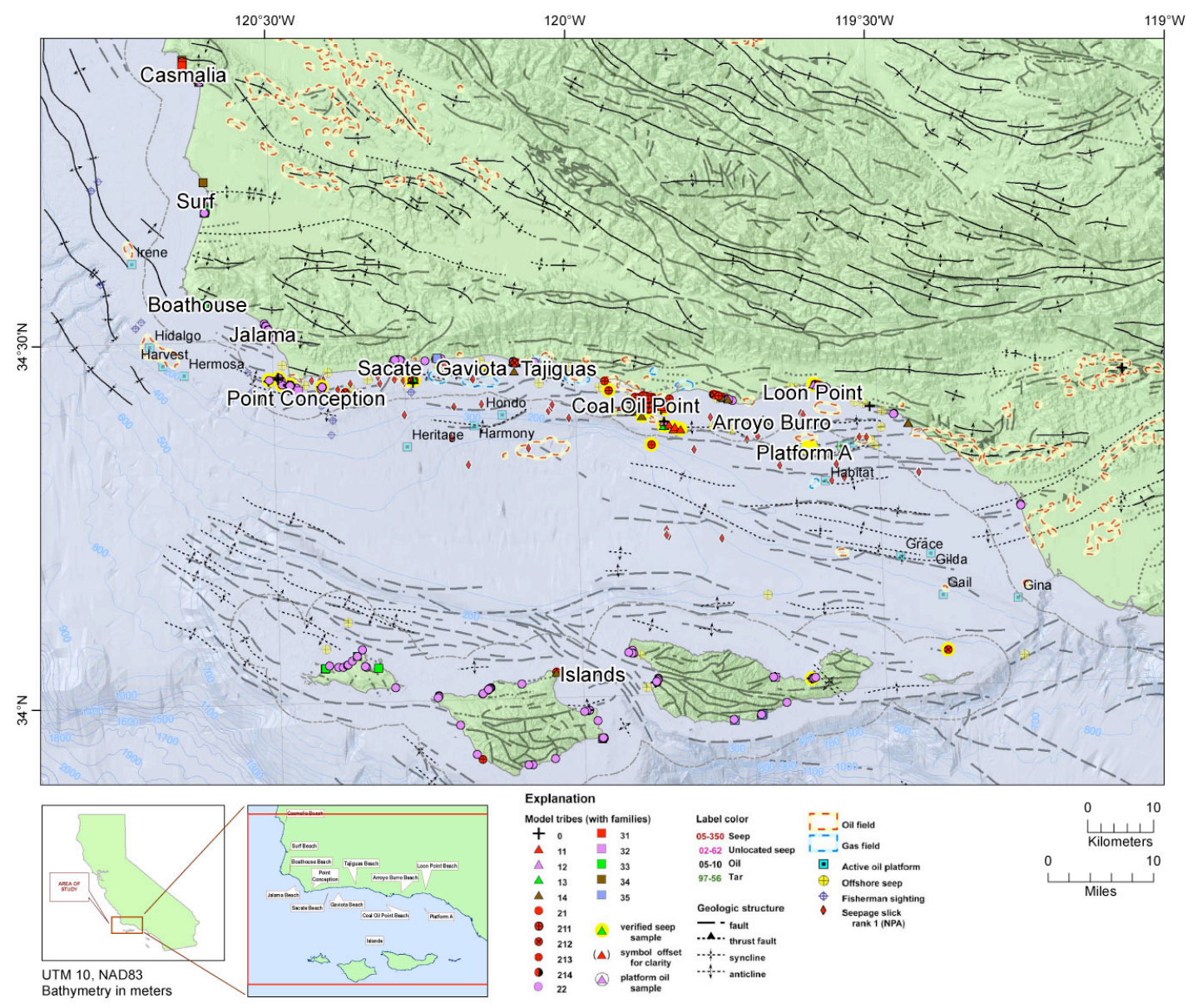

Figure 4-1. Map of the study area showing locations of beaches, selected oil platforms and natural seep samples. 


\section{Methods}

\section{Beach Sampling Protocols}

The selection of beaches for sampling was based on several factors- geographic distribution over the coastal length of Santa Barbara County, a variety of lengths ranging from 0.2 to $8 \mathrm{~km}$, access, and proximity to known oil seeps.

The beaches were sampled monthly or quarterly by teams of two to four people. Typically five perpendicular transects per beach were randomly chosen. Transects were located by walking an arbitrary number of minutes down the beach, determined by a digital counter. Each transect length was measured using a metric tape. The tape was left on the beach while team members picked up, counted and weighed tarballs found within 2 meters of the transect center line. A random tarball from each transect was weighed and stored in a chemically clean sample jar for chemical fingerprint analyses. The relative freshness of the sample was noted on a scale of 1 to 3,1 being fresh. Freshness assessment was based on visual and olfactory inspection. Fresh tar will retain more of the "aromatic" hydrocarbon components than a more degraded or old sample that can smell putred. Fresh tar often has sheen and is less encrusted with sand or other detritus; figs I-2 to I-5. A global positioning system receiver was used to record the location of each sample and transect. Additionally the date and time of collection, tidal condition, length and azimuth of transect, were recorded for each sampling event. The sampling method used is similar to that used by Coles and Al-Riyami (1996) to access tar accumulation in the Gulf of Oman. An example of a field recording sheet and data is seen in table 4-1.

The spatial record of the samples and transects is stored on a GIS (geographic information system) database located at the U.S. Geological Survey (USGS) and will be made available at a later date.

\section{Results}

\section{Tarball Mass and Tarball Number on Beaches}

Table 4-2 shows the diagnostic average parameters for each beach sampled during the program from July 2001 through August 2003. The north county beaches (Casmalia, Surf, Boathouse and Jalama) have a noticeably larger tarball mass and size as compared to south county beaches (figs. 4-2 and 4-3). This mass and size difference reflects oil and tar differences at their sources. The seeps impacting the north county beaches likely have tarwhip-like sources producing large, viscous tar masses. Figure I-2 shows a tar whip seep sample collected at the sea surface near Point Conception. 


\section{South Beach Team}

\begin{tabular}{|l|r|r|r|r|r|}
\hline Beach name: Sacate & $\begin{array}{l}\text { Date: } \\
\mathbf{3 / 8} / \mathbf{0 3}\end{array}$ & $\begin{array}{l}\text { Time: } \\
\mathbf{7 : 0 0 a}\end{array}$ & Tide: +1 & & \\
\hline Personnel: Sara \& Karen & & & & & \\
\hline Number of Tarballs & Transect 1 & Transect 2 & Transect 3 & Transect4 & Transect5 \\
\hline Total Tarball weight (gm) & 39 & 6 & 2 & 4 & 3 \\
\hline Tarball sample weight (gm) & 32 & 45 & 5 & 32 & 9 \\
\hline Tarball sample freshness 1-3 (1 fresh, 3 old) & - & 32 & -120 & 30 \\
\hline Latitude (ddd, WGS84) N & 34.46970 & 34.47020 & 34.47061 & 34.47082 & 34.47050 \\
\hline Longitude (ddd, WGS84) W & 120.29898 & 120.29829 & 120.29532 & 120.29452 & 120.29221 \\
\hline Length of Transect (m, from water to cliff) & 27 & 27 & 29 & 46 & 24 \\
\hline Azimuth of Transect (magnetic, 0-360 $)$ & 124 & 138 & 170 & 167 & 170 \\
\hline Time (min) to Transect & 3 & 2 & 4 & 2 & 5 \\
\hline Random Sample & & & & & \\
\hline Tarball sample weight (gm) & 8 & & & & \\
\hline Tarball sample freshness 1-3 (1 fr, 3 old) & 2 & & & & \\
\hline Latitude (ddd, WGS84) N & 34.46975 & & & & \\
\hline Longitude (ddd, WGS84) W & 120.29900 & & & & \\
\hline
\end{tabular}

Table 4-1. Example of a field data collected monthly at each beach. Two separate teams worked on the northern and southern beaches during the program.

In contrast, the southern beaches are more often impacted by proximal oil seeps that occur frequently from about offshore Gaviota east to beyond the study area into Santa Monica Bay. Here oil rises to the surface and undergoes weathering for some period, coalescing into smaller, more fragile tar patties seen in figure I-3. Areas near known oil seeps offshore Coal Oil Point (COP) impact COP with millions of small tar patties seen in figure I-4. Table 4-2 demonstrates that COP receives the greatest number of tarballs (about 930,000 at any one time; the average size of one of these tarballs is about $1 \mathrm{gm}$. In contrast, data from Jalama Beach has an estimated 4,200 tarballs on the beach, however, the average tarball mass is about $67 \mathrm{gm}$. In order to normalize the accumulation of tar mass on each beach, a calculation was made relating the weight of tar found on each beach in relation to the beach length, where Average Estimated Mass on Beach $(\mathrm{gm}) \times$ Beach Length $(\mathrm{km})=$ Average Tar Mass on Beach $(\mathrm{gm} / \mathrm{km})$; the results are shown in table 4-2. More tar mass was found on the four northern beaches relative to the six southern beaches. Notable exceptions to this are Casmalia Beach in the north, where less tar accumulates, and Arroyo Burro Beach in the south, where more tar accumulates. It is assumed the amount of tar mass accumulation on a beach is generally related to the distance and flux of a contributing seep or seeps. If this relationship is correct, then we speculate that Casmalia Beach is further from the Point Conception seep sources, also reflected in the abundance of Tribe 3 oils here rather than the abundant Tribe 2 tars present in the Point Conception area. 


\section{Timing of tarball deposition on beaches}

A goal of the sampling program was to document seasonal changes of tar deposition. Figures 4-4 and 4-5 show histograms of the average tar mass accumulation for both the northern and southern beaches. In general, tarballs accumulate at a faster rate, or remain longer on all beaches during the summer and fall months. The reasons for this are unclear based on our observations, however, we speculate that factors such as prevailing winds and currents combined with more quiescent wave conditions favors the accumulation and preservation of tarballs on the beach during the summer and fall months. In contrast, winter storms remove beach sand and other materials.

Specifically for the northern beaches, Surf and Jalama Beaches receive the largest quantity of tar residue peaking in summer and fall months, however from April through August, 2003, Surf Beach had higher accumulation rates than Jalama Beach, a trend in reverse of that established from July 2001 through March 2003.

The south county beach most impacted by tar deposition is COP (maximum estimated $88,000 \mathrm{gm} / \mathrm{km}$ beach in October 2002) followed by Arroyo Burro Beach (maximum estimated 20,000 gm/ $\mathrm{km}$ beach in June 2003). Other beaches had spikes of increased tar deposition in just one sampling period during the 15 month sampling program for the the southern beaches. Single month tar deposition highs for these beaches are perhaps one-time events that focus tar on that beach, or perhaps reflect an increase in nearby-seep activity.

Table 4-2. Average values of tarball parameters showing average values for each beach sampled by counting and weighing tarballs along 3 to 5 beach perpendicular transects each $4 \mathrm{~m}$ wide, then scaled up to the length of each beach (see text for details). Data from each beach represents measurements made on one day for each month sampled. Tarballs less than about $3 \mathrm{~mm}$ in diameter were not counted, however the mass of these accumulations was estimated when noted by beach survey personnel. Calculated numbers are rounded to 2 significant figures.

\begin{tabular}{|c|c|c|c|c|c|}
\hline Beach & $\begin{array}{c}\text { Estimated number } \\
\text { tarballs on beach }\end{array}$ & $\begin{array}{l}\text { Estimated tarball mass on } \\
\text { beach }(\mathrm{gm})\end{array}$ & $\begin{array}{c}\text { Average tarball } \\
\text { weight (gm) }\end{array}$ & $\begin{array}{c}\text { Average tarball } \\
\text { mass on beach } \\
(\mathrm{gm} / \mathrm{km})\end{array}$ & $\begin{array}{c}\text { Times } \\
\text { sampled }\end{array}$ \\
\hline Casmalia & 460 & 2,800 & 11.0 & 2,400 & 19 \\
\hline Surf & 8,700 & 400,000 & 36.0 & 50,000 & 17 \\
\hline Boathouse & 110 & 3,900 & 11.0 & 20,000 & 18 \\
\hline Jalama & 4,200 & 220,000 & 67.0 & 56,000 & 19 \\
\hline Secate & 5,900 & 3,000 & 3.3 & 1,800 & 13 \\
\hline Gaviota & 7,900 & 3,400 & 0.7 & 2,100 & 14 \\
\hline Tajiguas & 9,400 & 1,000 & 0.6 & 1,000 & 14 \\
\hline Coal Oil Point & 930,000 & 88,000 & 1.0 & 22,000 & 14 \\
\hline Arroyo Burro & 64,000 & 63,000 & 10.0 & 7,900 & 13 \\
\hline Loon Point & 3,500 & 3,600 & 2.0 & 1,120 & 14 \\
\hline
\end{tabular}




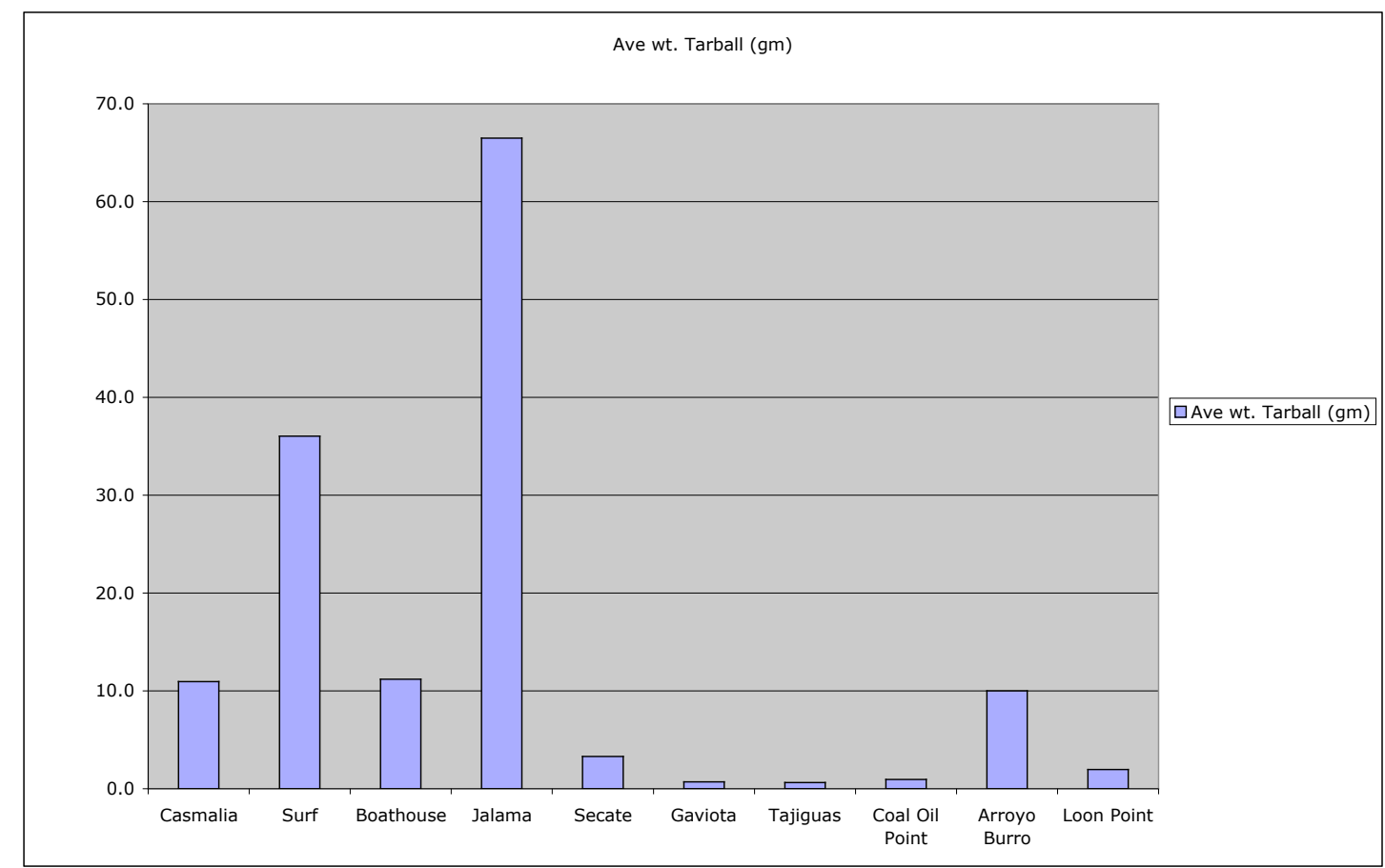

Figure 4-2. Average tarball weight for each beach measured during the program. The northern beaches collect the largest and heaviest tarballs.
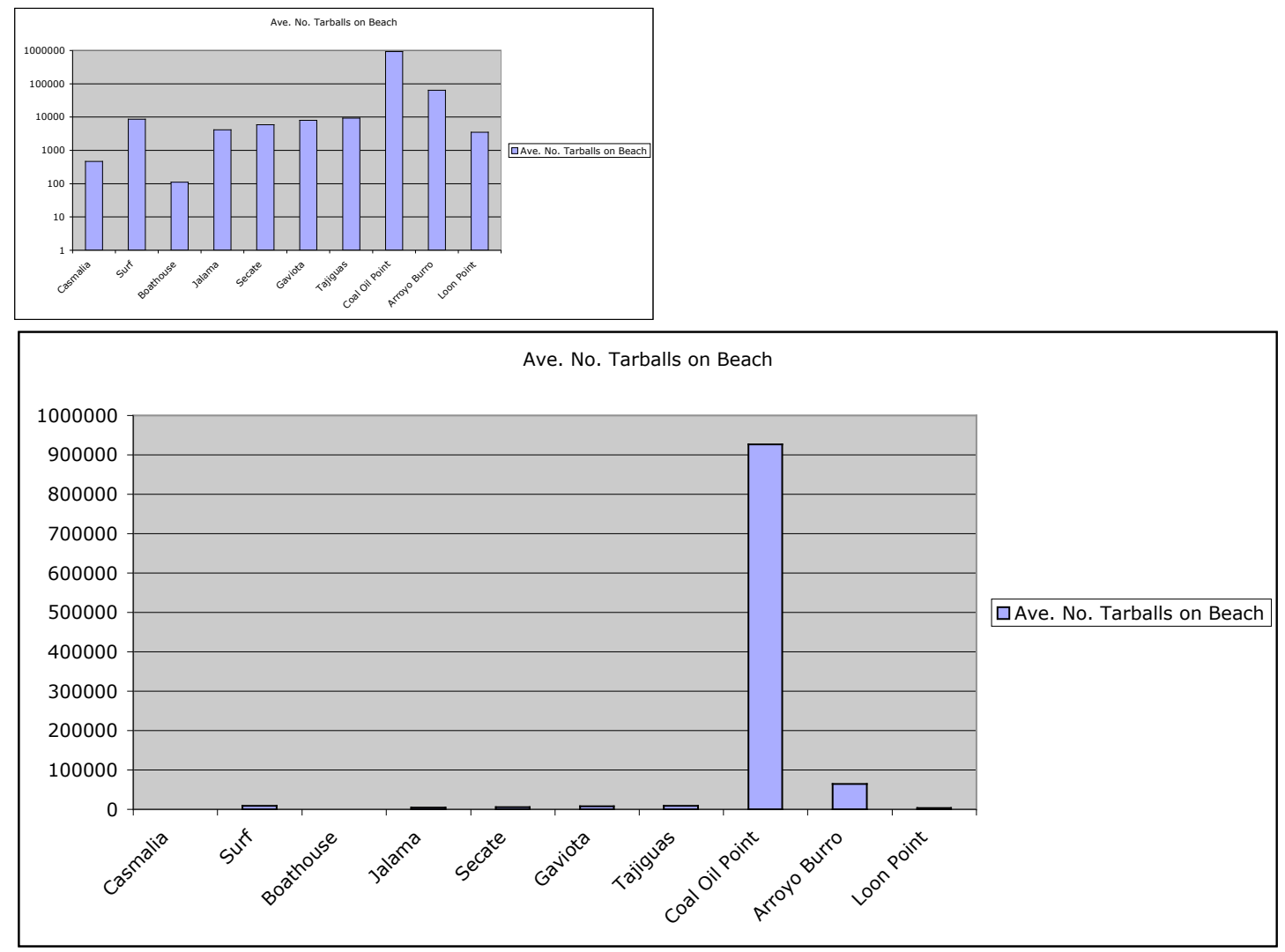

Figure 4-3. Average estimated number of tarballs observed on each beach. Coal Oil Point beach receives the highest number of tarballs. The upper figure displays the same data on a logarithmic scale. 


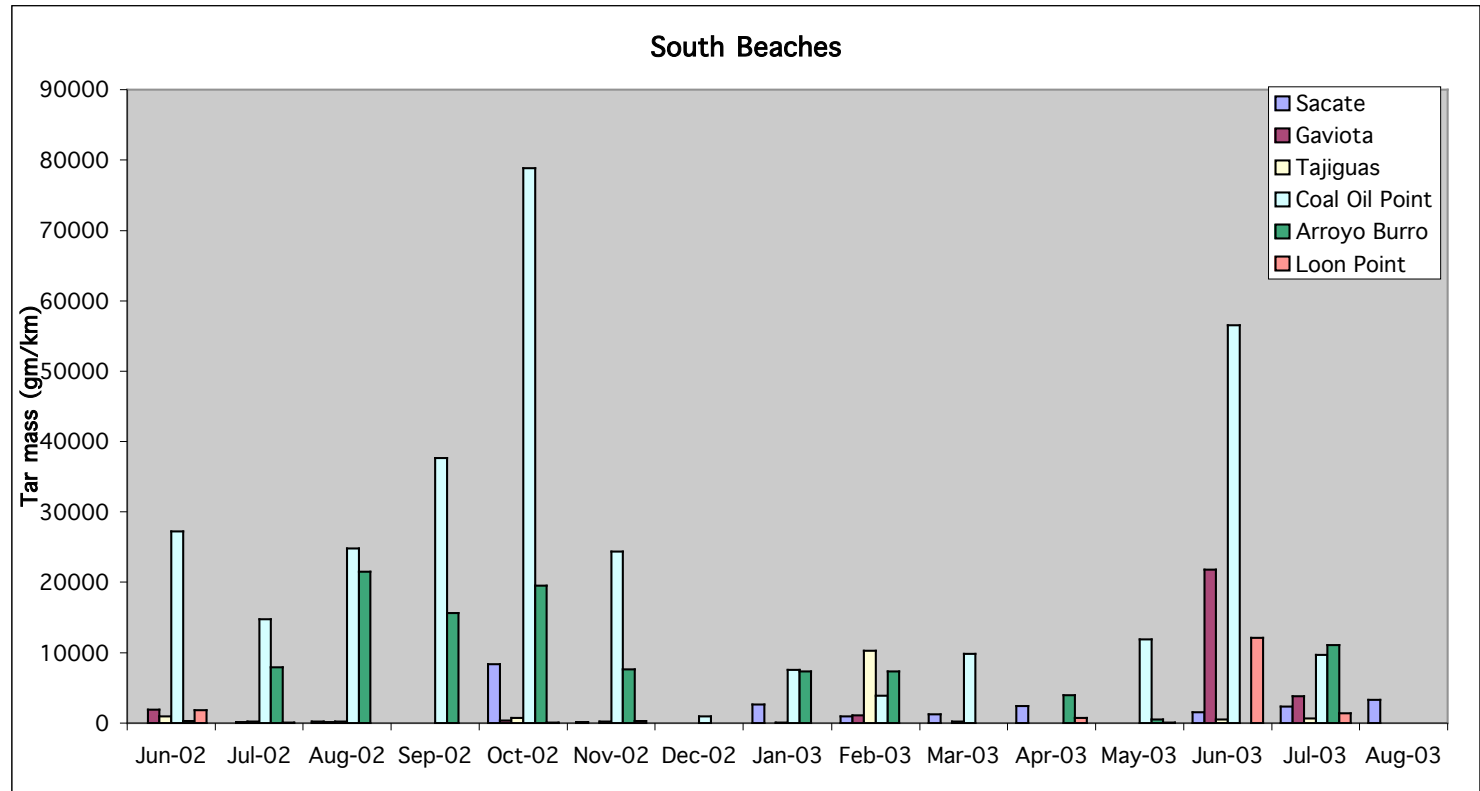

Figure 4-4. Composite histogram showing the estimated tar mass accumulation for six southern beaches during the sampling period. Tar masses are estimated as grams of tar per kilometer of beach. Coal Oil Point receives the largest quantity of tar residue, and the tar tends to accumulate more in the summer and fall months.

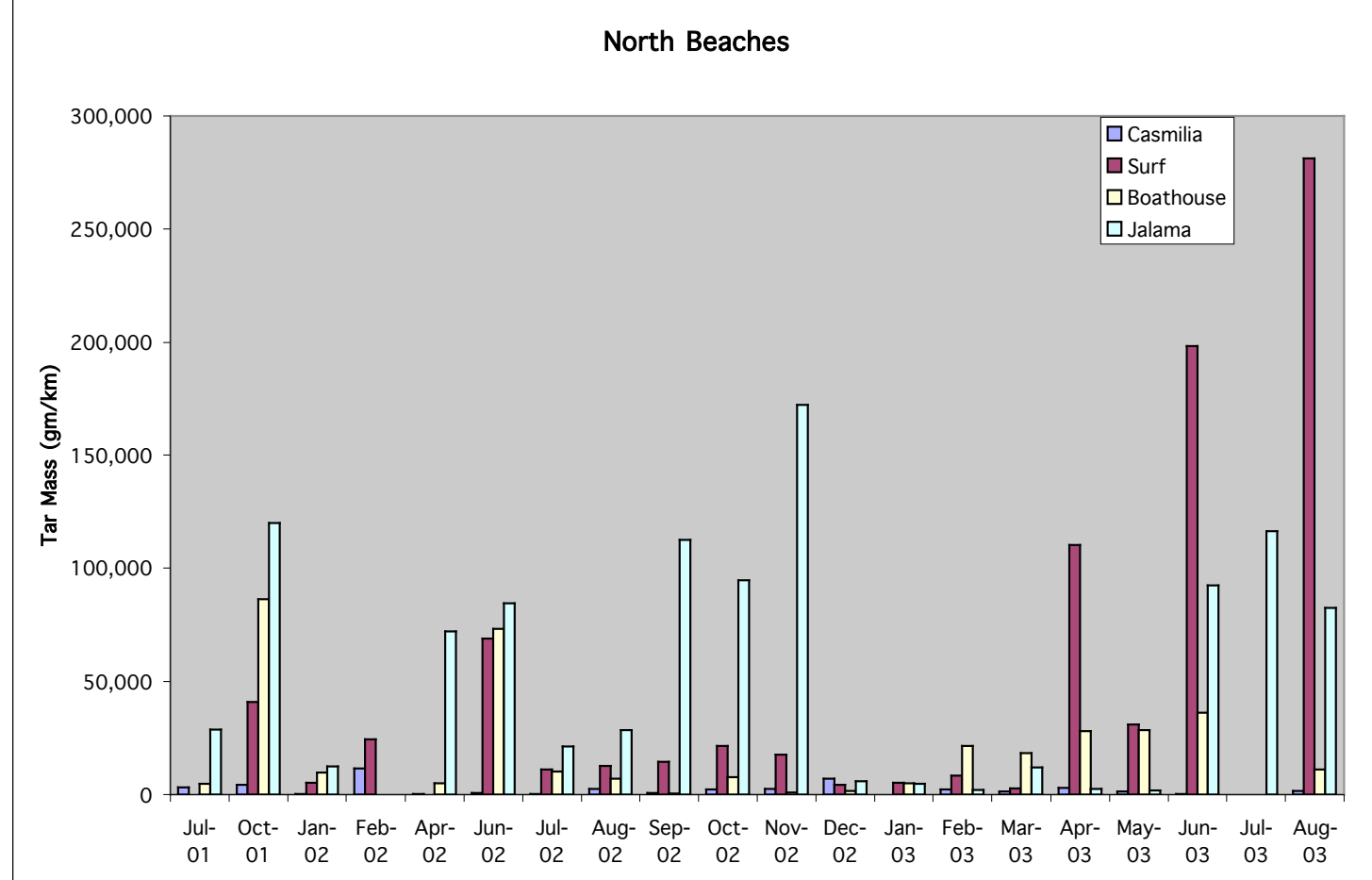

Figure 4-5. Composite histogram showing the estimated tar mass accumulation for four northern beaches during the study period. Tar masses are estimated as grams tar per kilometer of beach. Surf and Jalama beaches receive the largest quantity of tar residue, and the tar tends to accumulate more in the summer and fall months. 


\section{Statistical Data Analysis Methods}

The selection of data analyzed in a statistically rigorous fashion was collected monthly from ten beaches (fig. 4-1) between June 2002 and June 2003. A qualitative analysis of tarball count, total mass, and the average size of tarballs was completed at each of the ten beaches as described previously. All three quantities were examined for seasonality and the influence of tidal cycles was assessed using tarball count and total tar mass. The spatial relationship of the data was secondarily examined by looking for relationships between both the seasonal and tidal analyses. Analysis was performed

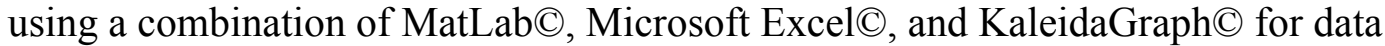
manipulation, analysis, and graphing.

To address the seasonality of the dataset, the data were grouped into two seasons, based on weather trends in southern California. The first season extends from JuneOctober and is referred to as summer/fall for the analysis. The second season from November to May, is called winter/spring for the analysis. The tarball count from each month during the season was summed a total value for the season for each beach. The total tar mass was treated in the same way as the tarball count data, and the calculated 95 percent confidence intervals for both tarball count and mass at each beach for each season.

The original data included both date and local time of sampling at each beach. Using this information the sampling times were categorized into spring or neap tides based on U.S. Naval Observatory data for the moon phase adjusted to local time. The tidal condition was classified as a spring tide for 3.5 days before and after a full and new moon, the remainder of the moon cycle was considered as neap tide. The average number of sampling events was 6.8 during neap tides and 6 for spring tides, eliminating a possible bias in the number of sampling events.

Beaches were ordered north to east to facilitate qualitative analysis of the data. The order is as follows - Casmalia, Surf, Boathouse, and Jalama, Sacate, Gaviota, Tajiguas, COP, Arroyo Burro, and Loon Point. The graphs shown in appendix 4 assess the seasonal and tidal signals and are arranged by beach in order to elucidate any overall spatial trend in the data. To simplify this assessment, this study focused on average tarball size at each beach in the two seasons.

\section{Statistical Analysis of Tar Deposition}

\section{Seasonality}

Six of the 10 beaches exhibited a strong seasonal trend in tarball deposition. Casmalia (appendix 4-1, fig 1) and Tajiguas (Appendix 4-1, fig. 7) beaches collected more tarballs during winter/spring, while more tarballs were deposited on Surf (appendix 4-1, fig. 2), COP (appendix 4-1, fig. 8), Arroyo Burro (appendix 4-1, fig. 9) and Loon Point (appendix 4-1, fig. 10) Beaches during the summer/fall season. The trend observed at Surf Beach is of questionable significance because of the overlap of the 95 percent confidence intervals between the two seasons. Both total number and total mass of tarballs were examined for a seasonal trend, and the beaches discussed above showed agreement between tarball mass and number. Boathouse (appendix 4-1, fig. 3), Jalama (appendix 4-1, fig. 4), Sacate (appendix 4-1, Figure 5), and Gaviota (appendix 4-1, fig. 6) 
displayed opposing trends for the total number and total mass of tarballs thereby confounding interpretation of the seasonal signal.

Data from these beaches (Boathouse, Jalama, Sacate, and Gaviota) displayed the same pattern of fewer tarballs with greater mass in the summer/fall, a trend not observed at the other beaches. Thus, the summer/fall season is described by a smaller number of larger tarballs, while the winter/spring season is dominated by greater numbers of small tarballs.

\section{Tidal cycle}

Seven of the beaches demonstrated more tar deposition coinciding with a neap or spring tide. Neap tide correlated with dominance of both number and mass of tarball deposition at Casmalia (appendix 4-1, fig. 11), Surf (appendix 4-1, fig. 12), Boathouse (appendix 4-1, fig. 13), and Loon Point (appendix 4-1, fig. 20) Beaches. An opposing trend of higher tarball number and mass coincident with spring tide occurred at Jalama (appendix 4-1, fig. 14), COP (appendix 4-1, fig. 18), and Arroyo Burro (appendix 4-1, fig. 19) Beaches. The three remaining beaches showed opposite trends for tarball mass and number in a similar fashion to the seasonal results. Sacate (appendix 4-1, fig. 15) and Gaviota (appendix 4-1, fig. 16) were again among the group with the divergent pattern as was Tajiguas (appendix 4-1, fig. 17). All three of these beaches displayed the same pattern of greater numbers of tarballs during the neap tide with tarballs of greater mass observed during the spring tide. The trends observed at all the beaches were statistically significant.

\section{Spatial Pattern}

The spatial trend of tar deposition was difficult to access using the figures for seasonality and tidal cycle. Figures 4-6 and 4-7 shows a more intuitive interpretation of the depositional trend relating to beach position. The data falls into roughly three groupings from north to east, Group 1 is comprised of the four northern most beaches, Casmalia, Surf, Boathouse, and Jalama. Beaches in Group 2 are Sacate, Gaviota, Tajiguas and COP beaches. Group 3 beaches include Arroyo Burro and Loon Point at the eastern most edge of the study area.

The average tarball size in Group 1 is $37.8 \mathrm{~g}$ in summer/fall and $16 \mathrm{~g}$ in winter/spring. Group 2 displays a significantly reduced average tarball size, $0.8 \mathrm{~g}$ during summer/fall and $1.4 \mathrm{~g}$ during winter/spring. The average tarball size in Group 3 is neither as large as one nor as small as two in either season. Group 2 displays a reverse trend of increased size in the winter/spring as does Group 3 with sizes of $4.2 \mathrm{~g}$ during summer/fall and $20.6 \mathrm{~g}$ in winter/spring. 
Summer/Fall Season

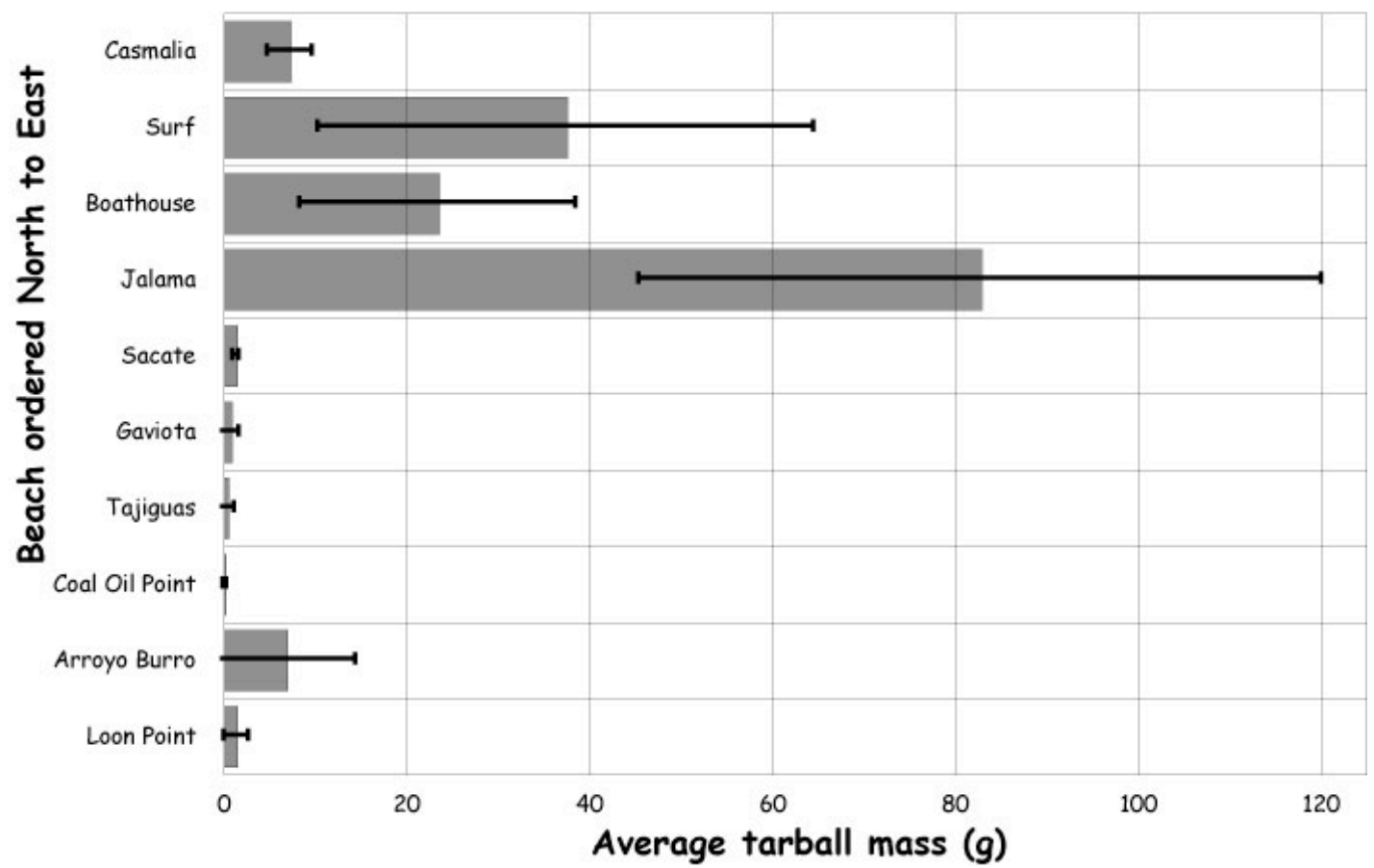

Figure 4-6. Average tarball mass collected on ten beaches arranged from north to east. During the Summer/Fall season, most tarball mass collects on the four northern-most beaches.

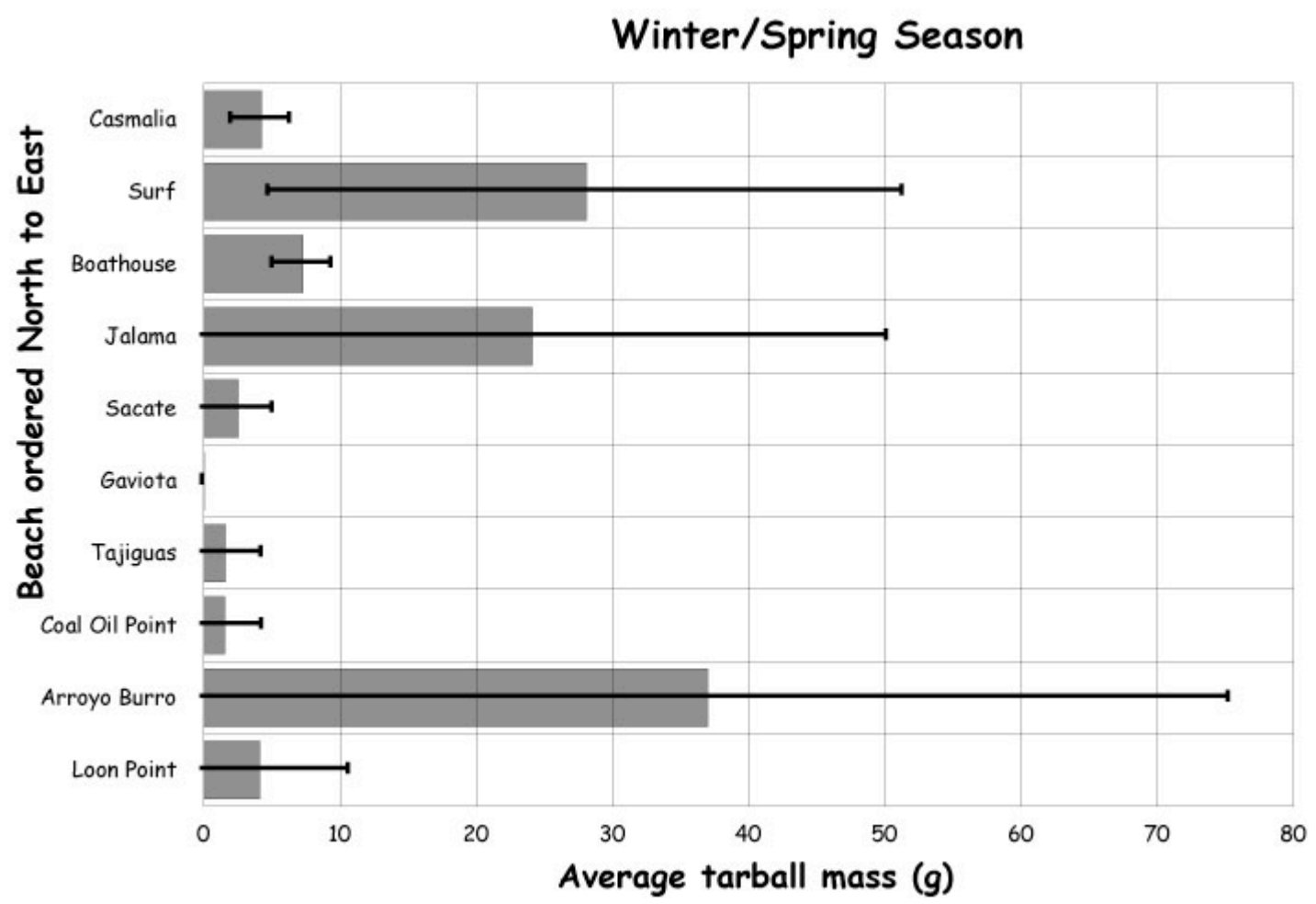

Figure 4-7. Average tarball mass collected on ten beaches arranged from north to east. During the Winter/Spring season, most tarball mass collects on the four northern-most beaches with the addition of one southern beach, Arroyo Burro. 


\section{Discussion}

The analysis performed addresses the presence of trends observed in tar deposition along the Santa Barbara County coast. Although the results presented are qualitative, there are some interesting patterns of tar deposition associated with the seasons, the tidal cycle, and the spatial variability.

This analysis suggests there is a seasonal variation in tar deposition, however, it may vary in the study area due to complex patterns of wind and currents not accounted for here. Strong seasonal variations were present at six of the study's 10 beaches, however, we cannot currently explain the spatial deviation in this signal. Perhaps there are too many variables to attempt to describe seasonality in the entire study area.

On a smaller scale with increased sampling frequency, a study in 2005 at COP was conducted to access temporal variability of tar accumulation and showed summer tar accumulation was ten times that observed in winter (Del Sontro and others, 2007). The data collected from 2002-2003 showed the same trend, COP Beach accumulated about four times the mass of tar in the summer/fall as it did during the winter/spring. Tar accumulation is facilitated during summer months because of characteristically small swells, low wind speeds and frequent onshore breezes (Del Sontro and others, 2007).

Oil and gas seepage has been shown to vary from sub-hourly to decadal timescales (Leifer and others, 2004), making it reasonable to assume that some of this periodicity may be observed in tar accumulation. The timing link between seepage and eventual tar accumulation on the beach is unclear and complex, however natural seepage is the main source of tar in this area (Hostettler and others, 2004). A study in the same area tracked an oil slick from formation until getting trapped in a kelp bed offshore COP; this took 95 minutes (Leifer and others, 2006b). This has been the only study attempting to track a seep-derived slick while monitoring the geochemical changes. Figure 4-8 shows a schematic of the processes acting on seep oil to illustrate the complexity linking seepage with beach accumulation of tar.

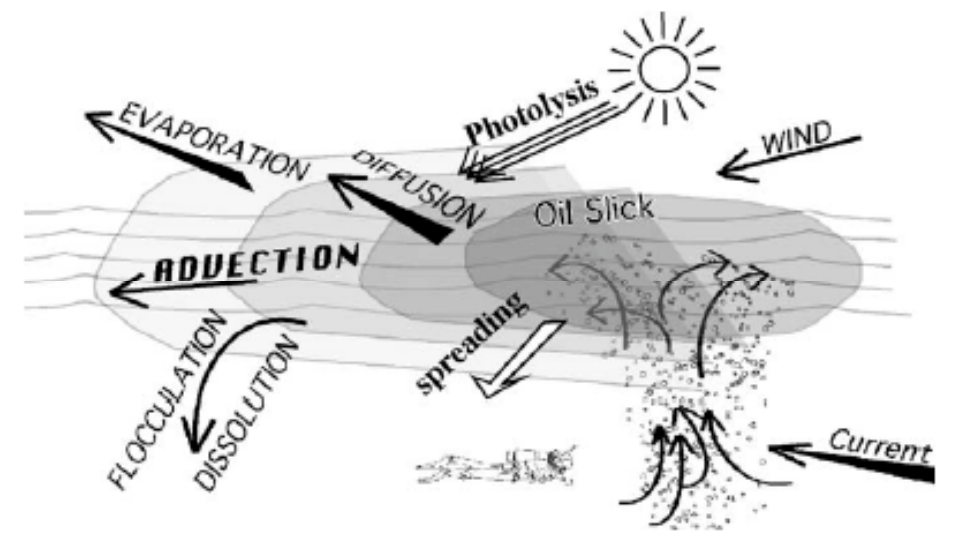

Figure 4-8. Schematic showing oil slick evolution during a 10 hour period (Leifer and others, 2006b).

Tarball deposition on seven of the beaches was tidally influenced. Unfortunately the tidal pattern is too complex in the study area to say much about countywide trends. Tides have been documented to affect oil and gas seepage in part of the study area (Boles and others, 2001, Mikolaj and Ampaya, 1973). Oil seepage was negatively correlated with tidal height (Mikolaj and Ampaya, 1973), and gas seepage displayed a similar trend, 
decreasing with high tides and increasing with low tides (Boles and others, 2001). Perhaps more robust results would be possible by examining the data during the low and high tides in the spring/neap cycle. Since the timing link between seepage and deposition are not well characterized it is difficult to link the tidal patterns in seepage to beach tar accumulations. Extrusion or seepage of tar from the seafloor has not been studied for tidal influence, and it is not possible to correlate these processes here, although empirical observation suggests a link. Tar extruded directly from the seafloor (different than what is depicted in fig. I-3) exhibits morphology observed primarily on the northern beaches and instigated the analysis of the data for a spatial pattern described next.

As introduced previously, two different basic tarball morphologies are observed on beaches in Santa Barbara County, smaller tar patties and larger tar bodies, owing to different formation processes. Figures I-3 and I-4 are a good example of the morphology typically associated with Group 2 beaches (Sacate, Gaviota, Tajiguas, and COP). Tarballs of this type are formed from the processes depicted in Figure 4-8. Formation of tar patties from agglomeration of a weathered oil slick is illustrated in figure 4-8. Tarballs with this morphology tend to have a maximum mass of about five grams, and this is in agreement with the results of the spatial analysis for Group 2. Loon Point Beach is a member of Group 3, however much of the tar deposited there resembles the morphology of Group 2. A confounding factor is that Arroyo Burro Beach lies between the Group 2 beaches and Loon Point Beach, and the tar accumulating at Arroyo Burro Beach is far closer to that observed from Group 1.

The cause of the observed divergence of tar morphology between these beaches is unclear. It is possible that complex ocean circulation is causing the large tarballs to accumulate on Arroyo Burro Beach, or perhaps they are the result of undetected, nearby seeps extruding tar similar to those observed offshore Point Conception. Such tar mounds also are known to occur between COP and Goleta point (Lorenson, unpublished data). Seeps located offshore of the beaches in Tribe 2 produce tar depicted in Figure 4-2. This is the second morphology observed in the study area and is based on extrusion of tar, rather than oil or gas, from the seafloor. Tar of this type is only found on the beaches in Group 2 and at Arroyo Burro Beach primarily in the winter/spring season, as evidenced by the larger average tarball size (appendix 4-1, fig. 23). There is a spatial pattern that corroborates the field observations, however, this data is primarily qualitative.

\section{Conclusion}

Tar deposition varies on a seasonal scale. Seepage is affected by the spring and neap tidal cycle, with more deposition during neap tides, however this may vary over timescales greater than one year. Larger, more massive tarballs, mainly of Tribe 2, occur near the Point Conception seep area, whereas smaller tar patties tend to occur on the southern coastline near the seeps that create them. Longer periods of monitoring are needed to address the variability in the data and provide a more robust statistical analysis. In the future we recommend that the study be conducted for multiple consecutive years with a time series analysis assessing what frequencies are most relevant to the variance in the data. Data could then be cross-correlated to wind and current data to determine the key mechanisms at play in delivering the constant supply of tarballs to the coast of Santa Barbara County and California. 


\section{Appendix 4-1}

\section{Graphs of tar mass and number as influenced by season and tidal cycle.}

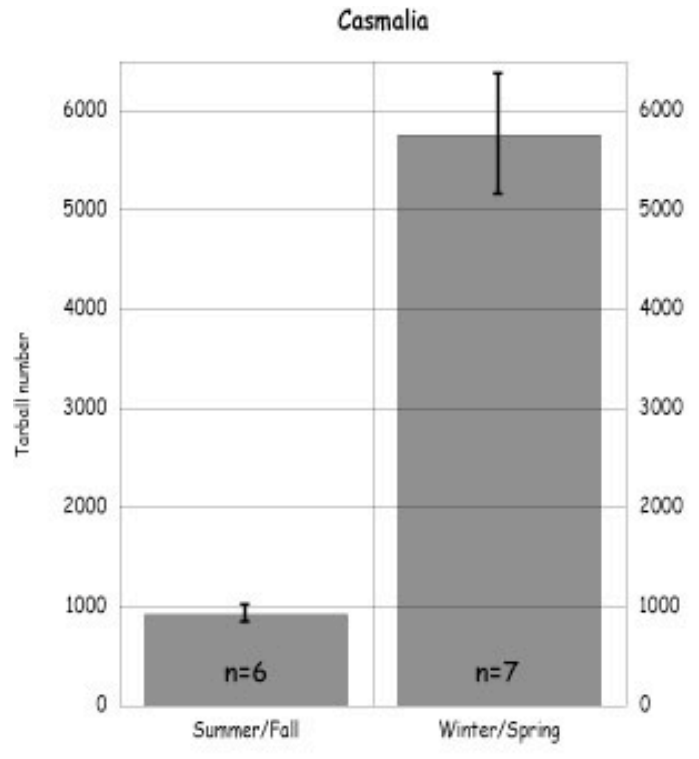

A. Seasonal influence on total tarball number. $\boldsymbol{n}$ in months. Bars are $95 \%$ confidence intervals.

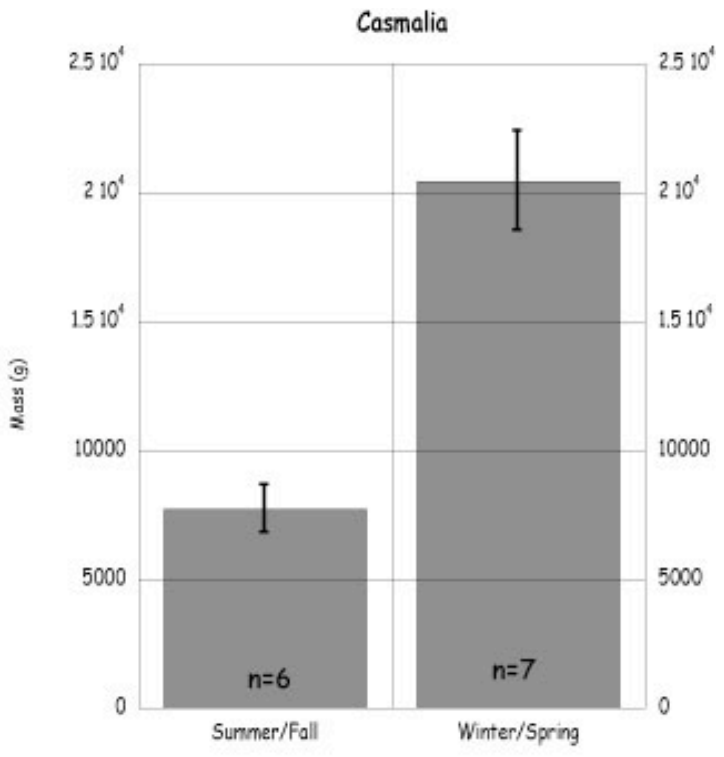

B. Seasonal influence on total tarball mass. $n$ in months. Bars are $95 \%$ confidence intervals.

Figure 1. Seasonal influence on tarball deposition, Casmalia Beach, California.

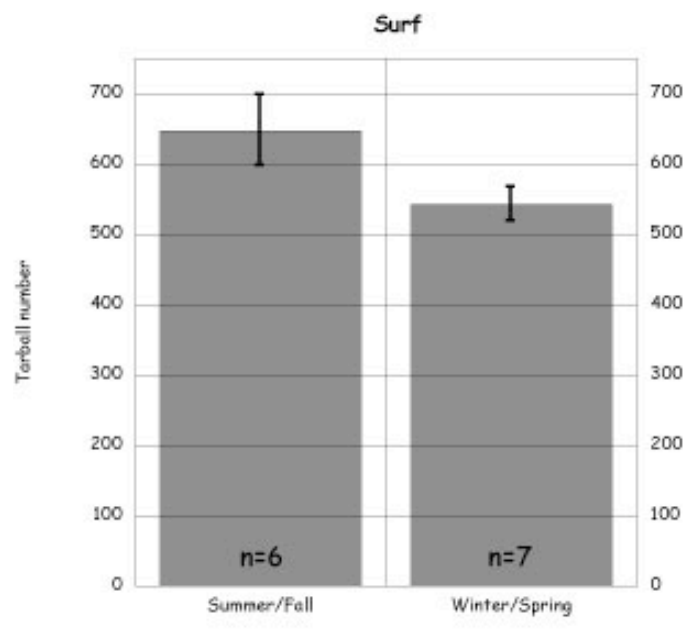

A. Seasonal influence on

total tarball number. $n$ in months.

Bars are $95 \%$ confidence intervals.

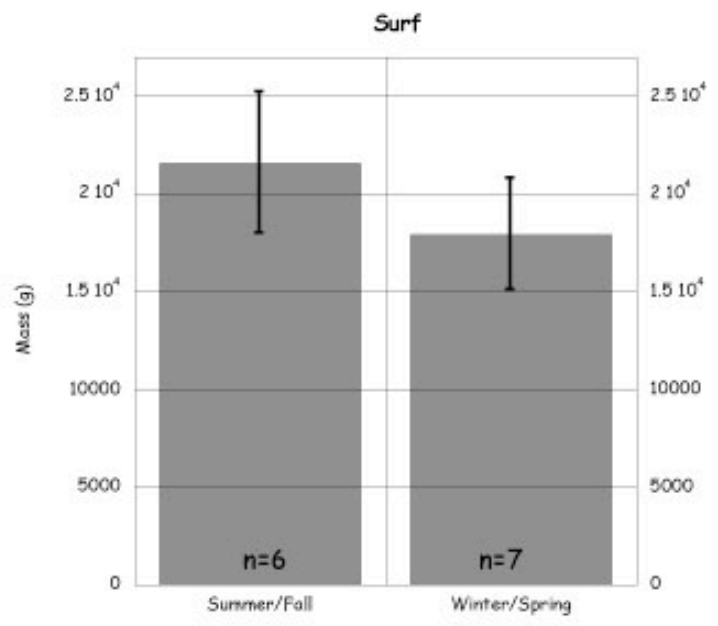

B. Seasonal influence on total tarball mass. $n$ in months. Bars are $95 \%$ confidence intervals.

Figure 2. Seasonal influence on tarball deposition, Surf Beach, California. 


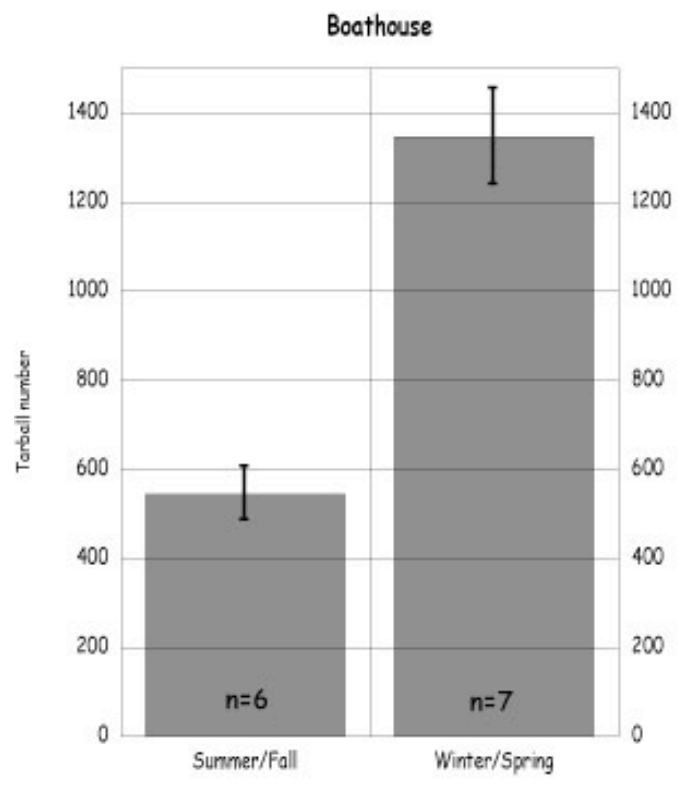

A. Seasonal influence on total tarball number. $\boldsymbol{n}$ in months. Bars are $95 \%$ confidence intervals.

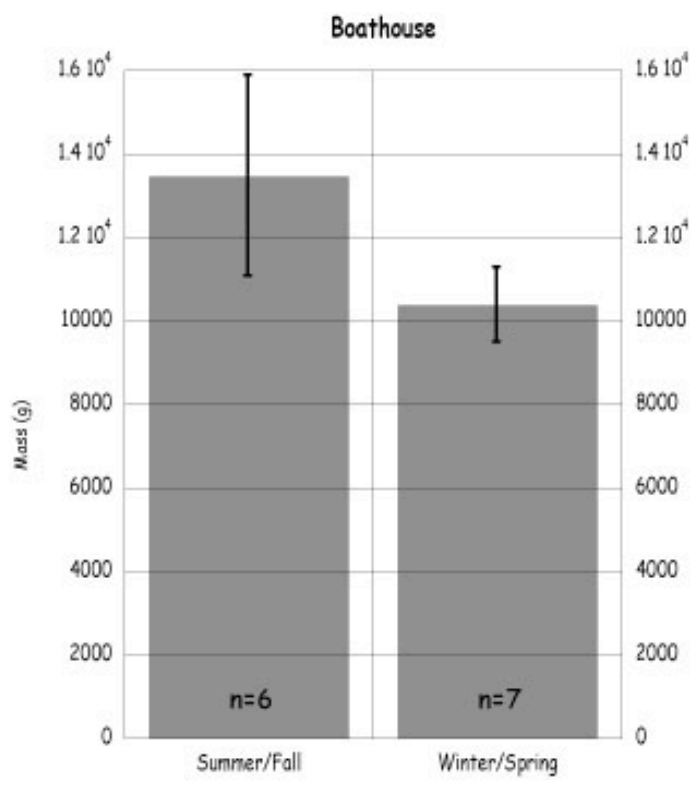

B. Seasonal influence on total tarball mass. $n$ in months. Bars are $95 \%$ confidence intervals.

Figure 3. Seasonal influence on tarball deposition, Boathouse Beach, California.

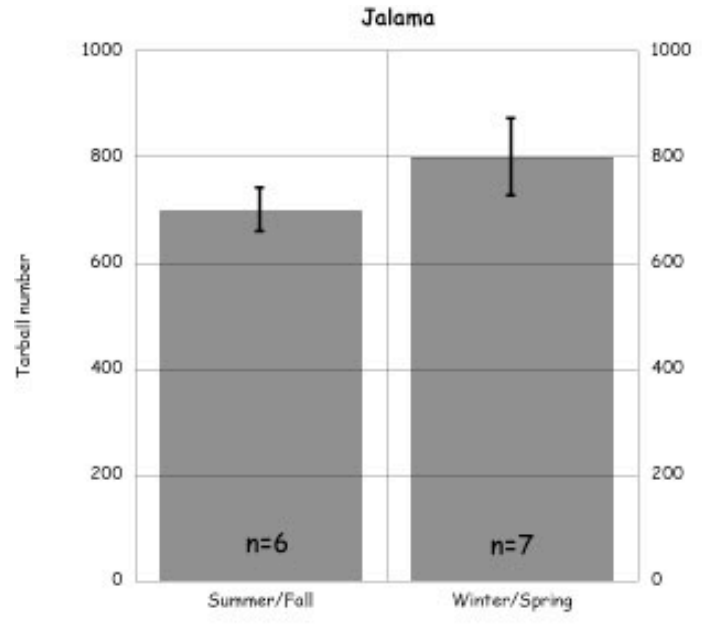

A. Seasonal influence on total tarball number. $\boldsymbol{n}$ in months. Bars are $95 \%$ confidence intervals.

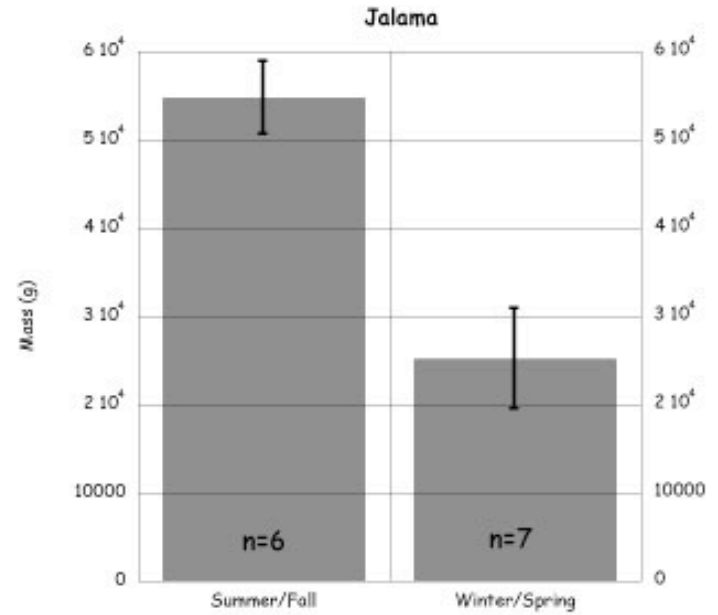

B. Seasonal influence on

total tarball mass. $n$ in months.

Bars are $95 \%$ confidence intervals.

Figure 4. Seasonal influence on tarball deposition, Jalama Beach, California. 


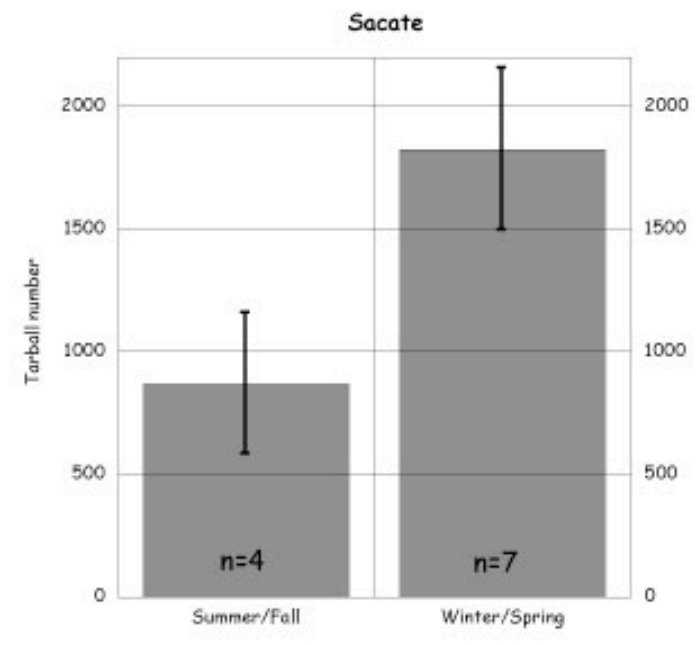

A. Seasonal influence on

total tarball number. $\mathrm{n}$ in months.

Bars are $95 \%$ confidence intervals.

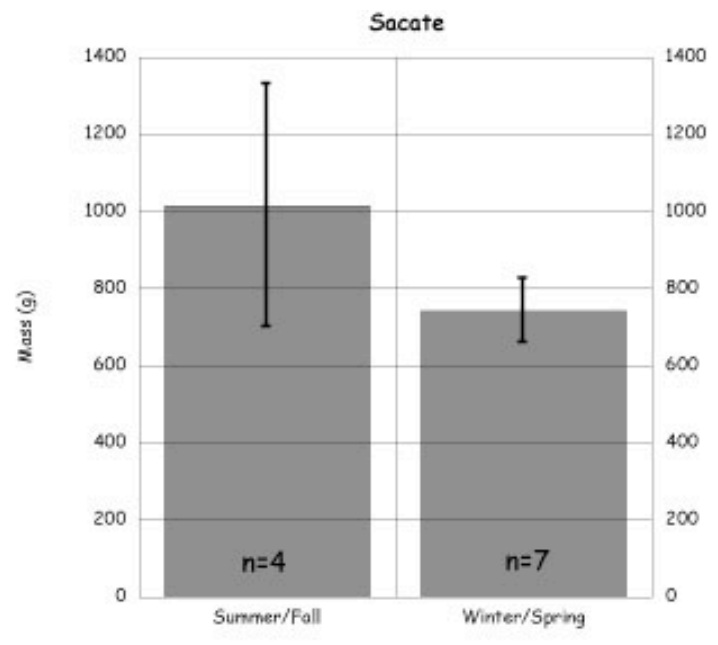

B. Seasonal influence on total tarball mass. $\boldsymbol{n}$ in months.

Bars are $95 \%$ confidence intervals.

Figure 5. Seasonal influence on tarball deposition, Secate Beach, California.

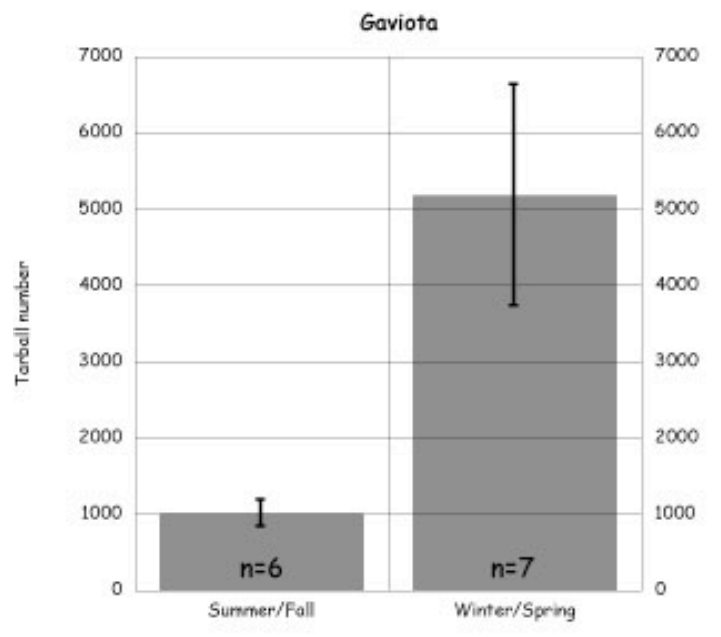

A. Seasonal influence on

total tarball number. $n$ in months.

Bars are $95 \%$ confidence intervals.

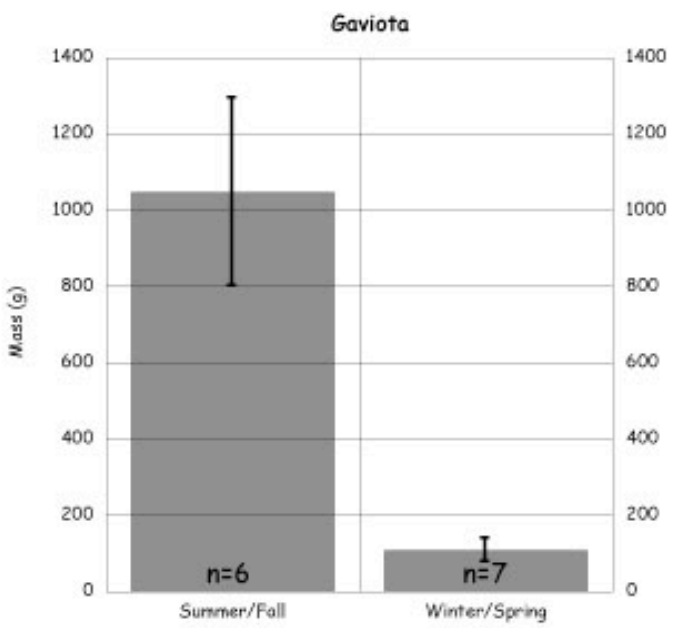

B. Seasonal influence on total tarball mass. $n$ in months. Bars are $95 \%$ confidence intervals.

Figure 6. Seasonal influence on tarball deposition, Gaviota Beach, California. 


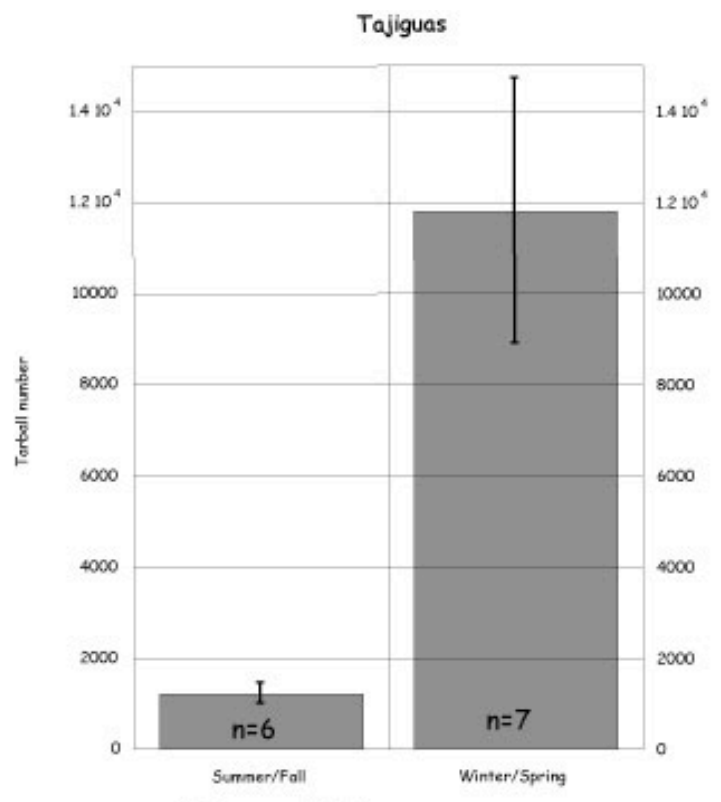

A. Seasonal influence on

total tarball number. $\mathrm{n}$ in months.

Bars are $95 \%$ confidence intervals.

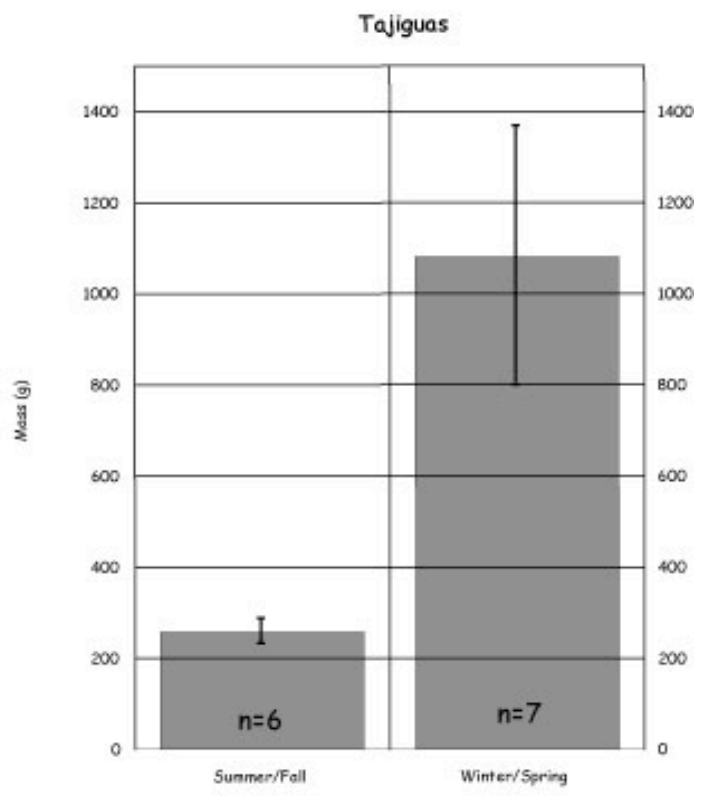

B. Seasonal influence on total tarball mass. $n$ in months. Bars are $95 \%$ confidence intervals.

Figure 7. Seasonal influence on tarball deposition, Tajiguas Beach, California.
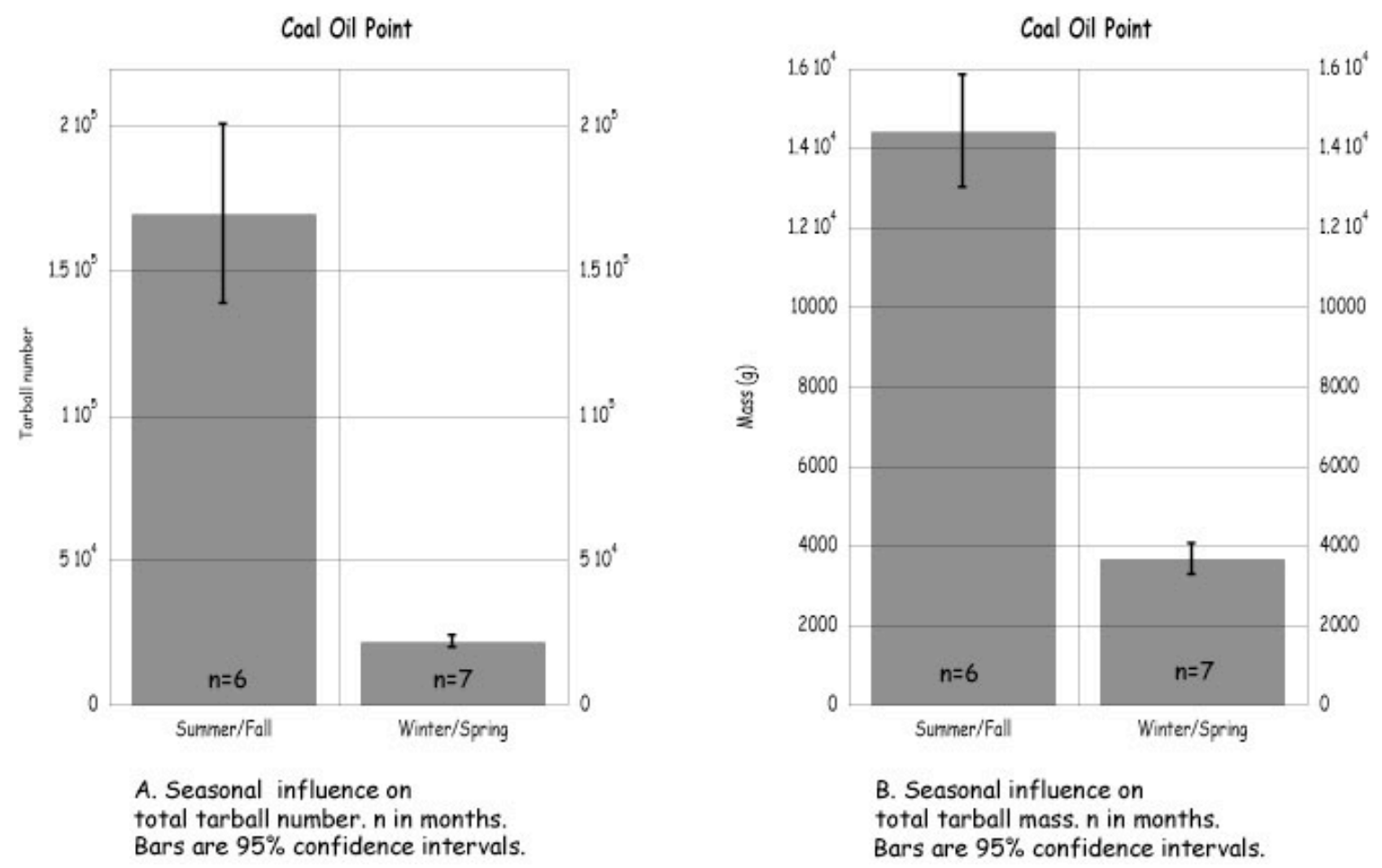

Figure 6. Seasonal influence on tarball deposition, Coal Oil Point Beach, California. 


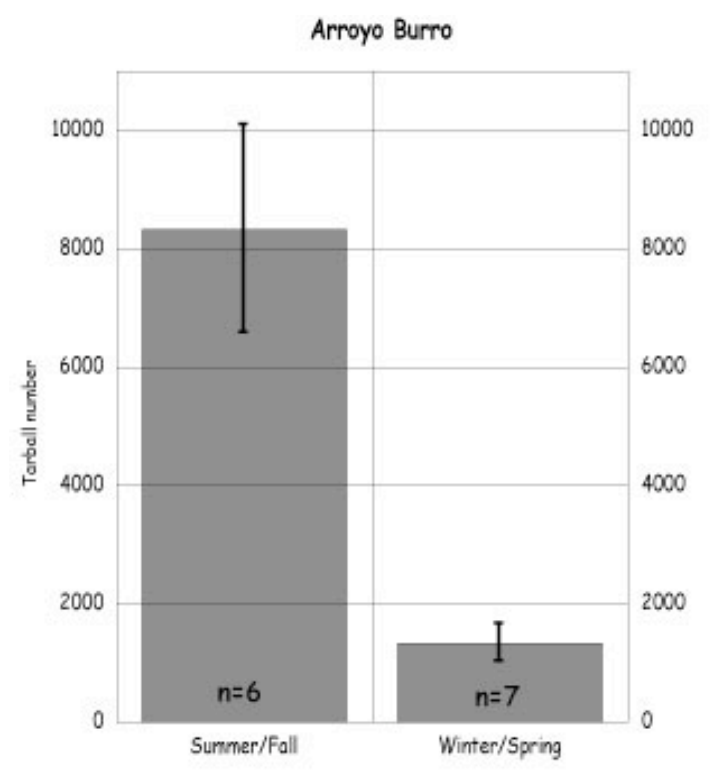

A. Seasonal influence on

total tarball number. $n$ in months.

Bars are $95 \%$ confidence intervals.

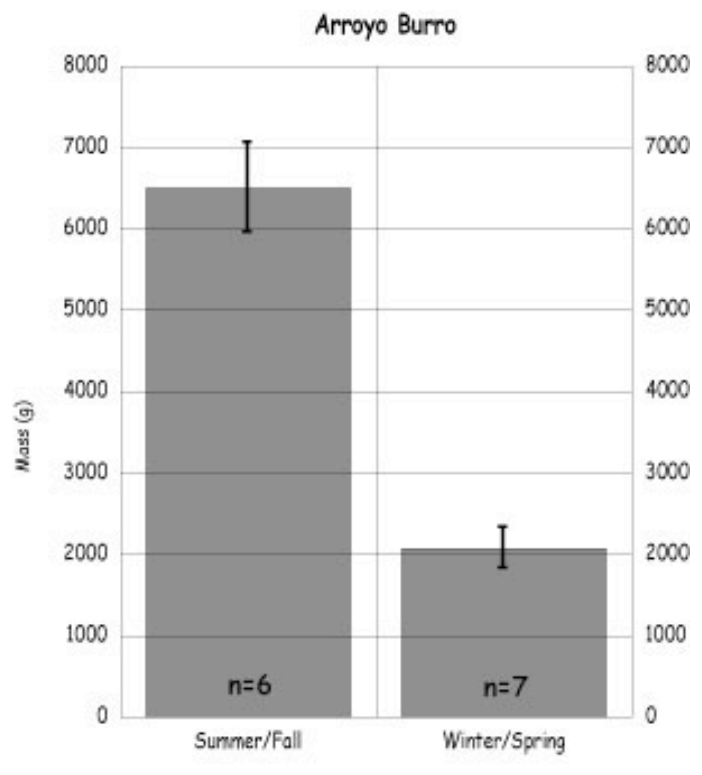

B. Seasonal influence on total tarball mass. $n$ in months. Bars are $95 \%$ confidence intervals.

Figure 9. Seasonal influence on tarball deposition, Arroyo Burro Beach, California.

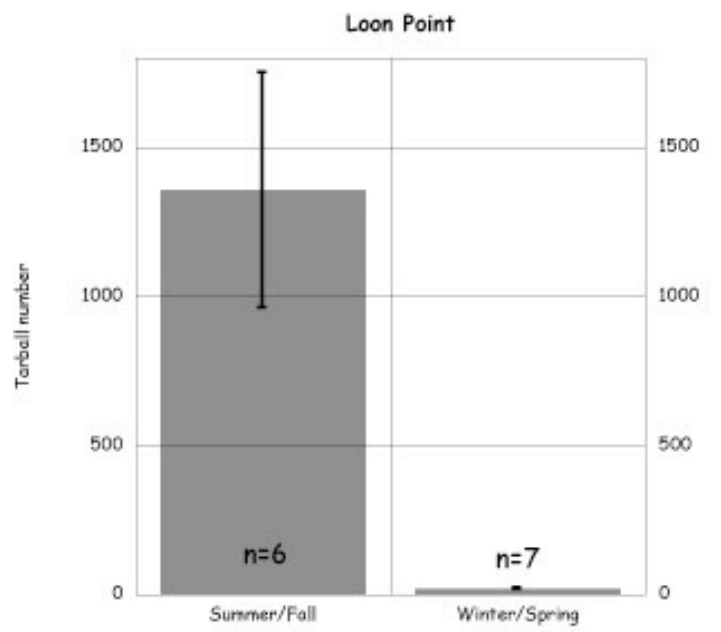

A. Seasonal influence on total tarball number. $\boldsymbol{n}$ in months. Bars are $95 \%$ confidence intervals.

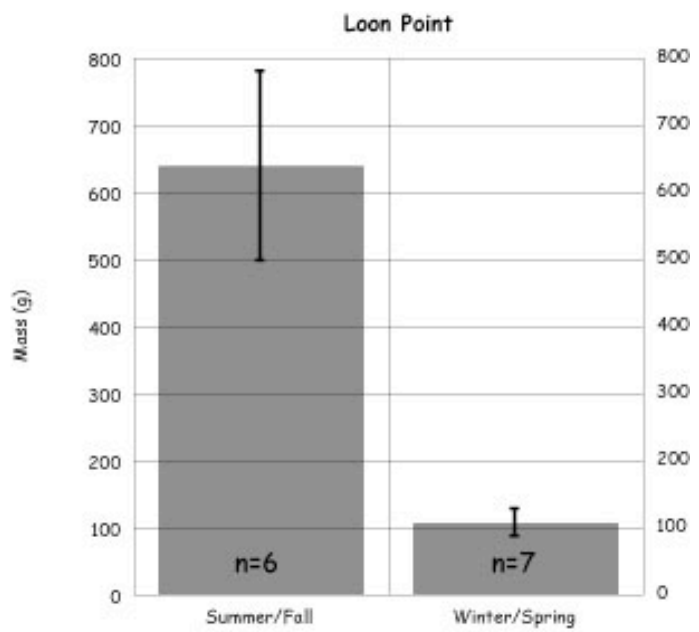

B. Seasonal influence on total tarball mass. $n$ in months. Bars are $95 \%$ confidence intervals.

Figure 10. Seasonal influence on tarball deposition, Loon Point Beach, California. 


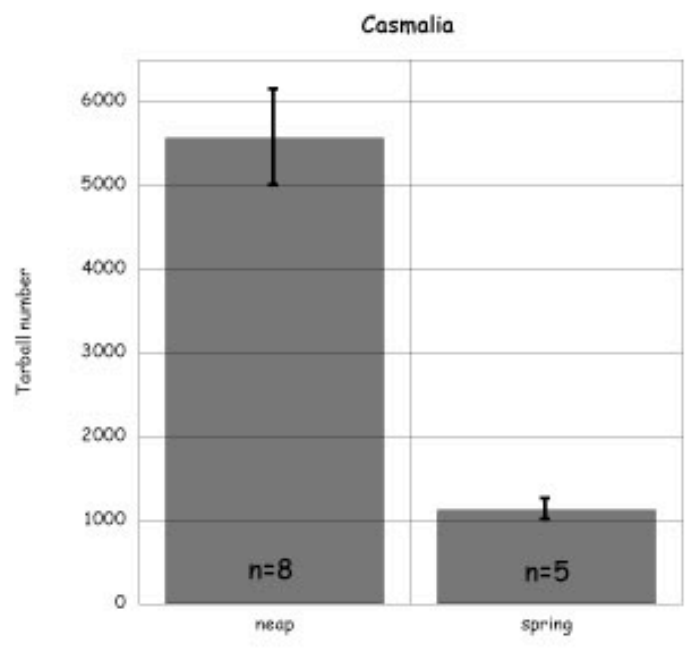

tide condition

A. Spring/Neap tide influence on total tarball number. $\mathrm{n}$ in months. Bars are $95 \%$ confidence intervals.

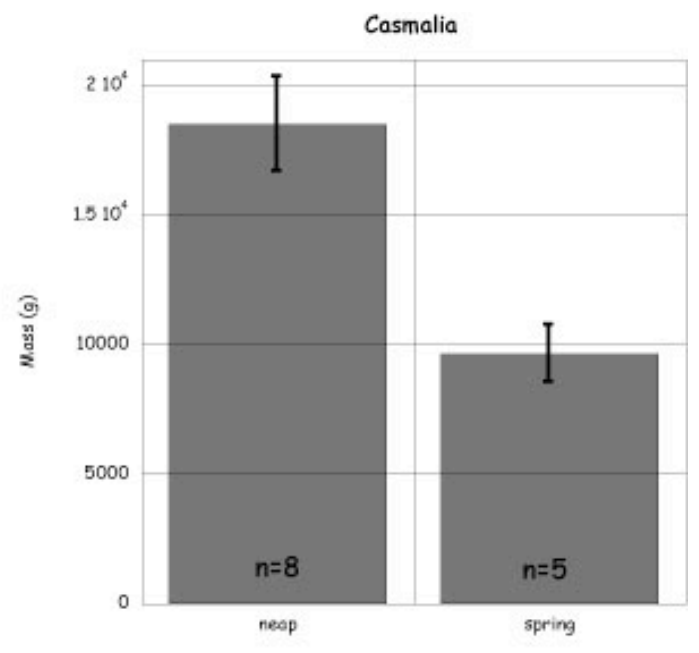

tide condition

B. Spring/Neap tide influence on total tarball mass. $n$ in months. Bars are $95 \%$ confidence intervals.

Figure 11. Spring and neap tidal influence on tarball deposition, Casmalia Beach, California.

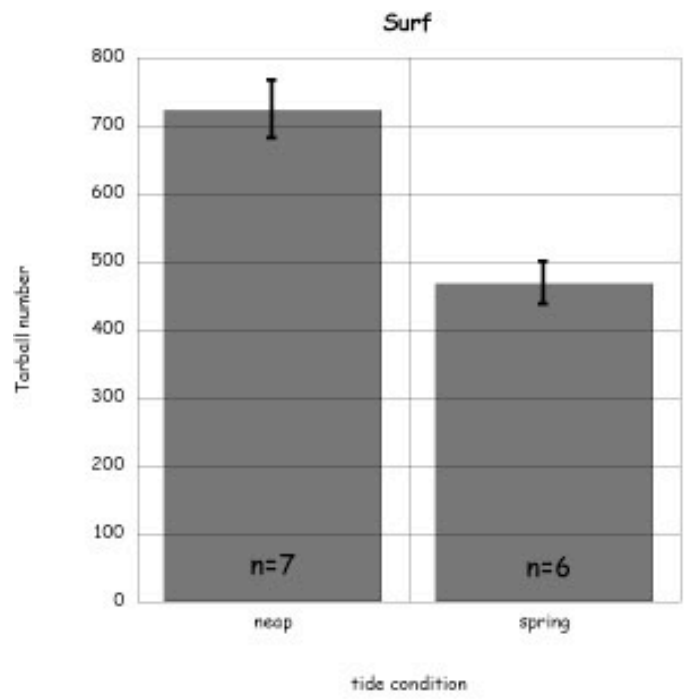

A. Spring/Neap tide influence on total tarball number. $n$ in months. Bars are $95 \%$ confidence intervals.

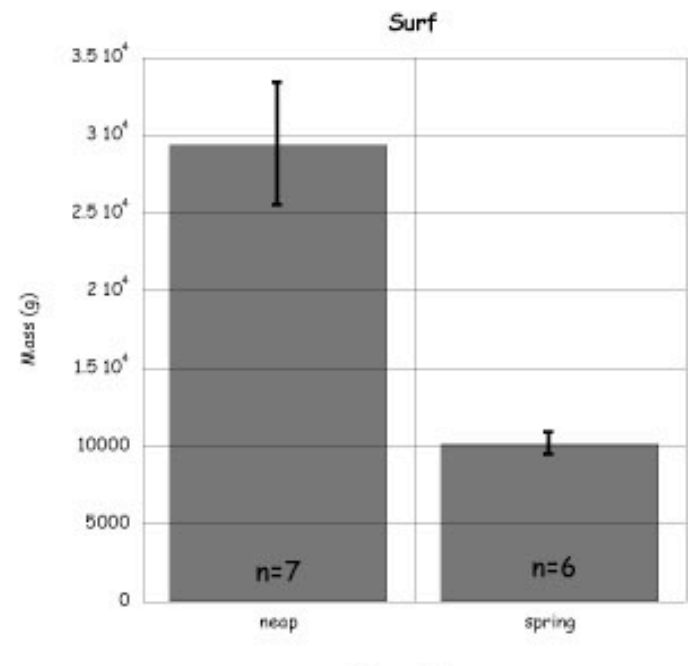

tide condition

B. Spring/Neap tide influence on total tarball mass. $n$ in months. Bars are $95 \%$ confidence intervals.

Figure 12. Spring and neap tidal influence on tarball deposition, Surf Beach, California. 


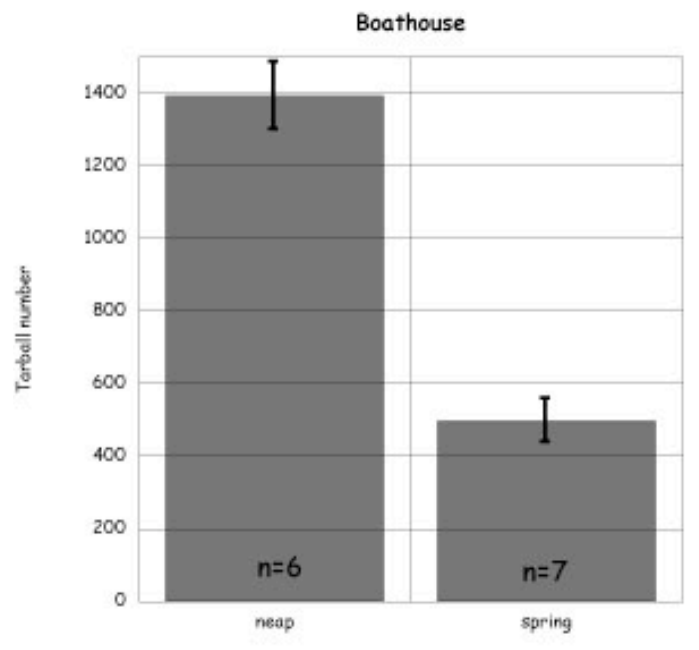

tide condition

A. Spring/Neap tide influence on total tarball number. $\boldsymbol{n}$ in months. Bars are $95 \%$ confidence intervals.

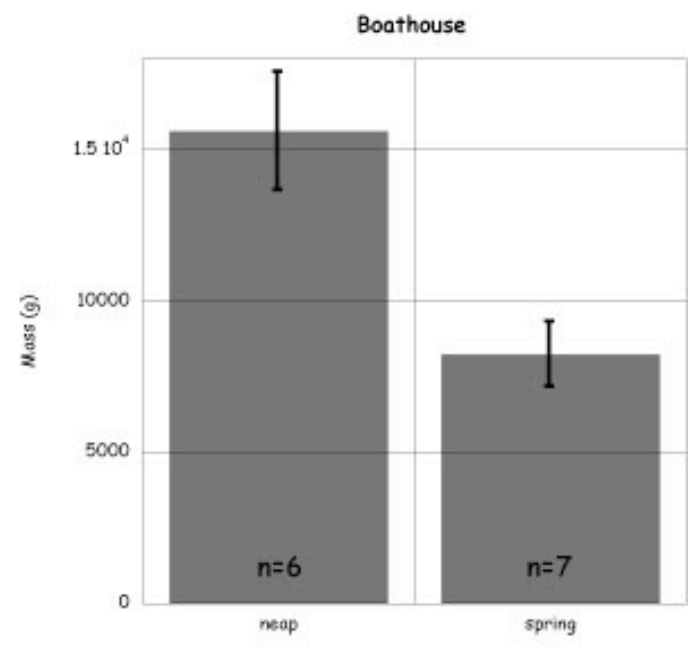

tide condition

B. Spring/Neap tide influence on total tarball mass. $n$ in months. Bars are $95 \%$ confidence intervals.

Figure 13. Spring and neap tidal influence on tarball deposition, Boathouse Beach, California.

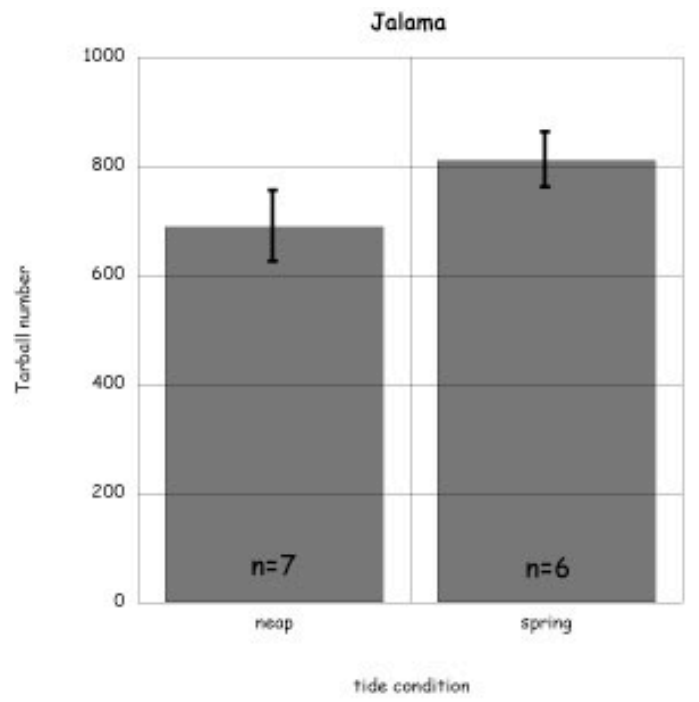

A. Spring/Neap tide influence on total tarball number. $\mathrm{n}$ in months. Bars are $95 \%$ confidence intervals.

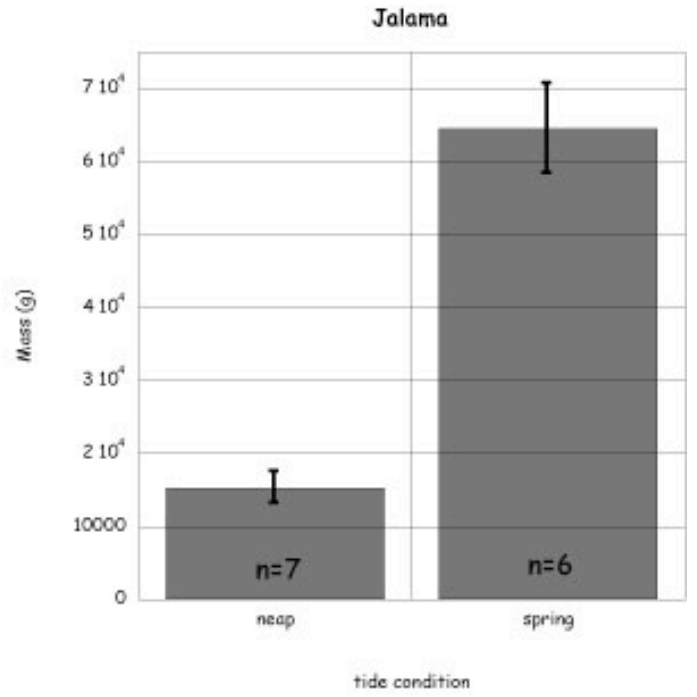

B. Spring/Neap tide nfluence on total tarball mass. $n$ in months. Bars are $95 \%$ confidence intervals.

Figure 14. Spring and neap tidal influence on tarball deposition, Jalama Beach, California. 


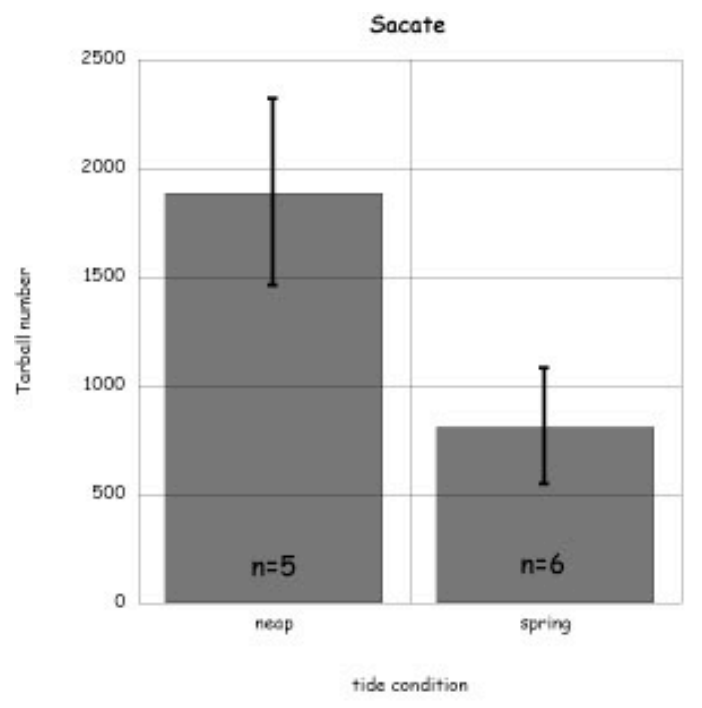

A. Spring/Neap tide influence on total tarball number. $\mathrm{n}$ in months. Bars are $95 \%$ confidence intervals.

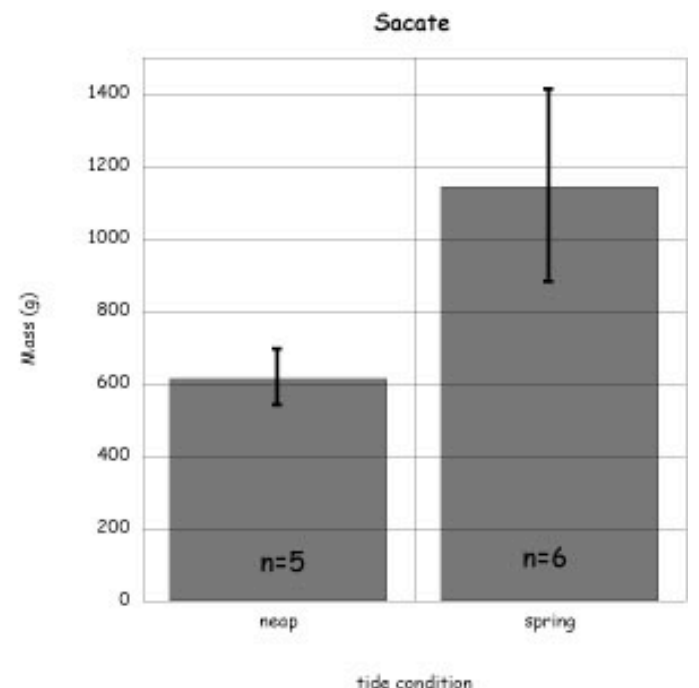

B. Spring/Neap tide influence on total tarball mass. $n$ in months. Bars are $95 \%$ confidence intervals.

Figure 15. Spring and neap tidal influence on tarball deposition, Secate Beach, California.

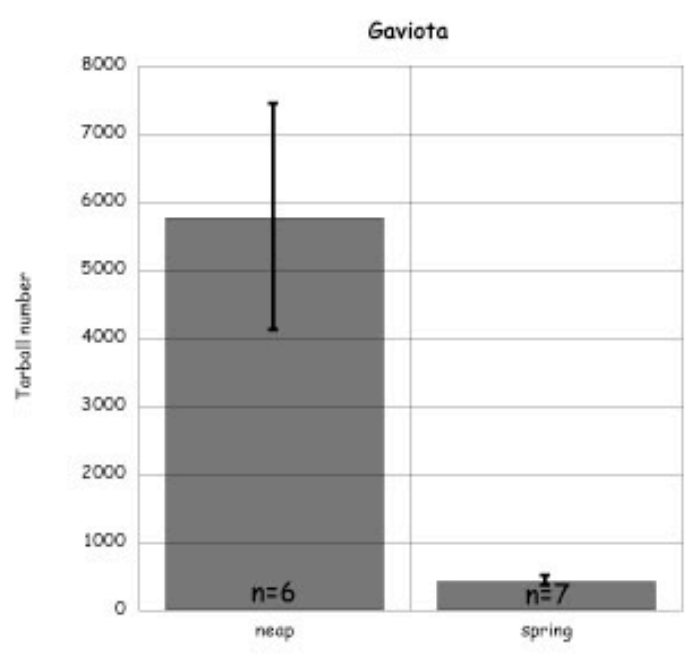

tide condition

A. Spring/Neap tideinfluence on total tarball number. $\mathrm{n}$ in months. Bars are $95 \%$ confidence intervals.

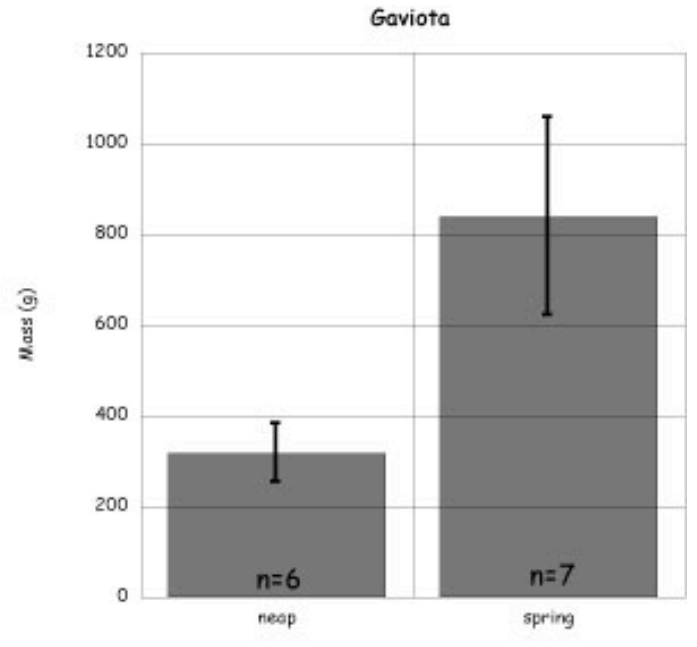

tide condition

B. Spring/Neap tide influence on total tarball mass. $n$ in months. Bars are $95 \%$ confidence intervals.

Figure 16. Spring and neap tidal influence on tarball deposition, Gaviota Beach, California. 


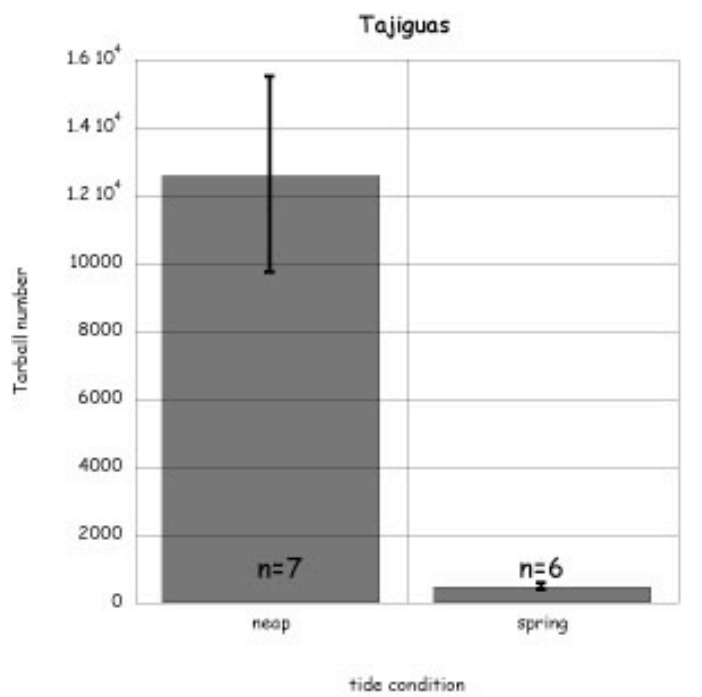

A. Spring/Neap tide influence on total tarball number. $\mathrm{n}$ in months. Bars are $95 \%$ confidence intervals.

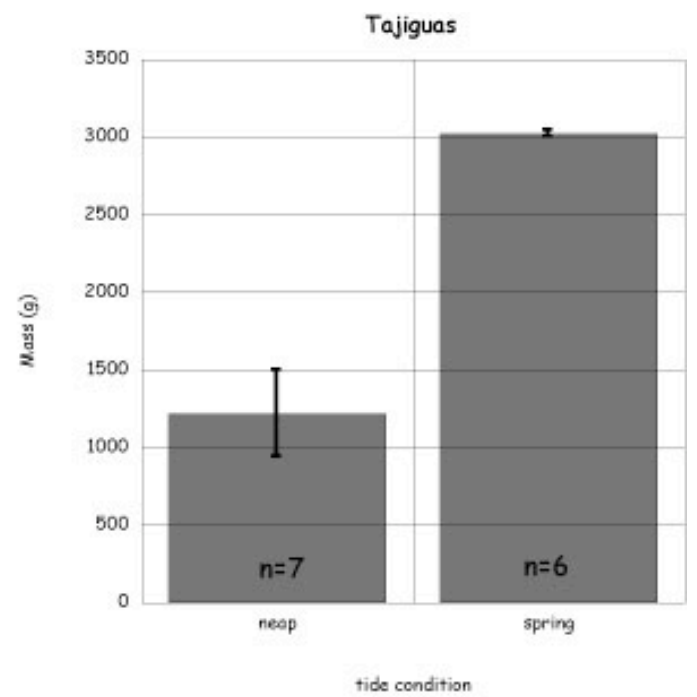

B. Spring/Neap tide influence on total tarball mass. $n$ in months. Bars are $95 \%$ confidence intervals.

Figure 17. Spring and neap tidal influence on tarball deposition, Tajiguas Beach, California.

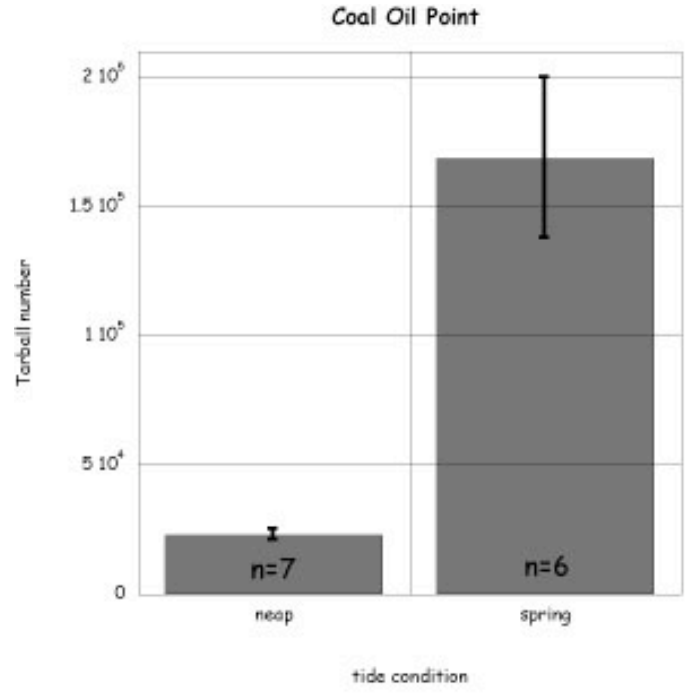

A. Spring/Neap tide influence on total tarball number. $n$ in months. Bars are $95 \%$ confidence intervals.

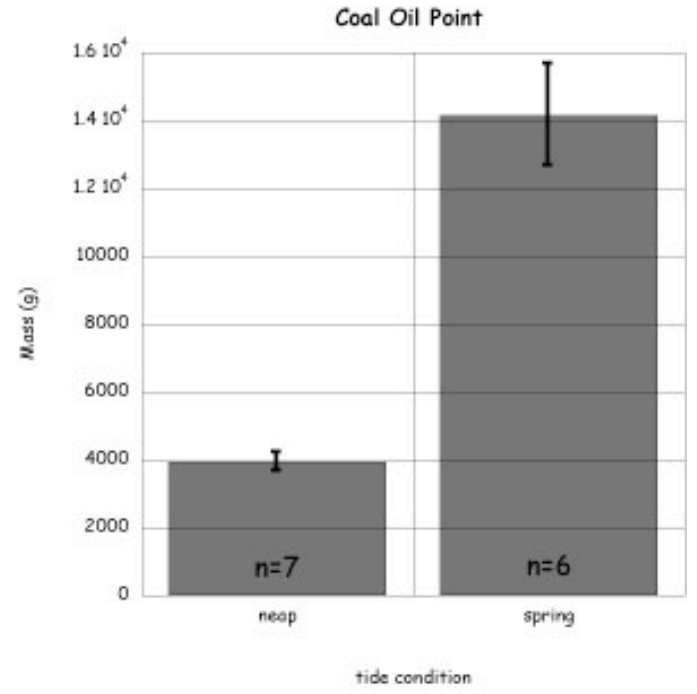

B. Spring/Neap tide influence on total tarball mass. $n$ in months. Bars are $95 \%$ confidence intervals.

Figure 18. Spring and neap tidal influence on tarball deposition, Coal Oil Point Beach, California. 


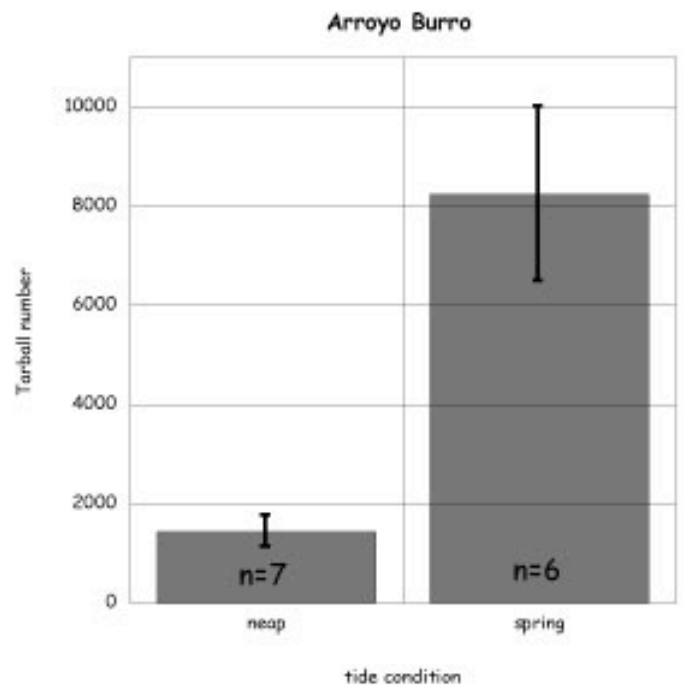

A. Spring/Neap tide influence on total tarball number. $\boldsymbol{n}$ in months. Bars are $95 \%$ confidence intervals.

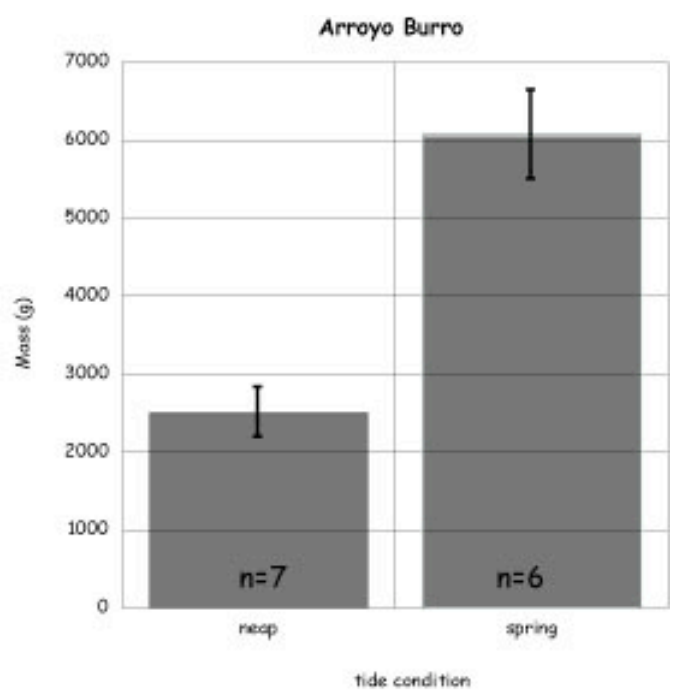

B. Spring/Neap tide influence on total tarball mass. $n$ in months. Bars are $95 \%$ confidence intervals.

Figure 19. Spring and neap tidal influence on tarball deposition, Arroyo Burro Beach, California.

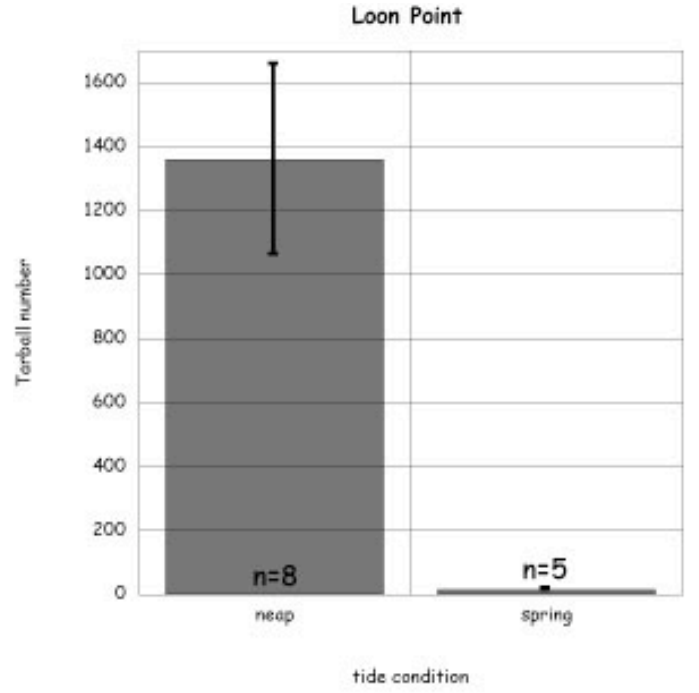

A. Spring/Neap tide influence on total tarball number. $\mathrm{n}$ in months. Bars are $95 \%$ confidence intervals.

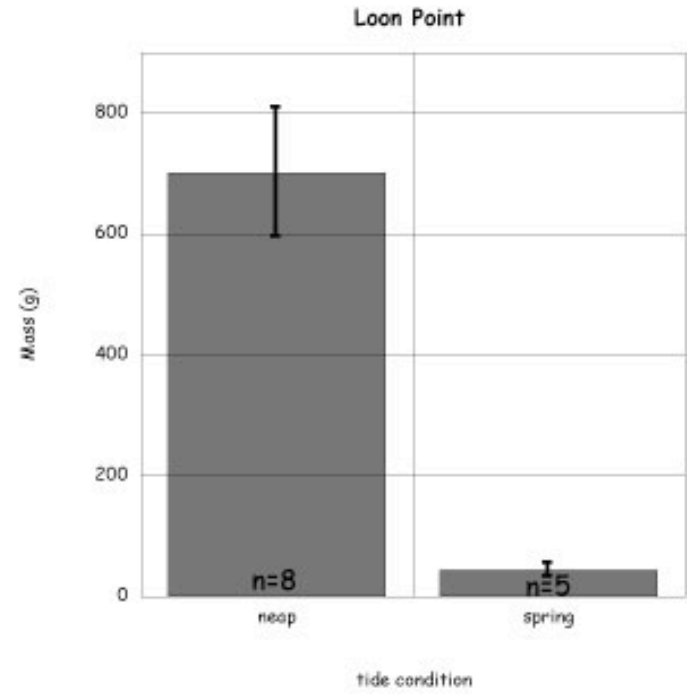

B. Spring/Neap tide influence on total tarball mass. $n$ in months. Bars are $95 \%$ confidence intervals.

Figure 20. Spring and neap tidal influence on tarball deposition, Loon Point Beach, California. 


\section{Conclusions}

Tar and oil derived from natural sources commonly occur in the waters of southern California. Active oil extraction and shipping occurs concurrently within the region. It is important that resource managers are able to distinguish between natural seepage and anthropogenic oil spillage.

The major goal of this study was to establish the geologic setting, sources, and ultimate dispersal of natural oil seeps in the offshore southern Santa Maria and Santa Barbara Basins. Our surveys focused on likely areas of hydrocarbon seepage that are known to occur between Pt. Arguello and Ventura, California.

We were successful in 1) documenting the locations and geochemically fingerprinting natural seep oils or tar; 2) geochemically fingerprinting coastal tar residues and potential tar sources in this region, both onshore and offshore; 3) establishing chemical correlations between offshore active seeps and coastal residues thus linking seep sources to oil residues; and 4) interpreting the petroleum system history for the natural seeps.

Early on in the study we measured the concentration of methane gas and found numerous gas plumes and measured high concentrations of methane in the water column as a proxy to locate seeps. The result of this work showed that the seeps were widely distributed between Pt. Conception east to the vicinity of Coal Oil Point, and that they occur with in the 3-mile limit of California State waters. The results of the methane survey guided the exploration of the area west of Point Conception east to Gaviota. Subsequent cruises used sidescan and high-resolution seismic surveys to map the sea floor from just south of Pt. Arguello, east to near Gaviota, California.

A total of 93 seep oils or tars along with 37 unlocated seep oil samples were sampled and analyzed. Sixty crude oil samples were analyzed from all over California, with a bias in number toward southern California. For this study 493 tarballs or oil residues were sampled and analyzed, again with a bias in number to southern California, and specifically the coastline of Santa Barbara County.

Biomarker and stable carbon isotope ratios were used to infer the age, lithology, organic matter input, and depositional environment of the source rocks for 388 samples of produced crude oil, seep oil, and tarballs mainly from coastal California. These samples were used to construct a chemometric fingerprint (multivariate statistics) decision tree to classify 288 additional samples, including tarballs of unknown origin collected from Monterey and San Mateo County beaches after a storm in early 2007. A subset of 9 of 23 active offshore platform oils and one inactive platform oil representing a few oil reservoirs from the western Santa Barbara Channel were used in this analysis. Thus this model is not comprehensive, and the findings are not yet conclusive.

The results identify three tribes of ${ }^{13} \mathrm{C}$-rich oil samples inferred to originate from thermally mature equivalents of the clayey-siliceous, carbonaceous marl, and lower calcareous-siliceous members of the Monterey Formation. Tribe 1 contains four oil families having geochemical traits of clay-rich marine shale source rock deposited under suboxic conditions with substantial higher-plant input. Tribe 2 contains four oil families with intermediate traits, except for abundant 28,30-bisnorhopane, indicating suboxic to anoxic marine marl source rock with hemipelagic input. Tribe 3 contains five oil families with traits of distal marine carbonate source rock deposited under anoxic conditions with 
pelagic, but little or no higher-plant input. Tribes 1 and 2 occur mainly south of Point Conception in paleogeographic settings where deep burial of the Monterey Formation source rock favored generation from all three members or their equivalents. In this area, oil from the clayey-siliceous and carbonaceous marl members (Tribes 1 and 2) may overwhelm that from the lower calcareous-siliceous member (Tribe 3) because the latter is thinner and less oil-prone than the overlying members. Tribe 3 occurs mainly north of Point Conception, where shallow burial caused preferential generation from the underlying lower calcareous-siliceous member or another unit with similar characteristics.

The tribes were further divided into a total of 13 different families, the largest group was Family 22 (316 samples) followed by nonclassified samples (73). The remaining family and sample number are as follows; 211 (51); 33 (40); 14, (37); 212 (29); 34 (27); 35 (21); 11, 12, and 13 (19 each); 213 (15); 32 (11); and 31 (7).

We attempted to clearly distinguish the naturally occurring seep oils from the anthropogenically derived platform oils. Within the 388-sample training set of oils and tars, the biomarker parameters are sometimes sufficient to allow unique discrimination of individual platform oils. However, produced platform oil samples and seep samples with sources geographically close to each other are too similar to each other, with respect to the biomarker parameters, to definitively differentiate them on that basis alone. In some cases other parameters can be helpful. These other parameters are related to the degree of biogeochemical degradation or weathering that the oils or tars have experienced. These components include the typical oil distribution of $n$-alkane hydrocarbons and isoprenoids pristane and phytane. All of the platform oils in our sample set contain these components.

Conversly, the seep oils have been exposed to significant biodegradation while in the near subsurface. The majority, but not all, of seep tars in our sample set have been biodegraded to, or beyond, the point of loss of $n$-alkanes and isoprenoids. Seep oils found in the vicinity of Coal Oil Point or Arroyo Burro are the least weathered and a combination of chemometric fingerprinting and the presence or absence of $n$-alkanes and isoprenoids help to differentiate these two classes (anthropogenic production oils as opposed to natural seeps) of oils and tars.

The differentiation between anthropogenic production oils and natural seeps is not always definitive because of the close chemical similarity of some samples and the variability in the biodegradation progression. This is the case near Coal Oil Point and Platform A (Dos Cuadros Field) where seep oils and Platform Holly and Platform A oils are genentically very similar and cannot be definitively distinguished after a period of a few days of weathering. In contrast, oils from the Point Conception platforms can be distinguished on the basis of chemometric fingerprinting alone. In the middle of this spectrum are oils from Platforms Harmony, Heritage, and Hondo, where it is expected that oil weathering would take on the order of 2 weeks to a month to produce tarballs similar to those seen near Point Conception. In this case there is a much greater degree of weathering needed to proceed from oil to the biodegraded tar characteristic of Family 22 commonly occurring on the coastline nearby the platforms.

Tar deposition on beaches was monitored during 2001-2003. We found tar deposition varies on a seasonal basis. In general, tarballs accumulate at a faster rate, or remain longer on all beaches during the summer and fall months. We speculate that factors such as prevailing winds and currents combined with more quiescent wave 
conditions favor the accumulation and preservation of tarballs on the beaches during the summer and fall months. In contrast, winter storms, having much greater wave energy, remove beach sand and other materials. Longer periods of monitoring are needed to address the variability in the data and to provide a more robust statistical analysis.

\section{Acknowledgments}

This study was funded in part by the U. S. Department of the Interior, Minerals Management Service (MMS), through an Interagency Agreement No. 18985 with the U.S. Geological Survey, Western Coastal and Marine Geology Team, as part of the MMS Environmental Studies Program. Mary Elaine Helix helped to initiate this study with Keith Kvenvolden (USGS, emeritus), and served deftly as the MMS Contract Officer Representative. The County Santa Barbara, Energy Division, partially supported this program during the years of 2002-2004 and was administered by John Day.

The National Park Service supplied people and resources during the collection of tar balls from the Channel Islands. We especially thank Dan Richards and Dave Kushner who exemplified the helpfulness of the all Park Service personnel who assisted us. During a stay on Santa Cruz Island, we benefited from the assistance and housing provided by the University of California and graciously administered by Lyndal Laughrin. Numerous days at sea searching for seeps and gas plumes were provided by Captain John Patterson on his boat Salsipuedes. David Slater, pilot of the Delta submersible helped in the collection of some deep submarine seeps offshore Coal Oil Point.

Personnel at the California Department of Fish and Game, Office of Spill Prevention and Response (Bill Castle, Susan Sugarman, Marida Martin) provided valuable collaboration with us in sharing, collecting, and analyzing selected tar residues.

We thank Larry Beyer (USGS, retired) and Margaret Keller (USGS) who provided assistance in locating samples from the Point Conception COST well OCS-Cal 78-164 No. 1. L. Scott Ramos (Infometrix, Inc.) provided assistance with Pirouette ${ }^{\circledR}$ and InStep ${ }^{\mathrm{TM}}$ and discussion of chemometrics applications. We thank Zenon Valin (USGS) and Grace Fong (consultant) for GIS and graphics support. Fugro-NPA satellite mapping services provided image analysis of SAR data.

Many people associated with UCSB added in many ways to this project and we thank them for their contributions: Bruce Luyendyk, Ira Leifer, Tonya Del Sontro, Sara Benjamin, Kris Broderick, Katie Hickling, Jamie Jones, Christy Till, and Karen Vasko. This project also benefited from the advice of members of the quality review board for this project: Cort Cooper (Chevron), John Day (Co. of Santa Barbara, Energy Division), Mark Kamerling (Veneco), and Bruce Luyendyk (UCSB). Initial work on methane in water was conducted in cooperation with Bill Ussler III and Charlie Paul (Monterey Bay Aquarium Research Institute). 


\section{References}

Allen, A.A., Schleuter, R.S. and Mikolaj, P.G., 1970, Natural oil seepage at Coal Oil Point, Santa Barbara, California. Science, no.170, p. 974-977.

Bartlett, W.L., 1998. Elwood oil field; Santa Barbara County, California: Pacific Section AAPG Miscellaneous Publication, MP-46 Structure and Petroleum Geology of Santa Barbara Channel, California. p. 217-237.

Bascom, W., 1980, Waves and beaches; the dynamics of the ocean surface: Anchor Press, Garden City, New York, 366 p.

Baskin, D.K. and K.E. Peters, 1992, Early generation characteristics of a sulfur-rich Monterey kerogen: AAPG Bulletin, v. 76, p. 1-13.

Bassin, C.J., Washburn, L., Brzezinski, M. and McPhee-Shaw, E., 2005, Sub-mesoscale coastal eddies observed by high frequency radar; A new mechanism for delivering nutrients to kelp forests in the Southern California Bight: Geophysical Research Letters, v. 32, n. 12 p. L12604.1 - L12604.4.

Bence, A.E., Kvenvolden, K.A., Kennicutt II, M.C., 1996, Organic geochemistry applied to environmental assessments of Prince William Sound, Alaska, after the Exxon Valdez oil spill; A review: Organic Geochemistry v. 24, p. 7-42.

Blake, G.H., 1981, Biostratigraphic relationship of Neogene benthic foraminifera from the southern California outer continental borderland to the Monterey Formation, in R.E. Garrison and R.G. Douglas, eds., The Monterey Formation and related siliceous rocks of California, Los Angeles, Pacific Section: SEPM Book 15, p. 1-13.

Boles, J.R., Clark, J.F., Leifer, I. and Washburn, L., 2001, Temporal variation in natural methane seep rate due to tides, Coal Oil point area, California: Journal Geophysical Research-Oceans, v. 106(C11), p. 27,077-27,086.

Brincat, D., and Abbott, G.D., 2001, Some aspects of the molecular biogeochemistry of laminated and massive rocks from the Naples Beach section (Santa Barbara-Ventura basin), in C.M. Isaacs and J. Rullkötter, eds., The Monterey Formation; from rocks to molecules: New York, Columbia University Press, p. 140-149.

California Offshore Gas, Oil, and Tar Seeps Prepared by the Staff of the State Lands Commission, D.J. Everitts, C.F. Eaton, R.G. Paul, E.E. Welday, California State Lands Commission Staff Report, 1977, 449 p.

Chung, H.M., Rooney, M.A., Toon, M.B., and Claypool, G.E., 1992, Carbon isotope composition of marine crude oils: AAPG Bulletin, v. 76, p. 1000-1007.

Clark JF, Washburn, L., Hornafius, J.S., Luyendyk B.P., 2000, Dissolved hydrocarbon flux from natural marine seeps to the Southern California Bight: Journal of Geophysical Research, v. 105, p. 11,509-11,522.

Clark, J.F., Leifer, I., Washburn, L., and Luyendyk, B.P., 2003. Compositional changes in natural gas bubble plumes; Observations from the Coal Oil Point marine hydrocarbon seep field: Geo-Marine Letters, v. 23 p. 187-193. doi:10.1007/s00367-003-0137-y.

Clester, S.M., Hornafius, J.S., Scepan, J., and Estes, J.E., 1996, Remote sensing study of historical changes in natural oil slick volumes in the Santa Barbara Channel: Final Report 1995/1996, California Energy Study Project, University of California Energy Institute, Berkeley, California.

Coles, S.L., and Al-Riyami, K.A., 1996, Beach tar concentrations on the Muscat coastline, Gulf of Oman, Indian Ocean 1993-1995: Marine Pollution Bulletin v. 32, no. 8-9, p. 609-614. 
Crain, W.E., Mero, W.E., and Patterson, D., 1987, Geology of the Point Arguello Field, in Ingersoll R.V., and Ernst, W.G., eds., Cenozoic basin development of coastal California: Englewood Cliffs, Prentice-Hall, p. 537-545.

Crouch, J. K. and Suppe, J., 1993, Late Cenozoic tectonic evolution of the Los Angeles basin and inner California borderland: A model for core complex-like crustal extension: Geological Society of America Bulletin, v. 105, p. 1415-1434.

Curiale, J. A., Cameron, D., and Davis, D.V., 1985, Biological marker distribution and significance in oils and rocks of the Monterey Formation, California: Geochimica et Cosmochimica Acta, v. 49, p. 271-288.

De Beukelaer, S.M., MacDonald, I.R., Guinnasso, N.L., and Murray, J.A., 2003, Distinct side-scan sonar, RADARSAT, SAR, and acoustic profiler signatures of gas and oil seeps on the Gulf of Mexico slope: Geo-Marine Letters, v. 23, no. 3-4, p. 177-186.

Del Sontro, T.S., Leifer, I., Luyendyk, B.P., and Broitman, B.R., 2007, Beach tar accumulation, transport mechanisms, and sources of variability at Coal Oil Point, Califoria: Marine Pollution Bulletin, v. 54, p. 1461-1471.

Dickinson, W.R., 1996, Kinematics of transrotational tectonism in the California Transverse Ranges and its contribution to cumulative slip along the San Andreas transform fault system: Geological Society of America Special Paper 305, 46 p.

Dickinson, W.R., Ducea, M., Rosenberg, L.I., Greene, H.G., Graham, S.A., Clark, J.C., Weber, G.E., Kidder, S., Ernst, W.G., and Brabb, E.E., 2005, Net dextral slip, Neogene San Gregorio-Hosgri fault zone, coastal California: Geologic evidence and tectonic implications: Geological Society of America, Special Paper 391, 43 p.

DiGiacomo, P. M., and Holt, B., 2001, Satellite observations of small coastal ocean eddies in the Southern California Bight: Journal of Geophysical Research v. 106, (C10), p. 22521-22544.

Draut, A.E., Hart, P.E., Lorenson, T.D., Ryan, H.F., Wong, F.L., Sliter, R.W., and Conrad, J.E., 2009, Late Pleistocene to Holocene sedimentation and hydrocarbon seeps on the continental shelf of a steep, tectonically active margin, southern California, USA: Marine Geophysical Researches, doi:10.1007/s11001-009-9076-y.

Ensminger, A. van Dorsselaer, A., Spykerelle, C., Albrecht, P., and Ourisson, G., 1974, Pentacyclic triterpanes of the hopane type as ubiquitous geochemical markers; Origin and significance. in Tissot, B. and Brenner, F., eds., Advances in Organic Geochemistry 1973: Editions Technip, Paris, p. 245-260.

Espedal, H.A., and Johannessen, O.M., 2000, Detection of oil spills near offshore installations using synthetic aperture radar (SAR): International Journal of Remote Sensing, v. 21, no. 11, p. 2141-2144.

Espedal, H.A., and Wahl, T., 1999, Satellite SAR oil spill detection using wind history information: International Journal of Remote Sensing, v. 20, no. 1, p.49-65.

Espedal, H.A., Johannessen, O.M., Johannessen, J.A., Dano, E., Lyzenga, D.R., Knulst, J.C., 1998. COASTWATCH 95: ERS $1 / 2$ SAR detection of natural film on the ocean surface. Journal of Geophysical Research, v. 103, p. 24969-24982.

Fingas, M.F., Brown, C.E., 1997, Review of oil spill remote sensing: Spill Science and Technology Bulletin, v.4, no.4, p. 199-208. 
Fischer, P.J., Stevenson, A.J., 1973, in Fischer, P.J. eds., Natural hydrocarbon seeps, Santa Barbara basin, California, Santa Barbara Channel area revisited Field Trip Guidebook, v. 3: American Association of Petroleum Geology, Tulsa, Oklahoma, p. 17-28.

Fischer, P.J., 1976, Late Neogene-Quaternary tectonics and depositional environments of the Santa Barbara basin, California, in Fritsche, A. E., and others, eds. The Neogene Symposium: Society of Economic Paleontologists and Mineralogists, Pacific Section Annual Meeting, p. 33-51.

Fischer, P.J., 1977, Natural gas and oil seeps, Santa Barbara basin, California: in Everitts, D.J. Eaton, C.F., Paul, R.G., and Welday E.E., eds. California Offshore Gas, Oil and Tar Seeps: prepared by the staff of the State Lands Commission, California State Lands Commission Staff Report, p. 1-62.

Fischer, P.J., 1998, Structure and Tectonics of the Northwestern Santa Barbara Basin, California State University, Northridge and MESA Cubed, Inc., Structure and Petroleum Geology, Santa Barbara Channel, California, p. 79-96.

Gade, M., and Alpers, W., 1999, Using ERS-2 SAR images for routine observation of marine pollution in European coastal waters: Science Total Environment v. 238, p. 441-448.

Gade, M., Alpers, W., Huhnerfuss, H., Masuko, H., Kobayashi, T., 1998, Imaging of biogenic and anthropogenic ocean surface films by the multifrequency/multipolarization SIR-C/X- SAR: Journal of Geophysical Research, v. 103, (C9), p. 18851-18866.

Galloway, J., 1998, Chronology of petroleum exploration and development in the Santa Barbara Channel area, offshore southern California: Pacific Section AAPG Miscellaneous Publication MP-46, Structure and Petroleum Geology of Santa Barbara Channel, California, p. 1-12.

Garrison, R.E., Kastner, M., and Kolodny, Y., 1987, Phosphorites and phosphatic rocks in the Monterey Formation and related Miocene units, coastal California, in Ingersoll R.V., and Ernst, W.G., eds., Cenozoic basin development of coastal California: Englewood Cliffs, Prentice-Hall, p. 348-381.

Gorsline, D. S. and Emery, D.O., 1959, Turbidity current deposits in San Pedro and Santa Monica Basins off southern California: AAPG Bulletin v. 70, p. 279-290.

Grantham, P.J. and Wakefield, L.L., 1988, Variations in the sterane carbon number distributions of marine source rock derived crude oils through geological time: Organic Geochemistry, v. 12, p. 61-73.

Harms, S., and Winant, C.D., 1998, Characteristic patterns of the circulation in the Santa Barbara Channel. Journal of Geophysical Research, v. 103, (C2), p. 3041-3065.

Hartman, B.A., Hammond, D.E., 1981, The use of carbon and sulfur isotopes as correlation parameters for the source identification of beach tar in the southern California borderland: Geochimica et Cosmochimica Acta, v. 45, p. 309-319.

Hickey, B.H., 1998, Coastal oceanography of western North America from the tip of Baja California to Vancouver Island, Coastal segment (8,E), in Robinson, A.R. and Brink, K.H. eds., The Sea, Volume 11, John Wiley \& Sons, Inc., p. 345-393.

Holba, A.G., Tegelaar, E.W., Huizinga, B.J., Moldowan, J.M., Singletary, M.S., McCaffrey, M.A., and Dzou, L.I.P., 1998, 24-norcholestanes as age sensitive molecular fossils: Geology v. 26, p. 783-786. 
Hornafius, J.S., 1991, Facies analysis of the Monterey Formation in the northern Santa Barbara Channel: AAPG Bulletin, v. 75, p. 894-909.

Hornafius, J.S., Luyendyk, B.P., Terres, R.R., and Kamerling, M.J., 1986, Timing and extent of Neogene tectonic rotation in the western Transverse Ranges, California: Geological Society of America Bulletin, v. 97, p. 1476-1487.

Hornafius J.S., Quigley, D., and Luyendyk, B.P., 1999. The world's most spectacular marine hydrocarbon seeps Coal Oil Point, Santa Barbara Channel, California, Quantification of emissions: Journal of Geophysical Research, v. 104, p. 20,703 20,711 .

Hostettler, F. D., R. J. Rosenbauer, K. A. Kvenvolden, 1999, PAH refractory index as a source discriminant of hydrocarbon input from crude oil and coal in Prince William Sound, Alaska: Organic Geochemistry, v. 30, p. 873-879.

Hostettler, F. D., R. J. Rosenbauer, T. D. Lorenson, and J. Dougherty, 2004, Geochemical characterization of tarballs on beaches along the California coast. Part I; shallow seepage impacting the Santa Barbara Channel Islands, Santa Cruz, Santa Rosa, and San Miguel: Organic Geochemistry v. 35, p. 725-746.

Isaacs, C. M., 1983, Compositional variation and sequence in the Miocene Monterey Formation, Santa Barbara coastal area, California, in Larue D.K., and Steel, R.J., eds., Cenozoic marine sedimentation, Pacific margin, U.S.A.: Pacific Section Society of Economic Paleontologists and Mineralogists Special Publication, p. 117-132.

Isaacs, C. M., 2001, Depositional framework of the Monterey Formation, California, in Isaacs C.M., and J. Rullkötter, eds., The Monterey Formation: from rocks to molecules: New York, Columbia University Press, p. 1-30.

Isaacs, C.M., Keller, M.A., Gennai, V.A., Stewart, K.C., and Taggart, J.E., Jr., 1983a, Preliminary evaluation of Miocene lithostratigraphy in the Point Conception COST well OCS-Cal 78-164 No. 1, off southern California, in Isaacs C.M., and Garrison, R.E., eds., Petroleum generation and occurrence in the Miocene Monterey Formation, California: Pacific Section Society of Economic Paleontologists and Mineralogists, Los Angeles, p. 99-110.

Isaacs, C.M., Pisciotto, K.A., and Garrison, R.E., 1983b, Facies and diagenesis of the Miocene Monterey Formation, California: in A Iijima, J. R. Hein, and R. Siever, eds., Siliceous deposits in the Pacific region: Amsterdam, Elsevier Scientific Publishing Co., p. 247-282.

Jarvie, D.M. and Lundell, L.L., 2001, Kerogen type and thermal transformation of organic matter in the Miocene Monterey Formation, in Isaacs C.M., and J. Rullkötter, eds., The Monterey Formation: from rocks to molecules: New York, Columbia University Press, p. 268-295.

Jones, R. W., 1987, Organic facies: in Brooks J., and Welte, D., eds., Advances in petroleum geochemistry: New York, Academic Press, p. 1-90.

Jones, B., 2001, A comparison of visual observations of surface oil with Synthetic Aperture Radar imagery of the Sea Empress oil spill: International Journal of Remote Sensing, v. 22, no. 9, p. 1619-1638.

Kaplan, I.R., Galperin, Y., Lu, S.T., and Lee, R.P., 1997, Forensic environmental geochemistry: differentiation of fuel-types, their sources and release times: Organic Geochemistry v. 27, p. 289-317. 
Katz, B.J. and Elrod, L.W., 1983, Organic geochemistry of DSDP Site 467, offshore California, middle Miocene to lower Pliocene strata: Geochimica et Cosmochimica Acta, v. 47, p. 389-396.

Katz, B.J., and Royle, R.A., 2001, Variability of source rock attributes in the Monterey Formation, California, in Isaacs C.M., and Rullkötter, J., eds., The Monterey Formation: from rocks to molecules: New York, Columbia University Press, p. 107130.

King, J.D., and Claypool, G.E., 1983, Biological marker compounds and implications for generation and migration of petroleum in rocks of the Point Conception deepstratigraphic test well, OCS-Cal 78-164 No. 1, offshore California: in Isaacs C.M,. and Garrison, R.E., eds., Petroleum generation and occurrence in the Miocene Monterey Formation, California: Pacific Section Society of Economic Paleontologists and Mineralogists, Los Angeles, p. 99-110.

Kolpack, R.L., 1977, Relationship of migration of natural seep material to oceanography of Santa Barbara Channel: in D.J. Everitts, C.F. Eaton, R.G. Paul, E.E. Welday, eds., California Offshore Gas, Oil, and Tar Seeps Californina State Lands Commission, State of California. Sacramento, p. 226-255.

Kvenvolden, K.A., Carlson, P.R., Threlkeld, C.N., and Warden, A., 1993, Possible connection between two Alaskan catastrophies occurring 25 years apart (1964 and 1989): Geology, v. 21, p. 813-816.

Kvenvolden, K.A., Hostettler, F.D., Carlson, P.R., Rapp, J.B., Threlkeld, C.N., Warden, A., 1995, Ubiquitous tar balls with a California-source signature on the shorelines of Prince William Sound, Alaska. Environmental Science and Technology v. 29, p. 2684-2694.

Kvenvolden, K.A., Rosenbauer, R.J., Hostettler, F.D., and Lorenson, T.D., 2000, Coastal tar residues on the shoreline of the Monterey Bay National Marine Sanctuary: Monterey Bay National Marine Sanctuary Symposium, Sanctuary Currents 2000, Causes of Ecosystem Change: Natural or Human?, p. 25.

Kvenvolden, K.A., Hostettler, F.D., Rosenbauer, R.W., Lorenson, T.D., Castle, W.T., Sugarman, S., 2002, Hydrocarbons in recent sediment of the Monterey Bay National Marine Sanctuary: Marine Geology, v.181, p. 101-113.

Kvenvolden, K.A., and Hostettler, F.D., 2004, Geochemistry of coastal tarballs in southern California; A tribute to I.R. Kaplan: In Geochemical Investigations in Earth and Space Science: A Tribute to Isaac R. Kaplan, The Geochemical Society, Publication No. 9, Elsevier, The Netherlands, p. 197-209.

Landes, K.K., 1973, Mother nature as an oil polluter. American Association of Petroleum Geologists Bulletin, v. 57, p. 637- 641.

Leifer, I., Luyendyk, B., and Broderick, K., 2002, Tracking seep oil from seabed to sea surface and beyond at Coal Oil Point, California: Proceedings of the Coastal World Oceans 2002 Conference, Santa Barbara, CA, October 24-27, 2002.

Leifer, I., Boles, J.R., Luyendyk, B.P., and Clark, J.F., 2004, Transient discharges from marine hydrocarbon seeps: spatial and temporal variability: Environmental Geology v. 46, p. 1038-1052.

Leifer, I., Luyendyk, B., and Broderick, K., 2006a, Tracking an oil slick from multiple natural sources, Coal Oil Point, California: Marine and Petroleum Geology, v. 23, no. 5, p.621-630. 
Leifer, I., Luyendyk, B., Boles, J. and Clark, J. F., 2006b, Natural marine seepage blowout: Contribution to atmospheric methane. Global Biogeochemical Cycles, v. 20, p. GB3008, 9 p., doi:10.1029/2005GB002668.

Lillis, P.G., Magoon, L.B., Stanley, R.G., McLaughlin, R.J., and Warden, A., 2001, Characterization of northern California petroleum by stable carbon isotope ratios: $U$. S. Geological Survey Open-File Report 99-164, 13 p.

Lorenson, T.D., Dougherty, J.A., Ussler, W. III, and Paull, C. K. 2003, Cruise Summary For P-1-02-SC: Acoustic imaging of natural oil and gas seeps and measurement of dissolved methane concentration in coastal waters near Pt. Conception, California: USGS Open File Report 03-122, 81p URL: http://geopubs.wr.usgs.gov/openfile/of03-122/.

Lorenson, T.D., Dougherty J.A., Hostettler F.D., and Rosenbauer R.J., 2004, Natural seep inventory and identification for the County of Santa Barbara, California, Final Report, March 25, 2004: USGS internal report, 84 p., CD-ROM. Published by the County of Santa Barbara at: http://www.countyofsb.org/energy/information/ NaturalSeepInventoryFinalReport.htm.

Lorenson, T.D., Hostettler, F.D., Dougherty, J.A., Rosenbauer, R.J., Peters, K.E., and Dunaway, M., 2006, Overview of Natural Oil Seepage in the Santa Barbara Channel and Southern Santa Maria Basin, Southern California: California and the World Ocean 2006, Book of Abstracts, p. 153-154.

Lorenson, T.D., Hostettler, F.D., Peters, K.E., Dougherty, J.A., Rosenbauer, R.J., and Helix, M., 2007, Natural oil seepage in southern California: Occurrence, sources, and ecology: in Petrotech 2007 Proceedings CD-ROM. 6p.

Lu, J., 2003, Marine oil spill detection, statistics and mapping with ERS SAR imagery in south- east Asia: International Journal of Remote Sensing, v. 24 n. 15, p. 3013-3032.

Luyendyk, B. P., 1991, A model for Neogene crustal rotations, transtension, and transpression in southern California: Geological Society of America Bulletin, v. 103, p. $1528-1536$.

Mackenzie, A.S., 1984, Applications of biological markers in petroleum geochemistry: in Brooks, J., and Welte, D., eds., Advances in Petroleum Geochemistry, v. 1, Academic Press, London, pp. 115-214.

Mackenzie, A.S., Patience, R.L., Maxwell, J.R., Vandenbroucke, M., and Durand, B., 1980, Molecular parameters of maturation in the Toarcian shales, Paris Basin, France; 1. Changes in the configuration of acyclic isoprenoid alkanes, steranes, and triterpanes: Geochimica et Cosmochimica Acta v. 44, p. 1709-1721.

Mau, S., Valentine, D.L., Clark, J.F., Reed, J., Camilli, R., and Washburn, L., 2007, Dissolved methane distributions and air-sea flux in the plume of a massive seep field, Coal Oil Point, California: Geophysical Research Letters, v. 34, p. L22603, doi:10.1029/2007GL031344.

Mello, M.R., Gaglianone, P.C., Brassell, S.C., and Maxwell, J.R., 1988, Geochemical and biological marker assessment of depositional environments using Brazilian offshore oils: Marine and Petroleum Geology, v. 5, p. 205-223.

Michael, G.E., 2001, Geochemical characterization of the Miocene Monterey Formation and oils in the Santa Barbara-Ventura and Santa Maria Basins: in C.M., Isaacs and Rullkötter, J., eds., The Monterey Formation: from rocks to molecules: New York, Columbia University Press, p. 241-267. 
Mikolaj, P.G and Ampaya, J.P., 1973, Tidal effects on the activity of natural submarine oil seeps: Marine Technical Society Journal, v. 7, p. 25-28.

Moldowan, J.M., Seifert, W.K., and Gallegos, E.J., 1985, Relationship between petroleum composition and depositional environment of petroleum source rocks: AAPG Bulletin, v. 69, p. 1255-1268.

Moldowan, J.M., Sundararaman, P., and Schoell, M., 1986, Sensitivity of biomarker properties to depositional environment and/or source input in the Lower Toarcian of S.W. Germany: Organic Geochemistry, v. 10, p. 915-926.

Moldowan, J.M., Lee, C.Y., Watt, D.S., Jeganathan, A., Slougui, N.E., and Gallegos, E.J., 1991, Analysis and occurrence of C26-steranes in petroleum and source rocks: Geochimica et Cosmochimica Acta v. 55, p. 1065-1081.

Moldowan, J.M., Dahl, J., Huizinga, B.J., Fago, F.J., Hickey, L.J. Peakman, T.M., and Taylor, D.W., 1994, The molecular fossil record of oleanane and its relation to angiosperms: Science, v. 265, p. 768-771.

Munk, W.H., Armi, L., Fischer, K., and Zachariasen, F., 2000, Spirals on the sea: Proc. R. Soc. London, Ser. A 456, p.1217-1280.

Noble, R., Alexander, R., and Kagi, R.I., 1985, The occurrence of bisnorhopane, trisnorhopane and 25-norhopanes as free hydrocarbons in some Australian shales: Organic Geochemistry, v. 8, p. 171-176.

Normark, W.R., Fisher, M.A., Gutmacher, C.E., Sliter, R., Hibbeler, L., Feingold, B., and Reid, J.A., 2003. Cruise report for A1-02-SC Southern Claifornia CABRILLO project, Earthquake Hazards Task; USGS Open File Report 03-110. 29p.

Ogle, B.A., Wallis, W.S., Heck, R.G., and Edwards, E.B., 1987, Petroleum geology of the Monterey Formation in the offshore Santa Maria/Santa Barbara areas: in Ingersoll, R.V., and Ernst, W.G., eds., Cenozoic basin development of coastal California: Englewood Cliffs, Prentice-Hall, p. 382-406.

Orr, W.L., 1986, Kerogen/asphaltene/sulfur relationships in sulfur-rich Monterey oils: Organic Geochemistry, v. 10, p. 499-516.

Palacas, J.G., Anders, D.E., and King, J.D., 1984, South Florida Basin; a prime example of carbonate source rocks of petroleum: in Palacas, J.G., ed., Petroleum Geochemistry and Source Rock Potential of Carbonate Rocks: American Association of Petroleum Geologists, Studies in Geology No. 18, p. 71-96.

Pavlakis, P., Tarchi, D., and Sieber, A.J., 2001, On the monitoring of illicit vessel discharges using spaceborne SAR remote sensing--a reconnaissance study in the Mediterranean sea: Annual. Telecommunication. v.56, no. 11-12, p. 700-718.

Peters, K.E. and Cassa, M.R., 1994, Applied source rock geochemistry, in Magoon, L.B., and Dow, W.G., eds., The petroleum system--from source to trap: AAPG Memoir 60, p. 93-117.

Peters, K.E. and Moldowan, J.M., 1991, Effects of source, thermal maturity, and biodegradation on the distribution and isomerization of homohopanes in petroleum: Organic Geochemistry, v. 17, p. 47-61.

Peters, K.E. and Moldowan, J.M., 1993, The biomarker guide: Englewood Cliffs, PrenticeHall, 363 p.

Peters, K.E., Moldowan, J.M., Schoell, M., and Hempkins, W.B., 1986, Petroleum isotopic and biomarker composition related to source rock organic matter and depositional environment: Organic Geochemistry, v. 10, p. 17-27. 
Peters, K.E., Moldowan, J.M., and Sundararaman, P., 1990, Effects of hydrous pyrolysis on biomarker thermal maturity parameters: Monterey phosphatic and siliceous members: Organic Geochemistry, v. 15, p. 249-265.

Peters, K.E., Elam, T.D., Pytte, M.H.,and Sundararaman, P.,1994, Identification of petroleum systems adjacent to the San Andreas Fault, California, U.S.A.: in Magoon L.B., and Dow, W.G.,eds., The petroleum system; from source to trap. AAPG Memoir 60, p. 423-436.

Peters, K.E., Walters, C.C., and Moldowan, J.M., 2005, The biomarker guide: Cambridge, Cambridge University Press, $1155 \mathrm{p}$.

Peters, K.E., Ramos, L.S., Zumberge, J.E., Valin, Z.C., Scotese, C.R., and Gautier, D.L., 2007, Circum-Arctic petroleum systems identified using decision-tree chemometrics: AAPG Bulletin, v. 91, p. 877-913.

Peters K.E., Hostettler, F.D., Lorenson, T.D., and Rosenbauer, R.R., 2008, Families of Miocene Monterey crude oil, seep, and tarball samples, coastal California, AAPG, v. 92, no. 9, p. 1131-1152.

Philp, R.P., 1985, Fossil Fuel Biomarkers, Applications and Spectra: Elsevier, Amsterdam, 294 p.

Pisciotto, K.A., and Garrison, R.E., 1981, Lithofacies and depositional environments of the Monterey Formation, California, in Garrison R.E., and Douglas, R.G.,eds., The Monterey Formation and related siliceous rocks of California: Los Angeles, Pacific Section Society of Economic Paleontologists and Mineralogists, Book 15, p. 97-122.

Quigley D.C., Hornafius, J.S., Luyendyk, B.P., Francis, R.D., Clark, J., and Washburn, L., 1999, Decrease in natural marine hydrocarbon seepage near Coal Oil Point, California, associated with offshore oil production: Geology. v. 27, p. 1047- 1050.

Reed, W.E. and Kaplan, I.R., 1977, Chemistry of marine petroleulm seeps and their relation to exploration and pollution: in Everitts, D.J. Eaton, C.F., Paul, R.G., and Welday E.E., eds. California Offshore Gas, Oil, and Tar Seeps: prepared by the staff of the State Lands Commission, California State Lands Commission Staff Report, p.155-225.

Saenz, J.M., 2002, Geological controls of hydrocarbon seeps in Santa Maria Basin, offshore California: M.S. Thesis, California State University at Northridge, Northridge, California, 292 p.

Schoell, M., McCaffrey, M.A., Fago, F.J., and Moldowan, J.M., 1992, Carbon isotopic compositions of 28,30-bisnorhopanes and other biological markers in a Monterey crude oil: Geochimica et Cosmochima Acta, v. 56, p. 1391-1399.

Schouten, S., Sinninghe Damste, J.S., Schoell, M., and DeLeeuw, J., 1994, A novel sterane, 27-nor-24-methyl-5a-cholestane, in sediments: Geochimica et Cosmochimica Acta, v. 58, p. 3741-3745.

Seifert, W.K., Moldowan, J.M., 1978, Application of steranes, terpanes, and monoaromatics to the maturation, migration and source of crude oils. Geochimica et Cosmochimica Acta 42, 77-95.

Sigalove J., 1985, Geochemical Identification of Resource Potential: Oil and Gas Journal, p. 164-168.

Sofer, Z., 1980, Preparation of carbon dioxide for stable carbon isotope analysis of petroleum fractions: Analytical Chemistry, v. 52, p. 1389-1391. 
Solberg, A.H.S., Storvik, G., Solberg, R., Volden, E., 1999. Automatic detection of oil spills in ERS SAR images. IEEE Transactions on Geoscience and Remote Sensing, v. 37 no. 4, p. 1916-1924.

Soutar, A. and Crill, P.A., 1977, Sedimentation and climatic patterns in the Santa Barbara Basin during the 19th and 20th centuries: AAPG Bulletin, v. 88, p. 1161-1172.

Stanley, R.G., Johnson, S.Y., Swisher, C.C., III, Mason, M.A., Obradovich, J.D., Cotton, M.L., Filewicz, M.V., and Vork, D.R., 1996, Age of the Lospe Formation (early Miocene) and origin of the Santa Maria basin, California: U. S. Geological Survey Bulletin, 1995-M, p. M1-M37.

Svejkovsky, J., and Jones, B., 2001, Satellite imagery detects coastal stormwater and sewage runoff. Eos Transactions. v.82 n0. 50, p. 621, 624, 625 and 630.

Tennyson, M.E., and Isaacs, C.M., 2001, Geologic setting and petroleum geology of Santa Maria and Santa Barbara basins: in Isaacs, C.M., and Rullkötter, J., eds., The Monterey Formation: from rocks to molecules: New York, Columbia University Press, p. 206-229.

Trivero, P., Fiscella, B., Gomez, F., Pavese, P., 1998, SAR detection and characterization of sea surface slicks: International Journal of Remote Sensing, v.19, no. 3, p. 543548.

U.S. National Academy of Sciences, 2002, Oil in the Sea III: Inputs, Fates, and Effects: National Academy Press, Washington, D.C., 265 p.

Venkatesan, M.I., 1988, Occurrence and possible sources of perylene in marine systems; A review: Marine Chemistry v. 25, p.1-27.

Vernon, J.W., and Slater, R.A., 1963, Submarine tar mounds, Santa Barbara County, California: AAPG Bulletin, v. 47, no. 8, p. 1624-1627.

Wang, Z., Fingas, M., Blenkinsopp, S., Sergy, G., Landriault, M., Sigouin, L., Foght, J., Semple, K. and Westlake, D.W.S., 1998, Comparison of oil composition changes due to biodegradation and physical weathering in different oils: Journal of Chromatography v. A 809, p. 89-107.

Waples, D.W., Machihara, T., 1991, Biomarkers for geologists; a practical guide to the application of steranes and triterpanes in petroleum geology: American Association of Petroleum Geologists, Methods in Exploration No. 9, 91 p.

Waples, D.W., andCuriale, J.A., 1999, Oil-oil and oil-source rock correlations, in Beaumont E.A., and Foster, N.H., eds., Exploring for oil and gas traps: AAPG, Tulsa, Oklahoma, p. 8-1 to 8-71.

Wardlow, G.D., Arey, J.S., Reddy, C.M., Nelson, R K., Ventura G.T., and Valentine D.L., 2008, Disentangling Oil Weathering at a Marine Seep Using GC $\times$ GC: Broad Metabolic Specificity Accompanies Subsurface Petroleum Biodegradation: Environmental Science and Technology, v. 42 no. 19, p. 7166-7173.

Washburn L.C., Johnson, L., Gotschalk, C., and Egland, E.T., 2001. A gas-capture buoy for measuring bubbling gas flux in oceans and lakes: Journal of Atmospheric and Oceanic Technology, v. 18, p. 1411-1420.

Williams, L.A., 1984, Subtidal stromatolites in Monterey Formation and other organic-rich rocks as suggested contributors to petroleum formation: AAPG Bulletin, v. 68, p. 1879-1893. 
Wilson, D.S., McCrory, P.A., and Stanley, R.G., 2005, Implications of volcanism in coastal California for the Neogene deformation history of western North America: Tectonics, v. 24, no. 3 (June), TC3008, 22 p.

Winant, C.D., Alden, D.J., Dever, E.P., Edwards, K.A., and Hendershott, M.C., 1999, Near surface trajectories off central and southern California: Journal of Geophysical Research, v.104, p.15713-15726.

Winant, C.D., Dever, E.P., and Hendershott, M.C., 2003, Characteristic patterns of shelf circulation at the boundary between central and southern California: Journal of Geophysical Research, v. 108, no. C2, p. 3-1 to 3-13, doi:10.1029/2001JC001302.

Wismann, V., Gade, M., Alpers, W., and Huhnerfuss, H., 1998, Radar signatures of marine mineral oil spills measured by an airborne multi-frequency radar: International Journal of Remote Sensing, v. 19, no. 18, p. 3607-3623.

Zumberge, J.E., 1987, Prediction of source rock characteristics based on terpane biomarkers in crude oils: a multivariate statistical approach: Geochimica et Cosmochimica Acta, v. 51, p. 1625-1637. 